Nevada

Environmental

Restoration

Project

\title{
Corrective Action Decision Document/ Closure Report for Corrective Action Unit 545: Dumps, Waste Disposal Sites, and Buried Radioactive Materials Nevada Test Site, Nevada
}

Controlled Copy No.:

Revision No.: 0

\section{April 2008}

Approved for public release; further dissemination unlimited.

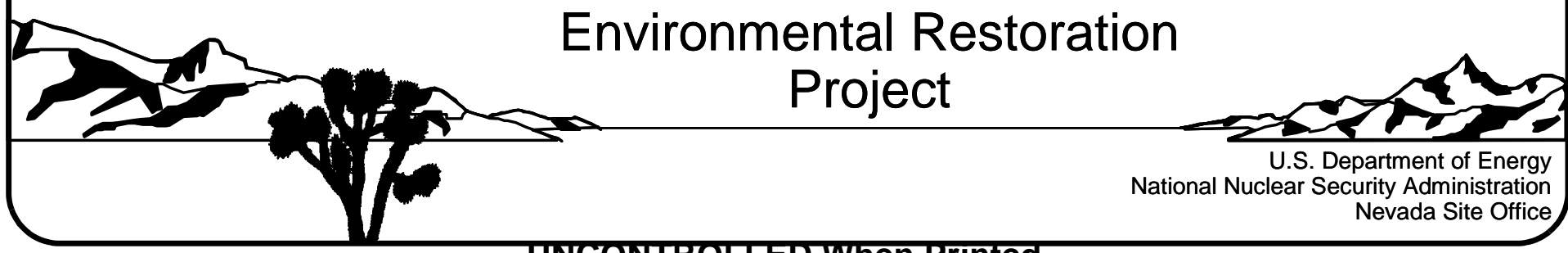


Available for public sale, in paper, from:

U.S. Department of Commerce

National Technical Information Service

5285 Port Royal Road

Springfield, VA 22161

Phone: 800.553 .6847

Fax: 703.605.6900

Email: orders@ntis.gov

Online ordering: http://www.ntis.gov/ordering.htm

Available electronically at http://www.osti.gov/bridge

Available for a processing fee to U.S. Department of Energy and its contractors, in paper, from:

\section{U.S. Department of Energy}

Office of Scientific and Technical Information

P.O. Box 62

Oak Ridge, TN 37831-0062

Phone: 865.576.8401

Fax: 865.576.5728

Email: reports@adonis.osti.gov

Reference herein to any specific commercial product, process, or service by trade name, trademark, manufacturer, or otherwise, does not necessarily constitute or imply its endorsement, recommendation, or favoring by the United States Government or any agency thereof or its contractors or subcontractors. 


\title{
CORRECTIVE ACTION DECISION DOCUMENTI CLOSURE REPORT FOR CORRECTIVE ACTION UNIT 545: DUMPS, WASTE DISPOSAL SITES, AND BURIED RADIOACTIVE MATERIALS NEVADA TEST SITE, NEVADA
}

\author{
U.S. Department of Energy \\ National Nuclear Security Administration \\ Nevada Site Office \\ Las Vegas, Nevada
}

Controlled Copy No.:

Revision No.: 0

April 2008

Approved for public release; further dissemination unlimited. 


\section{CORRECTIVE ACTION DECISION DOCUMENT/CLOSURE REPORT FOR CORRECTIVE ACTION UNIT 545: \\ DUMPS, WASTE DISPOSAL SITES, AND BURIED RADIOACTIVE MATERIALS NEVADA TEST SITE, NEVADA}

Kevin J. Cabble

Federal Sub-Project Director

Industrial Sites Sub-Project

Approved by: /S/ John Jones

Date: $3 / 27 / 2008$

John B. Jones

Acting Federal Project Director

Environmental Restoration Project 


\section{Table of Contents}

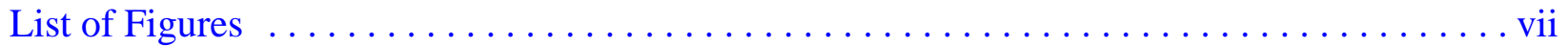

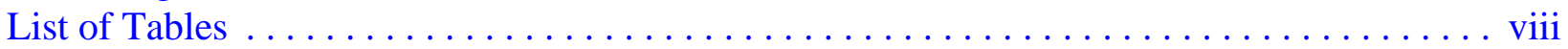

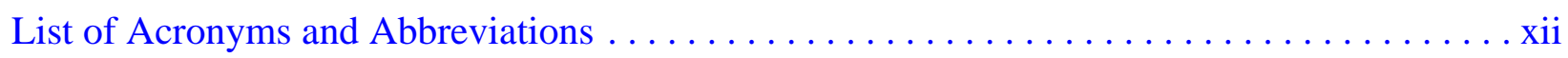

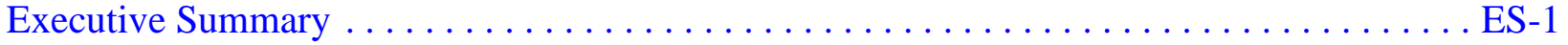

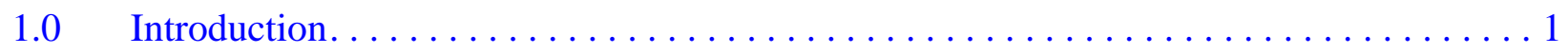

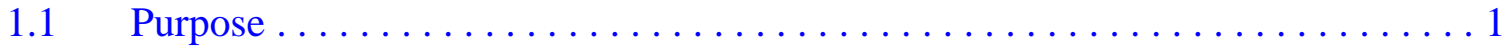

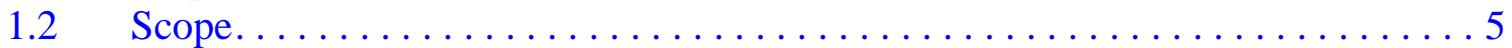

1.3 Corrective Action Decision Document/Closure Report Contents . . . . . . . . 6

1.3.1 Applicable Programmatic Plans and Documents ............. 7

1.3.2 Data Quality Assessment Summary .................. 7

$2.0 \quad$ Corrective Action Investigation Summary $\ldots \ldots \ldots \ldots \ldots \ldots \ldots \ldots \ldots$

$2.1 \quad$ Investigation Activities . ... $\ldots \ldots \ldots \ldots \ldots \ldots \ldots \ldots \ldots \ldots \ldots \ldots$

2.1.1 Mud Disposal Area (CAS 02-09-01) ................. 10

2.1.1.1 Radiological Survey $\ldots \ldots \ldots \ldots \ldots \ldots \ldots \ldots \ldots \ldots$

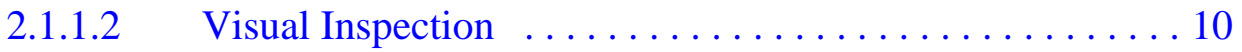

2.1.1.3 Field Screening $\ldots \ldots \ldots \ldots \ldots \ldots \ldots \ldots \ldots \ldots \ldots$

2.1.1.4 Sample Collection ........................ 11

2.1.1.5 Conceptual Site Model Validation ................ 12

2.1.2 Waste Consolidation Site 3B (CAS 03-17-01) . . . . . . . . . 12

2.1.2.1 Radiological Survey . ....................... 13

2.1.2.2 Geophysical Survey $\ldots \ldots \ldots \ldots \ldots \ldots \ldots \ldots \ldots \ldots$

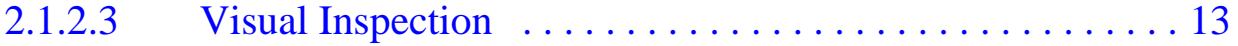

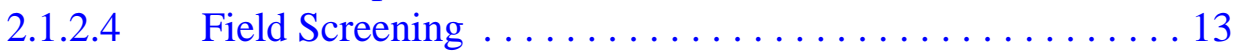

2.1.2.5 Sample Collection ...................... 13

2.1.2.6 Conceptual Site Model Validation ................ 14

2.1.3 Radioactive Material Disposal Area (CAS 03-99-14) . . . . . . . . . . 14

2.1.3.1 Radiological Survey . . . . . . . . . . . . . . . . . . . 14

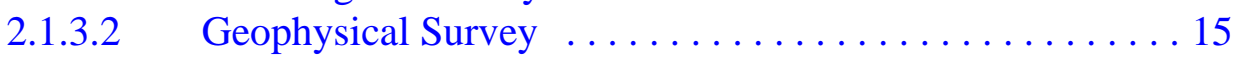

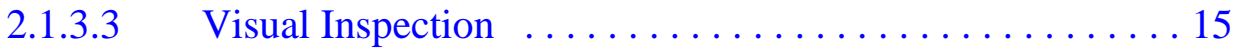

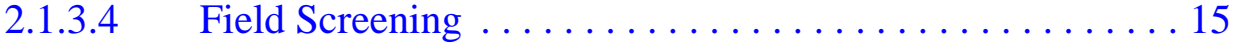

2.1.3.5 Sample Collection ....................... 15

2.1.3.6 Conceptual Site Model Validation .............. 16

2.1.4 U-9y Drilling Mud Disposal Crater (CAS 09-23-02) . . . . . . . . . . 16

2.1.4.1 Radiological Survey $\ldots \ldots \ldots \ldots \ldots \ldots \ldots \ldots \ldots \ldots$

2.1.4.2 Geophysical Survey $\ldots \ldots \ldots \ldots \ldots \ldots \ldots \ldots \ldots \ldots$

2.1.4.3 Visual Inspection $\ldots \ldots \ldots \ldots \ldots \ldots \ldots \ldots \ldots \ldots \ldots$

2.1.4.4 Field Screening . . . . . . . . . . . . . . . . . . . . 17

2.1.4.5 Sample Collection ......................... 17 


\section{Table of Contents (Continued)}

2.1.4.6 Conceptual Site Model Validation . . . . . . . . . . . . 19

2.1 .5 Waste Disposal Site (CAS 20-19-01) . . . . . . . . . . . . . 19

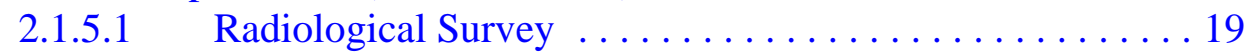

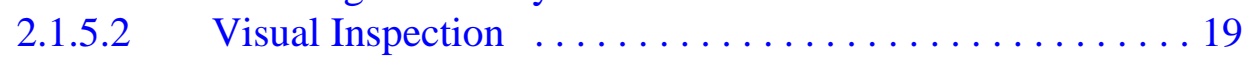

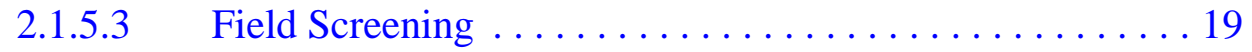

2.1.5.4 Sample Collection ....................... 20

2.1.5.5 Conceptual Site Model Validation . . . . . . . . . . . . 21

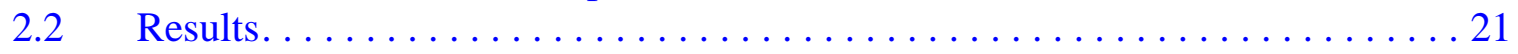

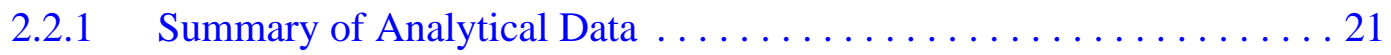

2.2.1.1 Mud Disposal Area (CAS 02-09-01) . . . . . . . . . . . 21

2.2.1.2 Waste Consolidation Site 3B (CAS 03-17-01) . . . . . . . 22

2.2.1.3 Radioactive Material Disposal Area (CAS 03-99-14) . . . 24

2.2.1.4 U-9y Drilling Mud Disposal Crater (CAS 09-23-02) . . . . 24

2.2.1.5 Waste Disposal Site (CAS 20-19-01) . . . . . . . . . 27

2.2 .2 Data Assessment Summary . . . . . . . . . . . . . . . . . . . . 28

2.3 Justification for No Further Action. . . . . . . . . . . . . . . . 29

2.3.1 Final Action Levels. . . . . . . . . . . . . . . . . . . 29

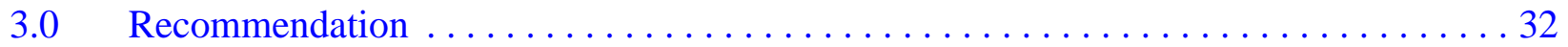

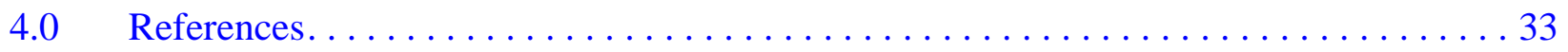

\section{Appendix A - Corrective Action Investigation Results}

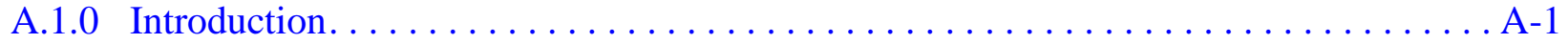

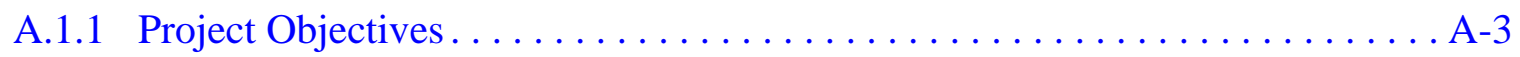

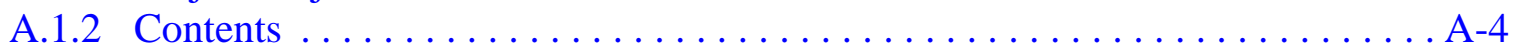

A.2.0 Investigation Overview $\ldots \ldots \ldots \ldots \ldots \ldots \ldots \ldots \ldots \ldots \ldots \ldots \ldots \ldots \ldots \ldots \ldots$

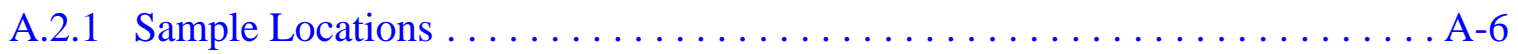

A.2.2 Investigation Activities . . . . . . . . . . . . . . . . . .

A.2.2.1 Radiological Surveys . . . . . . . . . . . . . . . . . A-7

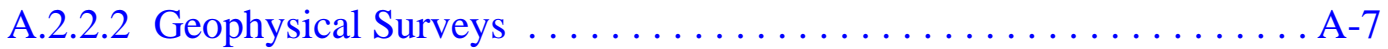

A.2.2.3 Field Screening . . . . . . . . . . . . . . . . . . A-7

A.2.2.4 Surface and Subsurface Soil Sampling. . . . . . . . . . . . . . A-8

A.2.2.5 Waste Characterization Sampling. . . . . . . . . . . . . . . . A A

A.2.3 Laboratory Analytical Information. . . . . . . . . . . . . . . A-9

A.2.4 Comparison to Action Levels . . . . . . . . . . . . . . . A-10

A.3.0 Corrective Action Site 02-09-01, Mud Disposal Area . . . . . . . . . . . . . . A-12

A.3.1 Corrective Action Investigation $\ldots \ldots \ldots \ldots \ldots \ldots \ldots \ldots \ldots \ldots \ldots \ldots \ldots \ldots$ 


\section{Table of Contents (Continued)}

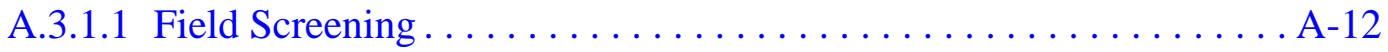

A.3.1.2 Radiological Surveys $\ldots \ldots \ldots \ldots \ldots \ldots \ldots \ldots \ldots \ldots \ldots$ A -12

A.3.1.3 Visual Inspections......................... A-16

A.3.1.4 Sample Collection ......................... A-16

A.3.1.5 Deviations................................ A-18

A.3.2 Investigation Results............................... A-19

A.3.2.1 Gamma-Emitting Radionuclides $\ldots \ldots \ldots \ldots \ldots \ldots \ldots \ldots$ A-19

A.3.2.2 Plutonium, Strontium-90, and Uranium Isotopes . . . . . . . . . A-19

A.3.3 Nature and Extent of Contamination $\ldots \ldots \ldots \ldots \ldots \ldots \ldots \ldots \ldots \ldots \ldots \ldots \ldots$

A.3.4 Revised Conceptual Site Model ............................ A-19

A.4.0 Corrective Action Site 03-17-01, Waste Consolidation Site 3B . . . . . . . . . . A-22

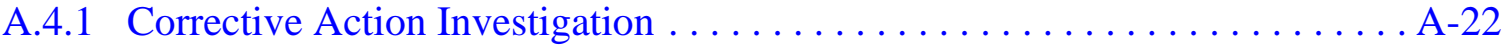

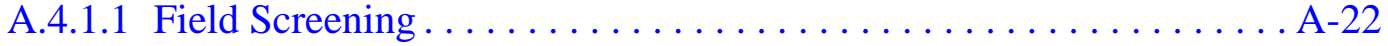

A.4.1.2 Radiological Survey ........................ A-26

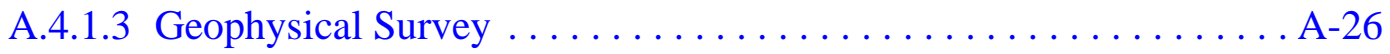

A.4.1.4 Visual Inspections.......................... A-26

A.4.1.5 Sample Collection.......................... A-26

A.4.1.6 Deviations ............................... A-28

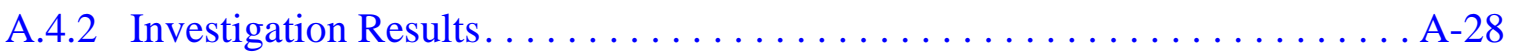

A.4.2.1 RCRA Metals ........................... A-29

A.4.2.2 Gamma-Emitting Radionuclides $\ldots \ldots \ldots \ldots \ldots \ldots \ldots \ldots$ A-30

A.4.2.3 Plutonium, Strontium-90, and Uranium Isotopes........... A-36

A.4.3 Nature and Extent of Contamination . . . . . . . . . . . . . . . . A-41

A.4.4 Revised Conceptual Site Model . . . . . . . . . . . . . . . . . . . . . . A-41

A.5.0 Corrective Action Site 03-99-14, Radioactive Material Disposal Area . . . . . . . . . . A-42

A.5.1 Corrective Action Investigation $\ldots \ldots \ldots \ldots \ldots \ldots \ldots \ldots \ldots \ldots \ldots$ A-42

A.5.1.1 Field Screening ........................... A-42

A.5.1.2 Radiological Survey ......................... A-42

A.5.1.3 Geophysical Survey ........................ A-46

A.5.1.4 Visual Inspections. . . . . . . . . . . . . . . . . . . . A-46

A.5.1.5 Sample Collection........................... A-46

A.5.1.6 Deviations............................... A-48

A.5.2 Investigation Results. .............................. A-48

A.5.2.1 Volatile Organic Compounds ...................... A-48

A.5.2.2 Semivolatile Organic Compounds . . . . . . . . . . . . . A-48

A.5.2.3 Total Petroleum Hydrocarbons. . . . . . . . . . . . . . . . . . A-49

A.5.2.4 RCRA Metals ............................. A-49

A.5.2.5 Polychlorinated Biphenyls ...................... A-49

A.5.2.6 Gamma-Emitting Radionuclides $\ldots \ldots \ldots \ldots \ldots \ldots \ldots \ldots$ A-52 


\section{Table of Contents (Continued)}

A.5.2.7 Plutonium, Strontium-90, and Uranium Isotopes . . . . . . . . . . A-52

A.5.2.8 Nature and Extent of Contamination . . . . . . . . . . . . . . A-52

A.5.3 Revised Conceptual Site Model . . . . . . . . . . . . . . . A-52

A.6.0 Corrective Action Site 09-23-02, U-9y Drilling Mud Disposal Crater . . . . . . . . . A-55

A.6.1 Corrective Action Investigation $\ldots \ldots \ldots \ldots \ldots \ldots \ldots \ldots \ldots \ldots \ldots \ldots \ldots$

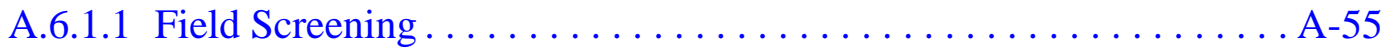

A.6.1.2 Radiological Survey . . . . . . . . . . . . . . . . . . A-55

A.6.1.3 Geophysical Survey . . . . . . . . . . . . . . . . . . . . A-59

A.6.1.4 Visual Inspections. . . . . . . . . . . . . . . . . . . . A-59

A.6.1.5 Sample Collection. . . . . . . . . . . . . . . . . . . . . . . A A-59

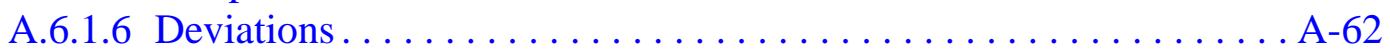

A.6.2 Investigation Results. . . . . . . . . . . . . . . . . . . . . A-62

A.6.2.1 Volatile Organic Compounds ... . . . . . . . . . . . . . . . . . A-62

A.6.2.2 Semivolatile Organic Compounds . . . . . . . . . . . . . . . A-62

A.6.2.3 Total Petroleum Hydrocarbons . . . . . . . . . . . . . . . . . A-63

A.6.2.4 RCRA Metals ........................ A-63

A.6.2.5 Gamma-Emitting Radionuclides . . . . . . . . . . . . . . A-64

A.6.2.6 Plutonium, Strontium-90, and Uranium Isotopes . . . . . . . . . . . . A A-64

A.6.3 Nature and Extent of Contamination . . . . . . . . . . . . . . A-68

A.6.4 Revised Conceptual Site Model . . . . . . . . . . . . . . . . A-68

A.7.0 Corrective Action Site 20-19-01, Waste Disposal Site. . . . . . . . . . . . . . . . A-69

A.7.1 Corrective Action Investigation $\ldots \ldots \ldots \ldots \ldots \ldots \ldots \ldots \ldots \ldots \ldots$ A-69

A.7.1.1 Field Screening . . . . . . . . . . . . . . . . . . A A-69

A.7.1.2 Radiological Survey . . . . . . . . . . . . . . . . . . . A-69

A.7.1.3 Visual Inspections. . . . . . . . . . . . . . . . . . . . A-69

A.7.1.4 Sample Collection. ....................... A-71

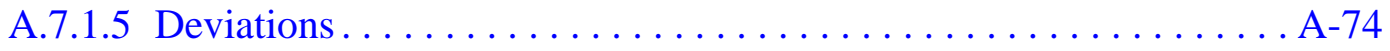

A.7.2 Investigation Results. . . . . . . . . . . . . . . . . A-74

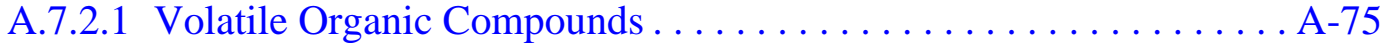

A.7.2.2 Semivolatile Organic Compounds . . . . . . . . . . . . . . . A-75

A.7.2.3 Total Petroleum Hydrocarbons . . . . . . . . . . . . . . . . . . A A-75

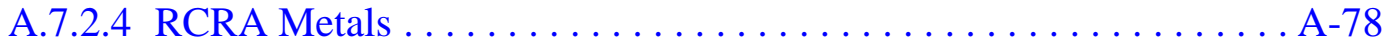

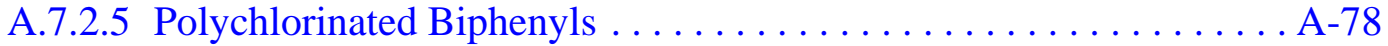

A.7.2.6 Gamma-Emitting Radionuclides . . . . . . . . . . . . . . . A-80

A.7.2.7 Plutonium and Uranium Isotopes . . . . . . . . . . . . . . . . . . . . . . . . A-80

A.7.3 Nature and Extent of Contamination . . . . . . . . . . . . . . A-80

A.7.4 Revised Conceptual Site Model . . . . . . . . . . . . . . . . . . . . . A-80 


\section{Table of Contents (Continued)}

A.8.0 Waste Management. . . . . . . . . . . . . . . . . . . . . . A-83

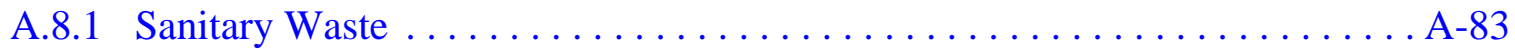

A.8.2 Waste Minimization . . . . . . . . . . . . . . . . . . . A-83

A.8.2.1 Waste Streams/Disposal . . . . . . . . . . . . . . . A-83

A.8.2.2 Waste Streams . . . . . . . . . . . . . . . . A-85

A.9.0 Quality Assurance............................... A-86

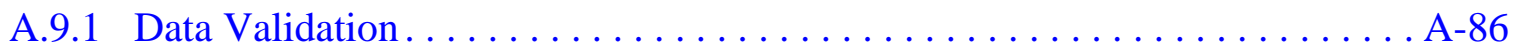

A.9.1.1 Tier I Evaluation . . . . . . . . . . . . . . . . . . A-86

A.9.1.2 Tier II Evaluation . . . . . . . . . . . . . . . . . . . A-87

A.9.1.3 Tier III Evaluation $\ldots \ldots \ldots \ldots \ldots \ldots \ldots \ldots \ldots \ldots \ldots \ldots$ A-88

A.9.2 Field Quality Control Samples . . . . . . . . . . . . . . . . . . A-90

A.9.2.1 Laboratory Quality Control Samples .... . . . . . . . . . . . A A-90

A.9.2.2 Field Nonconformances . . . . . . . . . . . . . . . . . . A-91

A.9.3 Laboratory Nonconformances . . . . . . . . . . . . . . . A-91

A.10.0 Summary . . . . . . . . . . . . . . . . . . . . . . .

A.11.0 References. . . . . . . . . . . . . . . . . . . . . . . . . . . A-94

\section{Appendix B - Data Assessment}

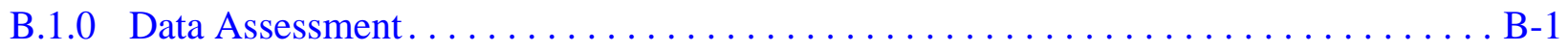

B.1.1 Review DQOs and Sampling Design . . . . . . . . . . . . . . B-2

B.1.1.1 Decision I . . . . . . . . . . . . . . . . . . . . . .

B.1.1.1.1 DQO Provisions To Limit

False Negative Decision Error $\ldots \ldots \ldots \ldots \ldots \ldots$ B-2

B.1.1.1.2 DQO Provisions To Limit

False Positive Decision Error . . . . . . . . . . B-10

B.1.1.2 Decision II . . . . . . . . . . . . . . . . . . . . B-10

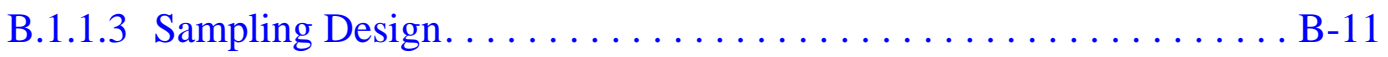

B.1.2 Conduct a Preliminary Data Review . . . . . . . . . . . . . . B-11

B.1.3 Select the Test and Identify Key Assumptions.... . . . . . . . . . . . . B-11

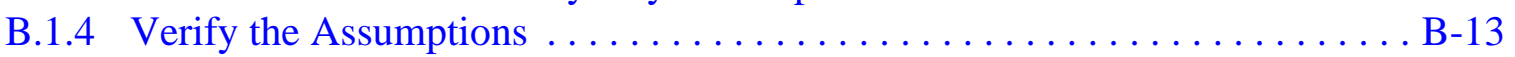

B.1.4.1 Other DQO Commitments . . ................... B-13

B.1.5 Draw Conclusions from the Data . . . . . . . . . . . . . . . . . . B-13

B.1.5.1 Decision Rules for Decision I. . . . . . . . . . . . . . B-14

B.2.0 References..................................... B-15 


\section{Table of Contents (Continued)}

\section{Appendix C - Risk Assessment}

C.1.0 Evaluation of Risk $\ldots \ldots \ldots \ldots \ldots \ldots \ldots \ldots \ldots \ldots \ldots \ldots \ldots \ldots \ldots \ldots \ldots \ldots \ldots$

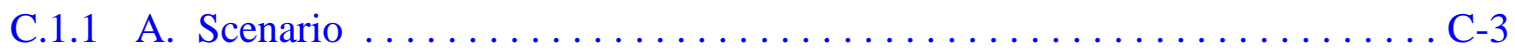

C.1.2 B. Site Assessment . . . . . . . . . . . . . . . . . . . C-5

C.1.3 C. Site Classification and Initial Response Action . . . . . . . . . . . . C-6

C.1.4 D. Development of Tier 1 Lookup Table of Risk-Based

Screening Levels. . . . . . . . . . . . . . . . . . . . . . C-7

C.1.5 E. Exposure Pathway Evaluation $\ldots \ldots \ldots \ldots \ldots \ldots \ldots \ldots \ldots \ldots$ C-11

C.1.6 F. Comparison of Site Conditions with Tier 1 Risk-Based

Screening Levels. . . . . . . . . . . . . . . . . . . . C-11

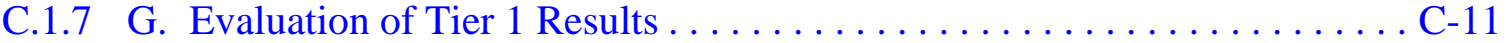

C.1.8 H. Tier 1 Remedial Action Evaluation . . . . . . . . . . . . . . . . C-11

C.1.9 I. Tier 2 Evaluation . . . . . . . . . . . . . . . . . . C-12

C.1.10 J. Development of Tier 2 Table of Site-Specific Target Levels. . . . . . . . . C C-13

C.1.11 K. Comparison of Site Conditions with Tier 2 Table Site-Specific

Target Levels . . . . . . . . . . . . . . . . . . . . . C-15

C.1.12 L. Tier 2 Remedial Action Evaluation .................. C-15

C.2.0 Recommendations............................. -17

C.3.0 References.................................. C-18

\section{Attachment A - RESRAD Report}

\section{Appendix D - Closure Activity Summary (Use Restriction)}

D.1.0 Closure Activity Summary . . . . . . . . . . . . . . . . . . . . D-1

D.1.1 CAS 03-08-03 Closure Activities. . . . . . . . . . . . . . . . . . . . . D-1

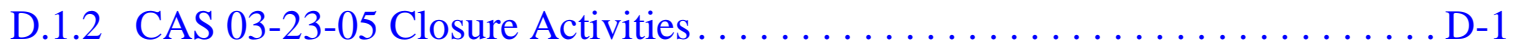

D.1.3 CAS 20-19-01 Closure Activities.................... D-4

D.1.4. Disposition of Drummed IDW for CAU $545 \ldots \ldots \ldots \ldots \ldots \ldots \ldots \ldots \ldots$

D.2.0 References...................................... D-11

\section{Attachment D-1 - Disposition of IDW}

\section{Appendix E - Sample Location Coordinates}

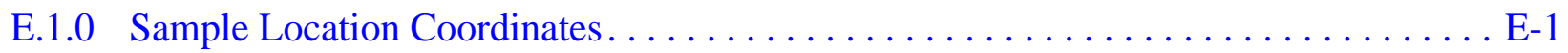

Appendix F - Nevada Division of Environmental Protection Comments 


\section{List of Figures}

Number

Title

Page

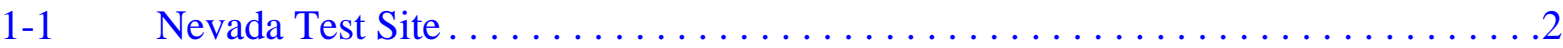

1-2 Corrective Action Unit 545, CAS Location Map ...................

A.1-1 Corrective Action Investigation Site Map for CAU 545 CASs . . . . . . . . . . A-2

A.3-1 Sample Locations at CAS 02-09-01, Mud Disposal Area ............ A-13

A.3-2 Radiological Survey for CAS 02-09-01, Mud Disposal Area . . . . . . . . . A A-15

A.3-3 Mounds of Drilling Mud at CAS 02-09-01 ................ A-17

A.4-1 Sample Locations at CAS 03-17-01, Waste Consolidation Site 3B . . . . . . . . A-23

A.4-2 Radiological Survey of CAS $03-17-01 \ldots \ldots \ldots \ldots \ldots \ldots \ldots \ldots \ldots$ A-27

A.5-1 Sample Locations at CAS 03-99-14, Radioactive Material Disposal Area ... A A-43

A.5-2 Radiological Survey for CAS $03-99-14 \ldots \ldots \ldots \ldots \ldots \ldots \ldots \ldots \ldots$ A-45

A.5-3 Geophysical Survey for CAS 03-99-14 . . . . . . . . . . . . . . A-47

A.6-1 Sample Locations at CAS 09-23-02, U-9y Drilling Mud Disposal Crater.... . A-56

A.6-2 Radiological Survey at CAS $09-23-02 \ldots \ldots \ldots \ldots \ldots \ldots \ldots \ldots$ A-58

A.6-3 Geophysical Survey at CAS $09-23-02 \ldots \ldots \ldots \ldots \ldots \ldots \ldots \ldots$ A-60

A.7-1 Sample Locations at CAS 20-19-01, Waste Disposal Site . . . . . . . . . A-70

A.7-2 Radiological Survey for CAS $20-19-01 \ldots \ldots \ldots \ldots \ldots \ldots \ldots \ldots$ A-72

A.7-3 Overall View of Debris at CAS $20-19-01 \ldots \ldots \ldots \ldots \ldots \ldots \ldots \ldots$ A-73

C.1-1 Risk-Based Corrective Action Decision Process $\ldots \ldots \ldots \ldots \ldots \ldots \ldots$ C-2

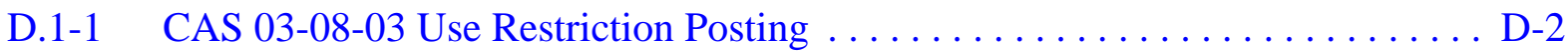

D.1-2 CAS 03-23-05 Use Restriction Postings................... D-3

D.1-3 CAS 03-08-03 Land Use Restriction Boundary $\ldots \ldots \ldots \ldots \ldots \ldots \ldots$ D-7

D.1-4 CAS 03-23-05 Land Use Restriction Boundary ................ D-10 


\section{List of Tables}

Number

Title

Page

2-1 Maximum Concentration of Detected Contaminants for CAS 02-09-01, Mud Disposal Area .................................. 22

2-2 Statistical Values for Corrective Action Investigation Probabilistic Results for Significant COPCs, CAS 03-17-01, Waste Consolidation Site 3B ....... 23

2-3 Maximum Concentration of Detected Contaminants for CAS 03-17-01, Waste Consolidation Site 3B ........................... 23

2-4 Maximum Concentration of Detected Contaminants for CAS 03-99-14, Radioactive Material Disposal Area.......................... 25

2-5 Maximum Concentration of Detected Contaminants for CAS 09-23-02, U-9y Drilling Mud Disposal Crater ........................ 26

2-6 Maximum Concentration of Detected Contaminants for CAS 20-19-01,

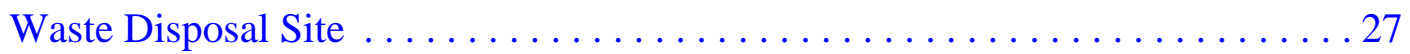

2-7 Definition of Final Action Levels for CAU 545

Contaminants of Potential Concern .......................... 31

A.2-1 Corrective Action Investigation Activities Conducted at Each

Corrective Action Site To Meet Corrective Action Investigation Plan

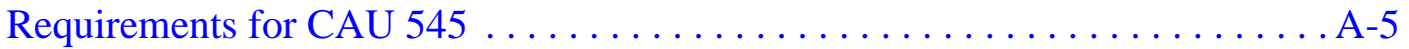

A.2-2 Laboratory Analytical Parameters and Methods,

CAU 545 Investigation Samples. .

A.3-1 Samples Collected at CAS 02-09-01, Mud Disposal Area. . . . . . . . . . . . A-14

A.3-2 Soil Sample Results for Gamma-Emitting Radionuclides Detected above Minimum Detectable Concentrations at CAS 02-09-01, Mud Disposal Area..................................

A.3-3 Soil Sample Results for Isotopes Detected above Minimum Detectable Concentrations at CAS 02-09-01, Mud Disposal Area . .

A.4-1 Samples Collected at CAS 03-17-01, Waste Consolidation Site 3B . . . . . . . A-24 


\section{List of Tables (Continued)}

Number

Title

Page

A.4-2 Soil Sample Results for RCRA Metals Detected above Minimum

Detectable Concentrations at CAS 03-17-01,

Waste Consolidation Site 3B .......................... A-29

A.4-3 Probabilistic Soil Sample Results for Gamma-Emitting Radionuclides

Detected above Minimum Detectable Concentrations at CAS 03-17-01,

Waste Consolidation Site 3B . . . . . . . . . . . . . . . . . . . . . . A-31

A.4-4 Judgmental Soil Sample Results for Gamma-Emitting Radionuclides

Detected above Minimum Detectable Concentrations at CAS 03-17-01,

Waste Consolidation Site 3B .......................... A-34

A.4-5 Probabilistic Soil Sample Results for Isotopes Detected above Minimum

Detectable Concentrations at CAS 03-17-01, Waste Consolidation Site 3B .. A-37

A.4-6 Judgmental Soil Sample Results for Isotopes Detected above Minimum

Detectable Concentrations at CAS 03-17-01, Waste Consolidation Site 3B .. A-39

A.5-1 Samples Collected at CAS 03-99-14, Radioactive Material Disposal Area ... A-44

A.5-2 Soil Sample Results for Total VOCs Detected above Minimum

Detectable Concentrations at CAS 03-99-14, Radioactive

Material Disposal Area . .............................. A-49

A.5-3 Soil Sample Results for TPH-DRO Detected above Minimum Detectable

Concentrations at CAS 03-99-14, Radioactive Material Disposal Area ..... A A-50

A.5-4 Soil Sample Results for RCRA Metals Detected above Minimum

Detectable Concentrations at CAS 03-99-14, Radioactive

Material Disposal Area . .......................... A-50

A.5-5 Soil Sample Results for PCBs Detected above Minimum Detectable

Concentrations at CAS 03-99-14, Radioactive Material Disposal Area ..... A A-51

A.5-6 Soil Sample Results for Gamma-Emitting Radionuclides Detected above Minimum Detectable Concentrations at CAS 03-99-14, Radioactive Material Disposal Area $\ldots \ldots \ldots \ldots \ldots \ldots \ldots \ldots \ldots \ldots$ A-53 


\section{List of Tables (Continued)}

Number

Title

Page

A.5-7 Soil Sample Results for Isotopes Detected above Minimum Detectable Concentrations at CAS 03-99-14, Radioactive Material Disposal Area ..... . A-54

A.6-1 Samples Collected at CAS 09-23-02, U-9y Drilling Mud Disposal Crater. . . A A-57

A.6-2 Soil Sample Results for Total VOCs Detected above Minimum Detectable Concentrations at CAS 09-23-02, U-9y Drilling Mud Disposal Crater. .

A.6-3 Soil Sample Results for TPH-DRO Detected above

Minimum Detectable Concentrations at CAS 09-23-02, U-9y Drilling Mud Disposal Crater...................... A-64

A.6-4 Soil Sample Results for RCRA Metals Detected above Minimum Detectable Concentrations at CAS 09-23-02, U-9y Drilling Mud Disposal Crater..................... A-65

A.6-5 Soil Sample Results for Gamma-Emitting Radionuclides Detected above Minimum Detectable Concentrations at CAS 09-23-02, U-9y Drilling Mud Disposal Crater..................... A-66

A.6-6 Soil Sample Results for Isotopes Detected above Minimum Detectable Concentrations at CAS 09-23-02, U-9y Drilling Mud Disposal Crater ..... A-67

A.7-1 Samples Collected at CAS 20-19-01, Waste Disposal Site........... A-71

A.7-2 Soil Sample Results for Total VOCs Detected above Minimum

Detectable Concentrations at CAS 20-19-01, Waste Disposal Site. ........ A-76

A.7-3 Soil Sample Results for Total SVOCs Detected above Minimum

Detectable Concentrations at CAS 20-19-01, Waste Disposal Site......... A-77

A.7-4 Soil Sample Results for TPH-DRO Detected above Minimum

Detectable Concentrations at CAS 20-19-01, Waste Disposal Site. ........ A-78

A.7-5 Soil Sample Results for RCRA Metals Detected above Minimum Detectable Concentrations at CAS 20-19-01, Waste Disposal Site. ....... A-79 


\section{List of Tables (Continued)}

Number

Title

Page

A.7-6 Soil Sample Results for PCBs Detected above Minimum Detectable Concentrations at CAS 20-19-01, Waste Disposal Site............... A-80

A.7-7 Soil Sample Results for Gamma-Emitting Radionuclides Detected above Minimum Detectable Concentrations at CAS 20-19-01, Waste Disposal Site . . . . . . . . . . . . . . . . . . . A-81

A.7-8 Soil Sample Results for Isotopes Detected above Minimum Detectable Concentrations at CAS 20-19-01, Waste Disposal Site. . . . . . . . . A-82

A.8-1 Waste Summary. . . . . . . . . . . . . . . . . . . . .

B.1-1 Input Values and VSP Determined Minimum Number of Samples for CAU 545, CAS $03-17-01 \ldots \ldots \ldots \ldots \ldots \ldots \ldots \ldots \ldots \ldots \ldots \ldots \ldots \ldots \ldots$

B.1-2 CAU 545 Analyses Performed $\ldots \ldots \ldots \ldots \ldots \ldots \ldots \ldots \ldots \ldots \ldots$

B.1-3 Analytes Failing Sensitivity Criteria $\ldots \ldots \ldots \ldots \ldots \ldots \ldots \ldots \ldots \ldots$

B.1-4 Precision Measurements $\ldots \ldots \ldots \ldots \ldots \ldots \ldots \ldots \ldots \ldots \ldots \ldots \ldots$

B.1-5 Accuracy Measurements $\ldots \ldots \ldots \ldots \ldots \ldots \ldots \ldots \ldots \ldots \ldots \ldots$

B.1-6 Rejected Measurements . . . . . . . . . . . . . . . . . . . . B-10

B.1-7 Key Assumptions.............................. B-12

C.1-1 Maximum Reported Value for Tier 1 Comparison . . . . . . . . . . . . . C-8

C.1-2 Contaminants of Potential Concern Detected above

Preliminary Action Levels $(\mu \mathrm{g} / \mathrm{kg}) \ldots \ldots \ldots \ldots \ldots \ldots \ldots \ldots$. . . . . . . . . .

C.1-3 Tier 2 SSTLs and CAU 545 Results for Hazardous Constituents of Diesel ... C-14

C.1-4 Final Action Levels for Radionuclides . . . . . . . . . . . . . . C-15

E.1-1 Sample Location Coordinates $\ldots \ldots \ldots \ldots \ldots \ldots \ldots \ldots \ldots \ldots \ldots \ldots \ldots$ 


\section{List of Acronyms and Abbreviations}

$\mathrm{Am}$

ASTM

bgs

CADD

CAI

CAIP

CAS

CAS

CAU

CLP

$\mathrm{cm}$

COC

COPC

cps

CR

Cs

CSM

$\mathrm{CZ}$

DOE

DQA

DQI

DQO

DRO

EPA

EPC

$\mathrm{Eu}$
Americium

American Society for Testing and Materials

Below ground surface

Corrective Action Decision Document

Corrective Action Investigation

Corrective Action Investigation Plan

Corrective Action Site

Chemical Abstracts Service

Corrective Action Unit

Contract Laboratory Program

Centimeter

Contaminant of concern

Contaminant of potential concern

Counts per second

Closure Report

Cesium

Conceptual site model

Contamination zone

U.S. Department of Energy

Data quality assessment

Data quality indicator

Data quality objective

Diesel-range organics

U.S. Environmental Protection Agency

Exposure point concentration

Europium 


\section{List of Acronyms and Abbreviations (Continued)}

\begin{tabular}{|c|c|}
\hline FAL & Final action level \\
\hline FD & Field duplicate \\
\hline FFACO & Federal Facility Agreement and Consent Order \\
\hline FID & Flame-ionization detector \\
\hline FSL & Field-screening level \\
\hline FSR & Field-screening result \\
\hline $\mathrm{ft}$ & Foot \\
\hline gal & Gallon \\
\hline $\mathrm{g} / \mathrm{m}^{3}$ & Grams per cubic meter \\
\hline $\mathrm{g} / \mathrm{yr}$ & Grams per year \\
\hline GPS & Global positioning system \\
\hline GRO & Gasoline-range organics \\
\hline HWAA & Hazardous waste accumulation area \\
\hline ID & Identification \\
\hline IDW & Investigation-derived waste \\
\hline in. & Inch \\
\hline LCS & Laboratory control sample \\
\hline $\mathrm{m}$ & Meter \\
\hline $\mathrm{m} / \mathrm{sec}$ & Meters per second \\
\hline $\mathrm{m}^{2}$ & Square meter \\
\hline MDC & Minimum detectable concentration \\
\hline $\mathrm{mg} / \mathrm{kg}$ & Milligrams per kilogram \\
\hline $\mathrm{mi}$ & Mile \\
\hline mrem & Millirem \\
\hline mrem/yr & Millirem per year \\
\hline MS & Matrix spike \\
\hline
\end{tabular}




\section{List of Acronyms and Abbreviations (Continued)}

\begin{tabular}{|c|c|}
\hline MSD & Matrix spike duplicate \\
\hline N/A & Not applicable \\
\hline NAC & Nevada Administrative Code \\
\hline NAD & North American Datum \\
\hline ND & Nondetect \\
\hline NDEP & Nevada Division of Environmental Protection \\
\hline NIOSH & National Institute for Occupational Safety and Health \\
\hline NIST & National Institute of Standards and Technology \\
\hline NNSA/NSO & $\begin{array}{l}\text { U.S. Department of Energy, National Nuclear Security Administration } \\
\text { Nevada Site Office }\end{array}$ \\
\hline NTS & Nevada Test Site \\
\hline $\mathrm{Pa}$ & Protactinium \\
\hline PAL & Preliminary action level \\
\hline PCB & Polychlorinated biphenyl \\
\hline $\mathrm{pCi} / \mathrm{g}$ & Picocuries per gram \\
\hline POC & Performance objective criteria \\
\hline PPE & Personal protective equipment \\
\hline ppm & Parts per million \\
\hline PRG & Preliminary Remediation Goal \\
\hline PSM & Potential source material \\
\hline $\mathrm{Pu}$ & Plutonium \\
\hline QA & Quality assurance \\
\hline QAPP & Quality Assurance Project Plan \\
\hline QC & Quality control \\
\hline $\mathrm{Ra}$ & Radium \\
\hline RadCon & Radiological Control \\
\hline RBCA & Risk-based corrective action \\
\hline
\end{tabular}




\section{List of Acronyms and Abbreviations (Continued)}

\begin{tabular}{|c|c|}
\hline RBSL & Risk-based screening level \\
\hline RCRA & Resource Conservation and Recovery Act \\
\hline RESRAD & Residual Radioactive \\
\hline RMA & Radioactive material area \\
\hline RPD & Relative percent difference \\
\hline RWMS & Radioactive Waste Management Site \\
\hline SCL & Sample collection log \\
\hline SDG & Sample delivery group \\
\hline $\mathrm{Sr}$ & Strontium \\
\hline SSTL & Site-specific target level \\
\hline SVOC & Semivolatile organic compound \\
\hline TCLP & Toxicity Characteristic Leaching Procedure \\
\hline Th & Thorium \\
\hline $\mathrm{TPH}$ & Total petroleum hydrocarbons \\
\hline $\mathrm{U}$ & Uranium \\
\hline UCL & Upper confidence level \\
\hline UR & Use restriction \\
\hline UTM & Universal Transverse Mercator \\
\hline UXO & Unexploded ordnance \\
\hline VOC & Volatile organic compound \\
\hline VSP & Visual Sample Plan \\
\hline $\mathrm{yr}$ & Year \\
\hline$\% \mathrm{R}$ & Percent recovery \\
\hline$\mu \mathrm{g} / \mathrm{kg}$ & Micrograms per kilogram \\
\hline
\end{tabular}




\section{Executive Summary}

This Corrective Action Decision Document (CADD)/Closure Report (CR) has been prepared for Corrective Action Unit (CAU) 545, Dumps, Waste Disposal Sites, and Buried Radioactive Materials, in Areas 2, 3, 9, and 20 of the Nevada Test Site, Nevada, in accordance with the Federal Facility Agreement and Consent Order that was agreed to by the State of Nevada; U.S. Department of Energy (DOE), Environmental Management; U.S. Department of Defense; and DOE, Legacy Management (1996, as amended February 2008). Corrective Action Unit 545 is comprised of the following eight Corrective Action Sites (CASs):

- 02-09-01, Mud Disposal Area

- 03-08-03, Mud Disposal Site

- 03-17-01, Waste Consolidation Site 3B

- 03-23-02, Waste Disposal Site

- 03-23-05, Europium Disposal Site

- 03-99-14, Radioactive Material Disposal Area

- 09-23-02, U-9y Drilling Mud Disposal Crater

- 20-19-01, Waste Disposal Site

While all eight CASs are addressed in this CADD/CR, sufficient information was available for the following three CASs; therefore, a field investigation was not conducted at these sites:

- For CAS 03-08-03, though the potential for subsidence of the craters was judged to be extremely unlikely, the data quality objective (DQO) meeting participants agreed that sufficient information existed about disposal and releases at the site and that a corrective action of close in place with a use restriction is recommended. Sampling in the craters was not considered necessary.

- For CAS 03-23-02, there were no potential releases of hazardous or radioactive contaminants identified. Therefore, the Corrective Action Investigation Plan for CAU 545 concluded that: "Sufficient information exists to conclude that this CAS does not exist as originally identified. Therefore, there is no environmental concern associated with CAS 03-23-02.” This CAS is closed with no further action.

- For CAS 03-23-05, existing information about the two buried sources and lead pig was considered to be sufficient, and safety concerns existed about the stability of the crater component. Therefore, a corrective action of close in place with a use restriction is recommended, and sampling at the site was not considered necessary. 
The purpose of this CADD/CR is to provide justification and documentation to support the recommendation for closure of CAU 545 with no further corrective action. To achieve this, corrective action investigation (CAI) activities were performed from August 20 through November 02, 2007, as set forth in the CAU 545 Corrective Action Investigation Plan. The purpose of the CAI was to fulfill the following data needs as defined during the DQO process:

- Determine whether contaminants of concern (COCs) are present.

- If COCs are present, determine their nature and extent.

- Provide sufficient information and data to complete appropriate corrective actions.

The CAU 545 dataset from the investigation results was evaluated based on the data quality indicator parameters. This evaluation demonstrated the quality and acceptability of the dataset for use in fulfilling the DQO data needs.

Analytes detected during the CAI were evaluated against final action levels established in this CADD/CR. The results of the CAI identified no COCs at the five CASs investigated in CAU 545.

As a best management practice, repair of the fence enclosing CAS 03-08-03 has been completed.

Therefore, the DOE, National Nuclear Security Administration Nevada Site Office provides the following recommendations:

- $\quad$ Close in place COCs at CASs 03-08-03 and 03-23-05 with use restrictions.

- $\quad$ No further corrective action for CAU 545.

- $\quad$ No Corrective Action Plan.

- Corrective Action Unit 545 should be moved from Appendix III to Appendix IV of the Federal Facility Agreement and Consent Order.

- A Notice of Completion to the DOE, National Nuclear Security Administration Nevada Site Office is requested from the Nevada Division of Environmental Protection for closure of CAU 545. 


\subsection{Introduction}

This Corrective Action Decision Document (CADD)/Closure Report (CR) presents information to support closure of Corrective Action Unit (CAU) 545, Dumps, Waste Disposal Sites, and Buried Radioactive Materials, Nevada Test Site (NTS), Nevada. The corrective actions described in this document are in accordance with the Federal Facility Agreement and Consent Order (FFACO) that was agreed to by the State of Nevada; U.S. Department of Energy (DOE), Environmental Management; U.S. Department of Defense; and DOE, Legacy Management (FFACO, 1996; as amended February 2008). The NTS is approximately 65 miles (mi) northwest of Las Vegas, Nevada (Figure 1-1).

Corrective Action Unit 545 is comprised of the eight Corrective Action Sites (CASs) that are shown on Figure 1-2 and listed below:

- 02-09-01, Mud Disposal Area

- 03-08-03, Mud Disposal Site

- 03-17-01, Waste Consolidation Site 3B

- 03-23-02, Waste Disposal Site

- 03-23-05, Europium Disposal Site

- 03-99-14, Radioactive Material Disposal Area

- 09-23-02, U-9y Drilling Mud Disposal Crater

- 20-19-01, Waste Disposal Site

A detailed discussion of the history of this CAU is presented in the Corrective Action Investigation Plan for Corrective Action Unit 545: Dumps, Waste Disposal Sites, and Buried Radioactive Materials (NNSA/NSO, 2007). This document provides or references the specific information necessary to support closure of this CAU.

\subsection{Purpose}

This CADD/CR provides justification why no further corrective action is necessary, how and why use restrictions (URs) will be applied, and the technical rationale for implemented closure activities. This justification is based on the corrective actions implemented and the results of investigative activities that were conducted in accordance with the CAU 545 Corrective Action Investigation Plan (CAIP) (NNSA/NSO, 2007). 


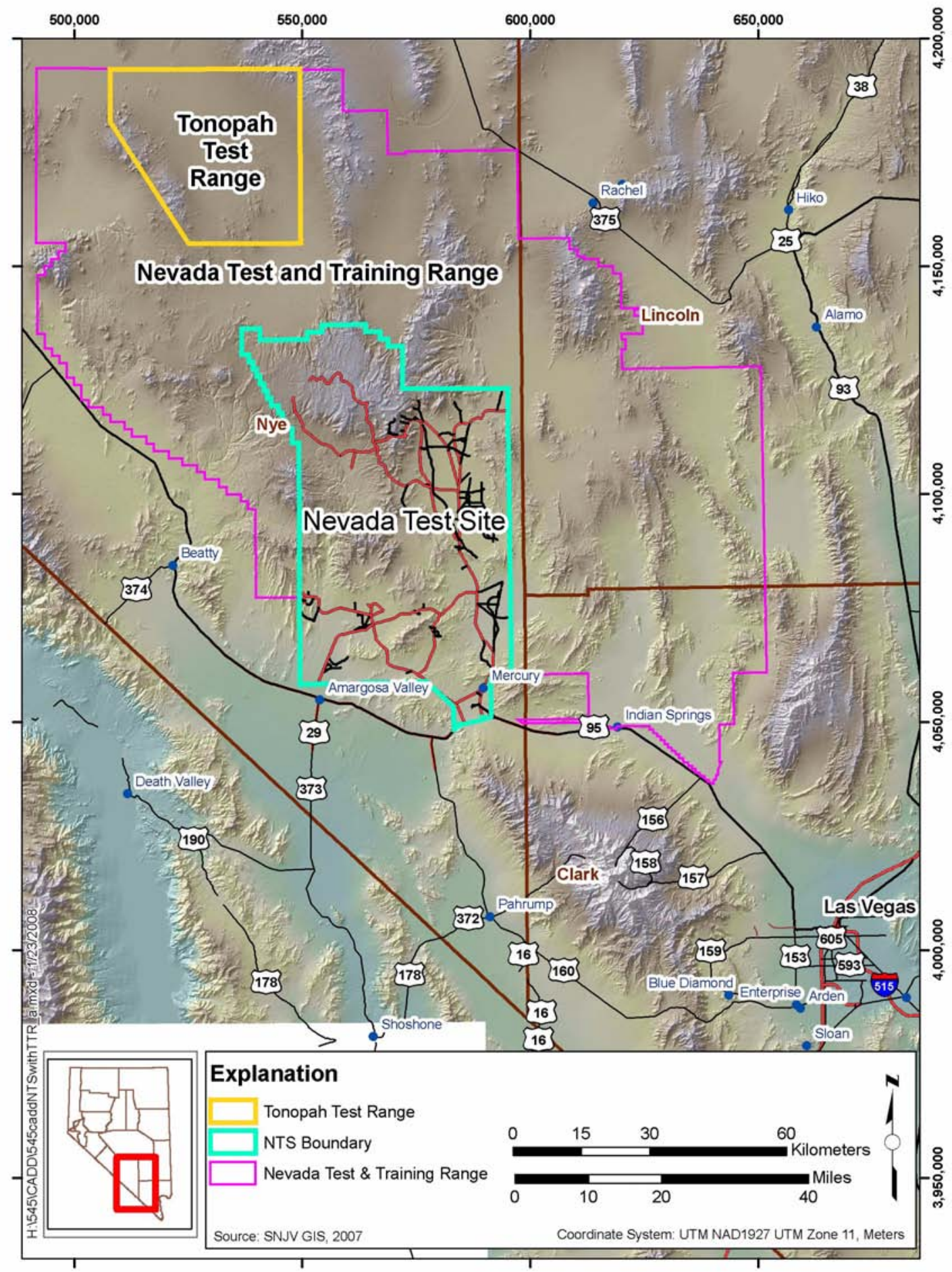

Figure 1-1

Nevada Test Site 


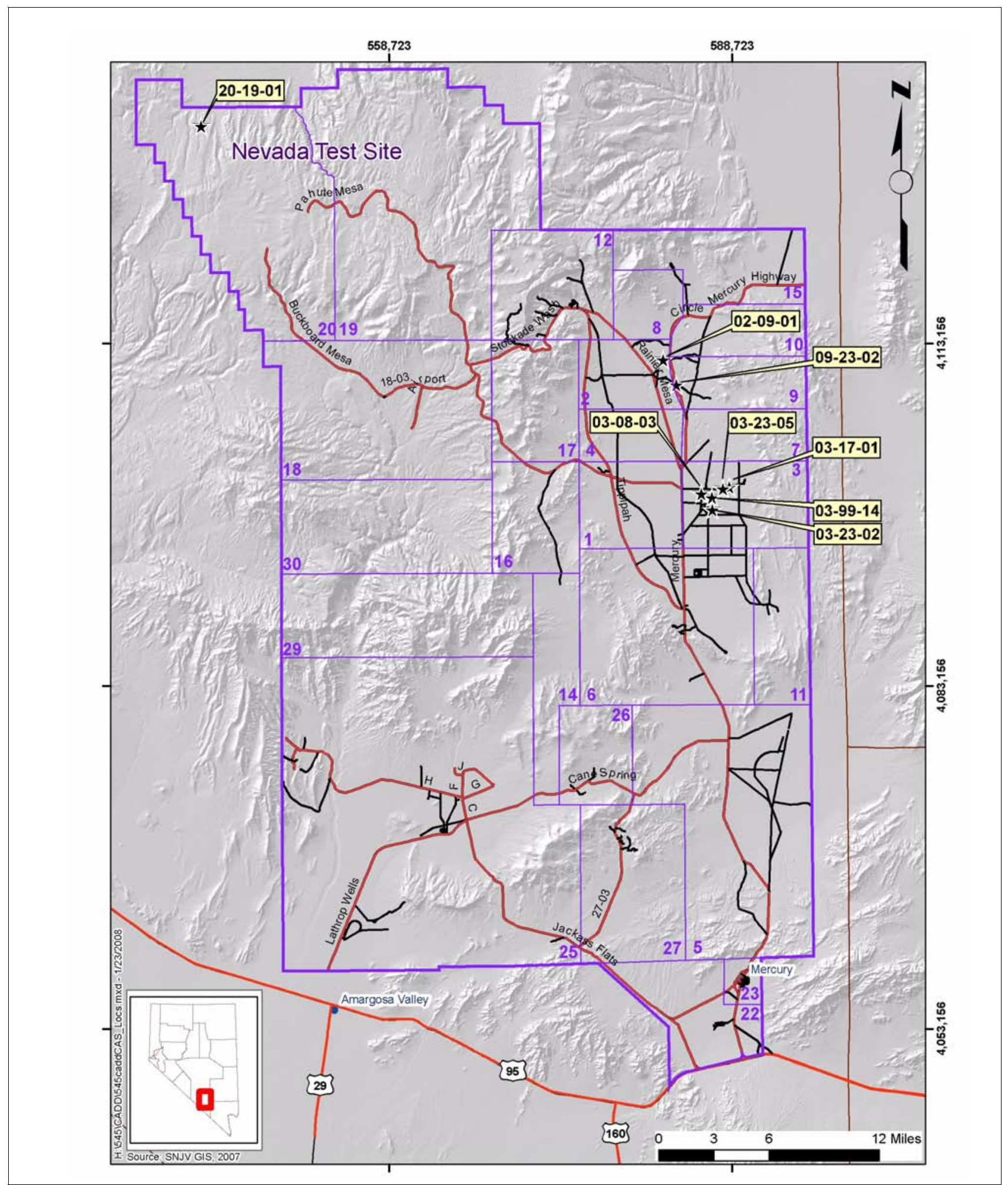

Figure 1-2

Corrective Action Unit 545, CAS Location Map 
Corrective Action Unit 545, Dumps, Waste Disposal Sites, and Buried Radioactive Materials, consists of eight inactive sites located in the northeastern portion of Area 2, in the west-central portion of Area 3, on the western side of Area 9, and in the northwestern portion of Area 20. The eight CASs at CAU 545 consist of craters used for mud disposal, surface or buried waste disposed within craters or potential crater areas, and sites where surface or buried waste was disposed. The CAU 545 sites were used to support nuclear testing conducted from the 1950s through the early 1990s.

Corrective Action Sites 02-09-01, 03-08-03, and 09-23-02 consist of crater components that were used for the disposal of drilling mud. Records for disposal activities exist for CASs 03-08-03 and 09-23-02, but no records for disposal at CAS 02-09-01 were identified. Disposal of drilling mud at CAS 02-09-01 was along the west, south and east sides of the U-2ei crater, and extends outward approximately $250 \mathrm{ft}$. Disposal of radioactively contaminated drilling mud at CAS 03-08-03 occurred at a ramp into the craters located at the north end of the U-3ai and U-3be double crater. Records indicate radioactively contaminated drilling mud was disposed at CAS 03-08-03. Disposal of drilling mud at CAS 09-23-02 occurred at the U-9y crater bottom. Mud disposal records for CAS 09-23-02 do not indicate the contamination status of the drilling mud; however, the overflow from the crater into a wash located immediately east of the crater was documented.

Corrective Action Sites 03-17-01, 03-23-05, and 20-19-01 were used for the storage and/or disposal of materials used in the testing program at NTS. Corrective Action Site 03-17-01 was used to store debris and soil that originated from aboveground testing sites, as well as a consolidation location for debris originating from other testing and disposal sites. Corrective Action Site 03-23-05 was used in the burial of two radioactive sources; one encapsulated in a lead pig buried in the northwest component of the site, and the other source, along with the contaminated third floor of a tower used at the site during the underground testing, buried within the uncollapsed U-3ee crater. Corrective Action Site 20-19-01 consists of construction debris (e.g., wood, plastic, metal), as well as used oil filters from activities related to the underground testing at the U-20p test hole.

For CASs 03-23-02 and 03-99-14, documentation for the storage or disposal of materials was not identified for either site. Corrective Action Site 03-23-02 consists of the uncollapsed crater at the U-3gi test hole. Corrective Action Site 03-99-14 consists of an approximately 300-ft-long trench and 
berm; the purpose is unknown. Corrective Action Site 03-99-14, along with the surrounding area, is posted as a "Radioactive Material Area," due to nearby aboveground nuclear testing associated with several tests. The area encompassing the radioactive material area (RMA) will be investigated by the Soils Project for CAU 104.

\subsection{Scope}

The scope of this CADD/CR is to justify that no further corrective action is required at CAU 545, Dumps, Waste Disposal Sites, and Buried Radioactive Materials. The activities conducted to accomplish this scope included the following:

- Removal of surface debris and/or materials to facilitate sampling

- Radiological surveys

- $\quad$ Field screening

- Collection of environmental samples for laboratory analysis

- Collection of step-out samples to define the lateral and vertical extent of the contamination

- Collection of waste samples to determine the proper disposal of wastes

- Collection of quality control (QC) samples

Although the following CASs were not included in the scope of the field sampling activities for CAU 545, they are included in the scope of the CADD/CR:

- For CAS 03-08-03, though the potential for subsidence of the craters was judged to be extremely unlikely, the data quality objective (DQO) meeting participants agreed that sufficient information existed about the disposal and releases and that a corrective action of close in place with a UR is recommended. Sampling in the craters was not considered necessary.

- For CAS 03-23-02, there were no potential releases of hazardous or radioactive contaminants identified. Therefore, the CAIP for CAU 545 concluded: "Sufficient information exists to conclude that this CAS does not exist as originally identified. Therefore, there is no environmental concern associated with CAS 03-23-02." This CAS is closed with no further action.

- For CAS 03-23-05, existing information about the two buried sources and lead pig was considered to be sufficient, and safety concerns existed about the stability of the crater component. Therefore, a corrective action of close in place with a UR is recommended, and sampling at the site was not considered necessary. 


\subsection{Corrective Action Decision Document/Closure Report Contents}

This CADD/CR is divided into the following sections and appendices:

Section 1.0 - Introduction: Summarizes the purpose, scope, and contents of this CADD/CR.

Section 2.0 - Corrective Action Investigation (CAI) Summary: Summarizes the investigation field activities, the results of the investigation, the need for corrective action, and a summary of the results of the data quality objective (DQO) assessment.

Section 3.0 - Recommendation: States why no further corrective action is required.

Section 4.0 - References: Provides a list of the referenced documents used in the preparation of this $\mathrm{CADD} / \mathrm{CR}$.

Appendix A - Corrective Action Investigation Results: Provides a description of the project objectives, field investigation and sampling activities, investigation results, waste management, and quality assurance (QA). Sections A.3.0 through A.7.0 provide specific information regarding field activities, sampling methods, and laboratory analytical results from the investigation.

Appendix B - Data Assessment: Provides a data quality assessment (DQA) that reconciles DQO assumptions and requirements to the investigation results.

Appendix C - Risk Assessment: Presents an evaluation of risk associated with the establishment of final action levels (FALs).

Appendix D - Closure Activity Summary: Provides details on the completed closure activities and includes the required verification activities and supporting documentation.

Appendix E - Sample Location Coordinates: Provides the geophysical coordinates of the locations sampled.

Appendix F - Nevada Division of Environmental Protection (NDEP) Comments: Contains NDEP comments on the draft version of this document. 


\subsubsection{Applicable Programmatic Plans and Documents}

Page 7 of 34

All investigation activities were performed in accordance with the following documents:

- $\quad$ The CAIP for CAU 545 (NNSA/NSO, 2007)

- Industrial Sites Quality Assurance Project Plan (QAPP) (NNSA/NV, 2002)

- FFACO (1996, as amended February 2008)

- Approved procedures

\subsubsection{Data Quality Assessment Summary}

The DQA is presented in Appendix B and includes an evaluation of the DQIs to determine the degree of acceptability and usability of the reported data in the decision-making process. The DQO process ensures that the right type, quality, and quantity of data will be available to support the resolution of those decisions at an appropriate level of confidence. Using both the DQO and DQA processes help to ensure that DQO decisions are sound and defensible.

The DQA process as presented in Appendix B is comprised of the following steps:

- Step 1: Review DQOs and Sampling Design

- Step 2: Conduct a Preliminary Data Review

- $\quad$ Step 3: Select the Test

- Step 4: Verify the Assumptions

- Step 5: Draw Conclusions from the Data

Sample locations that support the presence and/or extent of contamination at each CAS are shown in Appendix B. Based on the results of the DQA presented in Appendix B, the nature and extent of COCs at CAU 545 have been defined adequately to support decisions on corrective actions. The DQA also determined that information generated during the investigation support the conceptual site model (CSM) assumptions and the data collected met the DQOs and support their intended use in the decision-making process. 


\subsection{Corrective Action Investigation Summary}

The following sections summarize the investigation activities, investigation results, and justify why no further corrective action is needed at CAU 545. Detailed investigation activities and results for individual CAU 545 CASs are presented in Appendix A.

\section{$2.1 \quad$ Investigation Activities}

Corrective action investigation activities were performed as set forth in the CAIP for CAU 545 (NNSA/NSO, 2007) from August 20 through November 2, 2007, at the five CASs that were identified during the DQO process for sampling and further evaluation. The purpose of the CAU 545 CAI was to address the decision statements in the project-specific DQOs by:

- Determining whether contaminants of concern (COCs) are present in the soils associated with CASs 02-09-01, 03-17-01, 03-99-14, 09-23-02, and 20-19-01 in CAU 545.

- Determining the lateral and vertical extent of identified COCs.

- Ensuring adequate data have been collected to close the sites under NDEP, Resource Conservation and Recovery Act (RCRA) (CFR, 2006a), Toxic Substance Control Act (CFR, 2006b), and DOE requirements.

The scope of the CAI included the following activities:

- Performing radiological surveys (i.e., static, scanning, and swipe collection).

- Field screening soil samples for total alpha and beta/gamma radiation.

- Collecting environmental samples for laboratory analyses to determine the presence of COCs and to define the vertical and lateral extent of COCs, if present.

- Collecting QC samples for laboratory analyses to ensure that the data generated from the analysis of investigation samples meet the requirements of the DQIs.

A combination of judgmental and probabilistic sampling schemes were implemented to select sample locations and evaluate analytical results, as outlined in the CAIP for CAU 545 (NNSA/NSO, 2007). Judgmental sampling allows the methodical selection of sample locations that target the populations of interest (defined in the DQOs) rather than nonselective random locations. Probabilistic sampling 
uses random sample locations in the absence of adequate biasing factors to define site-wide contamination characteristics (e.g., average concentrations).

For the judgmental sampling scheme, individual sample results (rather than average concentrations) are used to compare to FALs. Therefore, statistical methods to generate site characteristics (averages) are not necessary (EPA, 2006). If good prior information is available on the target site of interest, then the sampling may be designed to collect samples only from areas known to have the highest concentration levels on the target site. If the observed concentrations from these samples are below the action level, then a decision can be made that the site does not contain unsafe levels of the contaminant without the samples being truly representative of the entire area.

The judgmental sampling design was used to confirm the existence of contamination at specific locations and provide information (such as extent of contamination) about specific areas of the site.

Confidence in judgmental sampling scheme decisions was established qualitatively by validation of the CSM and justification that sampling locations are the most likely locations to contain a COC, if a COC exists.

For the probabilistic sampling scheme, the average contaminant concentrations at the site in question were used to compare to FALs. The averages from sample analytical results for each constituent are an estimate of the true average contaminant concentrations. Because the average contaminant concentrations from samples is only an estimate of the true (unknown) average, it is uncertain how well the sample averages represent the actual averages. To reduce the probability of making a false negative decision error, the 95th percent upper confidence levels (UCLs) of the respective sample contaminant concentration averages were used to compare to FALs. Therefore, by definition, there is a 95 percent probability that the true average concentration is less than the 95th percent UCL of the sample average.

Confidence in probabilistic sampling scheme decisions was established by the validation of the CSM, justification that sampling locations are representative of site conditions, demonstration that a sufficient number of samples were collected, and contaminant distribution assumptions are valid and appropriate to the statistical test being performed. 
Waste characterization activities were conducted to gather sufficient information and data to support waste disposal decisions. Information regarding waste characterization is presented in Appendix A.

The following sections describe specific investigation activities conducted at each CAS. Additional information and details regarding the investigation is presented in Appendix A.

\subsubsection{Mud Disposal Area (CAS 02-09-01)}

The following subsections summarize the activities conducted at CAS 02-09-01.

\subsubsection{Radiological Survey}

Radiological walkover surveys were conducted over the mud spill areas inside and outside the fence, up to $50 \mathrm{ft}$ from the crater rim, at CAS 02-09-01. The survey did not identify elevated radioactivity on the mud-impacted area (Figure A.3-2); therefore, the radiological survey was not used in the selection of sample locations.

\subsubsection{Visual Inspection}

A visual inspection of the site did not identify any unusual staining or the presence of potentially containing hazardous or radiological materials (e.g., lead bricks, lead batteries, drums or other containers). The mounds of drilling mud (Figure A.3-1) and two sediment accumulation areas in the east disposal area were the only biasing factors. Because these were features identified for sample collection in the CAIP for CAU 545 (NNSA/NSO, 2007), no additional sample locations were identified.

\subsubsection{Field Screening}

Investigation samples were field screened for alpha and beta/gamma radiation. The field-screening results (FSRs) were compared to field-screening levels (FSLs) to guide subsequent sampling decisions where appropriate. Gross alpha radiation and beta/gamma radiation FSLs were not exceeded at CAS 02-09-01, and FSRs were not used in the selection of analytical samples. 


\subsubsection{Sample Collection}

Page 11 of 34

Decision I environmental sampling activities included the collection of biased surface and subsurface soil samples within the drilling mud disposal areas (Figure A.3-1) at this CAS.

Environmental samples were collected from six mounds of drilling mud and two sediment accumulation areas. Sample 545A001 was collected from the surface interval (0.0 to 0.5 foot (ft) below ground surface [bgs]) at location A01, the westernmost mound in the west disposal area (Figure A.3-1). As no biasing factors were detected within the mound profile the subsurface sample (545A006) was collected at the drilling mud/native soil interface (0.75 to $1.25 \mathrm{ft}$ bgs). At location A02, the second mound in the west disposal area, sample 545A002 was collected from the surface interval (0.0 to $0.5 \mathrm{ft}$ bgs) and the subsurface sample (545A007) was collected at the drilling mud/native soil interface (1.0 to $1.5 \mathrm{ft}$ bgs). For both mounds, gravel consistent with the surface rock in the area was mixed in with the drilling mud throughout the profiles. The presence of gravel in the mud suggests that either the mud has been used and the gravel represents drill cuttings; the mud was spilled onsite and mounded by dumping or pushing with mechanical equipment; or it was collected and transported to CAS 02-09-01.

Within the south disposal area, location A03 was established at the highest mound (approximately $7.0 \mathrm{ft}$ ) present outside of the 50-ft-worker-safety buffer. Samples collected at this location include the surface (545A003), a mid-mound subsurface sample (545A008) at 2.5 to $3.0 \mathrm{ft}$ bgs, and a sample (545A009) collected at the drilling mud/native soil interface (7.0 to $7.5 \mathrm{ft}$ bgs). The mud was fairly homogenous throughout the mound, though thin layers of the mud were present in the mid-section, and gravel was present through the entire profile.

Location A04 was at a mound, approximately 3.0 to $3.5 \mathrm{ft}$ high, selected for sampling because two T-posts were identified protruding from the mound at different angles. The mound and T-posts had the appearance of originating from a mud spill at another location. At location A04, a sample (545A004) and duplicate (545A005) were collected at the surface (0.0 to $0.5 \mathrm{ft}$ bgs); a sample (545A010) was collected from within the mound (2.0 to $2.5 \mathrm{ft}$ bgs), and a sample (545A011) was collected at the drilling mud/native soil interface (3.0 to $3.5 \mathrm{ft}$ bgs). The mound was homogenous throughout, with gravel present through the entire profile. 
Location A05 was also at a shorter mound (approximately $3.5 \mathrm{ft} \mathrm{high)} \mathrm{that} \mathrm{was} \mathrm{identified} \mathrm{for}$ sampling because the mud was a darker gray than the other mud at the site. The dried mud formed a subangular blocky structure which was unique to the mud in the area. A sample (545A012) was collected at the surface ( 0.0 to $0.5 \mathrm{ft}$ bgs), a sample (545A014) was collected within the mound (2.5 to $3.0 \mathrm{ft}$ bgs), and a sample (545A015) was collected at the drilling mud/native soil interface (3.0 to $3.5 \mathrm{ft}$ bgs).

Location A06 was at the highest mound (approximately $6 \mathrm{ft}$ high) in the eastern portion of the south disposal area. At location A06, a sample (545A013) was collected at the surface ( 0.0 to $0.5 \mathrm{ft}$ bgs), a sample (545A016) was collected within the mound (3.0 to $3.5 \mathrm{ft}$ bgs), and a sample (545A017) was collected at the drilling mud/native soil interface (5.5 to $6.0 \mathrm{ft}$ bgs).

Location A07 and A08 were selected at sediment accumulation points in the east disposal area. Before sampling, a rainstorm left several inches (in.) of runoff, from the surrounding mounds of drilling mud, at the two locations. Location A08 dried enough to be sampled a week later; however, location A07 had to be moved several feet to the west within the settling area, due to persistent standing water. Surface samples (545A018 and 545A019) were taken at locations A07 and A08 from 0.0 to 0.25 and 0.0 to $0.33 \mathrm{ft}$ bgs, respectively. Subsurface samples (545A020 and duplicate 545A021, and 545A022) were collected at locations A07 and A08 from 0.25 to $1.0 \mathrm{ft}$ bgs and 0.33 to $0.83 \mathrm{ft}$ bgs, respectively.

\subsubsection{Conceptual Site Model Validation}

From the data gathered at the site, there were no findings that conflicted with the CSM as presented in the CAIP for CAU 545 (NNSA/NSO, 2007).

\subsubsection{Waste Consolidation Site 3B (CAS 03-17-01)}

The following subsections summarize the activities conducted at CAS 03-17-01. Additional detail on the sampling activities is provided in Appendix A. 


\subsubsection{Radiological Survey}

A radiological walkover survey was conducted over the areas encompassing the circular and rectangular components of CAS 03-17-01 (Figure A.4-2). Several areas were found to have elevated radiological readings at approximately two times background and were used as biasing factors to select four locations for sampling.

\subsubsection{Geophysical Survey}

A geophysical survey was conducted over the areas encompassing the circular and rectangular components of CAS 03-17-01. The survey identified 101 discrete anomolies, interpreted to represent subsurface metal objects. Two of these locations were sampled. Details of the survey results, along with the survey map, are in the CAIP for CAU 545, Section A.2.3.1 (NNSA/NSO, 2007).

\subsubsection{Visual Inspection}

There were no visible biasing factors identified at this CAS. All locations were selected on the basis of the probabilistic sampling approach and from the geophysical and radiological survey data.

\subsubsection{Field Screening}

Investigation samples were field screened for alpha and beta/gamma radiation. The FSRs were compared to FSLs to guide subsequent sampling decisions where appropriate. Gross alpha radiation FSLs were exceeded in eight samples and beta/gamma radiation FSLs were exceeded in nine samples at CAS 03-17-01. For the eight background samples collected outside the CAS, the gross alpha radiation FSL was exceeded in one sample and beta/gamma radiation FSL was exceeded in three samples. All samples exceeding FSLs were analyzed for radiological constituents.

\subsubsection{Sample Collection}

Decision I environmental sampling activities at both the circular and rectangular components were conducted within the guidelines of a probabilistic sampling approach, with additional biased soil samples collected from the rectangular component (Figure A.4-1), and outside the fenced boundaries. At CAS 03-17-01, 24 probabilistic, 24 judgmental, and 8 background samples were collected. Locations B01 through B16, and B19 through B26 were predetermined randomized locations. 
Locations B17 and B18 were established at geophysical anomalies, and locations B27 through B30 were established at areas of elevated radiological readings. Step-out locations B31 through B38 were established at locations along the fence lines of both the circular and rectangular components. Background locations B39 through B46 were established in pairs, diagonally outward from the corners of the rectangular component. Locations B01 through B12 were established in the circular area, and B13 through B30, as well as B38, were established within the fence at the rectangular area.

Surface samples were collected at all locations from the interval of 0.0 to $0.5 \mathrm{ft}$ bgs. Brush obstructing several locations was cleared back. Other obstructions such as large rocks or scrap metal were not encountered at any sample location.

The FSLs for alpha were exceeded at locations B10, B13, B14, B27, B28, B29, and B41; from just above the FSL to 15 times FSL, and the FSLs for beta were exceeded at locations B14, B16, B17, B27, B28, B29, B30, B40, B41 and B42; from just above the FSL to 1.8 times the FSL. The values for the FSRs are maintained in the project files.

Because FSLs were exceeded, nine shallow subsurface samples were collected at the two components at six locations with the highest screening readings.

\subsubsection{Conceptual Site Model Validation}

From the data gathered at the site, there were no findings that conflicted with the CSM as presented in the CAIP for CAU 545 (NNSA/NSO, 2007).

\subsubsection{Radioactive Material Disposal Area (CAS 03-99-14)}

The following subsections summarize the activities conducted at CAS 03-99-14. Additional detail on the sampling activities is provided in Appendix A.

\subsubsection{Radiological Survey}

A radiological walkover survey was conducted over the area encompassing the berm and trench at CAS 03-99-14. Several areas were found to have elevated radiological readings at two to five times 
background. Trinity glass is present throughout the area and likely contributed to the elevated readings. Three of the four sample transects were placed across these areas (Figure A.5-2).

\subsubsection{Geophysical Survey}

A geophysical walkover survey was conducted at the CAS. Small surface and subsurface anomalies were detected, but no linear or significant subsurface features were found (Figure A.5-3). The geophysical survey was not used in the selection of sample locations.

\subsubsection{Visual Inspection}

No distinguishing features were visible in the trench or on the berm. The surface features for both components were uniform throughout the CAS.

\subsubsection{Field Screening}

Investigation samples were field screened for alpha and beta/gamma radiation. The FSRs were compared to FSLs to guide subsequent sampling decisions where appropriate. Gross alpha radiation FSLs were exceeded in two samples, and beta/gamma radiation FSLs were exceeded in three samples; all collected for background activities at CAS 03-99-14. All samples exceeding FSLs were analyzed.

\subsubsection{Sample Collection}

Decision I environmental sampling activities included the collection of biased surface and subsurface soil samples from both components (Figure A.5-1) at this CAS. Four transects were established across the trench and berm, and one location each was established on the trench and on berm, for a total of eight locations. Results from the radiological survey were employed to guide three transects across general areas of elevated radioactivity, while keeping the transects evenly spaced (approximately) apart across each quarter of the site. The fourth transect, encompassing locations C06 and C13, was an approximate equal distance between the third transect and the east end of the trench and berm.

Surface samples ( 0.0 to $0.5 \mathrm{ft}$ bgs) were collected from locations C01 through C05 outside the eastern, southern, and western perimeter of the CAS to measure the contribution of radiological 
contamination from sources other than the CAS. The two exceedences of the FSL for alpha, and the three for beta, were all from these background samples.

Surface samples were also collected at each of the eight locations (C06 through C13) in the four transects across the trench and berm. Neither the alpha nor the beta FSL were exceeded in any samples. Consequently, subsurface samples were not collected at the four locations in the trench, and just one shallow subsurface sample per location was collected from the berm/native soil interface at the four berm locations, as specified in the CAIP for CAU 545 (NNSA/NSO, 2007).

No staining or other biasing factors were found within the soil profile at any of the berm locations.

\subsubsection{Conceptual Site Model Validation}

From the data gathered at the site, there were no findings that conflicted with the CSM as presented in the CAIP for CAU 545 (NNSA/NSO, 2007).

\subsubsection{U-9y Drilling Mud Disposal Crater (CAS 09-23-02)}

The following subsections summarize the activities conducted at CAS 09-23-02. Because of safety concerns, only the wash component of this CAS was sampled. Additional detail on the sampling activities is provided in Appendix A.

\subsubsection{Radiological Survey}

A radiological walkover survey was conducted over the wash component of CAS 09-23-02. No areas of elevated radiological readings were found. Therefore, the radiological survey was not used in the selection of sample locations (Figure A.6-2).

\subsubsection{Geophysical Survey}

A geophysical walkover survey was conducted at the CAS. No linear or significant subsurface features were found (Figure A.6-3). Two anomalies, one along the south shoulder of the wash, and one along the east boundary of the CAS, were interpreted to possibly indicate areas of different soil type. One sample location was selected over each anomaly. 


\subsubsection{Visual Inspection}

Visible features that were used to establish biased locations were limited to areas where suspended solids (i.e., silts and clays) settled out of water moving through the wash (i.e., settling areas). Two locations within the CAS, and two locations downstream from the CAS, were established at these areas. Other visible biasing factors at the CAS were not present.

\subsubsection{Field Screening}

Investigation samples were field screened for alpha and beta/gamma radiation. The FSRs were compared to FSLs to guide subsequent sampling decisions where appropriate. Gross alpha radiation FSLs were not exceeded, but beta/gamma radiation FSLs were exceeded in four samples (and one duplicate) at CAS 09-23-02. All samples exceeding FSLs were analyzed.

\subsubsection{Sample Collection}

Decision I environmental sampling activities included the collection of biased surface and subsurface soil samples within the wash and in two settling areas immediately downgradient (Figure A.6-1).

Within CAS 09-23-02, two locations were selected based upon the geophysical survey and two locations were selected in areas where fine sediment settled out from flowing runoff. Location D01 was selected at the settling area in the wash closest to the U-9y crater. Sample 545D001 was collected from the surface interval ( 0.0 to $0.5 \mathrm{ft}$ bgs) but did not exceed FSLs. A shallow subsurface sample (545D009) was collected from 0.5 to $1.0 \mathrm{ft}$ bgs, which exceeded the FSL for beta. Further down the soil profile at location D01, a layer of light-colored fine material, that may have been drilling mud, was encountered at 2.0 to $2.5 \mathrm{ft}$ bgs. Sample 545D010 was collected from this layer but did not exceed FSLs. The interface of the wash material with the native soil was encountered at the interval of 4.0 to $4.5 \mathrm{ft}$ bgs. Sample 545D011 was collected at this interface but also did not exceed FSLs.

Location D02 was selected in the lower third of the wash within the CAS (Figure A.6-1), at an obvious settling area. A sample (545D002) was collected from the surface interval ( 0.0 to $0.5 \mathrm{ft}$ bgs), which did not exceed FSLs. Sample 545D013 was collected from the shallow subsurface interval between 2.0 and $2.5 \mathrm{ft}$ bgs and exceeded the FSL for beta. Sample 545D014 at this location was 
collected immediately below the wash/native soil interface between 3.0 and $3.5 \mathrm{ft}$ bgs and was below FSLs.

Location D03 was selected at a settling area just down gradient from the CAS. A sample (545D003) was collected from the surface interval ( 0.0 to $0.5 \mathrm{ft}$ bgs) and did not exceed FSLs. Sample (545D017) was collected from wash material between 1.5 and $2.0 \mathrm{ft}$ bgs and did not exceed FSLs.

Location D04 was also selected at a settling area, approximately $60 \mathrm{ft}$ downstream from the CAS boundary. A sample (545D004) and duplicate (545D005) was collected from the interval 0.0 to $0.5 \mathrm{ft}$ bgs and exceeded the FSL for beta. Sample (545D006) was collected from wash material (immediately above native soil) from the interval 0.5 to $1.0 \mathrm{ft}$ bgs and did not exceed FSLs. An additional shallow subsurface sample (545D018) was collected from the interval 1.0 to $1.17 \mathrm{ft}$ bgs in native soil, which included an approximately 3/8-in.-thick layer of black, decomposed, natural organic matter. The sample screening results were below FSLs.

Location D05 was selected approximately midway through the CAS, and partially up the south bank of the wash at a geophysical anomaly that was identified as likely being local soil changes, fill material, or buried nonmetallic material. Sample 545D007 was collected from the surface interval ( 0.0 to $0.5 \mathrm{ft}$ bgs) and was below FSLs. The location was excavated to native soil at $3.5 \mathrm{ft}$ bgs, which consisted of a compact sandy silt. No evidence of drilling mud was observed. A shallow subsurface sample (545D012) was collected from wash material in the interval of 1.5 to $2.0 \mathrm{ft}$ bgs, and exceeded FSL for beta.

Location D06 was selected at the east boundary of the CAS, along the wash bottom, also at a geophysical anomaly that indicated either local soil changes, buried nonmetallic debris, or fill material. Sample 545D008 was collected from the interval 0.0 to $0.5 \mathrm{ft}$ bgs and did not exceed FSLs. A second sample (545D015) was collected from wash material from 1.5 to $2.0 \mathrm{ft}$ bgs and did not exceed FSLs. A third sample (545D016) at this location was collected just below the wash material/native soil interface at 3.0 to $3.5 \mathrm{ft}$ bgs and did not exceed FSLs.

No staining, debris, or biasing factors other than elevated radiological readings, were found in any of the sample location profiles. 


\subsubsection{Conceptual Site Model Validation}

From the data gathered at the site, there were no findings that conflicted with the CSM as presented in the CAIP for CAU 545 (NNSA/NSO, 2007).

\subsubsection{Waste Disposal Site (CAS 20-19-01)}

The following subsections summarize the activities conducted at CAS 20-19-01. Additional detail on the sampling activities is provided in Appendix A.

\subsubsection{Radiological Survey}

A radiological walkover survey was conducted over CAS 20-19-01. No areas of elevated radiological readings were found. The radiological survey was not used in the selection of sample locations (Figure A.7-2).

\subsubsection{Visual Inspection}

Debris that was assumed to be related to the test conducted at U-20p was scattered throughout the site. Sample locations were established beneath the following visible materials: two locations at used oil filter(s), one location at a canister containing a greasy substance, two locations within the dried drilling mud spill that entered the site from the south, one location along the western edge where the soil was discolored yellowish tan and contained white flakes, one location at a small pile of what appeared to be corroded capacitors or batteries (slightly larger than D-cell size), one location within scattered photograph processing/fixing supplies, one location that was comprised of fine, whitish soil of a lower density than the native soil; and one location that appeared to be stained a darker shade of tan and that was adjacent to a yellow, solidified mass in the shape of a small (approximately 30-gallon [gal]) drum. An overall photograph of the debris at the site is shown in Figure A.7-3.

\subsubsection{Field Screening}

Investigation samples were field screened for alpha and beta/gamma radiation. The FSRs were compared to FSLs to guide subsequent sampling decisions where appropriate. Gross alpha radiation FSLs was exceeded in one sample, and the beta/gamma radiation FSL was not exceeded at CAS 20-19-01. The sample exceeding the FSL was analyzed. 


\subsubsection{Sample Collection}

Decision I environmental sampling activities included the collection of biased surface soil samples at potentially hazardous-containing materials (Figure A.7-1).

Environmental samples were collected from the soil containing the biasing factor (e.g., stained soil, drilling mud spill, oil stains). Sample 545E001 at location E01 was collected from the surface interval ( 0.0 to $0.5 \mathrm{ft}$ bgs) that was impacted by release of used motor oil from several oil filters. The soil beneath this interval did not appear impacted by the oil. Sample 545E002 at location E02 was collected from the surface interval ( 0.0 to $0.5 \mathrm{ft}$ bgs) that was impacted by release of used motor oil from a single oil filter. The soil beneath this interval also did not appear impacted by the oil. Sample 545E003 at location E03 was collected from the surface interval ( 0.0 to $0.5 \mathrm{ft}$ bgs) that was impacted by a spill of drilling mud that entered the site along the southern side. The layer of drilling mud was approximately 1 in. thick and did not appear to impact the underlying soil. Sample 545E004 at location E04 was also collected from the surface interval ( 0.0 to $0.5 \mathrm{ft}$ bgs) impacted by the release of drilling mud. The layer of drilling mud at this location was approximately 3 in. thick, and also did not appear to impact the underlying soil.

Sample 545E005 at location E05 was collected at the southwest extent of the debris, from the surface interval ( 0.0 to $0.5 \mathrm{ft}$ bgs) beneath a canister, in which grease had seeped from a connection. The soil directly beneath this canister was impacted by the grease, but the impact was not visible beyond $0.5 \mathrm{ft}$ bgs. Sample 545E006 at location E06 was collected from the surface interval ( 0.0 to $0.5 \mathrm{ft}$ bgs) from soil which had a yellowish hue and contained white flecks of an unknown material. Neither the yellow hue nor the white flecks extended below this interval. Sample 545E007 at location E07 was collected from the surface interval ( 0.0 to $0.5 \mathrm{ft}$ bgs) impacted by corroded capacitors or batteries. The impact from these materials did not appear to extend below this interval.

Sample 545E008 at location E08 was collected from 0.0 to $0.5 \mathrm{ft}$ bgs in an area impacted by photographic materials. The impact from these materials did not appear to extend below this interval. Samples 545E009 and duplicate 545E010 at location E09 were collected from 0.0 to $0.5 \mathrm{ft}$ bgs in an area of light-hued, loose, low-density material mixed in with soil. The impact of this material was limited to the surface. Sample 545E011 at location E10 was collected from 0.0 to $0.5 \mathrm{ft}$ bgs in an area 
of stained soil that was adjacent to a small, yellow, solidified mass in the shape of a small (approximately 30-gal) drum. The soil beneath this interval did not appear to be this darker hue.

\subsubsection{Conceptual Site Model Validation}

From the data gathered at the site, there were no findings that conflicted with the CSM as presented in the CAIP for CAU 545 (NNSA/NSO, 2007).

\subsection{Results}

The data summary provided in Section 2.2.1 defines the contaminants of potential concern (COPCs) that exceeded the FALs (i.e., COCs), within the CAU 545 CASs, and the extent of any identified COCs. Section 2.2.2 summarizes the data assessment in Appendix B, which demonstrates that the investigation results satisfy the DQO data requirements.

\subsubsection{Summary of Analytical Data}

Chemical and radiological results for environmental samples collected at each of the CASs are summarized in Sections 2.2.1.1 through 2.2.1.5. Environmental sample results are evaluated against FALs to determine the presence of COCs and the extent of COC contamination, if present.

The preliminary action levels (PALs) for the CAU 545 investigation were determined during the DQO process and are discussed in Section 3.3 of the CAIP for CAU 545 (NNSA/NSO, 2007). The FALs used for determining the presence of COCs and for evaluating the need for additional corrective action are defined in Section 2.3. Details about the methods used during this investigation and a comparison of environmental sample results to the FALs are presented in Appendix A.

\subsubsection{Mud Disposal Area (CAS 02-09-01)}

Corrective Action Site 02-09-01 was sampled at eight judgmental locations, and two or three depths per location. The analytical results for this CAS were below the PALs for all COPCs. Maximum results for all analytes detected at CAS 02-09-01 are listed in Table 2-1. Contamination in the mud disposal areas outside the crater is assumed to be representative of contamination within the crater. Therefore, no COCs are considered to be present in either CAS component. 
Table 2-1

Maximum Concentration of Detected

Contaminants for CAS 02-09-01, Mud Disposal Area

\begin{tabular}{|c|c|c|c|c|c|c||}
\hline Constituent & $\begin{array}{c}\text { Maximum } \\
\text { Result }\end{array}$ & $\begin{array}{c}\text { Sample } \\
\text { Number }\end{array}$ & $\begin{array}{c}\text { Depth } \\
\text { (ft bgs) }\end{array}$ & Location & FAL & Units \\
\hline \hline Actinium-228 & 2.67 & $545 \mathrm{~A} 018$ & $0.0-0.25$ & $\mathrm{~A} 07$ & 5 & $\mathrm{pCi} / \mathrm{g}$ \\
\hline Cesium-137 & 2.04 & $545 \mathrm{~A} 022$ & $0.33-0.83$ & $\mathrm{~A} 08$ & 12.2 & $\mathrm{pCi} / \mathrm{g}$ \\
\hline Lead-212 & 2.4 & $545 \mathrm{~A} 009$ & $7.0-7.5$ & $\mathrm{~A} 03$ & 5 & $\mathrm{pCi} / \mathrm{g}$ \\
\hline Lead-214 & 1.44 & $545 \mathrm{~A} 019$ & $0.0-0.33$ & $\mathrm{~A} 08$ & 5 & $\mathrm{pCi} / \mathrm{g}$ \\
\hline Plutonium-238 & 0.0578 & $545 \mathrm{~A} 022$ & $0.33-0.83$ & $\mathrm{~A} 08$ & 13 & $\mathrm{pCi} / \mathrm{g}$ \\
\hline Plutonium-239/240 & 0.818 & $545 \mathrm{~A} 006$ & $0.75-1.25$ & $\mathrm{~A} 01$ & 12.7 & $\mathrm{pCi} / \mathrm{g}$ \\
\hline Strontium-90 & 0.289 & $545 \mathrm{~A} 022$ & $0.33-0.83$ & $\mathrm{~A} 08$ & 838 & $\mathrm{pCi} / \mathrm{g}$ \\
\hline Thallium-208 & 0.859 & $545 \mathrm{~A} 018$ & $0.0-0.25$ & $\mathrm{~A} 07$ & 5 & $\mathrm{pCi} / \mathrm{g}$ \\
\hline Uranium-234 & 1.27 & $545 \mathrm{~A} 020$ & $0.25-1.0$ & $\mathrm{~A} 07$ & 143 & $\mathrm{pCi} / \mathrm{g}$ \\
\hline Uranium-238 & 1.18 & $545 \mathrm{~A} 019$ & $0.0-0.33$ & $\mathrm{~A} 08$ & 105 & $\mathrm{pCi} / \mathrm{g}$ \\
\hline
\end{tabular}

bgs = Below ground surface

$\mathrm{FAL}=$ Final action level

$\mathrm{ft}=$ Foot

$\mathrm{pCi} / \mathrm{g}=$ Picocuries per gram

\subsubsection{Waste Consolidation Site 3B (CAS 03-17-01)}

Corrective Action Site 03-17-01 was investigated, following a probabilistic sampling approach along with several judgmental locations, with 24 of the 31 locations within the fenced boundary being probabilistic sample locations. The analytical results for this CAS exceeded the PALs for americium (Am)-241 and/or plutonium (Pu)-239 at several locations in both the circular and rectangular components. A Tier 2 evaluation was conducted for these constituents using Residual Radioactive (RESRAD) computer code to determine the site-specific FALs. The probabilistic results for these two radionuclides (95 percent UCL of the mean) were compared to the FALs. The 95 percent UCLs (Table 2-2) and judgmental results were all below the FALs. Maximum results for all analytes detected at CAS 03-17-01 are listed in Table 2-3. This CAS is considered not to contain COCs. 
Table 2-2

Statistical Values for Corrective Action Investigation Probabilistic Results for Significant COPCs, CAS 03-17-01, Waste Consolidation Site 3B

\begin{tabular}{|c|c|c|c|c|c|c|}
\hline Constituent & Average & $\begin{array}{c}\text { Actual } \\
\text { Standard } \\
\text { Deviation }\end{array}$ & FAL $^{\mathrm{a}}$ & $\begin{array}{c}\text { Actual Required } \\
\text { Minimum Number } \\
\text { of Samples }\end{array}$ & UCL & UCL Value \\
\hline \hline Americium-241 & $5.70 \mathrm{pCi} / \mathrm{g}$ & 5.46 & $1,501 \mathrm{pCi} / \mathrm{g}$ & 8 & $\begin{array}{c}95 \% \text { ApproxImate } \\
\text { Gamma }\end{array}$ & $8.202 \mathrm{pCi} / \mathrm{g}$ \\
\hline Plutonium-239/240 & $13.53 \mathrm{pCi} / \mathrm{g}$ & 11.25 & $1,890 \mathrm{pCi} / \mathrm{g}$ & 8 & $\begin{array}{c}95 \% \text { Approximate } \\
\text { Gamma }\end{array}$ & $20.09 \mathrm{pCi} / \mathrm{g}$ \\
\hline
\end{tabular}

${ }^{a}$ Established in Appendix C.

$\mathrm{FAL}=$ Final action level

Table 2-3

Maximum Concentration of Detected Contaminants for CAS 03-17-01, Waste Consolidation Site 3B

(Page 1 of 2)

\begin{tabular}{|c|c|c|c|c|c|c|}
\hline Constituent & $\begin{array}{c}\text { Maximum } \\
\text { Result }\end{array}$ & $\begin{array}{l}\text { Sample } \\
\text { Number }\end{array}$ & $\begin{array}{c}\text { Depth } \\
\text { (ft bgs) }\end{array}$ & Location & $\mathrm{FAL}^{\mathrm{a}}$ & Units \\
\hline Actinium-228 & $\overline{2.18}$ & 545B032 & $\overline{0-0.5}$ & $\overline{B 29}$ & 5 & $\overline{\mathrm{pCi} / \mathrm{g}}$ \\
\hline Am-241 & 284 & 545B030 & $0-0.5$ & B27 & 1,501 & $\mathrm{pCi} / \mathrm{g}$ \\
\hline Arsenic & 7.6 & 545B019 & $0-0.5$ & B17 & 23 & $\mathrm{mg} / \mathrm{kg}$ \\
\hline Barium & $235(\mathrm{~J})$ & 545B031 & $0-0.5$ & B28 & 67,000 & $\mathrm{mg} / \mathrm{kg}$ \\
\hline Cadmium & $0.37(\mathrm{~J})$ & 545B013 & $0-0.5$ & B12 & 450 & $\mathrm{mg} / \mathrm{kg}$ \\
\hline Cesium-137 & 5.14 & 545B032 & $0-0.5$ & B29 & 12.2 & $\mathrm{pCi} / \mathrm{g}$ \\
\hline Chromium & 9.6 & 545B028 & $0-0.5$ & B25 & 450 & $\mathrm{mg} / \mathrm{kg}$ \\
\hline Europium-152 & 2.17 & 545B032 & $0-0.5$ & B29 & 5.67 & $\mathrm{pCi} / \mathrm{g}$ \\
\hline Lead & 13.3 & 545B031 & $0-0.5$ & B28 & 800 & $\mathrm{mg} / \mathrm{kg}$ \\
\hline Lead-212 & 1.98 & 545B035 & $0.5-1.0$ & B28 & 5 & $\mathrm{pCi} / \mathrm{g}$ \\
\hline Lead-214 & 1.35 & 545B030 & $0-0.5$ & B27 & 5 & $\mathrm{pCi} / \mathrm{g}$ \\
\hline Mercury & $0.04(\mathrm{~J}-)$ & 545B031 & $0-0.5$ & B28 & 310 & $\mathrm{mg} / \mathrm{kg}$ \\
\hline Plutonium-238 & 5.14 & 545B033 & $0.5-1.0$ & $\mathrm{~B} 27$ & 13 & $\mathrm{pCi} / \mathrm{g}$ \\
\hline Plutonium-239/240 & 455 & 545B035 & $0.5-1.0$ & $\mathrm{~B} 28$ & 1,890 & $\mathrm{pCi} / \mathrm{g}$ \\
\hline Selenium & $2.6(\mathrm{~J})$ & 545B028 & $0-0.5$ & B25 & 5,100 & $\mathrm{mg} / \mathrm{kg}$ \\
\hline Silver & $0.24(\mathrm{~J})$ & 545B021 & $0-0.5$ & B19 & 5,100 & $\mathrm{mg} / \mathrm{kg}$ \\
\hline Strontium-90 & 1.1 & 545B032 & $0-0.5$ & B29 & 838 & $\mathrm{pCi} / \mathrm{g}$ \\
\hline Thallium-208 & 0.781 & 545B031 & $0-0.5$ & B28 & 5 & $\mathrm{pCi} / \mathrm{g}$ \\
\hline Uranium-234 & 2.42 & 545B035 & $0.5-1.0$ & B28 & 143 & $\mathrm{pCi} / \mathrm{g}$ \\
\hline
\end{tabular}


Table 2-3

Maximum Concentration of Detected

Contaminants for CAS 03-17-01, Waste Consolidation Site 3B

(Page 2 of 2)

\begin{tabular}{|c|c|c|c|c|c|c|}
\hline Constituent & $\begin{array}{c}\text { Maximum } \\
\text { Result }\end{array}$ & $\begin{array}{c}\text { Sample } \\
\text { Number }\end{array}$ & $\begin{array}{c}\text { Depth } \\
\text { (ft bgs) }\end{array}$ & Location & FAL $^{\mathrm{a}}$ & Units $^{\text {bans }}$ \\
\hline \hline Uranium-235 & 0.116 & $545 \mathrm{~B} 032$ & $0-0.5$ & $\mathrm{~B} 29$ & 17.6 & $\mathrm{pCi} / \mathrm{g}$ \\
\hline Uranium-238 & 1.1 & $545 \mathrm{~B} 045$ & $1.0-1.75$ & B28 & 105 & $\mathrm{pCi} / \mathrm{g}$ \\
\hline
\end{tabular}

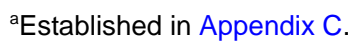

bgs $=$ Below ground surface

FAL $=$ Final action level

$\mathrm{ft}=$ Foot

$\mathrm{mg} / \mathrm{kg}=$ Milligrams per kilogram

$\mathrm{pCi} / \mathrm{g}=$ Picocuries per gram

$\mathrm{J}=$ Estimated value

$\mathrm{J}-=$ The result is an estimated quantity, but the result may be biased low.

\subsubsection{Radioactive Material Disposal Area (CAS 03-99-14)}

Corrective Action Site 03-99-14 was sampled at eight judgmental locations, two per transect, and one to two depths per location. The analytical results for this CAS were below the PALs for all chemical and radiological constituents. Maximum results for all analytes detected at CAS 03-99-14 are listed in Table 2-4. Five background locations outside of the CAS were also sampled; the background sample (545C003) taken at location C03 had the only result above PALs (i.e., for Pu-239), likely due to the nearby aboveground testing, and is not considered associated with this CAS. This CAS is therefore considered not to contain COCs.

\subsubsection{U-9y Drilling Mud Disposal Crater (CAS 09-23-02)}

Corrective Action Site 09-23-02 was sampled at four judgmental locations in the wash; within the CAS at two locations downstream from the lower CAS boundary, and two or three depths per location. The analytical results for this CAS were below the PALs for all COPCs. Maximum results for all analytes detected at CAS 09-23-02 are listed in Table 2-5. Contamination in the wash outside the crater is assumed to be representative of contamination within the crater. Therefore, no COCs are considered to be present in either CAS component. 
Table 2-4

Maximum Concentration of Detected

Contaminants for CAS 03-99-14, Radioactive Material Disposal Area

\begin{tabular}{|c|c|c|c|c|c|c|}
\hline Constituent & $\begin{array}{c}\text { Maximum } \\
\text { Result }\end{array}$ & $\begin{array}{l}\text { Sample } \\
\text { Number }\end{array}$ & $\begin{array}{c}\text { Depth } \\
\text { (ft bgs) }\end{array}$ & Location & FAL & Units \\
\hline$\overline{\text { Acetone }}$ & $0.00369(\mathrm{~J})$ & $\overline{545 C 015}$ & $\overline{0.0-0.5}$ & $\overline{\mathrm{C} 06}$ & $\overline{54,000}$ & $\overline{\mathrm{mg} / \mathrm{kg}}$ \\
\hline Actinium-228 & 1.96 & $545 C 013$ & $3.5-4.0$ & $\mathrm{CO9}$ & 5 & $\overline{\mathrm{pCi} / \mathrm{g}}$ \\
\hline Americium-241 & $1.05(\mathrm{~J})$ & $545 \mathrm{C003}$ & $0.0-0.5$ & $\mathrm{C03}$ & 12.7 & $\mathrm{pCi} / \mathrm{g}$ \\
\hline Aroclor 1260 & $0.0024(\mathrm{~J})$ & $545 C 009$ & $0.0-0.5$ & C11 & 0.74 & $\mathrm{mg} / \mathrm{kg}$ \\
\hline Arsenic & 5.6 & $545 \mathrm{C} 016$ & $3.5-4.0$ & $\mathrm{C08}$ & 23 & $\mathrm{mg} / \mathrm{kg}$ \\
\hline Arsenic & 5.6 & $545 C 015$ & $0.0-0.5$ & $\mathrm{C06}$ & 23 & $\mathrm{mg} / \mathrm{kg}$ \\
\hline Barium & 179 & $545 \mathrm{C} 010$ & $0.0-0.5$ & C10 & 67,000 & $\mathrm{mg} / \mathrm{kg}$ \\
\hline Cesium-137 & 10.3 & $545 C 001$ & $0.0-0.5$ & $\mathrm{C01}$ & 12.2 & $\overline{\mathrm{pCi} / \mathrm{g}}$ \\
\hline Chromium & 7.4 & $545 \mathrm{C018}$ & $2.0-2.5$ & $\mathrm{C} 06$ & 450 & $\mathrm{mg} / \mathrm{kg}$ \\
\hline Diesel-Range Organics & $2.53(\mathrm{~J})$ & $545 C 007$ & $0.0-0.5$ & C12 & 100 & $\mathrm{mg} / \mathrm{kg}$ \\
\hline Europium-152 & $4.62(\mathrm{~J})$ & $545 \mathrm{C005}$ & $0.0-0.5$ & $\mathrm{C05}$ & 5.67 & $\mathrm{pCi} / \mathrm{g}$ \\
\hline Lead & $19.2(\mathrm{~J})$ & $545 \mathrm{C011}$ & $0.0-0.5$ & $\mathrm{CO9}$ & 800 & $\mathrm{mg} / \mathrm{kg}$ \\
\hline Lead-212 & $1.94(\mathrm{~J})$ & $545 \mathrm{C} 018$ & $2.0-2.5$ & $\mathrm{C06}$ & 5 & $\mathrm{pCi} / \mathrm{g}$ \\
\hline Lead-214 & $1.35(\mathrm{~J})$ & $545 \mathrm{C} 017$ & $3.0-3.5$ & $\mathrm{CO}$ & 5 & $\mathrm{pCi} / \mathrm{g}$ \\
\hline Mercury & $0.012(\mathrm{~J}-)$ & $545 C 008$ & $0.0-0.5$ & C11 & 310 & $\mathrm{mg} / \mathrm{kg}$ \\
\hline Mercury & $0.012(\mathrm{~J}-)$ & $545 \mathrm{C016}$ & $3.5-4.0$ & $\overline{C 08}$ & 310 & $\mathrm{mg} / \mathrm{kg}$ \\
\hline Methylene chloride & 0.00513 & $545 \mathrm{C} 014$ & $0.0-0.5$ & $\mathrm{CO}$ & 21 & $\mathrm{mg} / \mathrm{kg}$ \\
\hline Plutonium-238 & 2.18 & $545 \mathrm{CO03}$ & $0.0-0.5$ & $\mathrm{CO3}$ & 13 & $\mathrm{pCi} / \mathrm{g}$ \\
\hline Plutonium-239/240 & 15.1 & $545 \mathrm{C003}$ & $0.0-0.5$ & $\mathrm{CO3}$ & 12.7 & $\mathrm{pCi} / \mathrm{g}$ \\
\hline Selenium & 1.9 & $545 C 008$ & $0.0-0.5$ & C11 & 5,100 & $\mathrm{mg} / \mathrm{kg}$ \\
\hline Selenium & 1.9 & $545 C 006$ & $0.0-0.5$ & $\overline{C 13}$ & 5,100 & $\mathrm{mg} / \mathrm{kg}$ \\
\hline Selenium & 1.9 & $545 \mathrm{C} 016$ & $3.5-4.0$ & $\mathrm{C08}$ & 5,100 & $\mathrm{mg} / \mathrm{kg}$ \\
\hline Silver & $0.33(\mathrm{~J})$ & $545 \mathrm{C} 012$ & $0.0-0.5$ & $\mathrm{C08}$ & 5,100 & $\mathrm{mg} / \mathrm{kg}$ \\
\hline Strontium-90 & 5.67 & $545 C 006$ & $0.0-0.5$ & $\mathrm{C} 13$ & 838 & $\mathrm{pCi} / \mathrm{g}$ \\
\hline Styrene & 0.00106 & $545 C 014$ & $0.0-0.5$ & $\mathrm{CO}$ & 1,700 & $\mathrm{mg} / \mathrm{kg}$ \\
\hline Thallium-208 & 0.61 & $545 \mathrm{C} 015$ & $0.0-0.5$ & C06 & 5 & $\mathrm{pCi} / \mathrm{g}$ \\
\hline Uranium-234 & 1.27 & $545 \mathrm{C} 017$ & $3.0-3.5$ & $\mathrm{CO}$ & 143 & $\overline{\mathrm{pCi} / \mathrm{g}}$ \\
\hline Uranium-235 & 0.108 & $545 \mathrm{C} 012$ & $0.0-0.5$ & $\mathrm{C08}$ & 17.6 & $\mathrm{pCi} / \mathrm{g}$ \\
\hline Uranium-238 & 1.15 & 545C011 & $0.0-0.5$ & C09 & 105 & $\mathrm{pCi} / \mathrm{g}$ \\
\hline
\end{tabular}

${ }^{2}$ The only exceedence of the FAL for Pu-239/240 was identified in a sample taken from a background location for the purpose of measuring the impact from nearby atmospheric testing (Section 2.2.1.3). This result is not associated with CAS 03-99-14 and is only included in the table for completeness. The area containing the background locations will be addressed by the Soils Project, CAS 03-23-10.

bgs = Below ground surface

$\mathrm{FAL}=$ Final action level

$\mathrm{ft}=$ Foot $\mathrm{mg} / \mathrm{kg}=$ Milligrams per kilogram

$\mathrm{pCi} / \mathrm{g}=$ Picocuries per gram

$\mathrm{Pu}=$ Plutonium

$\mathrm{J}=$ Estimated value

$\mathrm{J}-=$ The result is an estimated quantity, but the result may be biased low. 
Table 2-5

Maximum Concentration of Detected Contaminants for CAS 09-23-02, U-9y Drilling Mud Disposal Crater

\begin{tabular}{|c|c|c|c|c|c|c|}
\hline Constituent & $\begin{array}{l}\text { Maximum } \\
\text { Result }\end{array}$ & $\begin{array}{l}\text { Sample } \\
\text { Number }\end{array}$ & $\begin{array}{l}\text { Depth } \\
\text { (ft bgs) }\end{array}$ & Location & FAL & Units \\
\hline 1,2,4-Trimethylbenzene & 0.00151 & 545D007 & $0.0-0.5$ & $\overline{\mathrm{D} 05}$ & $\overline{170}$ & $\overline{\mathrm{mg} / \mathrm{kg}}$ \\
\hline 1,4-Dichlorobenzene & $0.000282(\mathrm{~J})$ & 545D007 & $0.0-0.5$ & D05 & 7.9 & $\mathrm{mg} / \mathrm{kg}$ \\
\hline Actinium-228 & 2.63 & 545D002 & $0.0-0.5$ & D02 & 5 & $\mathrm{pCi} / \mathrm{g}$ \\
\hline Americium-241 & $0.376(\mathrm{~J})$ & $545 \mathrm{D003}$ & $0.0-0.5$ & D03 & 12.7 & $\mathrm{pCi} / \mathrm{g}$ \\
\hline Americium-241 & 0.376 & 545D002 & $0.0-0.5$ & D02 & 12.7 & $\mathrm{pCi} / \mathrm{g}$ \\
\hline Arsenic & 7.7 & 545D012 & $1.5-2.0$ & D05 & 23 & $\mathrm{mg} / \mathrm{kg}$ \\
\hline Barium & $250(\mathrm{~J})$ & 545D015 & $1.5-2.0$ & D06 & 67,000 & $\mathrm{mg} / \mathrm{kg}$ \\
\hline Cadmium & $0.2(\mathrm{~J}-)$ & 545D001 & $0.0-0.5$ & D01 & 450 & $\mathrm{mg} / \mathrm{kg}$ \\
\hline Cesium-137 & 1.71 & 545D002 & $0.0-0.5$ & D02 & 12.2 & $\mathrm{pCi} / \mathrm{g}$ \\
\hline Chromium & 7.6 & 545D004 & $0.0-0.5$ & D04 & 450 & $\mathrm{mg} / \mathrm{kg}$ \\
\hline Dichlorodifluoromethane & $0.000951(\mathrm{~J})$ & 545D002 & $0.0-0.5$ & D02 & 310 & $\mathrm{mg} / \mathrm{kg}$ \\
\hline Diesel-Range Organics & 11.4 & $545 D 003$ & $0.0-0.5$ & D03 & 100 & $\mathrm{mg} / \mathrm{kg}$ \\
\hline Lead & $17.8(\mathrm{~J})$ & 545D015 & $1.5-2.0$ & D06 & 800 & $\mathrm{mg} / \mathrm{kg}$ \\
\hline Lead-212 & 2.42 & 545D002 & $0.0-0.5$ & D02 & 5 & $\mathrm{pCi} / \mathrm{g}$ \\
\hline Lead-214 & 1.65 & 545D011 & $4.0-4.5$ & D01 & 5 & $\mathrm{pCi} / \mathrm{g}$ \\
\hline Mercury & $0.043(\mathrm{~J})$ & $545 \mathrm{D} 016$ & $3.0-3.5$ & D06 & 310 & $\mathrm{mg} / \mathrm{kg}$ \\
\hline Methylene Chloride & $0.0023(\mathrm{~J})$ & 545D007 & $0.0-0.5$ & D05 & 21 & $\mathrm{mg} / \mathrm{kg}$ \\
\hline Plutonium-238 & 0.508 & $545 D 004$ & $0.0-0.5$ & D04 & 13 & $\mathrm{pCi} / \mathrm{g}$ \\
\hline Plutonium-239/240 & 7.3 & 545D005 & $0.0-0.5$ & D04 & 12.7 & $\mathrm{pCi} / \mathrm{g}$ \\
\hline Selenium & 2 & 545D018 & $1-1.17$ & D04 & 5,100 & $\mathrm{mg} / \mathrm{kg}$ \\
\hline Selenium & 2 & 545D016 & $3.0-3.5$ & D06 & 5,100 & $\mathrm{mg} / \mathrm{kg}$ \\
\hline Selenium & 2 & 545D015 & $1.5-2.0$ & D06 & 5,100 & $\mathrm{mg} / \mathrm{kg}$ \\
\hline Styrene & 0.00251 & 545D007 & $0.0-0.5$ & D05 & 1,700 & $\mathrm{mg} / \mathrm{kg}$ \\
\hline Thallium-208 & 0.845 & 545D004 & $0.0-0.5$ & D04 & 5 & $\mathrm{pCi} / \mathrm{g}$ \\
\hline Uranium-234 & 1.52 & 545D011 & $4.0-4.5$ & D01 & 143 & $\mathrm{pCi} / \mathrm{g}$ \\
\hline Uranium-235 & 0.113 & 545D016 & $3.0-3.5$ & D06 & 17.6 & $\mathrm{pCi} / \mathrm{g}$ \\
\hline Uranium-238 & 1.65 & 545D011 & $4.0-4.5$ & D01 & 105 & $\mathrm{pCi} / \mathrm{g}$ \\
\hline Total Xylenes & 0.0055 & 545D007 & $0.0-0.5$ & D05 & 420 & $\mathrm{mg} / \mathrm{kg}$ \\
\hline
\end{tabular}

bgs $=$ Below ground surface

$F A L=$ Final action level

$\mathrm{ft}=\mathrm{Foot}$

$\mathrm{mg} / \mathrm{kg}=$ Milligrams per kilogram

$\mathrm{pCi} / \mathrm{g}=$ Picocuries per gram

$\mathrm{J}=$ Estimated value

$\mathrm{J}-=$ The result is an estimated quantity, but the result may be biased low. 


\subsubsection{Waste Disposal Site (CAS 20-19-01)}

Corrective Action Site 20-19-01 was sampled at 10 judgmental locations; each at the surface. The analytical results for this CAS were below the PALs for all chemical and radiological constituents except total petroleum hydrocarbons (TPH)-diesel-range organics (DRO) at two locations. The TPH-DRO was moved on to a Tier 2 evaluation and FALs were established for the hazardous constituents of TPH-DRO (see Table C.1-3). Concentrations of the hazardous constituents of TPH-DRO did not exceed FALs. Therefore, TPH-DRO is not considered a COC. Maximum results for all analytes detected at CAS 20-19-01 are listed in Table 2-6. This CAS is therefore considered not to contain COCs.

Table 2-6

Maximum Concentration of Detected Contaminants for CAS 20-19-01, Waste Disposal Site (Page 1 of 2)

\begin{tabular}{||c|c|c|c|c|c|c||}
\hline Constituent & $\begin{array}{c}\text { Maximum } \\
\text { Result }\end{array}$ & $\begin{array}{c}\text { Sample } \\
\text { Number }\end{array}$ & $\begin{array}{c}\text { Depth } \\
\text { (ft bgs) }\end{array}$ & Location & FAL & Units \\
\hline \hline 2-Butanone & 0.0142 & $545 E 005$ & $0.0-0.5$ & E05 & 110,000 & $\mathrm{mg} / \mathrm{kg}$ \\
\hline 2-Hexanone & 0.00935 & $545 E 005$ & $0.0-0.5$ & E05 & 110,000 & $\mathrm{mg} / \mathrm{kg}$ \\
\hline Acetone & 0.408 & $545 E 008$ & $0.0-0.5$ & E08 & 54,000 & $\mathrm{mg} / \mathrm{kg}$ \\
\hline Actinium-228 & 2.33 & $545 E 005$ & $0.0-0.5$ & E05 & 5 & $\mathrm{pCi} / \mathrm{g}$ \\
\hline Americium-241 & 1.19 & $545 E 002$ & $0.0-0.5$ & E02 & 12.7 & $\mathrm{pCi} / \mathrm{g}$ \\
\hline Aroclor 1254 & $0.0066(\mathrm{~J})$ & $545 E 002$ & $0.0-0.5$ & E02 & 0.74 & $\mathrm{mg} / \mathrm{kg}$ \\
\hline Aroclor 1268 & 0.0437 & $545 E 006$ & $0.0-0.5$ & E06 & 0.74 & $\mathrm{mg} / \mathrm{kg}$ \\
\hline Arsenic & 9.1 & $545 E 009$ & $0.0-0.5$ & E09 & 23 & $\mathrm{mg} / \mathrm{kg}$ \\
\hline Barium & $291(\mathrm{~J})$ & $545 E 009$ & $0.0-0.5$ & E09 & 67,000 & $\mathrm{mg} / \mathrm{kg}$ \\
\hline Benzene & $0.000429(\mathrm{~J})$ & $545 E 006$ & $0.0-0.5$ & E06 & 1.4 & $\mathrm{mg} / \mathrm{kg}$ \\
\hline Benzoic Acid & 41.3 & $545 E 007$ & $0.0-0.5$ & E07 & 100,000 & $\mathrm{mg} / \mathrm{kg}$ \\
\hline Bis(2-ethylhexyl)phthalate & 3.99 & $545 E 008$ & $0.0-0.5$ & E08 & 120 & $\mathrm{mg} / \mathrm{kg}$ \\
\hline Cadmium & 2.7 & $545 E 007$ & $0.0-0.5$ & E07 & 450 & $\mathrm{mg} / \mathrm{kg}$ \\
\hline Cesium-137 & 1 & $545 E 002$ & $0.0-0.5$ & E02 & 12.2 & $\mathrm{pCi} / \mathrm{g}$ \\
\hline Chromium & 12.2 & $545 E 009$ & $0.0-0.5$ & E09 & 450 & $\mathrm{mg} / \mathrm{kg}$ \\
\hline Di-n-butyl phthalate & 0.936 & $545 E 002$ & $0.0-0.5$ & E02 & 62,000 & $\mathrm{mg} / \mathrm{kg}$ \\
\hline Dichlorodifluoromethane & 0.00215 & $545 E 009$ & $0.0-0.5$ & E09 & 310 & $\mathrm{mg} / \mathrm{kg}$ \\
\hline Diesel-Range Organics & 157 & $545 E 007$ & $0.0-0.5$ & E07 & $\mathrm{N} / \mathrm{A}^{\mathrm{a}}$ & $\mathrm{mg} / \mathrm{kg}$ \\
\hline Lead & $106(\mathrm{~J})$ & $545 E 009$ & $0.0-0.5$ & E09 & 800 & $\mathrm{mg} / \mathrm{kg}$ \\
\hline Lead-212 & 2.3 & $545 E 009$ & $0.0-0.5$ & E09 & 5 & $\mathrm{pCi/g}$ \\
\hline Lead-214 & 2.09 & $545 E 010$ & $0.0-0.5$ & E09 & 5 & $\mathrm{pCi/g}$ \\
\hline Mercury & $0.46(\mathrm{~J})$ & $545 E 007$ & $0.0-0.5$ & E07 & 310 & $\mathrm{mg} / \mathrm{kg}$ \\
\hline Methylene Chloride & 0.0103 & $545 E 005$ & $0.0-0.5$ & E05 & 21 & $\mathrm{mg} / \mathrm{kg}$ \\
\hline
\end{tabular}


Table 2-6

Maximum Concentration of Detected

Contaminants for CAS 20-19-01, Waste Disposal Site

(Page 2 of 2)

\begin{tabular}{|c|c|c|c|c|c|c|}
\hline Constituent & $\begin{array}{c}\text { Maximum } \\
\text { Result }\end{array}$ & $\begin{array}{c}\text { Sample } \\
\text { Number }\end{array}$ & $\begin{array}{c}\text { Depth } \\
\text { (ft bgs) }\end{array}$ & Location & FAL Units \\
\hline \hline Phenanthrene & $0.0157(\mathrm{~J})$ & $545 \mathrm{E} 006$ & $0.0-0.5$ & $\mathrm{E} 06$ & 100,000 & $\mathrm{mg} / \mathrm{kg}$ \\
\hline Phenol & 0.358 & $545 \mathrm{E} 006$ & $0.0-0.5$ & $\mathrm{E} 06$ & 100,000 & $\mathrm{mg} / \mathrm{kg}$ \\
\hline Plutonium-238 & $1.18(\mathrm{~J})$ & $545 \mathrm{E} 001$ & $0.0-0.5$ & $\mathrm{E} 01$ & 13 & $\mathrm{pCi} / \mathrm{g}$ \\
\hline Plutonium-239/240 & $2.73(\mathrm{~J})$ & $545 \mathrm{E} 007$ & $0.0-0.5$ & $\mathrm{E} 07$ & 12.7 & $\mathrm{pCi} / \mathrm{g}$ \\
\hline Selenium & $2.1(\mathrm{~J}-)$ & $545 \mathrm{E} 006$ & $0.0-0.5$ & $\mathrm{E} 06$ & 5,100 & $\mathrm{mg} / \mathrm{kg}$ \\
\hline Silver & 22.1 & $545 \mathrm{E} 008$ & $0.0-0.5$ & $\mathrm{E} 08$ & 5,100 & $\mathrm{mg} / \mathrm{kg}$ \\
\hline Styrene & $0.00049(\mathrm{~J})$ & $545 \mathrm{E} 005$ & $0.0-0.5$ & $\mathrm{E} 05$ & 1,700 & $\mathrm{mg} / \mathrm{kg}$ \\
\hline Thallium-208 & 0.778 & $545 \mathrm{E} 009$ & $0.0-0.5$ & $\mathrm{E} 09$ & 5 & $\mathrm{pCi} / \mathrm{g}$ \\
\hline Uranium-234 & 1.38 & $545 \mathrm{E} 001$ & $0.0-0.5$ & $\mathrm{E} 01$ & 143 & $\mathrm{pCi} / \mathrm{g}$ \\
\hline Uranium-235 & 0.0908 & $545 \mathrm{E} 010$ & $0.0-0.5$ & $\mathrm{E} 09$ & 17.6 & $\mathrm{pCi} / \mathrm{g}$ \\
\hline Uranium-238 & 1.43 & $545 \mathrm{E} 010$ & $0.0-0.5$ & $\mathrm{E} 09$ & 105 & $\mathrm{pCi} / \mathrm{g}$ \\
\hline
\end{tabular}

${ }^{a} F A L s$ are established for hazardous constituents of total petroleum hydrocarbons-diesel-range organics.

bgs $=$ Below ground surface

$\mathrm{FAL}=$ Final action level

$\mathrm{ft}=$ Foot

$\mathrm{mg} / \mathrm{kg}=$ Milligrams per kilogram

$\mathrm{N} / \mathrm{A}=$ Not applicable

$\mathrm{pCi} / \mathrm{g}=$ Picocuries per gram

$\mathrm{J}=$ Estimated value

$\mathrm{J}-=$ The result is an estimated quantity, but the result may be biased low.

\subsubsection{Data Assessment Summary}

The DQA is presented in Appendix B and includes an evaluation of the DQIs to determine the degree of acceptability and usability of the reported data in the decision-making process. The DQO process ensures that the correct type, quality, and quantity of data will be available to support the resolution of those decisions at an appropriate level of confidence. Using both the DQO and DQA processes helps to ensure that DQO decisions are sound and defensible.

The DQA process is comprised of the following steps, as presented in Appendix B:

- Step 1: Review DQOs and Sampling Design.

- Step 2: Conduct a Preliminary Data Review.

- Step 3: Select the Test.

- Step 4: Verify the Assumptions.

- Step 5: Draw Conclusions from the Data. 
Sample locations that support the presence and/or extent of contamination at each CAS are shown in Appendix A. Based on the results of the DQA (Appendix B), the DQO requirements have been met. The DQA also determined that information generated during the investigation support the CSM assumptions and the data collected support their intended use in the decision-making process.

\subsection{Justification for No Further Action}

No further corrective action is needed because:

- Corrective actions are implemented where needed.

- Use restrictions were implemented at CASs 03-08-03 and 03-23-05.

- $\quad$ Potential source material (PSM) (i.e., used oil filters) was removed at CAS 20-19-01.

- No COCs were identified at the remaining CASs.

Based on the results of the investigation, the remaining debris at CAS 20-19-01 was determined to not require corrective action. Soil samples were collected beneath the debris at locations identified as most likely to contain COCs. No COCs were identified; therefore, there is no indication that the debris is contributing contamination to the soil at concentrations that would require corrective action. Because removal of the debris from the potential crater area may pose a health and safety risk to workers (Pawloski, 2003), the debris was left in place.

\subsubsection{Final Action Levels}

The CAU 545 FALs are risk-based cleanup goals that, if met, will ensure that each release site will not pose an unacceptable risk to human health and the environment and that conditions at each site are in compliance with all applicable laws and regulations. The risk-based corrective action (RBCA) process used to establish FALs is described in the Industrial Sites Project Establishment of Final Action Levels (NNSA/NSO, 2006). This process conforms with Nevada Administration Code (NAC) Section 445A.227, which lists the requirements for sites with soil contamination (NAC, 2006a). For the evaluation of corrective actions, NAC Section 445A.22705 (NAC, 2006b) recommends the use of American Society for Testing and Materials (ASTM) Method E 1739-95 (ASTM, 1995) to “conduct an evaluation of the site, based on the risk it poses to public health and the environment, to determine the necessary remediation standards (i.e., FALs) or to establish that corrective action is not necessary.” 
This RBCA process defines three tiers (or levels) of evaluation involving increasingly sophisticated analyses:

- Tier 1 evaluation - Sample results from source areas (highest concentrations) are compared to action levels based on generic (nonsite-specific) conditions (i.e., the PALs established in the CAIP for CAU 545 [NNSA/NSO, 2007]). The FALs may then be established as the Tier 1 action levels or the FALs may be calculated using a Tier 2 evaluation.

- Tier 2 evaluation - Conducted by calculating Tier 2 site-specific target levels (SSTLs) using site-specific information as inputs to the same or similar methodology used to calculate Tier 1 action levels. The Tier 2 SSTLs are then compared to individual sample results from reasonable points of exposure (as opposed to the source areas as is done in Tier 1) on a point-by-point basis. Total TPH concentrations will not be used for risk-based decisions under Tier 2 or Tier 3. Rather, the individual chemicals of concern will be compared to the SSTLs.

- Tier 3 evaluation - Conducted by calculating Tier 3 SSTLs on the basis of more sophisticated risk analyses using methodologies described in Method E 1739-95 that consider site-, pathway-, and receptor-specific parameters.

A Tier 1 evaluation was conducted for all COPCs to determine whether contaminant levels satisfy the criteria for a quick regulatory closure or warrant a more site-specific assessment. This was accomplished by comparing individual source area contaminant concentration results to the Tier 1 action levels (the PALs established in the CAIP for CAU 545 [NNSA/NSO, 2007]).

The constituents detected at the CAU 545 CASs that exceeded Tier 1 action levels were:

- Total petroleum hydrocarbons at CAS 20-19-01

- Americium-241 at CAS 03-17-01

- Plutonium-239 at CAS 03-17-01

The concentrations of all constituents at CASs not listed above were below Tier 1 action levels (i.e., PALs) and the corresponding FALs were established as the Tier 1 action levels. Of the constituents at CASs that exceeded Tier 1 action levels, all were passed on to a Tier 2 evaluation.

The evaluation of TPH-DRO at CAS 20-19-01 was moved on to a Tier 2 evaluation. The Tier 2 evaluation of TPH-DRO consisted of evaluating the hazardous constituents of TPH to the Tier 2 SSTLs. The Tier 2 SSTLs for the hazardous constituents of TPH-DRO were established at the corresponding PAL concentrations. None of the individual hazardous constituents of TPH-DRO 
exceeded the Tier 2 SSTLs. Therefore, corresponding FALs were established the PAL concentrations, and neither TPH-DRO nor the individual hazardous constituents of TPH-DRO are considered COCs. Additional details of the Tier 2 evaluations for TPH-DRO are provided in Appendix C.

The evaluation for Am-241 and Pu-239/240 at CAS 03-17-01 compared the analytical results for these radionuclides at these CASs to the Tier 2 action levels. The Tier 2 action levels were calculated for an industrial scenario using site-specific information on the detected radionuclides and other site-specific physical characteristics using the RESRAD code (version 6.3). This calculation determined the needed activities of all detected radionuclides that, together, would sum to an exposed dose of 25 millirem per year (mrem/yr) to a site receptor (based on their relative abundances at each CAS). These calculated activities were then established as the FALs for each radionuclide at each CAS that exceeded a Tier 1 action level. Because site contamination levels did not exceed an industrial scenario-based FAL, an administrative UR was not necessary. Additional details of the Tier 2 evaluations for Am-241 and Pu-239/240 at CAS 03-17-01 are provided in Appendix C.

The bases for the derivation of FALs for all CAU 545 COPCs as presented in Appendix C are listed in Table 2-7.

Table 2-7

Definition of Final Action Levels for CAU 545 Contaminants of Potential Concern

\begin{tabular}{|c|c|c|c|}
\hline COPCs & Tier 1-Based FALs & Tier 2-Based FALs & Tier 3-Based FALs \\
\hline \hline VOCs & All CASs & None & None \\
\hline SVOCs & All CAS & None & None \\
\hline PCBs & All CAS & None & None \\
\hline RCRA Metals & All CAS & CAS 20-19-01 & None \\
\hline TPH-DRO & $\begin{array}{l}\text { All CAS except } \\
\text { CAS 20-19-01 }\end{array}$ & CAS 03-17-01 & None \\
\hline Radionuclides & $\begin{array}{l}\text { All CAS except } \\
\text { CAS 03-17-01 }\end{array}$ \\
\hline
\end{tabular}

COPC $=$ Contaminant of potential concern DRO $=$ Diesel-range organics

$\mathrm{FAL}=$ Final action level

N/A = Not applicable

$\mathrm{PAL}=$ Preliminary action level
PCB $=$ Polychlorinated biphenyl RCRA = Resource Conservation and Recovery Act SVOC = Semivolatile organic compound $\mathrm{TPH}=$ Total petroleum hydrocarbons VOC $=$ Volatile organic compound 


\subsection{Recommendation}

Page 32 of 34

No further corrective action is required at CAU 545. Selection of this corrective action is consistent with past practices for CASs that do not contain COCs. No further action was evaluated based on technical merits focusing on performance, reliability, feasibility, and safety.

The DOE National Nuclear Security Administration Nevada Site Office (NNSA/NSO) provides the following recommendations:

- Implement a UR for the radiologically impacted soil at CAS 03-08-03. The UR form and map are filed in the NNSA/NSO Facility Information Management System, the FFACO database, and the NNSA/NSO CAU/CAS files. Inspection of the sign postings will be conducted annually.

- Implement a UR for the lead and radiological source material present in the soil at CAS 03-23-05. The UR form and map are filed in the NNSA/NSO Facility Information Management System, the FFACO database, and the NNSA/NSO CAU/CAS files. Inspection of the sign postings will be conducted annually.

The NNSA/NSO requests that NDEP issues a Notice of Completion for this CAU and approval to move CAU 545 from Appendix III to Appendix IV of the FFACO. 


\subsection{References}

ASTM, see American Society for Testing and Materials.

American Society for Testing and Materials. 1995. Standard Guide for Risk-Based Corrective Action Applied at Petroleum Release Sites, ASTM E 1739-95 (Reapproved 2002). Philadelphia, PA.

CFR, see Code of Federal Regulations.

Code of Federal Regulations. 2006a. Title 40 CFR Parts 260 - 282, “Hazardous Waste Management.” Washington, DC: U.S. Government Printing Office.

Code of Federal Regulations. 2006b. Title 40 CFR Part 761, "Polychlorinated Biphenyls (PCBs) Manufacturing, Processing, Distribution in Commerce and Prohibitions." Washington, DC: U.S. Government Printing Office.

EPA, see U.S. Environmental Protection Agency.

FFACO, see Federal Facility Agreement and Consent Order.

Federal Facility Agreement and Consent Order. 1996 (as amended). Agreed to by the State of Nevada; U.S. Department of Energy, Environmental Management; U.S. Department of Defense; and U.S. Department of Energy, Legacy Management.

NAC, see Nevada Administrative Code.

NNSA/NSO, see U.S. Department of Energy, National Nuclear Security Administration Nevada Site Office.

NNSA/NV, see U.S. Department of Energy, National Nuclear Security Administration Nevada Operations Office.

Nevada Administrative Code. 2006a. NAC 445A.227, “Contamination of Soil: Order by Director for Corrective Action; Factors To Be Considered in Determining Whether Corrective Action Required.” Carson City, NV. As accessed at http://www.leg.state.nv.us/nac on 20 March 2007.

Nevada Administrative Code. 2006b. NAC 445A.22705, “Contamination of Soil: Evaluation of Site by Owner or Operator; Review of Evaluation by Division.” Carson City, NV. As accessed at http://www.leg.state.nv.us/nac on 20 March 2007.

Pawloski, G.A., Lawrence Livermore National Laboratory. 2003. Letter to B. Bangerter (NNSA/NSO) regarding summary statements on the status of surface crater collapse for selected LLNL tests on Pahute Mesa and Yucca Flat, 27 January. Livermore, CA. 
SNJV GIS, see Stoller-Navarro Joint Venture Geographic Information Systems.

Stoller-Navarro Joint Venture Geographic Information Systems. 2007. ESRI ArcGIS Software.

U.S. Department of Energy, National Nuclear Security Administration Nevada Operations Office. 2002. Industrial Sites Quality Assurance Project Plan, Nevada Test Site, Nevada, Rev. 4, DOE/NV--372. Las Vegas, NV.

U.S. Department of Energy, National Nuclear Security Administration Nevada Site Office. 2006. Industrial Sites Project Establishment of Final Action Levels, Rev. 0, DOE/NV--1107. Las Vegas, NV.

U.S. Department of Energy, National Nuclear Security Administration Nevada Site Office. 2007. Corrective Action Investigation Plan for Corrective Action Unit 545: Dumps, Waste Disposal Sites, and Buried Radioactive Materials, Nevada Test Site, Nevada, Rev. 0, DOE/NV--1210. Las Vegas, NV.

U.S. Environmental Protection Agency. 2004 (as revised). Region 9 Preliminary Remediation Goals (PRGs). As accessed at www.epa.gov/region09/waste/sfund/prg/htm on 20 March 2007.

U.S. Environmental Protection Agency. 2006. EPA Guidance on Systematic Planning Using the Data Quality Objectives Process, EPA QA/G-4. Washington, DC. 


\section{Appendix A}

\section{Corrective Action Investigation Results}




\section{A.1.0 Introduction}

This appendix presents the CAI activities and analytical results for CAU 545, which is located in Areas 2, 3, 9, and 20 of the NTS (Figure 1-1), and comprised of the eight CASs listed below:

- 02-09-01, Mud Disposal Area

- 03-08-03, Mud Disposal Site

- 03-17-01, Waste Consolidation Site 3B

- 03-23-02, Waste Disposal Site

- 03-23-05, Europium Disposal Site

- 03-99-14, Radioactive Material Disposal Area

- 09-23-02, U-9y Drilling Mud Disposal Crater

- 20-19-01, Waste Disposal Site

Corrective Action Sites 03-08-03, 03-23-02, and 03-23-05 were not investigated because sufficient data existed in the CAU 545 CAIP to support the decisions necessary for site closure (NNSA/NSO, 2007).

Corrective Action Site 02-09-01, Mud Disposal Area, is located immediately to the west of the 2-05 Road and Circle Road intersection in Area 2 of the NTS. The CAS consists of potentially contaminated drilling mud released within and outside of the U-2ei crater, which formed as a result of the Coulommiers underground nuclear test conducted on September 27, 1977. The specific history of mud disposal activities at the U-2ei crater is unknown; however aerial photography indicates mud was disposed at the site between 1977 and 1984. The mud released at CAS 02-09-01 is assumed to be associated with NTS drilling operations, and therefore may either be pre-use material or else used pre-test and/or post-test drilling mud.

Corrective Action Site 03-17-01, Waste Consolidation Site 3B, is located 1.0 mi east of the Area 3 Radioactive Waste Management Site (RWMS) at the NTS. The CAS consists of an area used for storage of suspected radioactive materials associated with nearby atmospheric tests, which was cleaned up in the 1980s. Two components comprise the site: a rectangular area measuring 950 by $750 \mathrm{ft}$, posted as a contamination area; and an unposted, circular area measuring $145 \mathrm{ft}$ in diameter. Some metallic debris, including the remnants of an ecology study, remain at the site. 


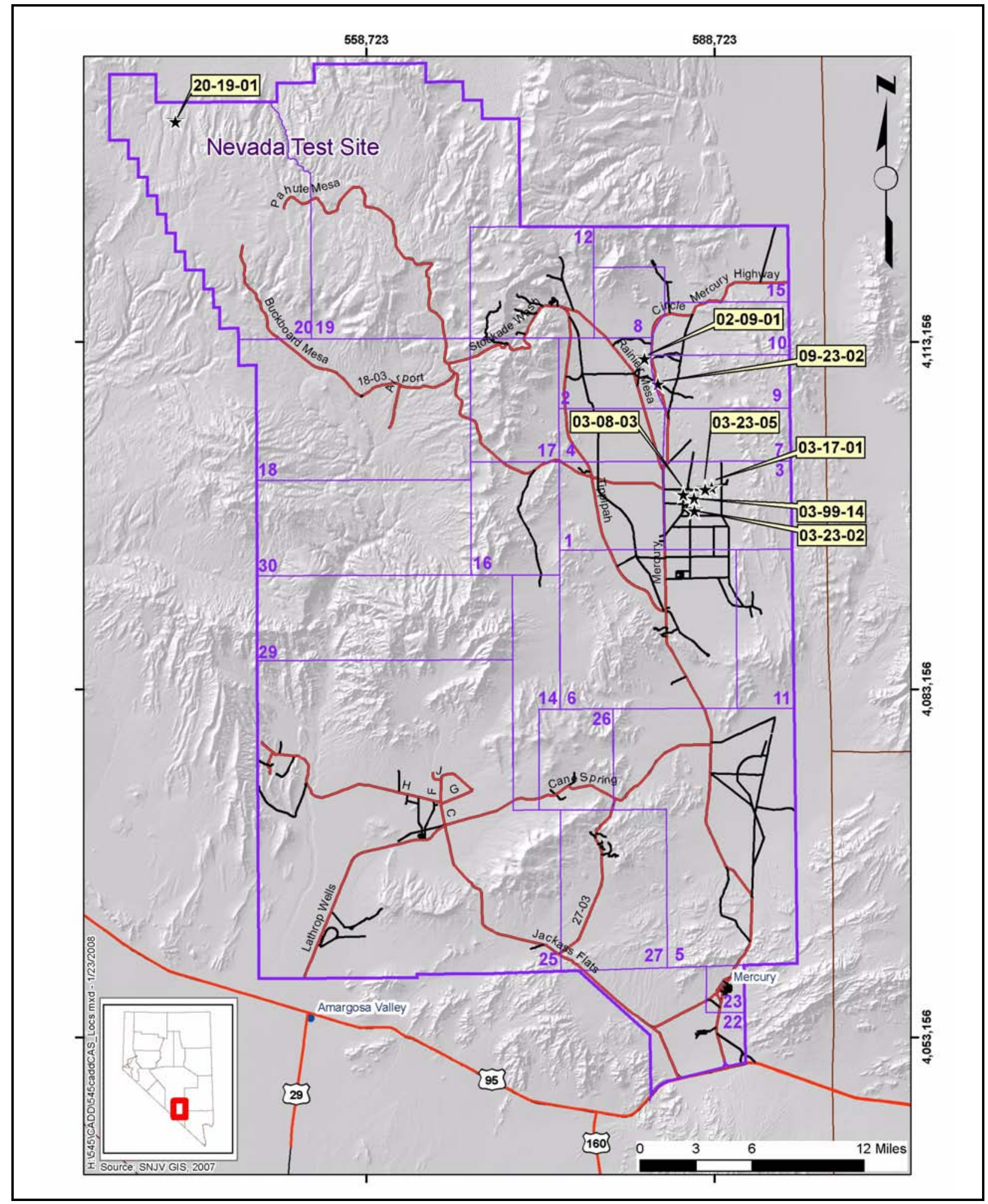

Figure A.1-1

Corrective Action Investigation Site Map for CAU 545 CASs 
Corrective Action Site 03-99-14, Radioactive Materials Disposal Area, is located approximately $1.0 \mathrm{mi}$ southeast of the Area 3 RWMS. The CAS consists of potential soil contamination associated with a soil berm and an associated trench approximately $350 \mathrm{ft}$ long. The volume of soil on the berm appears to be equivalent to that missing from the trench. The original purpose for the berm and trench is unknown. The site, along with adjoining lands, is posted as an RMA. The posting is likely due to atmospheric testing that was conducted just to the west of the site. The area encompassing the RMA will be investigated by the Soils Project for CAU 104.

Corrective Action Site 09-23-02, U-9y Drilling Mud Disposal Crater, is located approximately $600 \mathrm{ft}$ southeast of the 9-01 and Circle Roads intersection. The CAS consists of potentially radiological-contaminated drilling fluids and decontamination wastewater disposed of in the U-9y crater. This crater formed as a result of the Wichita underground nuclear test conducted on July 27, 1962. At some time between 1979 and 1980, the fluids inside the crater overflowed into the wash to the east, and use of the crater for disposal was discontinued. The wash is posted as a buried RMA, but it is not known if the posting is related to the overflow of the crater.

Corrective Action Site 20-19-01, Waste Disposal Site, is located to the east-northeast of the U-20p test hole, within the potential crater area, in the northwestern portion of Area 20. The CAS consists of the debris pile to the east-northeast of the test hole. The history of the debris is not known, but the contents are consistent with general construction debris. Several used oil filters were identified at the site. A drilling mud spill entering the site from the south was also identified at the site.

Additional information regarding the history of each site, planning, and the scope of the investigation is presented in the CAIP for CAU 545 (NNSA/NSO, 2007).

\section{A.1.1 Project Objectives}

The primary objective of the investigation was to provide sufficient information and data to develop appropriate corrective action alternatives for each CAS in CAU 545. This objective was achieved by identifying the absence or presence of COCs and the vertical and lateral extent of the COCs, if present. Corrective Action Sites 03-08-03, 03-23-02, and 03-23-05 were not investigated because sufficient information existed about the sites. 
The selection of soil and/or waste characterization sample locations was based on site conditions and the strategy developed during the DQO process as presented in the CAIP for CAU 545 (NNSA/NSO, 2007). The sampling strategy implemented a judgmental sampling approach at CASs 02-09-01, 03-99-14, 09-23-02 and 20-19-01, and a combination of probabilistic and judgmental sampling approaches at CAS 03-17-01.

\section{A.1.2 Contents}

This appendix describes the investigation and presents the results. The contents of this appendix are as follows:

- Section A.1.0 describes the investigation background, objectives, and content.

- Section A.2.0 provides an investigation overview.

- Sections A.3.0 through A.7.0 provide CAS-specific information regarding the field activities, sampling methods, and laboratory analytical results from investigation sampling.

- Section A.8.0 summarizes waste management activities.

- Section A.9.0 discusses the QA and QC processes followed and the results of the QA/QC activities.

- $\quad$ Section A.10.0 provides a summary of the investigation results.

- Section A.11.0 provides a list of the referenced documents used in the preparation of this document.

The complete field documentation and laboratory data, including Field Activity Daily Logs (FADLs), sample collection logs (SCLs), analysis request/chain-of-custody forms, soil sample descriptions, laboratory certificates of analyses, analytical results, and surveillance results are retained in project files as hard copy files and electronic media. 


\section{A.2.0 Investigation Overview}

Field investigation and sampling activities for the CAU 545 CAI were conducted from August 20 through November 2, 2007. Table A.2-1 lists the CAI activities conducted at each of the five CAU 545 CASs identified for sampling during the DQOs.

Table A.2-1

Corrective Action Investigation Activities Conducted at Each Corrective Action Site To Meet Corrective Action Investigation Plan Requirements for CAU 545

\begin{tabular}{|c|c|c|c|c|c|}
\hline \multirow[b]{2}{*}{ Corrective Action Investigation Activities } & \multicolumn{5}{|c|}{ Corrective Action Site } \\
\hline & 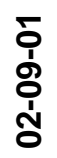 & 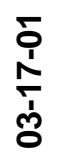 & 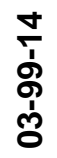 & $\begin{array}{l}\text { No } \\
\text { ஸे } \\
\text { ò }\end{array}$ & 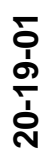 \\
\hline $\begin{array}{l}\text { Inspected and verified the CAS components identified in the Corrective Action } \\
\text { Investigation Plan. }\end{array}$ & $\mathrm{X}$ & $X$ & $\mathrm{X}$ & $X$ & $\mathrm{x}$ \\
\hline Performed site walkovers to identify biased sampling locations. & $\mathrm{X}$ & $\mathrm{X}$ & $\mathrm{X}$ & $\mathrm{X}$ & $\mathrm{X}$ \\
\hline $\begin{array}{l}\text { Conducted scanning radiological walkover surveys (i.e., soil, concrete surfaces, } \\
\text { debris) using a handheld detector and a global positioning system (GPS) } \\
\text { receiver with a TSCITM data logger. }\end{array}$ & $\mathrm{X}$ & $\mathrm{X}$ & $X$ & $X$ & $\mathrm{X}$ \\
\hline $\begin{array}{l}\text { Performed swipe sampling for removable radioactivity using a handheld survey } \\
\text { instrument and/or a gamma scintillator (Building 23-153, Mercury, NV). }\end{array}$ & $X$ & $\mathrm{X}$ & $X$ & $\mathrm{X}$ & $\mathrm{x}$ \\
\hline Conducted geophysical surveys. & -- & $\mathrm{X}$ & $\mathrm{X}$ & $\mathrm{X}$ & -- \\
\hline Collected biased soil samples. & $\mathrm{X}$ & $\mathrm{X}$ & $\mathrm{X}$ & $\mathrm{X}$ & $\mathrm{X}$ \\
\hline Collected randomly located soil samples. & -- & $\mathrm{X}$ & -- & -- & -- \\
\hline $\begin{array}{l}\text { Collected soil samples from step-out sample locations (Decision II) based on the } \\
\text { outer boundary sample locations where contaminants of concern were detected } \\
\text { in Decision I soil samples. }\end{array}$ & -- & -- & -- & -- & -- \\
\hline $\begin{array}{l}\text { Field screened samples for alpha and beta/gamma radiation using a handheld } \\
\text { survey instrument. }\end{array}$ & $\mathrm{X}$ & $\mathrm{X}$ & $\mathrm{X}$ & $X$ & $\mathrm{X}$ \\
\hline Submitted select samples for offsite laboratory analysis. & $\mathrm{X}$ & $\mathrm{X}$ & $\mathrm{X}$ & $\mathrm{X}$ & $\mathrm{x}$ \\
\hline Collected GPS coordinates for sample locations and points of interest. & $\mathrm{X}$ & $\mathrm{X}$ & $\mathrm{X}$ & $\mathrm{X}$ & $\mathrm{X}$ \\
\hline
\end{tabular}

$--=$ Not applicable

The investigation and sampling program was managed in accordance with the requirements set forth in the CAIP for CAU 545 (NNSA/NSO, 2007). Field activities were performed in compliance with safety documents that are consistent with the DOE Integrated Safety Management System. Samples were collected and documented following approved protocols and procedures. Quality control 
samples (e.g., field blanks, equipment rinsate blanks, trip blanks, and duplicate samples) were collected as required by the Industrial Sites QAPP (NNSA/NV, 2002) and the CAIP for CAU 545 (NNSA/NSO, 2007).

Weather conditions at the site varied to include sun (high temperatures), below average rainfall, haze, and light to strong winds. Strong wind gusts delayed site operations due to the potential for airborne debris. Lightning strikes within $10 \mathrm{mi}$ of several work sites also led to suspension of work on several occasions.

The CASs were investigated by conducting radiological surface screening and surveys, and sampling surface and subsurface soils. Surface soil samples were collected by hand excavation. Subsurface soil samples were collected using hand augering or a backhoe. The soil samples were field screened at specific locations for alpha and beta/gamma radiation. The results were compared against screening levels to guide in the CAS-specific investigations. Soil samples were field screened to guide in the selection of the samples shipped to offsite laboratories for analysis. Field screening was also for health and safety controls and to meet transportation requirements.

Except as noted in the following CAS-specific sections, CAU 545 Decision I sampling locations were accessible and sampling activities at planned locations were not restricted. Decision II step-out sample locations were accessible and remained within anticipated spatial boundaries.

Sections A.2.1 through A.2.4 provide the investigation methodology and laboratory analytical information.

\section{A.2.1 Sample Locations}

Investigation locations selected for sampling were based on interpretation of aerial and land photographs, interviews with former and current site employees, information obtained during site visits, and site conditions as provided in the CAIP for CAU 545 (NNSA/NSO, 2007). Sampling points for each site were selected based on the approach provided in the CAIP. The planned biased and random sample locations are discussed in text and represented on figures in the CAIP. Actual environmental sample locations are shown on the figures included in Sections A.3.0 through A.7.0. In some cases, the review of FSRs and/or laboratory analytical results identified the need for step-out sampling. All sample locations were staked, labeled, and surveyed with a global positioning system 
(GPS) instrument. A Trimble GeoXT GPS instrument was used to determine sample location coordinates as well as CAS points of interest. Appendix E presents the coordinates in a tabular format.

\section{A.2.2 Investigation Activities}

The investigation activities performed at CAU 545 were based on field investigation activities discussed in the CAIP for CAU 545 (NNSA/NSO, 2007). The technical approach consisted of the activities listed in Table A.2-1. The investigation strategy allowed the nature and extent of contamination associated with each CAS to be established. The following sections describe the specific investigation activities that took place at CAU 545.

\section{A.2.2.1 Radiological Surveys}

Radiological surveys (i.e., walkover) were performed at each CAS during the CAI. Radiological surveys were performed to identify the presence, the nature, and the extent of radiological contaminants at activities statistically greater than background.

\section{A.2.2.2 Geophysical Surveys}

Geophysical surveys were conducted at CAS 03-17-01 before the CAI, and at CASs 03-99-14 and 09-23-02 during the CAI, to identify subsurface anomalies. The geophysical results were only useful for identifying smaller anomalies at CAS 03-17-01, where two anomaly locations were sampled. Additionally, two locations of less distinct anomalies at CAS 09-23-02 were also sampled. Additional information is retained in the project files.

\section{A.2.2.3 Field Screening}

Field-screening activities for alpha and beta/gamma radiation were performed as specified in the CAIP for CAU 545 (NNSA/NSO, 2007). Site-specific FSLs for alpha and beta/gamma radiation were defined as the mean background activity level plus two times the standard deviation of readings from 10 background locations selected near each CAS. The radiation FSLs are instrument-specific and were established for each instrument and CAS before use. 
All field screening for alpha and beta/gamma radiation screening was performed at each CAS using a NE Technology Electra or E-600 fitted with a DP6 dual-alpha and beta/gamma radiation scintillation probe.

The CAS-specific sections of this document identify the CASs where field screening was conducted and how the FSLs were used to aid in the selection of samples to submit for analyses. The FSRs are recorded on SCLs that are retained in project files.

\section{A.2.2.4 Surface and Subsurface Soil Sampling}

Soil samples were collected using “scoop and trowel” (surface hand-grab sampling), hand auger and backhoe. All sample locations were initially field screened for alpha and beta/gamma radiation before the start of sampling. Additional screening was conducted during sample collection to both guide the investigation and serve as a health and safety control to protect the sampling team. Labeled sample containers were filled according to a prescribed sequence. Volatile organic compounds (VOCs) sample containers were filled with soil directly from the sample location. Additional soil was transferred into a contaminant-free pan, homogenized, and field screened for alpha and beta/gamma radiation. Samples for the analysis of gamma radiation and TPH-DRO were then collected from the homogenized soil. All remaining sample containers were then filled. Excess soil was returned to its original location, and the sample containers appropriately disposed of, based on FSR and/or analytical results.

Surface soil samples were collected from 0.0 to $0.5 \mathrm{ft}$ bgs at biased locations focusing on stained soil, aboveground features (e.g., presence of oil filters, photograph development supplies), settling areas, mounds of drilling mud, subsurface geophysical anomalies, or areas with elevated radiological measurements. Subsurface soil samples were also collected at surface sample locations where field-screening and analytical results indicated contamination. In addition to the collection of samples from biased locations, probabilistic surface sample locations were established for both the circular and rectangular components of CAS 03-17-01 due to the limited number of biasing factors. The probabilistic sample locations were generated using the Visual Sample Plan (VSP) program (PNNL, 2002). 


\section{A.2.2.5 Waste Characterization Sampling}

Characterization of decontamination rinsate waste was performed to support recommendations for disposal.

Samples were analyzed in accordance with the CAIP for CAU 545 (NNSA/NSO, 2007). The specific analyses for each CAS are listed in CAS-specific sections, and the analytical results were compared to the federal limits for hazardous waste, NDEP hydrocarbon action limit, landfill acceptance criteria, and the limits in the NTS performance objective criteria (POC) (BN, 1995). The POC limits have been established for NTS hazardous waste generators to ensure that all hazardous waste being shipped offsite contains no “added radioactivity.”

\section{A.2.3 Laboratory Analytical Information}

Chemical and radiological analyses were performed by General Engineering Laboratories, LLC, of Charleston, South Carolina. The analytical suites and laboratory analytical methods used to analyze investigation samples are listed in Table A.2-2. Analytical results are reported in this appendix if they were detected above the minimum detectable concentrations (MDCs). The complete laboratory data packages are maintained in the project files.

Table A.2-2

Laboratory Analytical Parameters and Methods, CAU 545 Investigation Samples ${ }^{a}$ (Page 1 of 2)

\begin{tabular}{|c|c|}
\hline Analytical Parameter & Analytical Method ${ }^{b}$ \\
\hline Volatile Organic Compounds & EPA SW-846 8260B ${ }^{c}$ \\
\hline Semivolatile Organic Compounds & EPA SW-846 $8270 C^{c}$ \\
\hline RCRA Metals ${ }^{d}$ Plus Beryllium & EPA SW-846 6010B/7470A/7471A ${ }^{c}$ \\
\hline TPH-DRO & EPA SW-846 $8015^{c}$ Modified \\
\hline TPH-GRO & EPA SW-846 $8015^{c}$ Modified \\
\hline Polychlorinated Biphenyls & EPA SW-846 $8082^{c}$ \\
\hline Gamma Spectroscopy & DOE EML HASL $300^{\mathrm{e}}$ Approved Laboratory SOPs ${ }^{\dagger}$ \\
\hline Isotopic Uranium & DOE EML HASL-300 U-02-RC Modified, Approved Laboratory SOPs ${ }^{\dagger}$ \\
\hline Isotopic Plutonium & $\begin{array}{l}\text { DOE EML HASL-300 PU-02-RC/PU-10-RC Modified, Approved } \\
\text { Laboratory SOPs }^{\dagger}\end{array}$ \\
\hline
\end{tabular}


Table A.2-2

Laboratory Analytical Parameters and Methods, CAU 545 Investigation Samples ${ }^{a}$ (Page 2 of 2)

\begin{tabular}{|c|c|}
\hline Analytical Parameter & Analytical Method ${ }^{b}$ \\
\hline Strontium-90 & EPA 905.09 Modified, Approved Laboratory SOPs ${ }^{\dagger}$ \\
\hline Gross Alpha/Beta & EPA $900.0^{9}$ Modified, Approved Laboratory SOPs ${ }^{\dagger}$ \\
\hline Tritium & EPA 906. $0^{g}$ Modified, Approved Laboratory SOPs ${ }^{\dagger}$ \\
\hline
\end{tabular}

\footnotetext{
anvestigation samples include both environmental and waste characterization samples and associated quality control samples. ${ }^{\mathrm{b}}$ The most current EPA, DOE, ASTM, or NIOSH or equivalent accepted analytical method may be used.

${ }^{\mathrm{c}}$ Test Methods for Evaluating Solid Waste, Physical/Chemical Methods, $3{ }^{\text {rd }}$ edition, Parts 1-4, SW-846 CD-ROM (EPA, 1996).

${ }^{\mathrm{d} A}$ Arsenic, barium, cadmium, chromium, lead, mercury, selenium and silver.

${ }^{\mathrm{e}}$ The Procedures Manual of the Environmental Measurements Laboratory, HASL-300 (DOE, 1997).

'Laboratory Standard Operating Procedures approved by SNJV in accordance with industry standards and the SNJV Model Statement of Work requirements (SNJV, 2006).

${ }^{9}$ Prescribed Procedures for Measurement of Radioactivity in Drinking Water (EMSL/ORD, 1980).
}

Note: The term "modified" indicates modifications of approved methods. All modifications have been approved by the SNJV Analytical Services Department.

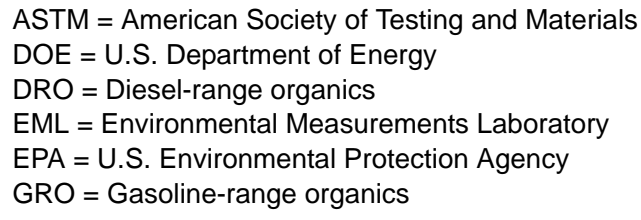

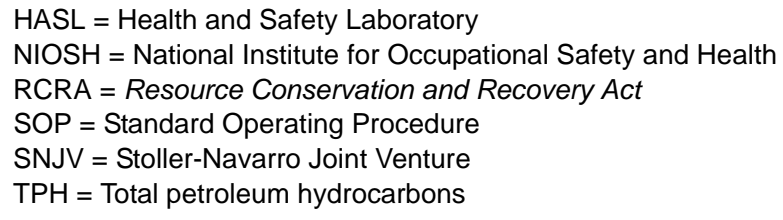

Validated analytical data for CAU 545 investigation samples have been compiled and evaluated to confirm the presence of contamination and define the extent of contamination, if present. The analytical results for each CAS are presented in Sections A.3.0 through A.7.0.

The analytical parameters are CAS-specific and were selected through application of the DQOs process as documented in the CAIP for CAU 545 (NNSA/NSO, 2007). Samples collected during step-out sampling were only analyzed for the COPCs that exceeded FALs in the original samples.

\section{A.2.4 Comparison to Action Levels}

A COC is defined as any contaminant present in environmental media exceeding a FAL. A COC may also be defined as a contaminant that, in combination with other like contaminants, is determined to jointly pose an unacceptable risk based on a multiple constituent analysis (NNSA/NSO, 2006). Multiple constituent analyses are presented in Appendix C. 
If COCs are present, corrective action must be considered for the CAS. The FALs for the CAU 545 investigation are defined in Section 2.3.1 for each CAS. Results that are equal to or greater than FALs are identified by bold text in the CAS-specific results tables (Sections A.3.0 through A.7.0).

The evaluation of the need for corrective action included the potential for wastes that are present at a site to cause the future contamination of site environmental media if the wastes were to be released. To evaluate the potential for waste material to result in the introduction of a COC to the surrounding environmental media, the following conservative assumptions were made:

- That any containment would fail at some point and the contents would be released to the surrounding media.

- That the resulting concentration of contaminants in the surrounding media would be equal to the concentration of contaminants in the nonliquid waste.

- That any contaminant in the liquid wastes exceeding the RCRA toxicity characteristic concentration can result in introduction of a COC to the surrounding media.

Oil filters with contaminant concentrations exceeding an equivalent FAL would be considered a PSM. 


\section{A.3.0 Corrective Action Site 02-09-01, Mud Disposal Area}

Corrective Action Site 02-09-01 is located immediately to the west of the 2-05 Road and Circle Road intersection in Area 2 of the NTS (Figure A.1-1). The site encompasses the U-2ei crater and three adjacent mud disposal areas. Due to safety concerns, a worker safety buffer was established $50 \mathrm{ft}$ from the rim of the crater and was precluded from sampling activities. During the DQOs, it was agreed that the material within the crater and buffer zone is the same as the material outside at the three disposal areas. Therefore, the sampling results from the material collected outside these two areas would be applied to all components of the CAS including the crater and the buffer zone. Additional detail is provided in the CAIP for CAU 545 (NNSA/NSO, 2007).

\section{A.3.1 Corrective Action Investigation}

A total of 22 characterization samples (including two field duplicates [FDs]) were collected during investigation activities at CAS 02-09-01. The sample locations are shown on Figure A.3-1. The sample locations, identifications (IDs), types, and analyses are listed in Table A.3-1. The specific CAI activities conducted to satisfy the CAIP requirements at this CAS (NNSA/NSO, 2007) are described in the following sections.

\section{A.3.1.1 Field Screening}

Investigation samples were field screened for alpha and beta/gamma radiation. The FSRs were compared to FSLs to guide subsequent sampling decisions where appropriate. Gross alpha radiation and beta/gamma radiation FSLs were not exceeded at CAS 02-09-01, and FSRs were not used in the selection of analytical samples.

\section{A.3.1.2 Radiological Surveys}

Radiological walkover surveys were conducted over the mud spill areas inside and outside the fence, up to $50 \mathrm{ft}$ from the crater rim, at CAS 02-09-01. The survey did not identify elevated radioactivity on the mud-impacted area (Figure A.3-2); therefore, the radiological survey was not used in the selection of sample locations. 


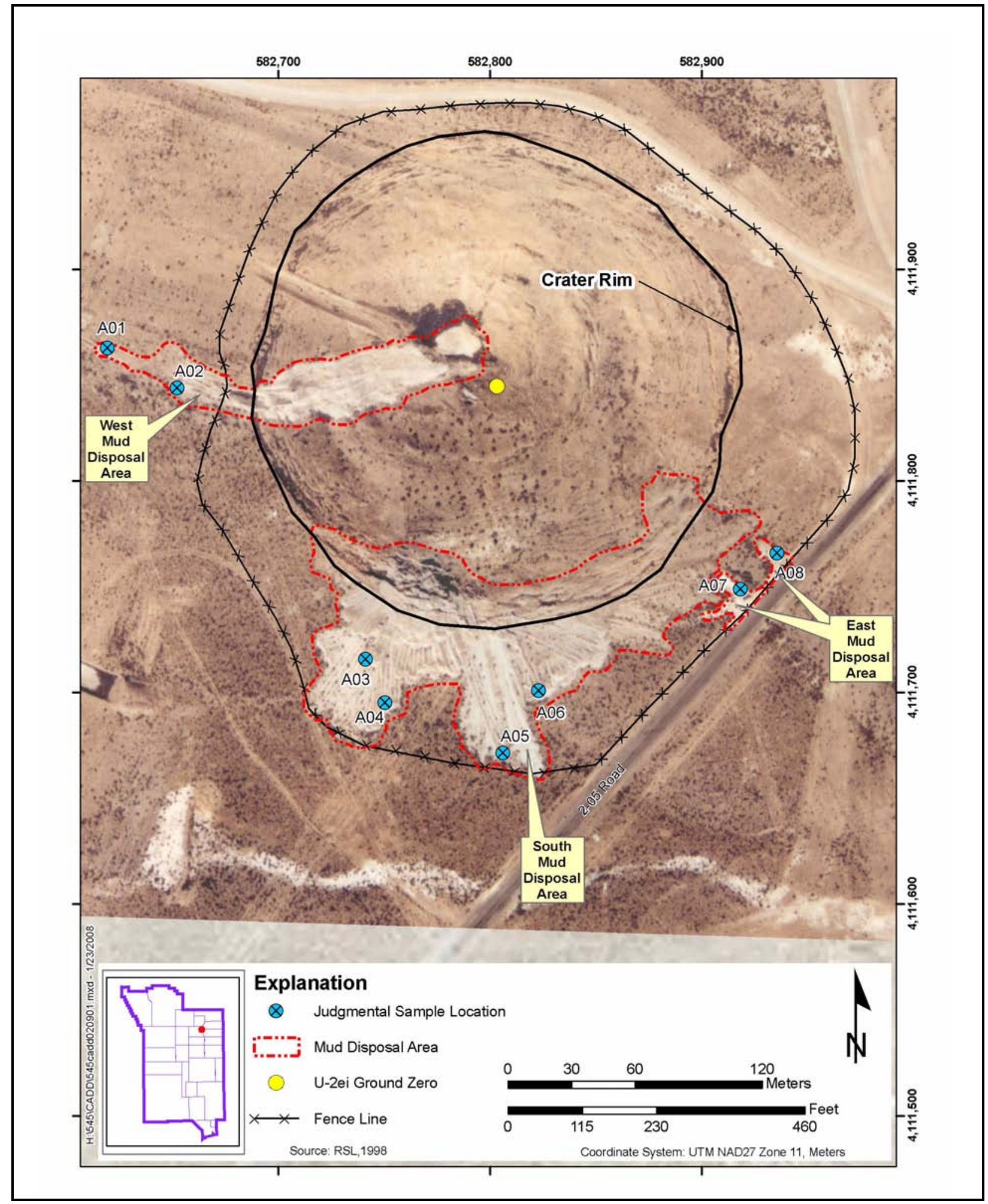

Figure A.3-1

Sample Locations at CAS 02-09-01, Mud Disposal Area 
Table A.3-1

Samples Collected at CAS 02-09-01, Mud Disposal Area

\begin{tabular}{|c|c|c|c|c|c|}
\hline $\begin{array}{l}\text { Sample } \\
\text { Location }\end{array}$ & $\begin{array}{l}\text { Sample } \\
\text { Number }\end{array}$ & $\begin{array}{l}\text { Depth } \\
\text { (ft bgs) }\end{array}$ & Matrix & Purpose & Analyses \\
\hline \multirow{2}{*}{ A01 } & $\overline{545 \mathrm{A001}}$ & $\overline{0.0-0.5}$ & 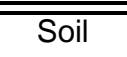 & Environmental & 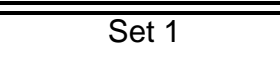 \\
\hline & $545 A 006$ & $0.75-1.25$ & Soil & Environmental & Set 1 \\
\hline \multirow{2}{*}{ A02 } & 545A002 & $0.0-0.5$ & Soil & Environmental, Full Lab QC & Set 1 \\
\hline & 545A007 & $1.0-1.5$ & Soil & Environmental & Set 1 \\
\hline \multirow{3}{*}{ A03 } & 545A003 & $0.0-0.5$ & Soil & Environmental & Set 1 \\
\hline & $545 A 008$ & $2.5-3.0$ & Soil & Environmental & Set 1 \\
\hline & $545 A 009$ & $7.0-7.5$ & Soil & Environmental & Set 1 \\
\hline \multirow{4}{*}{ A04 } & 545A004 & $0.0-0.5$ & Soil & Environmental & Set 1 \\
\hline & 545A005 & $0.0-0.5$ & Soil & Field Duplicate of \#545A004 & Set 1 \\
\hline & $545 A 010$ & $2.0-2.5$ & Soil & Environmental & Set 1 \\
\hline & $545 A 011$ & $3.0-3.5$ & Soil & Environmental & Set 1 \\
\hline \multirow{3}{*}{ A05 } & $545 \mathrm{~A} 012$ & $0.0-0.5$ & Soil & Environmental & Set 1 \\
\hline & $545 \mathrm{~A} 014$ & $2.5-3.0$ & Soil & Environmental & Set 1 \\
\hline & 545A015 & $3.5-4.0$ & Soil & Environmental & Set 1 \\
\hline \multirow{3}{*}{ A06 } & $545 \mathrm{~A} 013$ & $0.0-0.5$ & Soil & Environmental & Set 1 \\
\hline & $545 \mathrm{~A} 016$ & $3.0-3.5$ & Soil & Environmental & Set 1 \\
\hline & $545 \mathrm{~A} 017$ & $5.5-6.0$ & Soil & Environmental & Set 1 \\
\hline \multirow{3}{*}{ A07 } & 545A018 & $0.0-0.25$ & Soil & Environmental & Set 1 \\
\hline & $545 \mathrm{~A} 020$ & $0.25-1.0$ & Soil & Environmental & Set 1 \\
\hline & 545A021 & $0.25-1.0$ & Soil & Field Duplicate of \#545A020 & Set 1 \\
\hline \multirow{2}{*}{ A08 } & 545A019 & $0.0-0.33$ & Soil & Environmental, Full Lab QC & Set 1 \\
\hline & $545 \mathrm{~A} 022$ & $0.33-0.83$ & Soil & Environmental & Set 1 \\
\hline $\mathrm{N} / \mathrm{A}$ & 545A301 & $\mathrm{N} / \mathrm{A}$ & Water & Field Blank & Set 1 \\
\hline $\mathrm{N} / \mathrm{A}$ & 545A302 & $\mathrm{N} / \mathrm{A}$ & Water & Equipment Rinsate & Set 1 \\
\hline $\mathrm{N} / \mathrm{A}$ & 545A501 & NA & Liquid & Waste Management & $\begin{array}{c}\text { Set 1, Gross } \\
\text { Alpha/Beta, Tritium }\end{array}$ \\
\hline N/A & 545A502 & N/A & Liquid & Waste Management & $\begin{array}{c}\text { Set 1, Gross } \\
\text { Alpha/Beta, Tritium }\end{array}$ \\
\hline
\end{tabular}

Set 1 = Gamma Spectroscopy, Isotopic Uranium, Isotopic Plutonium, Strontium-90

bgs $=$ Below ground surface

$\mathrm{ft}=$ Foot

$\mathrm{N} / \mathrm{A}=$ Not applicable

$\mathrm{QC}=$ Quality control 


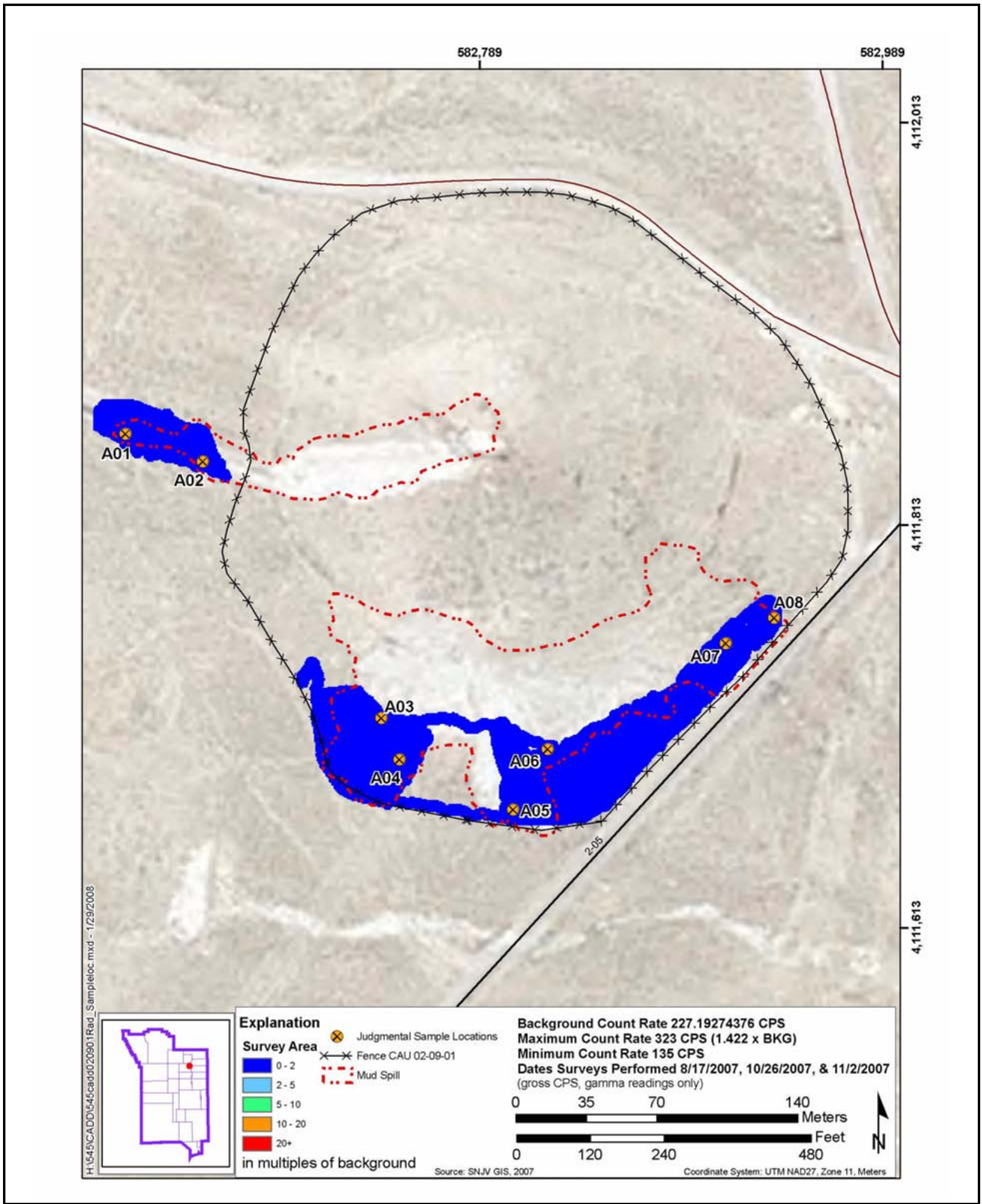

Figure A.3-2

Radiological Survey for CAS 02-09-01, Mud Disposal Area 


\section{A.3.1.3 Visual Inspections}

A visual inspection of the site did not identify any unusual staining or the presence of potentially containing hazardous or radiological materials and debris (e.g., lead bricks, lead batteries, drums or other containers). The drilling mud (Figure A.3-3), and two sediment accumulation areas in the east disposal area, were the only biasing factors. As these were features identified for sample collection in the CAIP (NNSA/NSO, 2007), no additional sample locations were identified.

\section{A.3.1.4 Sample Collection}

Decision I environmental sampling activities included the collection of biased surface and subsurface soil samples within the drilling mud disposal areas (Figure A.3-1) at this CAS.

Environmental samples were collected from six mounds of drilling mud and two sediment accumulation areas. Sample 545A001 was collected from the surface interval ( 0.0 to $0.5 \mathrm{ft}$ bgs) at location A01, the westernmost mound in the west disposal area (Figure A.3-1). As no biasing factors were detected within the mound profile the subsurface sample (545A006) was collected at the drilling mud/native soil interface ( 0.75 to $1.25 \mathrm{ft}$ bgs). At location A02 at the second mound in the west disposal area, Sample 545A002 was collected from the surface interval (0.0 to $0.5 \mathrm{ft}$ bgs) and the subsurface sample (545A007) was collected at the drilling mud/native soil interface (1.0 to $1.5 \mathrm{ft}$ bgs). For both mounds, gravel consistent with the surface rock in the area was mixed in with the drilling mud throughout the profiles. The presence of gravel in the mud suggests that either the mud has been used, and the gravel represents drill cuttings; the mud was spilled onsite and mounded by dumping or pushing with mechanical equipment; or it was collected and transported to CAS 02-09-01.

Within the south disposal area, location A03 was established at the highest mound (approximately $7.0 \mathrm{ft}$ ) present outside of the 50 -ft worker safety buffer. Samples collected at this location include the surface (545A003), a mid-mound subsurface sample (545A008) at 2.5 to $3.0 \mathrm{ft}$ bgs, and a sample (545A009) collected at the drilling mud/native soil interface ( 7.0 to $7.5 \mathrm{ft} \mathrm{bgs).} \mathrm{The} \mathrm{mud} \mathrm{was} \mathrm{fairly}$ homogenous throughout the mound; though thin layers of the mud were present in the mid-section, and gravel was present through the entire profile. 


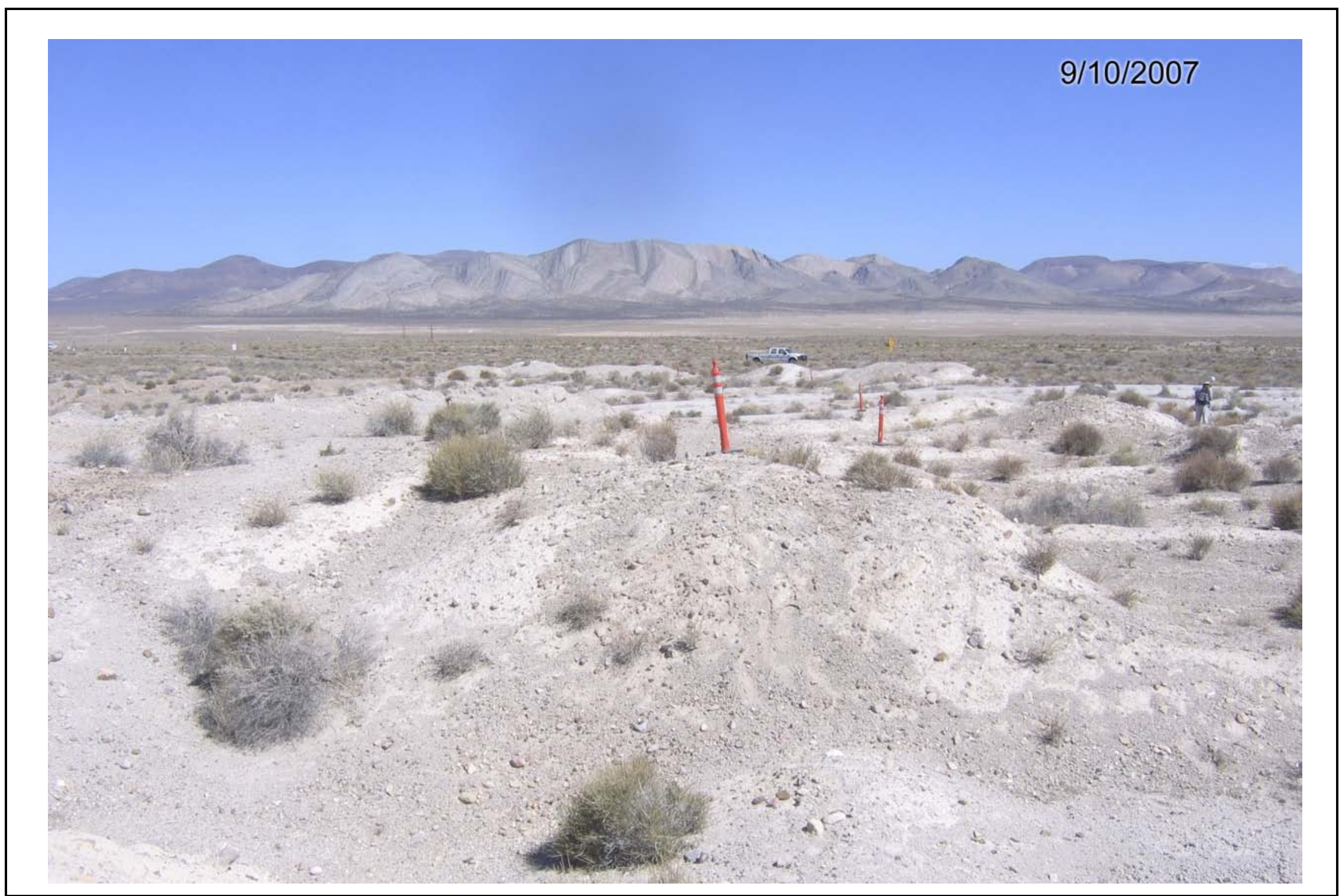

Figure A.3-3

Mounds of Drilling Mud at CAS 02-09-01

\section{UNCONTROLLED When Printed}


Location A04 was at a mound approximately 3.0 to $3.5 \mathrm{ft}$ high selected for sampling because two T-posts protruding from the mound at different angles were identified. The mound and T-posts had the appearance of originating from a mud spill at another location. At location A04, a sample (545A004) and duplicate (545A005) were collected at the surface (0.0 to $0.5 \mathrm{ft}$ bgs), a sample (545A010) was collected from within the mound (2.0 to $2.5 \mathrm{ft}$ bgs), and a sample (545A011) was collected at the drilling mud/native soil interface (3.0 to $3.5 \mathrm{ft}$ bgs). The mound was homogenous throughout with gravel present through the entire profile.

Location A05 was also at a shorter mound (approximately $3.5 \mathrm{ft}$ high) identified for sampling because the mud was a darker gray than other mud at the site. The dried mud formed a subangular blocky structure which was unique to the mud in the area. A sample (545A012) was collected at the surface ( 0.0 to $0.5 \mathrm{ft}$ bgs), a sample (545A014) was collected within the mound (2.5 to $3.0 \mathrm{ft}$ bgs), and a sample (545A013) was collected at the drilling mud/native soil interface (3.0 to $3.5 \mathrm{ft}$ bgs).

Location A06 was at the highest mound (approximately $6.0 \mathrm{ft}$ high) in the eastern portion of the south disposal area. A sample (545A013) was collected at the surface (0.0 to $0.5 \mathrm{ft}$ bgs), a sample (545A016) was collected within the mound (3.0 to $3.5 \mathrm{ft} \mathrm{bgs),} \mathrm{and} \mathrm{a} \mathrm{sample} \mathrm{(545A017)} \mathrm{was} \mathrm{collected}$ at the drilling mud/native soil interface (5.5 to $6.0 \mathrm{ft}$ bgs).

Locations A07 and A08 were selected at sediment accumulation points in the east disposal area. Before sampling, a rainstorm left several inches of runoff from the surrounding mounds of drilling mud at the two locations. Location A08 was dry enough to be sampled a week later; however, location A07 had to be moved a several feet to the west within the settling area, due to persistent standing water. Surface samples (545A018 and 545A019) were taken at locations A07 and A08 from 0.0 to 0.25 and 0.0 to $0.33 \mathrm{ft}$ bgs, respectively. Subsurface samples (545A020 and duplicate 545A021, and 545A022) were collected at locations A07 and A08 from 0.25 to $1.0 \mathrm{ft}$ bgs and 0.33 to $0.83 \mathrm{ft}$ bgs, respectively.

\section{A.3.1.5 Deviations}

Investigation samples were collected as outlined in the CAIP for CAU 545 (NNSA/NSO, 2007) and submitted for laboratory analysis. There were no deviations to the planned sampling. 


\section{A.3.2 Investigation Results}

The following sections provide analytical results from the samples collected at CAS 02-09-01 to complete investigation activities as outlined in the CAIP for CAU 545 (NNSA/NSO, 2007).

Table A.3-1 lists the sample-specific analytical suite for CAS 02-09-01, which included gamma-emitting radionuclides, isotopic Pu, strontium (Sr)-90, and isotopic uranium (U). The analytical parameters and laboratory methods used to analyze the investigation samples are listed in Table A.2-2. The waste characterization analytical results are discussed in Section A.8.0.

Analytical results from the soil samples with concentrations exceeding MDCs are summarized in the following sections. An evaluation was conducted on all contaminants detected above MDCs by comparing individual concentration or activity results against the FALs. Establishment of the FALs is presented in Appendix C. The FALs were established as the corresponding PAL concentrations or activities if the contaminant concentrations were below their respective PALs.

\section{A.3.2.1 Gamma-Emitting Radionuclides}

Gamma-emitting radionuclides analytical results for environmental samples collected at this CAS that were detected above MDCs are presented in Table A.3-2. No gamma-emitting radionuclide exceeded the FALs. The FALs were established at the PAL concentrations.

\section{A.3.2.2 Plutonium, Strontium-90, and Uranium Isotopes}

Isotopic Pu and isotopic $\mathrm{U}$ analytical results for environmental samples collected at this CAS that were detected above MDCs are presented in Table A.3-3. No isotopic Pu, isotopic U, or Sr-90 exceeded the FALs. The FALs were established at the PAL concentrations.

\section{A.3.3 Nature and Extent of Contamination}

Based on the analytical results for soil samples collected during the CAI, no COCs were identified at CAS 02-09-01.

\section{A.3.4 Revised Conceptual Site Model}

The CAIP requirements (NNSA/NSO, 2007) were met at this CAS, and no revisions were necessary to the CSM. 
Table A.3-2

Soil Sample Results for Gamma-Emitting Radionuclides Detected above Minimum Detectable Concentrations at CAS 02-09-01, Mud Disposal Area

\begin{tabular}{|c|c|c|c|c|c|c|c|}
\hline \multirow[b]{2}{*}{$\begin{array}{l}\text { Sample } \\
\text { Location }\end{array}$} & \multirow[b]{2}{*}{$\begin{array}{l}\text { Sample } \\
\text { Number }\end{array}$} & \multirow[b]{2}{*}{$\begin{array}{l}\text { Depth } \\
\text { (ft bgs) }\end{array}$} & \multicolumn{5}{|c|}{ Contaminants of Potential Concern (pCi/g) } \\
\hline & & & 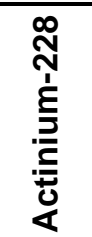 & 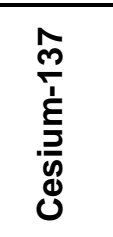 & 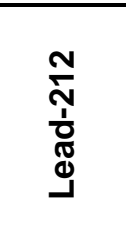 & 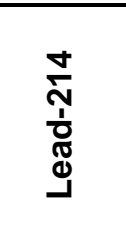 & 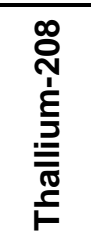 \\
\hline \multicolumn{3}{|c|}{ Final Action Levels } & $5^{a}$ & $12.2^{b}$ & $5^{a}$ & $5^{a}$ & $5^{a}$ \\
\hline \multirow{2}{*}{ A01 } & 545A001 & $\overline{0.0-0.5}$ & $\overline{2.14}$ & $\overline{---}$ & $\overline{2.21}$ & $\overline{1.31}$ & $\overline{0.751}$ \\
\hline & 545A006 & $0.75-1.25$ & 1.78 & 1.23 & 1.96 & 1.26 & 0.725 \\
\hline \multirow{2}{*}{$\mathrm{A} 02$} & $545 \mathrm{~A} 002$ & $0.0-0.5$ & 1.82 & -- & 1.88 & 1.25 & 0.686 \\
\hline & 545A007 & $1.0-1.5$ & 2.06 & $\overline{--}$ & 1.83 & 1.05 & 0.572 \\
\hline \multirow{3}{*}{ A03 } & 545A003 & $0.0-0.5$ & 1.94 & -- & 2.05 & 1.08 & 0.503 \\
\hline & 545A008 & $2.5-3.0$ & 1.42 & -- & 2.02 & 1.21 & 0.624 \\
\hline & 545A009 & $7.0-7.5$ & 1.9 & -- & 2.4 & 1.37 & 0.65 \\
\hline \multirow{4}{*}{ A04 } & 545A004 & $0.0-0.5$ & 1.75 & -- & 1.71 & 1.08 & 0.539 \\
\hline & 545A005 & $0.0-0.5$ & 1.64 & -- & 1.95 & 1.23 & 0.506 \\
\hline & $545 \mathrm{~A} 010$ & $2.0-2.5$ & 2.03 & -- & 2.03 & 1.31 & 0.655 \\
\hline & 545A011 & $3.0-3.5$ & 1.92 & -- & 1.73 & 1.03 & 0.572 \\
\hline \multirow{3}{*}{ A05 } & 545A012 & $0.0-0.5$ & 2.3 & -- & $1.81(\mathrm{~J})$ & $1.4(\mathrm{~J})$ & 0.496 \\
\hline & 545A014 & $2.5-3.0$ & 1.61 & -- & $1.8(\mathrm{~J})$ & $1.34(\mathrm{~J})$ & 0.469 \\
\hline & 545A015 & $3.5-4.0$ & 2.31 & 0.727 & $1.96(\mathrm{~J})$ & $1.25(\mathrm{~J})$ & 0.652 \\
\hline \multirow{3}{*}{ A06 } & $545 \mathrm{~A} 013$ & $0.0-0.5$ & 2.01 & -- & 2.12 & 1.25 & 0.685 \\
\hline & $545 \mathrm{~A} 016$ & $3.0-3.5$ & 2.05 & -- & 2.16 & 1.24 & 0.662 \\
\hline & 545A017 & $5.5-6.0$ & 1.95 & 0.201 & $1.87(\mathrm{~J})$ & $1.32(\mathrm{~J})$ & 0.627 \\
\hline \multirow{3}{*}{ A07 } & $545 \mathrm{~A} 018$ & $0.0-0.25$ & 2.67 & 0.504 & 2.38 & 1.43 & 0.859 \\
\hline & $545 \mathrm{~A} 020$ & $0.25-1.0$ & 2.06 & 0.625 & 1.94 & 1.41 & 0.7 \\
\hline & $545 \mathrm{~A} 021$ & $0.25-1.0$ & 2.18 & 0.74 & 1.96 & 1.27 & 0.65 \\
\hline \multirow{2}{*}{ A08 } & 545A019 & $0.0-0.33$ & 2.12 & 0.542 & 2.39 & 1.44 & 0.737 \\
\hline & $545 \mathrm{~A} 022$ & $0.33-0.83$ & 1.6 & 2.04 & 2.2 & 1.32 & 0.741 \\
\hline
\end{tabular}

a Taken from the generic guidelines for residual concentrations of actinium-228, bismuth-214, lead-212, lead-214, thallium-208, and thorium-232, as found in Chapter IV of DOE Order 5400.5, Change 2, "Radiation Protection of the Public and Environment" (DOE, 1993). The PALs for these isotopes are specified as $5 \mathrm{pCi} / \mathrm{g}$ averaged over the first $15 \mathrm{~cm}$ of soil and $15 \mathrm{pCi} / \mathrm{g}$ for deeper soils (DOE, 1993). For purposes of this document, $15 \mathrm{~cm}$ is assumed to be equivalent to $0.5 \mathrm{ft}$ ( 6 inches); therefore, $5 \mathrm{pCi} / \mathrm{g}$ represents the PALs for these radionuclides in the surface soil (0 to $0.5 \mathrm{ft}$ depth).

${ }^{\mathrm{b}}$ Taken from the construction, commercial, industrial land-use scenario in Table 2.1 of the NCRP Report No. 129, Recommended Screening Limits for Contaminated Surface Soil and Review Factors Relevant to Site-Specific Studies (NCRP, 1999). The values provided in this source document were scaled to a 25-millirem-per-year dose.

bgs $=$ Below ground surface

$\mathrm{cm}=$ Centimeter

DOE = U.S. Department of Energy

$\mathrm{J}=$ Estimated value

-- = Not detected above minimum detectable concentrations. $\mathrm{ft}=$ Foot

NCRP $=$ National Council on Radiation Protection and Measurements

$\mathrm{pCi} / \mathrm{g}=$ Picocuries per gram 
Table A.3-3

Soil Sample Results for Isotopes Detected above Minimum Detectable Concentrations at CAS 02-09-01, Mud Disposal Area

\begin{tabular}{|c|c|c|c|c|c|c|c|}
\hline \multirow[b]{2}{*}{ 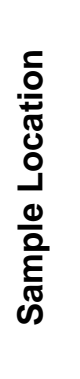 } & \multirow[b]{2}{*}{ 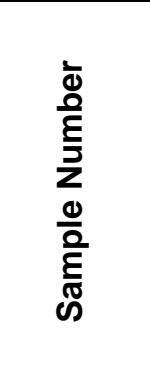 } & \multirow[b]{2}{*}{ 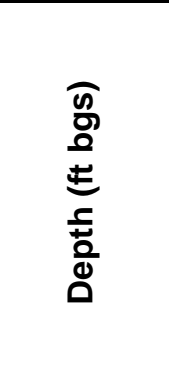 } & \multicolumn{5}{|c|}{ Contaminants of Potential Concern (pCi/g) } \\
\hline & & & 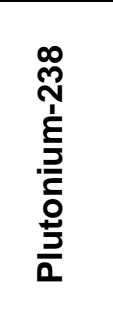 & 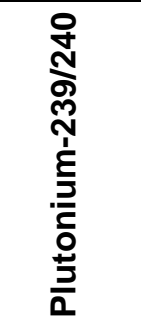 & 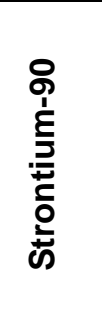 & 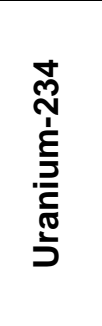 & 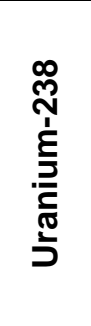 \\
\hline \multicolumn{3}{|c|}{ Final Action Levels ${ }^{a}$} & 13 & 12.7 & 838 & 143 & 105 \\
\hline \multirow{2}{*}{ A01 } & 545A001 & $0.0-0.5$ & $\overline{--}$ & -- & 0.255 & 1.11 & 0.912 \\
\hline & 545A006 & $0.75-1.25$ & -- & 0.818 & -- & 0.892 & 0.685 \\
\hline \multirow{2}{*}{ A02 } & $545 A 002$ & $0.0-0.5$ & -- & -- & -- & 0.992 & 1.08 \\
\hline & $545 A 007$ & $1.0-1.5$ & -- & -- & -- & 0.841 & 0.765 \\
\hline \multirow{3}{*}{ A03 } & 545A003 & $0.0-0.5$ & -- & -- & -- & 1.08 & 0.986 \\
\hline & 545A008 & $2.5-3.0$ & -- & -- & -- & 0.944 & 0.866 \\
\hline & 545A009 & $7.0-7.5$ & -- & -- & -- & 1.21 & 0.928 \\
\hline \multirow{4}{*}{ A04 } & 545A004 & $0.0-0.5$ & -- & 0.0551 & -- & 0.934 & 0.956 \\
\hline & 545A005 & $0.0-0.5$ & -- & -- & -- & 0.861 & 0.784 \\
\hline & $545 A 010$ & $2.0-2.5$ & -- & -- & -- & 1.25 & 1.04 \\
\hline & 545A011 & $3.0-3.5$ & -- & -- & -- & 0.91 & 0.885 \\
\hline \multirow{3}{*}{ A05 } & $545 A 012$ & $0.0-0.5$ & -- & 0.18 & -- & 0.808 & 0.798 \\
\hline & $545 \mathrm{~A} 014$ & $2.5-3.0$ & -- & 0.288 & -- & 0.9 & 0.942 \\
\hline & 545A015 & $3.5-4.0$ & -- & 0.294 & -- & 0.7 & 0.724 \\
\hline \multirow{3}{*}{ A06 } & $545 A 013$ & $0.0-0.5$ & -- & -- & -- & 1.14 & 0.954 \\
\hline & 545A016 & $3.0-3.5$ & -- & -- & -- & 0.978 & 0.964 \\
\hline & 545A017 & $5.5-6.0$ & -- & -- & -- & 0.917 & 0.898 \\
\hline \multirow{3}{*}{ A07 } & 545A018 & $0.0-0.25$ & -- & $0.407(\mathrm{~J})$ & -- & 1.15 & 1.09 \\
\hline & 545A020 & $0.25-1.0$ & 0.0249 & $0.152(\mathrm{~J})$ & -- & 1.27 & 0.792 \\
\hline & 545A021 & $0.25-1.0$ & -- & $0.188(\mathrm{~J})$ & -- & 0.714 & 0.915 \\
\hline \multirow{2}{*}{ A08 } & 545A019 & $0.0-0.33$ & - & $0.461(\mathrm{~J})$ & -- & 1.26 & 1.18 \\
\hline & $545 \mathrm{~A} 022$ & $0.33-0.83$ & 0.0578 & $0.725(\mathrm{~J})$ & 0.289 & 1.14 & 1.15 \\
\hline
\end{tabular}

aTaken from the construction, commercial, industrial land-use scenario in Table 2.1 of the NCRP Report No. 129, Recommended Screening Limits for Contaminated Surface Soil and Review Factors Relevant to Site-Specific Studies (NCRP, 1999). The values provided in this source document were scaled to a 25-millirem-per-year-dose.

bgs $=$ Below ground surface

$\mathrm{ft}=$ Foot
NCRP = National Council on Radiation Protection and Measurements $\mathrm{pCi} / \mathrm{g}=$ Picocuries per gram

$\mathrm{J}=$ Estimated value

-- = Not detected above minimum detectable concentrations. 


\section{A.4.0 Corrective Action Site 03-17-01, Waste Consolidation Site 3B}

Corrective Action Site 03-17-01 is located 1.0 mi east of the Area 3 RWMS at the NTS

(Figure A.1-1). The site served as the consolidation area for debris from atmospheric testing during the 1950s and 1960s, which was then removed during the 1980s. The site consists of two components: a rectangular area measuring 950 by $750 \mathrm{ft}$, posted as a contamination area; and a unposted circular area measuring $145 \mathrm{ft}$ in diameter. The site was sampled by a combined probabilistic and judgmental approach. Additional detail is provided in the CAIP for CAU 545 (NNSA/NSO, 2007).

\section{A.4.1 Corrective Action Investigation}

A total of 58 characterization samples (including three FDs) were collected at 46 locations during investigation activities at CAS 03-17-01. Surface samples taken for the probabilistic approach were collected at locations B01 through B16, and B19 through B26, for a total of 24 samples. All other surface samples, and all subsurface samples, were collected as judgmental samples. The sample locations are shown on Figure A.4-1. The sample locations, IDs, types, and analyses are listed in Table A.4-1. The specific CAI activities conducted to satisfy the CAIP requirements at this CAS (NNSA/NSO, 2007) are described in the following sections.

\section{A.4.1.1 Field Screening}

Investigation samples were field screened for alpha and beta/gamma radiation. The FSRs were compared to FSLs to guide subsequent sampling decisions where appropriate. Gross alpha radiation FSLs were exceeded in eight samples and beta/gamma radiation FSLs were exceeded in nine samples at CAS 03-17-01. For the eight background samples collected outside the CAS, the gross alpha radiation FSL was exceeded in one sample and beta/gamma radiation FSL was exceeded in three samples. All samples exceeding FSLs were analyzed for radiological constituents. 


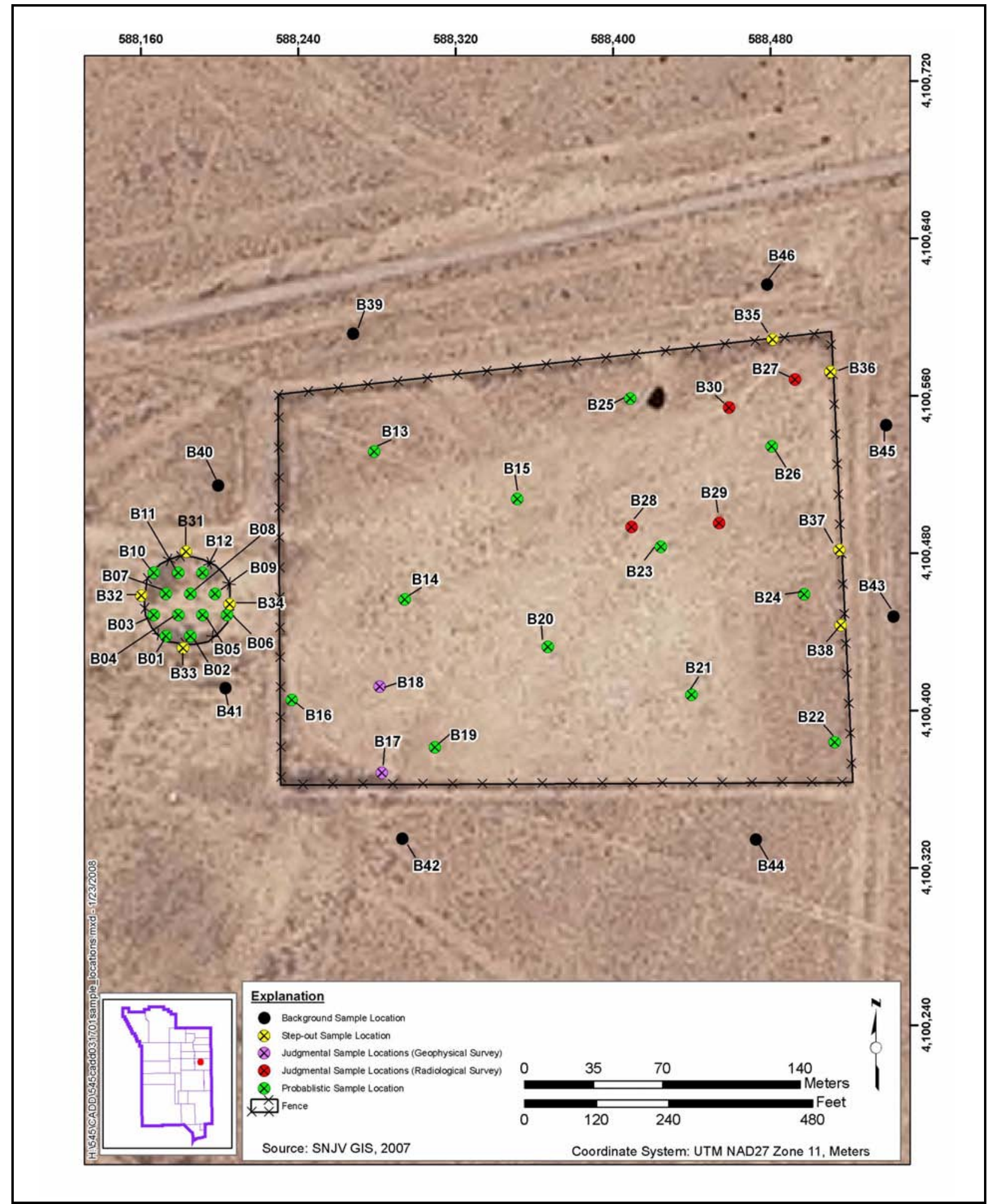

Figure A.4-1

Sample Locations at CAS 03-17-01, Waste Consolidation Site 3B 
Table A.4-1

Samples Collected at CAS 03-17-01, Waste Consolidation Site 3B (Page 1 of 2)

\begin{tabular}{|c|c|c|c|c|c|}
\hline $\begin{array}{c}\text { Sample } \\
\text { Location }\end{array}$ & $\begin{array}{l}\text { Sample } \\
\text { Number }\end{array}$ & $\begin{array}{l}\text { Depth } \\
\text { (ft bgs) }\end{array}$ & Matrix & Purpose & Analyses \\
\hline$\overline{\mathrm{B} 01}$ & 545B001 & $0.0-0.5$ & Soil & Environmental & Set 2 \\
\hline B02 & 545B002 & $0.0-0.5$ & Soil & Environmental & Set 2 \\
\hline B03 & 545B003 & $0.0-0.5$ & Soil & Environmental, Full Lab QC & Set 2 \\
\hline B04 & 545B004 & $0.0-0.5$ & Soil & Environmental & Set 2 \\
\hline B05 & 545B005 & $0.0-0.5$ & Soil & Environmental & Set 2 \\
\hline B06 & 545B006 & $0.0-0.5$ & Soil & Environmental & Set 2 \\
\hline \multirow{2}{*}{ B07 } & 545B007 & $0.0-0.5$ & Soil & Environmental & Set 2 \\
\hline & 545B008 & $0.0-0.5$ & Soil & Field Duplicate of \#545B007 & Set 2 \\
\hline B08 & 545B009 & $0.0-0.5$ & Soil & Environmental & Set 2 \\
\hline B09 & 545B010 & $0.0-0.5$ & Soil & Environmental & Set 2 \\
\hline \multirow{2}{*}{$\mathrm{B} 10$} & 545B011 & $0.0-0.5$ & Soil & Environmental & Set 2 \\
\hline & 545B014 & $0.5-1.0$ & Soil & Environmental & Set 2 \\
\hline \multirow{2}{*}{ B11 } & 545B012 & $0.0-0.5$ & Soil & Environmental & Set 2 \\
\hline & 545B050 & $1.0-1.5$ & Soil & Environmental & Set 1 \\
\hline B12 & 545B013 & $0.0-0.5$ & Soil & Environmental & Set 2 \\
\hline $\mathrm{B} 13$ & 545B015 & $0.0-0.5$ & Soil & Environmental & Set 2 \\
\hline B14 & 545B016 & $0.0-0.5$ & Soil & Environmental & Set 2 \\
\hline B15 & 545B017 & $0.0-0.5$ & Soil & Environmental & Set 2 \\
\hline B16 & 545B018 & $0.0-0.5$ & Soil & Environmental & Set 2 \\
\hline B17 & 545B019 & $0.0-0.5$ & Soil & Environmental & Set 2 \\
\hline B18 & 545B020 & $0.0-0.5$ & Soil & Environmental & Set 2 \\
\hline B19 & 545B021 & $0.0-0.5$ & Soil & Environmental & Set 2 \\
\hline B20 & 545B022 & $0.0-0.5$ & Soil & Environmental & Set 2 \\
\hline B21 & 545B023 & $0.0-0.5$ & Soil & Environmental & Set 2 \\
\hline $\mathrm{B} 22$ & 545B024 & $0.0-0.5$ & Soil & Environmental & Set 2 \\
\hline B23 & 545B025 & $0.0-0.5$ & Soil & Environmental & Set 2 \\
\hline B24 & 545B026 & $0.0-0.5$ & Soil & Environmental & Set 2 \\
\hline \multirow{2}{*}{ B25 } & 545B027 & $0.0-0.5$ & Soil & Environmental & Set 2 \\
\hline & 545B028 & $0.0-0.5$ & Soil & Field Duplicate of \#545B027 & Set 2 \\
\hline $\mathrm{B} 26$ & 545B029 & $0.0-0.5$ & Soil & Environmental & Set 2 \\
\hline \multirow{3}{*}{$\mathrm{B} 27$} & 545B030 & $0.0-0.5$ & Soil & Environmental, Full Lab QC & Set 2 \\
\hline & $545 \mathrm{~B} 033$ & $0.5-1.0$ & Soil & Environmental & Set 2 \\
\hline & 545B041 & $1.0-1.5$ & Soil & Environmental & Set 1 \\
\hline \multirow{3}{*}{$\mathrm{B} 28$} & $545 B 031$ & $0.0-0.5$ & Soil & Environmental & Set 2 \\
\hline & 545B035 & $0.5-1.0$ & Soil & Environmental & Set 2 \\
\hline & $545 B 045$ & $1.0-1.75$ & Soil & Environmental & Set 1 \\
\hline
\end{tabular}


Table A.4-1

Samples Collected at CAS 03-17-01, Waste Consolidation Site 3B (Page 2 of 2)

\begin{tabular}{|c|c|c|c|c|c|}
\hline $\begin{array}{c}\text { Sample } \\
\text { Location }\end{array}$ & $\begin{array}{l}\text { Sample } \\
\text { Number }\end{array}$ & $\begin{array}{c}\text { Depth } \\
\text { (ft bgs) }\end{array}$ & Matrix & Purpose & Analyses \\
\hline \multirow{4}{*}{ B29 } & 545B032 & $0.0-0.5$ & Soil & Environmental & Set 2 \\
\hline & 545B036 & $0.5-1.0$ & Soil & Environmental & Set 2 \\
\hline & 545B043 & $1.0-2.0$ & Soil & Environmental & Set 1 \\
\hline & 545B044 & $1.0-2.0$ & Soil & Field Duplicate of \#545B043 & Set 1 \\
\hline \multirow{2}{*}{ B30 } & 545B034 & $0.0-0.5$ & Soil & Environmental & Set 2 \\
\hline & 545B042 & $1.0-1.5$ & Soil & Environmental & Set 1 \\
\hline B31 & 545B053 & $0.0-0.25$ & Soil & Environmental & Set 1 \\
\hline B32 & 545B054 & $0.0-0.5$ & Soil & Environmental & Set 1 \\
\hline B33 & 545B052 & $0.0-0.5$ & Soil & Environmental & Set 1 \\
\hline B34 & 545B051 & $0.0-0.5$ & Soil & Environmental & Set 1 \\
\hline B35 & 545B037 & $0.0-0.5$ & Soil & Environmental & Set 1 \\
\hline B36 & 545B038 & $0.0-0.5$ & Soil & Environmental & Set 1 \\
\hline B37 & 545B039 & $0.0-0.5$ & Soil & Environmental & Set 1 \\
\hline B38 & 545B040 & $0.0-0.5$ & Soil & Environmental, Full Lab QC & Set 1 \\
\hline B39 & 545B055 & $0.0-0.5$ & Soil & Environmental, Background & Set 1 \\
\hline B40 & 545B056 & $0.0-0.5$ & Soil & Environmental, Background & Set 1 \\
\hline B41 & 545B057 & $0.0-0.5$ & Soil & Environmental, Background & Set 1 \\
\hline B42 & 545B058 & $0.0-0.5$ & Soil & Environmental, Background & Set 1 \\
\hline B43 & 545B049 & $0.0-0.5$ & Soil & Environmental, Background & Set 1 \\
\hline B44 & 545B048 & $0.0-0.5$ & Soil & Environmental, Background & Set 1 \\
\hline B45 & 545B047 & $0.0-0.5$ & Soil & Environmental, Background & Set 1 \\
\hline B46 & 545B046 & $0.0-0.5$ & Soil & Environmental, Background & Set 1 \\
\hline $\mathrm{N} / \mathrm{A}$ & 545B301 & $\mathrm{N} / \mathrm{A}$ & Water & Field Blank & Set 2 \\
\hline $\mathrm{N} / \mathrm{A}$ & 545B302 & $\mathrm{N} / \mathrm{A}$ & Water & Equipment Rinsate & Set 1 \\
\hline N/A & 545B501 & $\mathrm{N} / \mathrm{A}$ & Liquid & Waste Management & Set 2, Gross Alpha/Beta, Tritium \\
\hline $\mathrm{N} / \mathrm{A}$ & 545B502 & $\mathrm{N} / \mathrm{A}$ & Liquid & Waste Management & Set 1, Gross Alpha/Beta, Tritium \\
\hline
\end{tabular}

Set 1 = Gamma Spectroscopy, Isotopic Uranium, Isotopic Plutonium, Strontium-90

Set 2 = RCRA Metals, Gamma Spectroscopy, Isotopic Uranium, Isotopic Plutonium, Strontium-90

bgs = Below ground surface

$\mathrm{ft}=$ Foot

$\mathrm{N} / \mathrm{A}=$ Not applicable
$\mathrm{QC}=$ Quality control

RCRA = Resource Conservation and Recovery Act 


\section{A.4.1.2 Radiological Surveys}

A radiological walkover survey was conducted over the areas encompassing the circular and rectangular components of CAS 03-17-01 (Figure A.4-2). Several areas were found to have elevated radiological readings at approximately two times background and were used as biasing factors to select four locations for sampling.

\section{A.4.1.3 Geophysical Survey}

A geophysical survey was conducted over the areas encompassing the circular and rectangular components of CAS 03-17-01. The survey identified 101 discrete anomolies, interpreted to represent subsurface metal objects. Two of these locations were sampled. Details of the survey results, along with the survey map, are in the CAIP for CAU 545, Section A.2.3.1 (NNSA/NSO, 2007).

\section{A.4.1.4 Visual Inspections}

There were no visible biasing factors identified at this CAS. All locations were selected on the basis of the probabilistic sampling approach and from the geophysical and radiological survey data.

\section{A.4.1.5 Sample Collection}

Decision I environmental sampling activities at both the circular and rectangular components were conducted within the guidelines of a probabilistic sampling approach, with additional biased soil samples collected from the rectangular component (Figure A.4-1), and outside the fenced boundaries. Locations B01 through B16 and B19 through B26 were predetermined randomized locations. Locations B17 and B18 were established at geophysical anomalies, and locations B27 through B30 were established at areas of elevated radiological readings. Step-out locations B31 through B38 were established at locations along the fence lines of both the circular and rectangular components. Background locations B39 through B46 were established in pairs diagonally outward from the corners of the rectangular component. Locations B01 through B12 were established in the circular area, and B13 through B30, as well as B38, were established within the fence at the rectangular area.

Surface samples were collected at all locations from the interval of 0.0 to $0.5 \mathrm{ft}$ bgs. Brush obstructing several locations was cleared back. Other obstructions such as large rocks or scrap metal were not encountered at any sample location. 


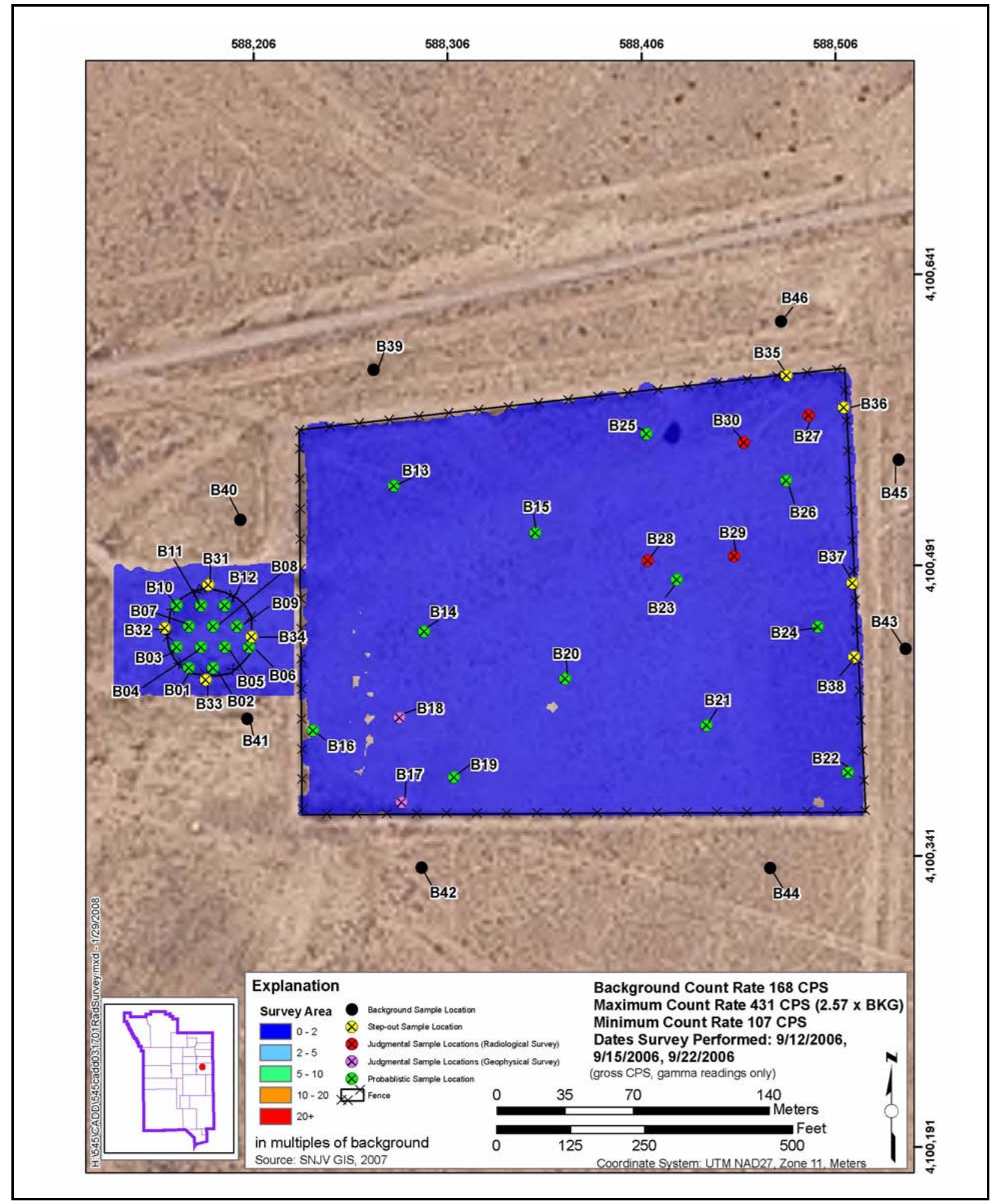

Figure A.4-2

Radiological Survey of CAS 03-17-01 
The FSLs for alpha were exceeded at locations B10, B13, B14, B27, B28, B29, and B41, from just above the FSL to 15 times FSL; and the FSLs for beta were exceeded at locations B14, B16, B17, B27, B28, B29, B30, B40, B41, and B42, from just above the FSL to 1.8 times the FSL. The values for the FSRs are maintained in the project files.

Because FSLs were exceeded, nine shallow subsurface samples were collected at the two components at six locations with the highest screening readings.

\section{A.4.1.6 Deviations}

Investigation samples were collected as outlined in the CAIP for CAU 545 (NNSA/NSO, 2007) and submitted for laboratory analysis. All sample locations were accessible and each probabilistic sample was collected at its predetermined location.

\section{A.4.2 Investigation Results}

The following sections provide analytical results from the samples collected to complete investigation activities as outlined in the CAIP for CAU 545 (NNSA/NSO, 2007). Investigation samples were analyzed for the CAIP-specified COPCs, which included RCRA metals, gamma-emitting radionuclides, isotopic $\mathrm{Pu}, \mathrm{Sr}-90$, and isotopic U. The analytical parameters and laboratory methods used during this investigation are listed in Table A.2-2. Table A.4-1 lists the sample-specific analytical suite for CAS 03-17-01. The waste characterization analytical results are discussed in Section A.8.0.

Analytical results from the soil samples with concentrations exceeding MDCs are summarized in the following sections. An evaluation was conducted on all contaminants detected above MDCs by comparing individual concentration or activity results against the FALs. The FALs were established as the corresponding PAL concentrations or activities if the contaminant concentrations were below their respective PALs. For constituents that were reported at concentrations exceeding their respective PAL, the FAL determinations are presented in Appendix C. 


\section{A.4.2.1 RCRA Metals}

The RCRA metals analytical results for environmental samples collected at this CAS that were detected above MDCs are presented in Table A.4-2. No RCRA metals were detected at concentrations exceeding the respective PALs. The FALs were established at the PAL concentrations.

Table A.4-2

Soil Sample Results for RCRA Metals Detected above Minimum Detectable Concentrations at CAS 03-17-01, Waste Consolidation Site 3B (Page 1 of 2)

\begin{tabular}{|c|c|c|c|c|c|c|c|c|c|c|}
\hline \multirow{2}{*}{ 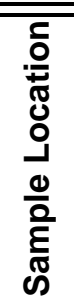 } & \multirow{2}{*}{ 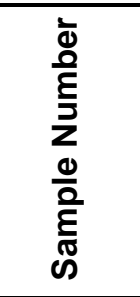 } & \multirow{2}{*}{ 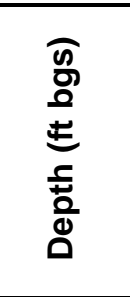 } & \multicolumn{8}{|c|}{ Contaminants of Potential Concern (mg/kg) } \\
\hline & & & $\begin{array}{l}\frac{0}{C} \\
\frac{\bar{d}}{d} \\
\stackrel{0}{\alpha} \\
\frac{0}{\alpha}\end{array}$ & 占 & 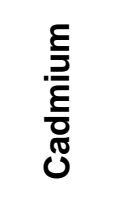 & 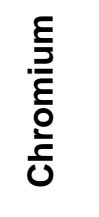 & 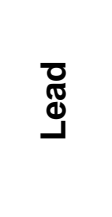 & $\begin{array}{l}\stackrel{\lambda}{\bar{J}} \\
\stackrel{d}{d} \\
\sum\end{array}$ & $\begin{array}{l}\frac{\xi}{D} \\
\frac{\bar{d}}{d} \\
\text { 山े }\end{array}$ & $\frac{\grave{D}}{\overline{\bar{\omega}}}$ \\
\hline \multicolumn{3}{|c|}{ Final Action Levels } & $23^{a}$ & $67,000^{b}$ & $450^{b}$ & $450^{b}$ & $800^{b}$ & $310^{\mathrm{b}}$ & $5,100^{\mathrm{b}}$ & $5,100^{b}$ \\
\hline$\overline{\mathrm{B} 01}$ & $\overline{\text { 545B001 }}$ & $\overline{0.0-0.5}$ & 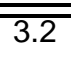 & 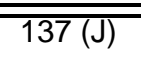 & $\overline{0.22(\mathrm{~J})}$ & 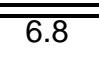 & $\overline{77.7}$ & $\overline{0.0081(\mathrm{~J}-)}$ & $\overline{0.55(\mathrm{~J}+)}$ & $\overline{---}$ \\
\hline B02 & 545B002 & $0.0-0.5$ & 4.1 & $134(\mathrm{~J})$ & $0.16(\mathrm{~J})$ & 7.5 & 8.6 & $0.006(\mathrm{~J}-)$ & $0.78(\mathrm{~J}+)$ & -- \\
\hline B03 & 545B003 & $0.0-0.5$ & 3.8 & $127(\mathrm{~J})$ & $0.19(\mathrm{~J})$ & 8.6 & 8.5 & $0.0087(\mathrm{~J}-)$ & $0.66(\mathrm{~J}+)$ & -- \\
\hline B04 & 545B004 & $0.0-0.5$ & 3.7 & $137(\mathrm{~J})$ & $0.32(\mathrm{~J})$ & 7.6 & 7.7 & $0.0049(\mathrm{~J}-)$ & -- & -- \\
\hline B05 & 545B005 & $0.0-0.5$ & 4.2 & $223(\mathrm{~J})$ & $0.23(\mathrm{~J})$ & 6.8 & 8.7 & $0.0086(\mathrm{~J}-)$ & $0.88(\mathrm{~J}+)$ & -- \\
\hline B06 & 545B006 & $0.0-0.5$ & 3.3 & $158(\mathrm{~J})$ & $0.23(\mathrm{~J})$ & 7 & 8.7 & $0.0088(\mathrm{~J}-)$ & -- & $\overline{--}$ \\
\hline \multirow{2}{*}{ B07 } & 545B007 & $0.0-0.5$ & 3.3 & $129(\mathrm{~J})$ & $0.3(\mathrm{~J})$ & 8.1 & 8.5 & $0.0076(\mathrm{~J}-)$ & $0.64(\mathrm{~J}+)$ & $0.1(\mathrm{~J})$ \\
\hline & 545B008 & $0.0-0.5$ & 3.6 & $131(\mathrm{~J})$ & $0.32(\mathrm{~J})$ & 7.8 & 8.3 & $0.0083(\mathrm{~J}-)$ & -- & $\overline{--}$ \\
\hline B08 & 545B009 & $0.0-0.5$ & 3.6 & $147(\mathrm{~J})$ & $0.32(\mathrm{~J})$ & 7.8 & 9.9 & $0.0064(\mathrm{~J}-)$ & $0.75(\mathrm{~J}+)$ & -- \\
\hline B09 & 545B010 & $0.0-0.5$ & 3.4 & $174(\mathrm{~J})$ & $0.33(\mathrm{~J})$ & 7.8 & 7.7 & $0.0053(\mathrm{~J}-)$ & $0.53(\mathrm{~J}+)$ & -- \\
\hline \multirow{2}{*}{ B10 } & 545B011 & $0.0-0.5$ & 3.2 & $146(\mathrm{~J})$ & $0.29(\mathrm{~J})$ & 6.9 & 9.7 & $0.01(\mathrm{~J}-)$ & -- & $0.23(\mathrm{~J})$ \\
\hline & 545B014 & $0.5-1.0$ & 3.8 & $121(\mathrm{~J})$ & $0.24(\mathrm{~J})$ & 7 & 6.8 & $0.0047(\mathrm{~J}-)$ & $0.82(\mathrm{~J}+)$ & $0.1(\mathrm{~J})$ \\
\hline B11 & 545B012 & $0.0-0.5$ & 3.3 & $166(\mathrm{~J})$ & $0.3(\mathrm{~J})$ & 7.2 & 9.5 & $0.0087(\mathrm{~J}-)$ & -- & $0.1(\mathrm{~J})$ \\
\hline B12 & 545B013 & $0.0-0.5$ & 3.6 & $133(\mathrm{~J})$ & $0.37(\mathrm{~J})$ & 7.6 & 7.8 & $0.01(\mathrm{~J}-)$ & $0.99(\mathrm{~J}+)$ & -- \\
\hline B13 & 545B015 & $0.0-0.5$ & 4.1 & $129(\mathrm{~J})$ & -- & 8.4 & 8.9 & $0.015(\mathrm{~J}-)$ & $1.7(\mathrm{~J}-)$ & -- \\
\hline B14 & 545B016 & $0.0-0.5$ & 3.2 & $159(\mathrm{~J})$ & -- & 8 & 8.8 & $0.006(\mathrm{~J}-)$ & $1.4(\mathrm{~J}-)$ & -- \\
\hline B15 & 545B017 & $0.0-0.5$ & 3.9 & $164(\mathrm{~J})$ & -- & 8.2 & 8.5 & $0.0078(\mathrm{~J}-)$ & $1.8(\mathrm{~J}-)$ & -- \\
\hline B16 & 545B018 & $0.0-0.5$ & 4.5 & $153(\mathrm{~J})$ & -- & 8.2 & 9.9 & $0.013(\mathrm{~J}-)$ & $1.6(\mathrm{~J}-)$ & $\overline{--}$ \\
\hline B17 & 545B019 & $0.0-0.5$ & 7.6 & $137(\mathrm{~J})$ & -- & 7.7 & 7.9 & $0.0088(\mathrm{~J}-)$ & $1.4(\mathrm{~J}-)$ & -- \\
\hline B18 & 545B020 & $0.0-0.5$ & 7.3 & $118(\mathrm{~J})$ & -- & 7.9 & $8.5(\mathrm{~J})$ & -- & -- & -- \\
\hline B19 & 545B021 & $0.0-0.5$ & 4.6 & $127(\mathrm{~J})$ & -- & 8.1 & $9.4(\mathrm{~J})$ & -- & -- & $0.24(\mathrm{~J})$ \\
\hline B20 & 545B022 & $0.0-0.5$ & 4.1 & $116(\mathrm{~J})$ & -- & 6.6 & $8.1(\mathrm{~J})$ & $0.031(\mathrm{~J})$ & -- & -- \\
\hline B21 & 545B023 & $0.0-0.5$ & 4 & $133(\mathrm{~J})$ & -- & 7 & $6.7(\mathrm{~J})$ & -- & -- & -- \\
\hline B22 & 545B024 & $0.0-0.5$ & 4.8 & $144(\mathrm{~J})$ & -- & 8.3 & $10(\mathrm{~J})$ & -- & -- & -- \\
\hline
\end{tabular}




\section{Table A.4-2 \\ Soil Sample Results for RCRA Metals Detected above Minimum Detectable Concentrations at CAS 03-17-01, Waste Consolidation Site 3B} (Page 2 of 2 )

\begin{tabular}{|c|c|c|c|c|c|c|c|c|c|c|}
\hline \multirow{2}{*}{ 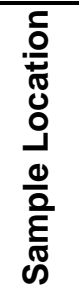 } & \multirow{2}{*}{ 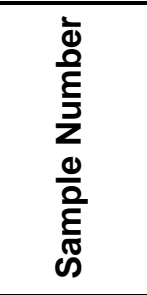 } & \multirow[b]{2}{*}{ 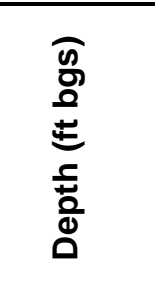 } & \multicolumn{8}{|c|}{ Contaminants of Potential Concern (mg/kg) } \\
\hline & & & $\begin{array}{l}\frac{0}{c} \\
\frac{0}{\Phi} \\
\frac{\omega}{\alpha}\end{array}$ & 占 & 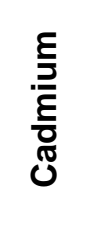 & 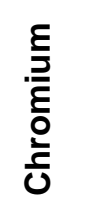 & ర్త్ర & 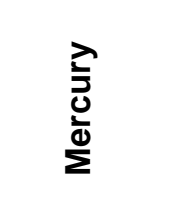 & 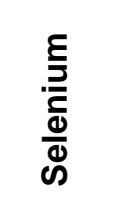 & 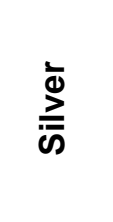 \\
\hline$\overline{\mathrm{B} 23}$ & 545B025 & $0.0-0.5$ & 4.7 & $140(\mathrm{~J})$ & $\overline{---}$ & $\overline{7.5}$ & $9.7(\mathrm{~J})$ & -- & $\overline{---}$ & -- \\
\hline B24 & 545B026 & $0.0-0.5$ & 5.4 & $155(\mathrm{~J})$ & -- & 9 & $11.9(\mathrm{~J})$ & -- & -- & -- \\
\hline \multirow{2}{*}{ B25 } & 545B027 & $0.0-0.75$ & 3.9 & $132(\mathrm{~J})$ & -- & 9 & 8 & $0.012(\mathrm{~J}-)$ & 1.9 & -- \\
\hline & 545B028 & $0.0-0.5$ & 4.8 & $121(\mathrm{~J})$ & -- & 9.6 & 7.7 & $0.012(\mathrm{~J}-)$ & $2.6(\mathrm{~J})$ & -- \\
\hline \multirow{2}{*}{ B28 } & 545B031 & $0.0-0.5$ & 4.9 & $235(\mathrm{~J})$ & -- & 8.2 & 13.3 & $0.04(\mathrm{~J}-)$ & $1.5(\mathrm{~J})$ & -- \\
\hline & 545B035 & $0.5-1.0$ & 4 & $212(\mathrm{~J})$ & -- & 6.6 & 9.7 & $0.011(\mathrm{~J}-)$ & 1.6 & -- \\
\hline \multirow{2}{*}{ B29 } & 545B032 & $0.0-0.5$ & 4.3 & $172(\mathrm{~J})$ & -- & 7 & 10.8 & $0.011(\mathrm{~J}-)$ & 1.6 & -- \\
\hline & 545B036 & $0.5-1.0$ & 3.2 & $100(\mathrm{~J})$ & -- & 6 & 6.5 & 0.0087 (J-) & $1.3(\mathrm{~J})$ & -- \\
\hline B30 & 545B034 & $0.0-0.5$ & 3.8 & $133(\mathrm{~J})$ & -- & 8.8 & 9.4 & $0.011(\mathrm{~J}-)$ & 2 & -- \\
\hline
\end{tabular}

aBased on the background concentrations for metals. Background is considered the mean plus two times the standard deviation for sediment samples collected by the Nevada Bureau of Mines and Geology throughout the Nevada Test and Training Range (NBMG, 1998; Moore, 1999).

${ }^{\mathrm{b} B}$ Based on U.S. Environmental Protection Agency, Region 9 Preliminary Remediation Goals (PRGs) (EPA, 2004).

bgs $=$ Below ground surface

$\mathrm{ft}=$ Foot

$\mathrm{mg} / \mathrm{kg}=$ Milligrams per kilogram

$\mathrm{J}=$ Estimated value

$\mathrm{J}+=$ The result is an estimated quantity, but the result may be biased high.

$\mathrm{J}-=$ The result is an estimated quantity, but the result may be biased low.

$--=$ Not detected above minimum detectable concentrations.

\section{A.4.2.2 Gamma-Emitting Radionuclides}

Analytical results for gamma-emitting radionuclides are discussed separately for samples collected through a probabilistic approach (i.e., most surface samples at this CAS) and samples collected through a judgmental approach (i.e., some surface samples within the CAS and all surface samples outside the CAS, as well as all subsurface samples at the CAS). 
Probabilistic Sampling Results: Gamma-emitting radionuclides analytical results for environmental samples collected at this CAS that were detected above MDCs are presented in Table A.4-3. The probabilistic sampling design as described in the CAIP for CAU 545 (NNSA/NSO, 2007) stipulates comparing the 95th percent UCL of the mean of each significant COPC (i.e., contaminants present at concentrations greater than PALs) to the FAL to determine whether a COC is present. Therefore, only significant COPCs are evaluated for the presence of COCs. To demonstrate the selection of significant COPCs, Table A.4-3 lists the PALs for gamma-emitting radionuclides.

Table A.4-3

Probabilistic Soil Sample Results for Gamma-Emitting Radionuclides Detected above Minimum Detectable Concentrations at CAS 03-17-01, Waste Consolidation Site 3B

(Page 1 of 2)

\begin{tabular}{|c|c|c|c|c|c|c|c|c|c|}
\hline \multirow[b]{2}{*}{$\begin{array}{l}\text { Sample } \\
\text { Location }\end{array}$} & \multirow[b]{2}{*}{$\begin{array}{l}\text { Sample } \\
\text { Number }\end{array}$} & \multirow[b]{2}{*}{$\begin{array}{l}\text { Depth } \\
\text { (ft bgs) }\end{array}$} & \multicolumn{7}{|c|}{ Contaminants of Potential Concern (pCi/g) } \\
\hline & & & 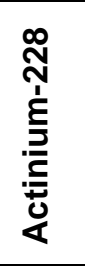 & 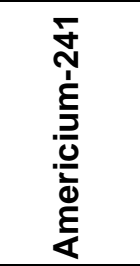 & 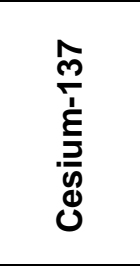 & 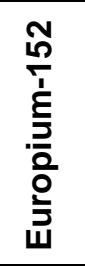 & 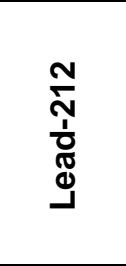 & 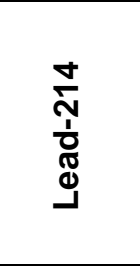 & 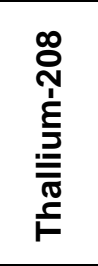 \\
\hline \multicolumn{3}{|c|}{ Preliminary Action Levels $^{a}$} & $\overline{5}$ & 12.7 & $\overline{12.2}$ & 5.7 & $\overline{5}$ & $\overline{5}$ & $\overline{5}$ \\
\hline \multicolumn{3}{|c|}{ Final Action Levels ${ }^{b}$} & 5 & 1,501 & 12.2 & 5.7 & 5 & 5 & 5 \\
\hline \multicolumn{3}{|c|}{ Average } & $\mathrm{NC}$ & 5.70 & NC & $\mathrm{NC}$ & NC & NC & NC \\
\hline \multicolumn{3}{|c|}{ Standard Deviation } & $\mathrm{NC}$ & 5.46 & NC & $\mathrm{NC}$ & NC & NC & NC \\
\hline \multicolumn{3}{|c|}{$\begin{array}{l}\text { VSP Required Minimum Number } \\
\text { of Samples }\end{array}$} & $\mathrm{NC}$ & 8 & NC & $\mathrm{NC}$ & NC & NC & NC \\
\hline \multicolumn{3}{|c|}{ Maximum Result } & 1.93 & 29.1 & 2.2 & 1.19 & 1.92 & 1.283 & 0.623 \\
\hline \multicolumn{3}{|c|}{$95 \%$ UCL $^{c}$} & $\mathrm{NC}$ & 8.202 & $\mathrm{NC}$ & $\mathrm{NC}$ & $\mathrm{NC}$ & $\mathrm{NC}$ & $\mathrm{NC}$ \\
\hline$\overline{\overline{\text { B01 }}}$ & $\overline{\text { 545B001 }}$ & $0.0-0.5$ & 1.65 & $\overline{c 6.35(\mathrm{~J})}$ & $\overline{0.462(\mathrm{~J})}$ & $\overline{---}$ & 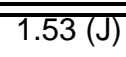 & 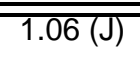 & $\overline{0.439}$ \\
\hline B02 & 545B002 & $0.0-0.5$ & 1.54 & $4.8(\mathrm{~J})$ & $0.291(\mathrm{~J})$ & -- & $1.57(\mathrm{~J})$ & $1.13(\mathrm{~J})$ & 0.466 \\
\hline B03 & 545B003 & $0.0-0.5$ & 1.42 & $3.05(\mathrm{~J})$ & $0.63(\mathrm{~J})$ & -- & $1.92(\mathrm{~J})$ & $1.09(\mathrm{~J})$ & 0.498 \\
\hline B04 & 545B004 & $0.0-0.5$ & 1.73 & $0.828(\mathrm{~J})$ & -- & $\overline{--}$ & $1.52(\mathrm{~J})$ & $1.06(\mathrm{~J})$ & 0.432 \\
\hline B05 & 545B005 & $0.0-0.5$ & 1.7 & $6.48(\mathrm{~J})$ & $0.553(\mathrm{~J})$ & -- & $1.64(\mathrm{~J})$ & $1.06(\mathrm{~J})$ & 0.479 \\
\hline B06 & 545B006 & $0.0-0.5$ & 1.53 & $5.21(\mathrm{~J})$ & $0.424(\mathrm{~J})$ & -- & $1.46(\mathrm{~J})$ & $0.959(\mathrm{~J})$ & 0.523 \\
\hline \multirow{2}{*}{ B07 } & 545B007 & $0.0-0.5$ & 1.9 & $1.3(\mathrm{~J})$ & -- & -- & $1.49(\mathrm{~J})$ & $1.06(\mathrm{~J})$ & 0.506 \\
\hline & 545B008 & $0.0-0.5$ & 1.69 & $1.14(\mathrm{~J})$ & $0.131(\mathrm{~J})$ & -- & $1.6(\mathrm{~J})$ & $1.2(\mathrm{~J})$ & 0.391 \\
\hline B08 & 545B009 & $0.0-0.5$ & 1.93 & $15.8(\mathrm{~J})$ & $0.627(\mathrm{~J})$ & -- & $1.55(\mathrm{~J})$ & $1.1(\mathrm{~J})$ & 0.454 \\
\hline B09 & $545 \mathrm{~B} 010$ & $0.0-0.5$ & 1.56 & $4.17(\mathrm{~J})$ & $0.335(\mathrm{~J})$ & $\overline{--}$ & $1.54(\mathrm{~J})$ & $0.972(\mathrm{~J})$ & 0.465 \\
\hline $\mathrm{B} 10^{\mathrm{d}}$ & 545B011 & $0.0-0.5$ & 1.71 & $29.1(\mathrm{~J})$ & $1.37(\mathrm{~J})$ & -- & $1.49(\mathrm{~J})$ & $0.941(\mathrm{~J})$ & 0.537 \\
\hline B11 & 545B012 & $0.0-0.5$ & 1.64 & $21(\mathrm{~J})$ & $1.05(\mathrm{~J})$ & $\overline{--}$ & $1.73(\mathrm{~J})$ & $1.25(\mathrm{~J})$ & 0.48 \\
\hline
\end{tabular}


Table A.4-3

Probabilistic Soil Sample Results for Gamma-Emitting Radionuclides Detected above Minimum Detectable Concentrations at CAS 03-17-01, Waste Consolidation Site 3B (Page 2 of 2)

\begin{tabular}{|c|c|c|c|c|c|c|c|c|c|}
\hline \multirow[b]{2}{*}{$\begin{array}{l}\text { Sample } \\
\text { Location }\end{array}$} & \multirow[b]{2}{*}{$\begin{array}{l}\text { Sample } \\
\text { Number }\end{array}$} & \multirow[b]{2}{*}{$\begin{array}{c}\text { Depth } \\
\text { (ft bgs) }\end{array}$} & \multicolumn{7}{|c|}{ Contaminants of Potential Concern (pCi/g) } \\
\hline & & & 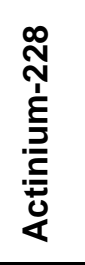 & 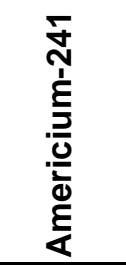 & 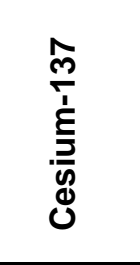 & 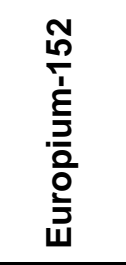 & 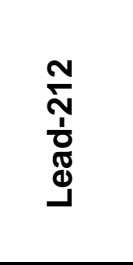 & 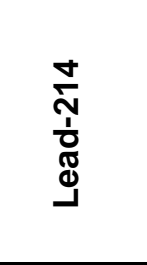 & 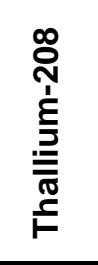 \\
\hline$\overline{\mathrm{B} 12}$ & 545B013 & $0.0-0.5$ & 1.36 & $10.6(\mathrm{~J})$ & $0.646(\mathrm{~J})$ & $\overline{---}$ & $1.64(\mathrm{~J})$ & $\overline{1.04(\mathrm{~J})}$ & $\overline{0.528}$ \\
\hline B13 & 545B015 & $0.0-0.5$ & 1.66 & $1.79(\mathrm{~J})$ & 0.959 & -- & $1.65(\mathrm{~J})$ & $1.15(\mathrm{~J})$ & 0.472 \\
\hline B14 & 545B016 & $0.0-0.5$ & 1.39 & $16.2(\mathrm{~J})$ & 0.47 & $0.57(\mathrm{~J})$ & $1.55(\mathrm{~J})$ & $0.961(\mathrm{~J})$ & 0.437 \\
\hline B15 & 545B017 & $0.0-0.5$ & 1.64 & $4.33(\mathrm{~J})$ & 0.267 & -- & $1.67(\mathrm{~J})$ & $1.12(\mathrm{~J})$ & 0.565 \\
\hline B16 & 545B018 & $0.0-0.5$ & 1.56 & $2.93(\mathrm{~J})$ & 1.29 & $1.19(\mathrm{~J})$ & $1.62(\mathrm{~J})$ & $1.16(\mathrm{~J})$ & 0.509 \\
\hline B19 & 545B021 & $0.0-0.5$ & 1.58 & 0.81 & 0.257 & -- & 1.87 & 1.23 & 0.582 \\
\hline $\mathrm{B} 20$ & 545B022 & $0.0-0.5$ & 1.52 & -- & -- & -- & $1.67(\mathrm{~J})$ & $1.09(\mathrm{~J})$ & 0.476 \\
\hline B21 & 545B023 & $0.0-0.5$ & 1.55 & $3.2(\mathrm{~J})$ & -- & -- & $1.39(\mathrm{~J})$ & $0.832(\mathrm{~J})$ & 0.617 \\
\hline B22 & 545B024 & $0.0-0.5$ & 1.33 & $2.57(\mathrm{~J})$ & 2.2 & -- & $1.76(\mathrm{~J})$ & $1.25(\mathrm{~J})$ & 0.577 \\
\hline B23 & 545B025 & $0.0-0.5$ & 1.54 & $1.42(\mathrm{~J})$ & -- & -- & $1.89(\mathrm{~J})$ & $1.28(\mathrm{~J})$ & 0.422 \\
\hline B24 & 545B026 & $0.0-0.5$ & 1.73 & $4.74(\mathrm{~J})$ & 0.353 & -- & $1.67(\mathrm{~J})$ & $1.09(\mathrm{~J})$ & 0.534 \\
\hline \multirow{2}{*}{ B25 } & 545B027 & $0.0-0.75$ & 1.81 & $2.4(\mathrm{~J})$ & 0.485 & -- & $1.68(\mathrm{~J})$ & $1.01(\mathrm{~J})$ & 0.535 \\
\hline & 545B028 & $0.0-0.75$ & 1.48 & $3.99(\mathrm{~J})$ & 0.69 & -- & $1.56(\mathrm{~J})$ & $0.923(\mathrm{~J})$ & 0.443 \\
\hline B26 & 545B029 & $0.0-0.5$ & 1.71 & 9.37 & 0.403 & -- & 1.63 & 1.16 & 0.623 \\
\hline
\end{tabular}

aDefined in the CAIP for CAU 545 (NNSA/NSO, 2007).

${ }^{b}$ Established in Appendix C.

'Value for Am-241 derived as the 95\% Approximate Gamma UCL, a nonparametric distribution, and used as a proxy for the $95 \%$ UCL.

${ }^{\mathrm{d}}$ The result for Am-241 from sample 545B011 was identified as a statistical outlier and was not included in the calculation of the $95 \%$ UCL of the mean. The result is included with the probabilistic data for completeness. If this result was included with the other 23 sample results in calculations, the value for the 95\% UCL would be 9.757 (95\% Approximate Gamma).

Am $=$ Americium

bgs $=$ Below ground surface

CAIP = Corrective Action Investigation Plan

$\mathrm{ft}=$ Foot

$\mathrm{J}=$ Estimated value

$\mathrm{NC}=$ Not calculated, as the contaminant did not qualify as a significant contaminant of potential concern.

-- = Not detected above minimum detectable concentrations.

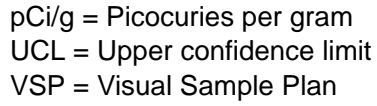

$\mathrm{pCi} / \mathrm{g}=$ Picocuries per gram

$\mathrm{UCL}=$ Upper confidence limit

VSP $=$ Visual Sample Plan

One gamma-emitting radionuclide (Americium [Am]-241) met the criteria established in the CAIP for CAU 545 (NNSA/NSO, 2007) to be a significant COPC at CAS 03-17-01 for the probabilistic sampling (i.e., any result exceeds a PAL). The statistics for this radionuclide are presented in Table A.4-3. 
Based on the initial data review it was determined by the ProUCL test for outliers that the result of $29.1 \mathrm{pCi} / \mathrm{g}$ for sample 545B011 is an outlier and should not be included in the dataset. The outlier value of $29.1 \mathrm{pCi} / \mathrm{g}$ was compared directly to the FAL for Am-241 along with the judgmental sample results.

The statistics were run by ProUCL for the Am-241 results from CAS 03-17-01 for remaining dataset. The resulting estimation of the variability was found to be reasonable and representative of the population being sampled. Based on the process established in the CAIP for establishing minimum sample size (NNSA/NSO, 2007), the required minimum number of samples needed for valid statistical analysis is eight. Because more than eight samples were collected (23), a UCL of the mean was calculated for comparison to the FAL.

To derive the UCL of the mean for the Am-241 results, computations by the ProUCL software (e.g., for determination of data distributions and the 95 percent UCL) determined that the dataset met the criteria for a gamma distribution. The recommended 95 percent Approximate Gamma UCL of 8.202 picocuries per gram (pCi/g) based on the gamma distribution was selected.

The site-specific FAL for Am-241 was calculated with RESRAD using the industrial scenario in a Tier 2 evaluation. The FAL for Am-241 was determined to be 1,501 pCi/g. The calculation of the FAL for Am-241 is presented in Appendix C. The outlier and the 95 percent Approximate Gamma UCL for the remaining probabilistic dataset are below the FAL for Am-241, and Am-241 is not considered a COC.

Judgmental Sampling Results: Analytical results for gamma-emitting radionuclides in judgmental samples taken from outside the CAS and the subsurface soil at the CAS that were detected above MDCs are presented in Table A.4-4. The radionuclide Am-241 was detected at activities that exceeded the PAL of $12.7 \mathrm{pCi} / \mathrm{g}$ in surface samples taken at nine locations (B27, B28, B29, B30, B31, B33, B34, B36, and B41), and in subsurface samples taken at locations B27 and B28 as shown on Figure A.4-1. Americium-241 was advanced onto a Tier 2 evaluation in which RESRAD was used to determine a site-specific FAL for Am-241 under an industrial scenario. Americium-241 results did not exceed the industrial FAL of 1,501 pCi/g at any location, and therefore is not considered a COC at this CAS. The calculation of the FAL for Am-241 is presented in Appendix C. No other 
Table A.4-4

Judgmental Soil Sample Results for Gamma-Emitting Radionuclides Detected above Minimum Detectable Concentrations at CAS 03-17-01, Waste Consolidation Site 3B (Page 1 of 2)

\begin{tabular}{|c|c|c|c|c|c|c|c|c|c|}
\hline \multirow[b]{2}{*}{$\begin{array}{l}\text { Sample } \\
\text { Location }\end{array}$} & \multirow[b]{2}{*}{$\begin{array}{l}\text { Sample } \\
\text { Number }\end{array}$} & \multirow[b]{2}{*}{$\begin{array}{l}\text { Depth } \\
\text { (ft bgs) }\end{array}$} & \multicolumn{7}{|c|}{ Contaminants of Potential Concern (pCi/g) } \\
\hline & & & 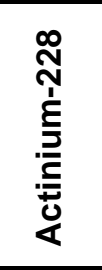 & 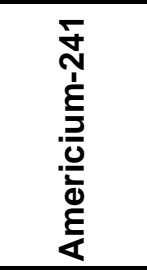 & 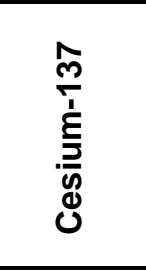 & 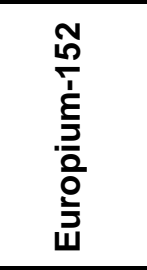 & 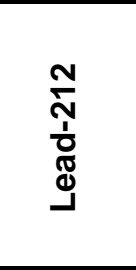 & 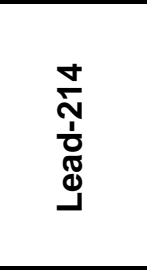 & 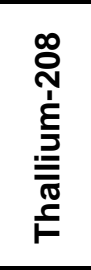 \\
\hline \multicolumn{3}{|c|}{ Final Action Levels } & $5^{a}$ & $1,501^{b}$ & $12.2^{\mathrm{c}}$ & $5.7^{\mathrm{C}}$ & $5^{a}$ & $5^{a}$ & $5^{a}$ \\
\hline$\overline{\mathrm{B} 10}$ & 545B014 & $0.5-1.0$ & 1.28 & $1.29(\mathrm{~J})$ & $0.205(\mathrm{~J})$ & 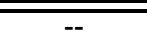 & $1.45(\mathrm{~J})$ & $1.02(\mathrm{~J})$ & $\overline{0.44}$ \\
\hline B11 & 545B050 & $1.0-1.5$ & 1.51 & -- & $\begin{array}{l}- \\
-\end{array}$ & -- & $1.56(\mathrm{~J})$ & $0.852(\mathrm{~J})$ & 0.483 \\
\hline B17 & 545B019 & $0.0-0.5$ & 1.61 & $1.81(\mathrm{~J})$ & 1.14 & $\overline{--}$ & $1.51(\mathrm{~J})$ & $1.04(\mathrm{~J})$ & 0.534 \\
\hline B18 & 545B020 & $0.0-0.5$ & 1.75 & $2.67(\mathrm{~J})$ & 0.463 & -- & $1.69(\mathrm{~J})$ & $0.998(\mathrm{~J})$ & 0.552 \\
\hline \multirow{3}{*}{ B27 } & 545B030 & $0.0-0.5$ & 1.98 & 284 & 3.36 & 1.49 & 1.97 & 1.35 & 0.481 \\
\hline & 545B033 & $0.5-1.0$ & 1.93 & $73.8(\mathrm{~J})$ & 1.79 & -- & $1.76(\mathrm{~J})$ & $1.12(\mathrm{~J})$ & 0.536 \\
\hline & 545B041 & $1.0-1.5$ & 1.76 & 134 & 1.71 & -- & 1.59 & 1.17 & 0.508 \\
\hline \multirow{3}{*}{ B28 } & 545B031 & $0.0-0.5$ & 1.85 & 57.2 & 3.41 & 1.77 & 1.69 & 1.26 & 0.781 \\
\hline & 545B035 & $0.5-1.0$ & 1.69 & 71.9 & 3.97 & 1.88 & 1.98 & 1.14 & 0.642 \\
\hline & 545B045 & $1.0-1.75$ & 1.34 & $3.55(\mathrm{~J})$ & 0.329 & -- & $1.69(\mathrm{~J})$ & $0.865(\mathrm{~J})$ & 0.504 \\
\hline \multirow{4}{*}{ B29 } & 545B032 & $0.0-0.5$ & 2.18 & 132 & 5.14 & 2.17 & 1.74 & 1.18 & 0.583 \\
\hline & 545B036 & $0.5-1.0$ & 1.48 & $1.72(\mathrm{~J})$ & 0.494 & -- & $1.4(\mathrm{~J})$ & $1.05(\mathrm{~J})$ & 0.491 \\
\hline & 545B043 & $1.0-2.0$ & 1.57 & $5.02(\mathrm{~J})$ & 0.319 & -- & $1.48(\mathrm{~J})$ & $0.994(\mathrm{~J})$ & 0.47 \\
\hline & 545B044 & $1.0-2.0$ & 1.47 & $4.03(\mathrm{~J})$ & 0.295 & -- & $1.56(\mathrm{~J})$ & $0.876(\mathrm{~J})$ & 0.574 \\
\hline \multirow{2}{*}{ B30 } & 545B034 & $0.0-0.5$ & 1.58 & 28.4 & 1.03 & $\overline{--}$ & 1.47 & 1.05 & 0.424 \\
\hline & 545B042 & $1.0-1.5$ & 1.64 & $0.952(\mathrm{~J})$ & -- & -- & $1.72(\mathrm{~J})$ & $0.761(\mathrm{~J})$ & 0.58 \\
\hline B31 & 545B053 & $0.0-0.25$ & 1.46 & $25.9(\mathrm{~J})$ & 2.18 & $0.602(\mathrm{~J})$ & $1.71(\mathrm{~J})$ & $1.02(\mathrm{~J})$ & 0.536 \\
\hline B32 & 545B054 & $0.0-0.5$ & 1.56 & $7.94(\mathrm{~J})$ & 0.664 & -- & $1.4(\mathrm{~J})$ & $1(\mathrm{~J})$ & 0.442 \\
\hline B33 & 545B052 & $0.0-0.5$ & 1.39 & $30.8(\mathrm{~J})$ & 2.08 & -- & $1.51(\mathrm{~J})$ & $1.04(\mathrm{~J})$ & 0.403 \\
\hline B34 & 545B051 & $0.0-0.5$ & 1.34 & $14.5(\mathrm{~J})$ & 0.627 & -- & $1.5(\mathrm{~J})$ & $1.14(\mathrm{~J})$ & 0.441 \\
\hline B35 & 545B037 & $0.0-0.5$ & 1.26 & $8.91(\mathrm{~J})$ & 0.404 & -- & $1.6(\mathrm{~J})$ & $0.893(\mathrm{~J})$ & 0.538 \\
\hline B36 & 545B038 & $0.0-0.5$ & 1.46 & $32.2(\mathrm{~J})$ & 0.75 & -- & $1.39(\mathrm{~J})$ & $0.897(\mathrm{~J})$ & 0.467 \\
\hline B37 & 545B039 & $0.0-0.5$ & 1.7 & $5.75(\mathrm{~J})$ & 0.866 & -- & $1.26(\mathrm{~J})$ & $1.02(\mathrm{~J})$ & 0.508 \\
\hline B38 & 545B040 & $0.0-0.5$ & 1.65 & $2.32(\mathrm{~J})$ & 1.07 & -- & $1.6(\mathrm{~J})$ & $1.04(\mathrm{~J})$ & 0.485 \\
\hline B39 & 545B055 & $0.0-0.5$ & 0.846 & $0.765(\mathrm{~J})$ & 0.517 & -- & $1.41(\mathrm{~J})$ & $0.867(\mathrm{~J})$ & 0.426 \\
\hline B40 & 545B056 & $0.0-0.5$ & 1.74 & $5.16(\mathrm{~J})$ & 1.47 & $\overline{--}$ & $1.62(\mathrm{~J})$ & $0.977(\mathrm{~J})$ & 0.494 \\
\hline B41 & 545B057 & $0.0-0.5$ & 1.81 & 12.9 & 0.375 & -- & 1.8 & 1.2 & 0.522 \\
\hline B42 & 545B058 & $0.0-0.5$ & 1.32 & $0.811(\mathrm{~J})$ & 0.947 & $0.388(\mathrm{~J})$ & $1.36(\mathrm{~J})$ & $0.885(\mathrm{~J})$ & 0.499 \\
\hline B43 & 545B049 & $0.0-0.5$ & 1.97 & $3.07(\mathrm{~J})$ & 1.23 & -- & $1.65(\mathrm{~J})$ & $1.03(\mathrm{~J})$ & 0.505 \\
\hline B44 & 545B048 & $0.0-0.5$ & 1.76 & $3.66(\mathrm{~J})$ & 1.24 & -- & $1.51(\mathrm{~J})$ & $0.883(\mathrm{~J})$ & 0.603 \\
\hline
\end{tabular}


Table A.4-4

Judgmental Soil Sample Results for Gamma-Emitting Radionuclides Detected above Minimum Detectable Concentrations at CAS 03-17-01, Waste Consolidation Site 3B

(Page 2 of 2)

\begin{tabular}{|c|c|c|c|c|c|c|c|c|c|}
\hline \multirow[b]{2}{*}{$\begin{array}{l}\text { Sample } \\
\text { Location }\end{array}$} & \multirow[b]{2}{*}{$\begin{array}{l}\text { Sample } \\
\text { Number }\end{array}$} & \multirow[b]{2}{*}{$\begin{array}{c}\text { Depth } \\
\text { (ft bgs) }\end{array}$} & \multicolumn{7}{|c|}{ Contaminants of Potential Concern (pCi/g) } \\
\hline & & & 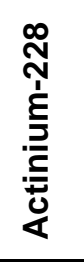 & 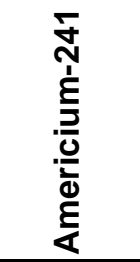 & 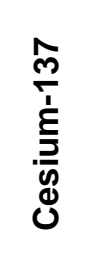 & 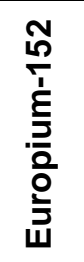 & 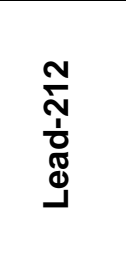 & 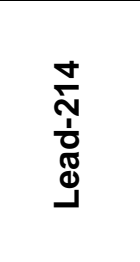 & 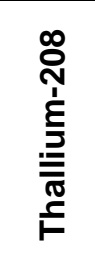 \\
\hline \multicolumn{3}{|c|}{ Final Action Levels } & $5^{a}$ & $1,501^{b}$ & $12.2^{\mathrm{c}}$ & $5.7^{c}$ & $5^{a}$ & $5^{a}$ & $5^{a}$ \\
\hline$\overline{\mathrm{B} 45}$ & 545B047 & $0.0-0.5$ & 1.55 & $2.25(\mathrm{~J})$ & 0.898 & 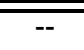 & $1.44(\mathrm{~J})$ & $0.918(\mathrm{~J})$ & $\overline{0.426}$ \\
\hline B46 & 545B046 & $0.0-0.5$ & 1.48 & $0.899(\mathrm{~J})$ & 0.153 & -- & $1.52(\mathrm{~J})$ & $0.975(\mathrm{~J})$ & 0.618 \\
\hline
\end{tabular}

${ }^{2}$ Taken from the generic guidelines for residual concentrations of actinium-228, bismuth-214, lead-212, lead-214, thallium-208, and thorium-232, as found in Chapter IV of DOE Order 5400.5, Change 2, "Radiation Protection of the Public and Environment"

(DOE, 1993). The PALs for these isotopes are specified as $5 \mathrm{pCi} / \mathrm{g}$ averaged over the first $15 \mathrm{~cm}$ of soil and $15 \mathrm{pCi} / \mathrm{g}$ for deeper soils (DOE, 1993). For purposes of this document, $15 \mathrm{~cm}$ is assumed to be equivalent to $0.5 \mathrm{ft}$ ( 6 inches); therefore, $5 \mathrm{pCi} / \mathrm{g}$ represents the PALs for these radionuclides in the surface soil (0 to $0.5 \mathrm{ft}$ depth).

${ }^{\mathrm{b}} \mathrm{FALs}$ are established in Appendix C.

'Taken from the construction, commercial, industrial land-use scenario in Table 2.1 of the NCRP Report No. 129, Recommended Screening Limits for Contaminated Surface Soil and Review Factors Relevant to Site-Specific Studies (NCRP, 1999). The values provided in this source document were scaled to a 25-millirem-per-year-dose.

bgs $=$ Below ground surface

$\mathrm{cm}=$ Centimeter

DOE = U.S. Department of Energy

$\mathrm{ft}=$ Foot

$\mathrm{J}=$ Estimated value

-- = Not detected above minimum detectable concentrations.

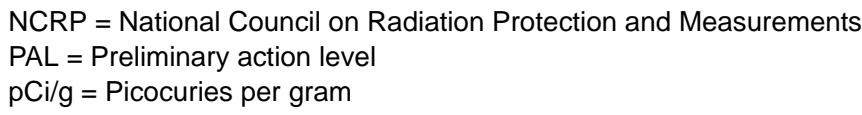

gamma-emitting radionuclides were detected at activities exceeding their PALs, therefore the FALs were established as the corresponding PAL activities for all gamma-emitting radionuclides other than Am-241.

Summary of Gamma-Emitting Radionuclide Results: Americium-241 concentrations detected at CAS 03-17-01 were moved on to a Tier 2 evaluation in which RESRAD was used to determine the site-specific FALs for radionuclides under an industrial scenario. Americium-241 did not exceed the FAL of 1,501 pCi/g at any location. No other gamma-emitting radionuclides were detected at activities exceeding their PALs, therefore the FALs were established as the corresponding PAL activities for all gamma-emitting radionuclides other than Am-241. No gamma-emitting radionuclide COCs were identified at CAS 03-17-01. 


\section{A.4.2.3 Plutonium, Strontium-90, and Uranium Isotopes}

Analytical results for $\mathrm{Pu}, \mathrm{Sr}-90$, and $\mathrm{U}$ isotopic radionuclides are discussed separately for those samples collected through a probabilistic approach (i.e., most surface samples at this CAS) and those samples collected through a judgmental approach (i.e., some surface samples within the CAS and all surface samples outside the CAS, as well as all subsurface samples at the CAS).

Probabilistic Sampling Results: Isotopic Pu and isotopic U analytical results for environmental samples collected at this CAS that were detected above MDCs are presented in Table A.4-5. The probabilistic sampling design as described in the CAIP for CAU 545 (NNSA/NSO, 2007) stipulates comparing the 95th percent UCL of the mean of each significant COPC (i.e., contaminants present at concentrations greater than PALs) to the FAL to determine whether a COC is present. Therefore, only significant COPCs are evaluated for the presence of COCs. To demonstrate the selection of significant COPCs, Table A.4-5 lists the PALs for isotopic radionuclides.

Of these radioisotopes, only Pu-239/240 met the criteria established in the CAIP for CAU 545 (NNSA/NSO, 2007) to be a significant COPC at CAS 03-17-01 for the probabilistic sampling (i.e., any result exceeds a PAL). The statistics for this radionuclide are presented in Table A.4-5.

Based on the initial data review, it was determined by the ProUCL test for outliers that the results of $93.9 \mathrm{pCi} / \mathrm{g}$ for sample 545B012 is an outlier, and 71.1 pCi/g for sample 545B013 is an outlier, and both should not be included in the dataset. The outlier values of 93.9 and $71.1 \mathrm{pCi} / \mathrm{g}$ were compared directly to the FAL for Pu-239/230 along with the judgmental sample results.

The statistics were run by ProUCL for the Pu-239/230 results from CAS 03-17-01 for remaining dataset. The resulting estimation of the variability was found to be reasonable and representative of the population being sampled. Based on the process for establishing minimum sample size, established in the CAIP for CAU 545 (NNSA/NSO, 2007), the required minimum number of samples needed for valid statistical analysis is eight. Because more than eight samples were collected (22), a UCL of the mean was calculated for comparison to the FAL.

To derive the UCL of the mean for the Pu-239/230 results, computations by the ProUCL software (e.g., for determination of data distributions and the 95 percent UCL) determined that the dataset met 
Table A.4-5

Probabilistic Soil Sample Results for Isotopes Detected above Minimum Detectable Concentrations at CAS 03-17-01, Waste Consolidation Site 3B (Page 1 of 2 )

\begin{tabular}{|c|c|c|c|c|c|c|c|}
\hline \multirow[b]{2}{*}{$\begin{array}{l}\text { Sample } \\
\text { Location }\end{array}$} & \multirow[b]{2}{*}{$\begin{array}{l}\text { Sample } \\
\text { Number }\end{array}$} & \multirow[b]{2}{*}{$\begin{array}{l}\text { Depth } \\
\text { (ft bgs) }\end{array}$} & \multicolumn{5}{|c|}{ Contaminants of Potential Concern (pCi/g) } \\
\hline & & & 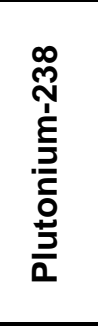 & 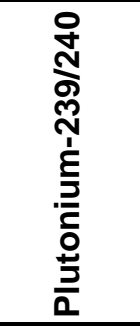 & 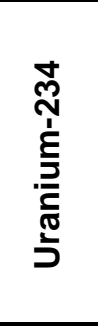 & 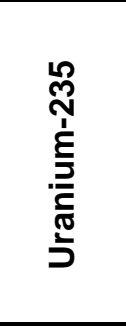 & 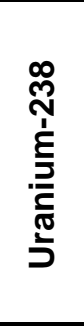 \\
\hline \multicolumn{3}{|c|}{ Preliminary Action Levels ${ }^{a}$} & 13 & 12.7 & 143 & 17.5 & 105 \\
\hline \multicolumn{3}{|c|}{ Final Action Levels ${ }^{b}$} & 13 & 1,890 & 143 & 17.5 & 105 \\
\hline \multicolumn{3}{|c|}{ Average } & NC & 13.53 & NC & NC & NC \\
\hline \multicolumn{3}{|c|}{ Standard Deviation } & NC & 11.25 & NC & NC & NC \\
\hline \multicolumn{3}{|c|}{$\begin{array}{l}\text { VSP Required Minimum Number of } \\
\text { Samples }\end{array}$} & NC & 8 & NC & NC & NC \\
\hline \multicolumn{3}{|c|}{ Maximum Result } & 3.73 & 93.9 & 1.11 & 0.0927 & 1.08 \\
\hline \multicolumn{3}{|c|}{$95 \% \mathrm{UCL}^{\mathrm{c}}$} & NC & 20.09 & NC & NC & NC \\
\hline$\overline{\mathrm{B} 01}$ & $\overline{545 B 001}$ & $0.0-0.5$ & $\overline{---}$ & 7.99 & $\overline{0.771}$ & $\overline{\overline{---}}$ & $\overline{0.78}$ \\
\hline B02 & 545B002 & $0.0-0.5$ & 0.251 & 14.3 & 0.888 & -- & 1.08 \\
\hline B03 & 545B003 & $0.0-0.5$ & -- & $8.59(\mathrm{~J})$ & 0.777 & -- & 0.943 \\
\hline B04 & 545B004 & $0.0-0.5$ & - & 1.23 & 0.862 & -- & 0.748 \\
\hline B05 & 545B005 & $0.0-0.5$ & 0.337 & 25 & 0.935 & -- & 0.879 \\
\hline B06 & 545B006 & $0.0-0.5$ & 0.337 & 22.1 & 1.11 & -- & 0.996 \\
\hline \multirow{2}{*}{ B07 } & 545B007 & $0.0-0.5$ & -- & 2.65 & 0.586 & -- & 0.74 \\
\hline & 545B008 & $0.0-0.5$ & -- & 2.72 & 0.793 & -- & 0.891 \\
\hline B08 & 545B009 & $0.0-0.5$ & -- & 25.7 & 0.823 & -- & 0.901 \\
\hline B09 & 545B010 & $0.0-0.5$ & 3.73 & 33.9 & 0.66 & -- & 0.9 \\
\hline B10 & 545B011 & $0.0-0.5$ & -- & $31.7(\mathrm{~J})$ & 0.746 & -- & 0.752 \\
\hline$B 11^{d}$ & 545B012 & $0.0-0.5$ & 1.3 & 93.9 & 0.88 & -- & 0.75 \\
\hline $\mathrm{B} 12^{\mathrm{d}}$ & 545B013 & $0.0-0.5$ & -- & 71.1 & 0.953 & -- & 0.65 \\
\hline B13 & 545B015 & $0.0-0.5$ & -- & 2.08 & 0.796 & -- & 0.732 \\
\hline B14 & 545B016 & $0.0-0.5$ & -- & 28.7 & 1.09 & 0.0927 & 0.855 \\
\hline B15 & 545B017 & $0.0-0.5$ & 0.119 & $7.54(\mathrm{~J})$ & 0.727 & -- & 0.851 \\
\hline B16 & 545B018 & $0.0-0.5$ & 0.154 & 10.6 & 0.867 & -- & 0.824 \\
\hline B19 & 545B021 & $0.0-0.5$ & -- & $1.2(\mathrm{~J})$ & 0.739 & -- & 0.851 \\
\hline B20 & 545B022 & $0.0-0.5$ & -- & $0.263(\mathrm{~J})$ & 0.787 & -- & 0.687 \\
\hline B21 & 545B023 & $0.0-0.5$ & 0.144 & 9.46 & 0.708 & 0.0716 & 0.726 \\
\hline B22 & 545B024 & $0.0-0.5$ & -- & 6.09 & 0.811 & -- & 0.68 \\
\hline B23 & 545B025 & $0.0-0.5$ & -- & 6.12 & 0.725 & -- & 0.726 \\
\hline
\end{tabular}


Table A.4-5

Probabilistic Soil Sample Results for Isotopes Detected above Minimum Detectable Concentrations at CAS 03-17-01, Waste Consolidation Site 3B (Page 2 of 2)

\begin{tabular}{|c|c|c|c|c|c|c|c|}
\hline \multirow[b]{2}{*}{$\begin{array}{l}\text { Sample } \\
\text { Location }\end{array}$} & \multirow[b]{2}{*}{$\begin{array}{l}\text { Sample } \\
\text { Number }\end{array}$} & \multirow[b]{2}{*}{$\begin{array}{c}\text { Depth } \\
\text { (ft bgs) }\end{array}$} & \multicolumn{5}{|c|}{ Contaminants of Potential Concern (pCi/g) } \\
\hline & & & 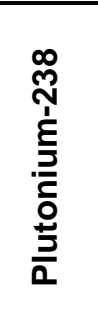 & 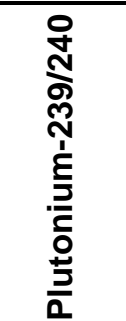 & 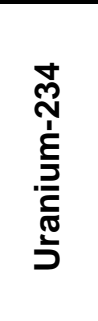 & 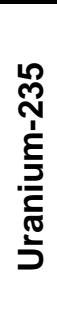 & 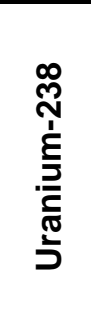 \\
\hline$\overline{\mathrm{B} 24}$ & 545B026 & $0.0-0.5$ & 0.221 & 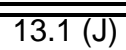 & 0.814 & $\overline{---}$ & $\overline{0.749}$ \\
\hline \multirow{2}{*}{ B25 } & 545B027 & $0-0.75$ & -- & 4.03 & 0.678 & $\overline{--}$ & 0.847 \\
\hline & 545B028 & $0.0-0.5$ & 0.298 & 7.45 & 0.592 & $\overline{--}$ & 0.631 \\
\hline B26 & 545B029 & $0.0-0.5$ & 0.602 & 31.9 & 0.773 & -- & 0.671 \\
\hline
\end{tabular}

aDefined in the CAIP for CAU 545 (NNSA/NSO, 2007).

${ }^{b}$ Established in Appendix C.

'Value for Pu-239 derived as the 95\% Approximate Gamma UCL, a nonparametric distribution, and used as a proxy for the 95\% UCL.

${ }^{\mathrm{d}}$ The results for Pu-239/240 from samples 545B012 and 545B013 were identified as statistical outliers and were not included in the calculation of the $95 \% \mathrm{UCL}$ of the mean. The results are included with the probabilistic data for completeness. If these results were included with the other 22 sample results in calculations, the value for the $95 \%$ UCL would be 29.52 (95\% Approximate Gamma).

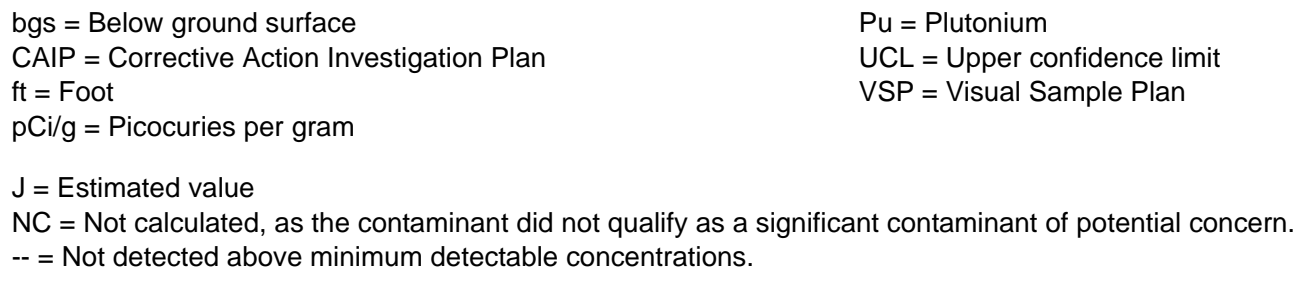

the criteria for a gamma distribution. The recommended 95 percent Approximate Gamma UCL of 20.09 pCi/g based on the gamma distribution was selected.

The site-specific FAL for Pu-239/230 was calculated with RESRAD using the industrial scenario in a Tier 2 evaluation. The FAL for Pu-239/230 was determined to be 1,890 pCi/g. The calculation of the FAL for $\mathrm{Pu}-239 / 230$ is presented in Appendix C. The outliers and the 95 percent Approximate Gamma UCL for the remaining probabilistic dataset are below the FAL for Pu-239/230, and $\mathrm{Pu}-239 / 230$ is not considered a COC.

Judgmental Sampling Results: Analytical results for isotopic radionuclides in judgmental samples taken from outside the CAS and from subsurface soil at the CAS that were detected above MDCs are 
presented in Table A.4-6. The radionuclide Pu-239/240 was detected at activities that exceeded the PAL of 12.7 pCi/g in surface samples taken at locations: B27, B28, B29, B30, B31, B32, B33, B34, B36, B38 and B40; and in subsurface samples taken at locations B27, B28, and B29 (Figure A.4-1). Plutonium-239/240 was moved to a Tier 2 evaluation in which RESRAD was used to determine the site-specific FALs for radionuclides under an industrial scenario. Plutonium-239/240 did not exceed the FAL of 1,890 pCi/g at any location, and therefore is not considered a COC at this CAS. The calculation of the FAL for Pu-239/240 is presented in Appendix C. No other isotopic radionuclides were detected at activities exceeding their PALs, therefore the FALs were established as the corresponding PAL activities for all gamma-emitting radionuclides other than $\mathrm{Pu}-239 / 240$.

Table A.4-6

Judgmental Soil Sample Results for Isotopes Detected above Minimum Detectable Concentrations at CAS 03-17-01, Waste Consolidation Site 3B (Page 1 of 2)

\begin{tabular}{|c|c|c|c|c|c|c|c|c|}
\hline \multirow[b]{2}{*}{$\begin{array}{c}\text { Sample } \\
\text { Location }\end{array}$} & \multirow[b]{2}{*}{$\begin{array}{l}\text { Sample } \\
\text { Number }\end{array}$} & \multirow[b]{2}{*}{$\begin{array}{l}\text { Depth } \\
\text { (ft bgs) }\end{array}$} & \multicolumn{6}{|c|}{ Contaminants of Potential Concern (pCi/g) } \\
\hline & & & 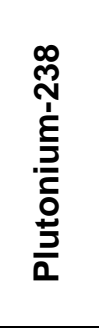 & 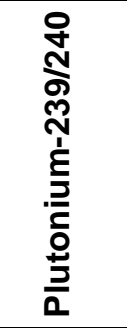 & 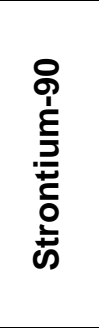 & 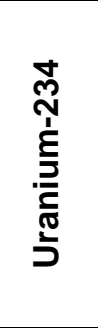 & 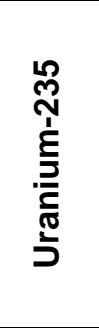 & 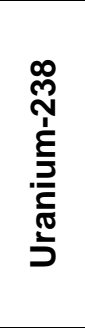 \\
\hline \multicolumn{3}{|c|}{ Final Action Levels } & $13^{\mathrm{a}}$ & $1,890^{b}$ & $838^{a}$ & $143^{a}$ & $17.6^{\mathrm{a}}$ & $105^{a}$ \\
\hline$\overline{\mathrm{B} 10}$ & 545B014 & $0.5-1.0$ & $\overline{---}$ & 3.3 & $\overline{---}$ & 0.813 & $\overline{---}$ & 0.717 \\
\hline B11 & 545B050 & $1.0-1.5$ & -- & -- & -- & 0.899 & -- & 0.649 \\
\hline B17 & 545B019 & $0.0-0.5$ & 0.115 & 7.39 & -- & 0.88 & $\overline{--}$ & 0.746 \\
\hline B18 & 545B020 & $0.0-0.5$ & 0.105 & 10.1 & -- & 0.654 & -- & 0.665 \\
\hline \multirow{3}{*}{ B27 } & 545B030 & $0.0-0.5$ & -- & 231 & 0.556 & 1.55 & -- & 0.827 \\
\hline & 545B033 & $0.5-1.0$ & 5.14 & 413 & 0.35 & 0.935 & -- & 0.742 \\
\hline & 545B041 & $1.0-1.5$ & 1.67 & 91.4 & -- & 1.37 & -- & 0.942 \\
\hline \multirow{3}{*}{ B28 } & 545B031 & $0.0-0.5$ & -- & 245 & 0.785 & 1.68 & -- & 0.856 \\
\hline & 545B035 & $0.5-1.0$ & -- & 455 & 0.989 & 2.42 & -- & 0.81 \\
\hline & 545B045 & $1.0-1.75$ & -- & 18.7 & -- & 1.14 & -- & 1.1 \\
\hline \multirow{4}{*}{ B29 } & 545B032 & $0.0-0.5$ & 3.12 & 270 & 1.1 & 1.83 & 0.116 & 0.888 \\
\hline & 545B036 & $0.5-1.0$ & -- & 10.6 & -- & 0.827 & -- & 0.721 \\
\hline & 545B043 & $1.0-2.0$ & -- & 34.8 & 0.249 & 0.856 & -- & 0.716 \\
\hline & 545B044 & $1.0-2.0$ & -- & 51.2 & -- & 1.05 & -- & 0.719 \\
\hline \multirow{2}{*}{ B30 } & 545B034 & $0.0-0.5$ & 0.952 & 72.7 & -- & 0.656 & -- & 0.615 \\
\hline & 545B042 & $1.0-1.5$ & -- & 1.21 & -- & 0.783 & -- & 0.647 \\
\hline
\end{tabular}


Table A.4-6

Judgmental Soil Sample Results for Isotopes Detected above Minimum Detectable Concentrations at CAS 03-17-01, Waste Consolidation Site 3B (Page 2 of 2)

\begin{tabular}{|c|c|c|c|c|c|c|c|c|}
\hline \multirow[b]{2}{*}{$\begin{array}{l}\text { Sample } \\
\text { Location }\end{array}$} & \multirow[b]{2}{*}{$\begin{array}{l}\text { Sample } \\
\text { Number }\end{array}$} & \multirow[b]{2}{*}{$\begin{array}{c}\text { Depth } \\
\text { (ft bgs) }\end{array}$} & \multicolumn{6}{|c|}{ Contaminants of Potential Concern (pCi/g) } \\
\hline & & & 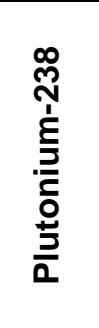 & 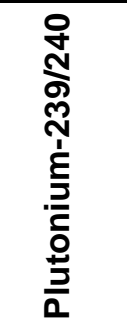 & 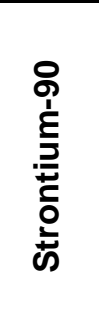 & 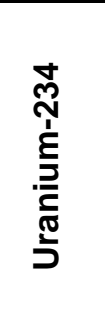 & 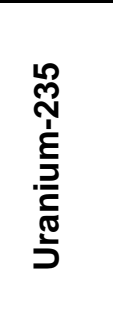 & 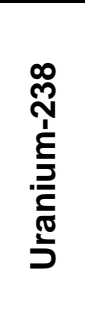 \\
\hline \multicolumn{3}{|c|}{ Final Action Levels } & $13^{\mathrm{a}}$ & $1,890^{b}$ & $838^{a}$ & $143^{a}$ & $17.6^{\mathrm{a}}$ & $105^{\mathrm{a}}$ \\
\hline$\overline{\mathrm{B} 31}$ & $\overline{545 \mathrm{~B} 053}$ & $0-0.25$ & $\overline{---}$ & $\overline{54.3(\mathrm{~J})}$ & $\overline{0.451}$ & $\overline{---}$ & $\overline{---}$ & 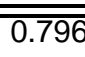 \\
\hline B32 & 545B054 & $0.0-0.5$ & 0.224 & $19.8(\mathrm{~J})$ & -- & 0.821 & -- & 0.857 \\
\hline B33 & 545B052 & $0.0-0.5$ & -- & $89.1(\mathrm{~J})$ & 0.483 & 1.08 & -- & 0.788 \\
\hline B34 & 545B051 & $0.0-0.5$ & -- & 25.4 & 0.244 & 0.89 & -- & 0.882 \\
\hline B35 & 545B037 & $0.0-0.5$ & -- & 8.01 & -- & 0.681 & -- & 0.755 \\
\hline $\bar{B} 36$ & 545B038 & $0.0-0.5$ & 0.452 & 26.8 & -- & 0.818 & -- & 0.812 \\
\hline B37 & 545B039 & $0.0-0.5$ & -- & 6.76 & -- & 0.612 & -- & 0.827 \\
\hline B38 & 545B040 & $0.0-0.5$ & -- & 13.8 & -- & 0.849 & -- & 0.776 \\
\hline B39 & 545B055 & $0.0-0.5$ & -- & $3.95(\mathrm{~J})$ & -- & 0.813 & -- & 0.913 \\
\hline B40 & 545B056 & $0.0-0.5$ & 0.161 & $13.9(\mathrm{~J})$ & 0.245 & 0.902 & -- & 0.631 \\
\hline B41 & 545B057 & $0.0-0.5$ & 0.103 & $8.51(\mathrm{~J})$ & -- & 1.4 & -- & 1.01 \\
\hline B42 & 545B058 & $0.0-0.5$ & & $2.87(\mathrm{~J})$ & -- & 0.96 & -- & 0.715 \\
\hline B43 & 545B049 & $0.0-0.5$ & 0.167 & 4.87 & -- & 0.693 & -- & 0.668 \\
\hline B44 & 545B048 & $0.0-0.5$ & -- & 5.99 & -- & 0.71 & -- & 0.77 \\
\hline B45 & 545B047 & $0.0-0.5$ & -- & 4.59 & -- & 0.672 & -- & 0.719 \\
\hline B46 & 545B046 & $0.0-0.5$ & -- & 5.16 & -- & 0.906 & -- & 0.851 \\
\hline
\end{tabular}

aTaken from the construction, commercial, industrial land-use scenario in Table 2.1 of the NCRP Report No. 129, Recommended Screening Limits for Contaminated Surface Soil and Review Factors Relevant to Site-Specific Studies (NCRP, 1999). The values provided in this source document were scaled to a 25-millirem-per-year-dose.

${ }^{\mathrm{b}}$ FALs are established in Appendix C.

bgs $=$ Below ground surface

$\mathrm{ft}=$ Foot

NCRP $=$ National Council on Radiation Protection and Measurements

$\mathrm{pCi} / \mathrm{g}=$ Picocuries per gram

$\mathrm{J}=$ Estimated value

$--=$ Not detected above minimum detectable concentrations.

Summary of Isotopic Radionuclide Results: Plutonium-239/240 concentrations detected at CAS 03-17-01 were moved onto a Tier 2 evaluation in which RESRAD was used to determine the site-specific FALs for radionuclides under the industrial scenario. Plutonium-239/240 did not exceed 
the FAL of 1,890 pCi/g at any location. No other isotopic radionuclides were detected at activities exceeding their PALs, therefore the FALs were established as the corresponding PAL activities for all gamma-emitting radionuclides other than $\mathrm{Pu}-239 / 240$. No isotopic radionuclide COCs were identified at CAS 03-17-01.

\section{A.4.3 Nature and Extent of Contamination}

Based on the analytical results for soil samples collected within CAS 03-17-01, no COCs were identified at this CAS.

\section{A.4.4 Revised Conceptual Site Model}

The CAIP requirements were met at this CAS (NNSA/NSO, 2007), and no revisions were necessary to the CSM. 


\section{A.5.0 Corrective Action Site 03-99-14, Radioactive Material Disposal Area}

Corrective Action Site 03-99-14 is located at the immediate southeast corner of the Area 3 RWMS, on the south side of the 3-14 Road (Figure A.1-1). The site consists of a berm and adjacent trench, approximately $350 \mathrm{ft}$ in length. The purpose for these features at this site has not been determined. The entire area was impacted by atmospheric testing to the west, and the areas adjacent to the 3-14 Road are posted as RMAs. In addition to sampling the CAS on the berm and trench, five locations along the west, south and east perimeter were sampled at the surface to establish background radiological activities for comparison to the site data. Additional detail is provided in the CAIP for CAU 545 (NNSA/NSO, 2007).

\section{A.5.1 Corrective Action Investigation}

A total of 18 characterization samples (including one FD, and five background) were collected during investigation activities at CAS 03-99-14. The sample locations are shown on Figure A.5-1. The sample locations, IDs, types, and analyses are listed in Table A.5-1. The specific CAI activities conducted to satisfy the CAIP requirements at this CAS (NNSA/NSO, 2007) are described in the following sections.

\section{A.5.1.1 Field Screening}

Investigation samples were field screened for alpha and beta/gamma radiation. The FSRs were compared to FSLs to guide subsequent sampling decisions where appropriate. Gross alpha radiation FSLs were exceeded in two samples, and beta/gamma radiation FSLs were exceeded in three samples; all collected for background activities at CAS 03-99-14. All samples exceeding FSLs were analyzed.

\section{A.5.1.2 Radiological Survey}

A radiological walkover survey was conducted over the area encompassing the berm and trench at CAS 03-99-14. Several areas were found to have elevated radiological readings at two to five times background. Trinity glass is present throughout the area and likely contributed to the elevated readings. Three of the four sample transects were placed across these areas (Figure A.5-2). 


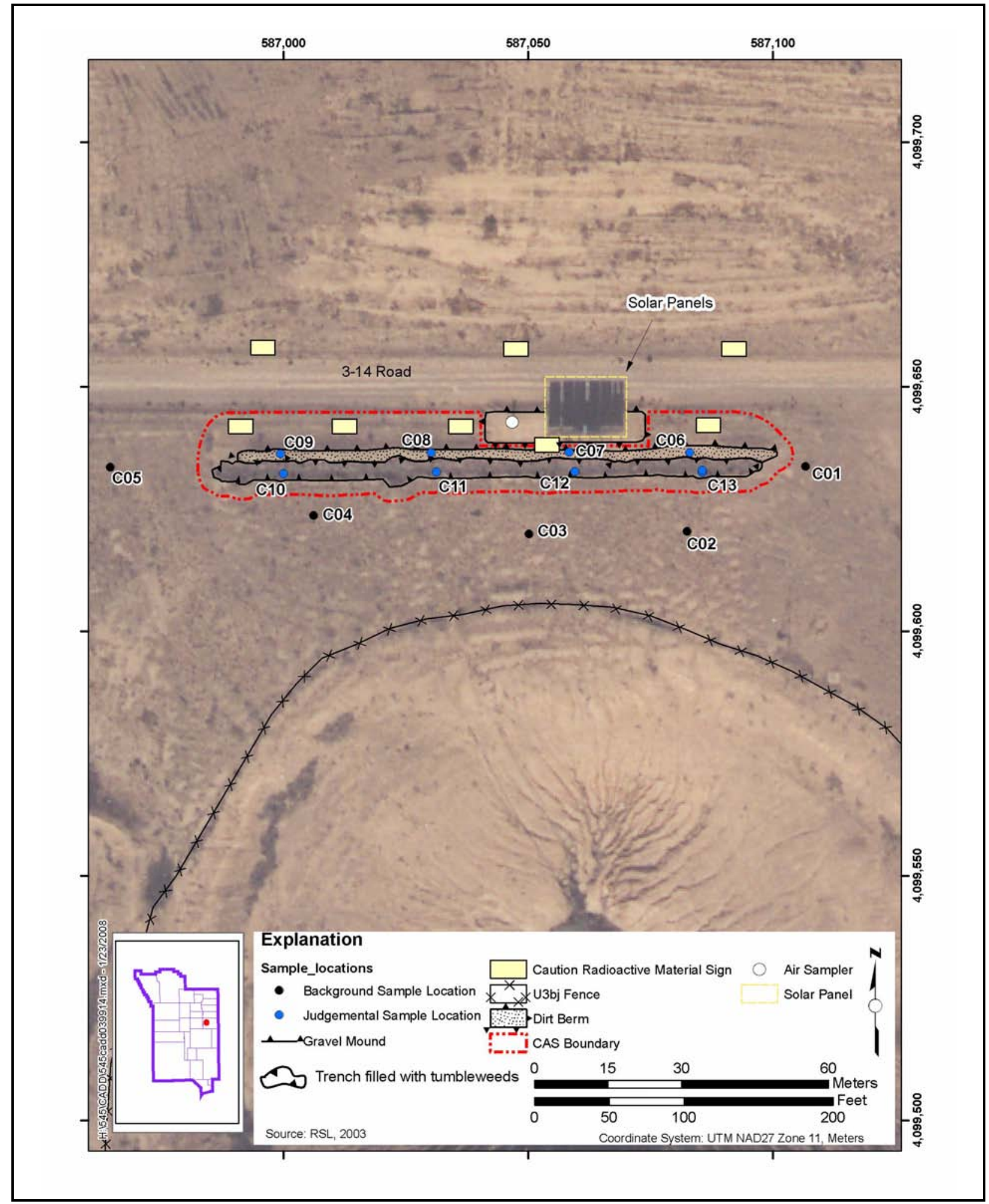

Figure A.5-1

Sample Locations at CAS 03-99-14, Radioactive Material Disposal Area 
Table A.5-1

Samples Collected at CAS 03-99-14, Radioactive Material Disposal Area

\begin{tabular}{|c|c|c|c|c|c|}
\hline $\begin{array}{c}\text { Sample } \\
\text { Location }\end{array}$ & $\begin{array}{l}\text { Sample } \\
\text { Number }\end{array}$ & $\begin{array}{c}\text { Depth } \\
\text { (ft bgs) }\end{array}$ & Matrix & Purpose & Analyses \\
\hline$\overline{\mathrm{CO} 01}$ & 545C001 & $0.0-0.5$ & $\overline{\text { Soil }}$ & Environmental, Background & Set 1 \\
\hline $\mathrm{CO2}$ & $545 \mathrm{C002}$ & $0.0-0.5$ & Soil & Environmental, Background & Set 1 \\
\hline $\mathrm{CO3}$ & $545 C 003$ & $0.0-0.5$ & Soil & Environmental, Background & Set 1 \\
\hline $\mathrm{CO4}$ & $545 \mathrm{CO04}$ & $0.0-0.5$ & Soil & Environmental, Background & Set 1 \\
\hline $\mathrm{C05}$ & $545 C 005$ & $0.0-0.5$ & Soil & Environmental, Background & Set 1 \\
\hline \multirow{2}{*}{ C06 } & $545 C 015$ & $0.0-0.5$ & Soil & Environmental & Set 3 \\
\hline & $545 C 018$ & $2.0-2.5$ & Soil & Environmental & Set 3 \\
\hline \multirow{2}{*}{$\mathrm{C07}$} & $545 \mathrm{CO} 014$ & $0.0-0.5$ & Soil & Environmental & Set 3 \\
\hline & $545 \mathrm{C017}$ & $3.0-3.5$ & Soil & Environmental & Set 3 \\
\hline \multirow{2}{*}{ C08 } & $545 \mathrm{C} 012$ & $0.0-0.5$ & Soil & Environmental & Set 3 \\
\hline & $545 \mathrm{C} 016$ & $3.5-4.0$ & Soil & Environmental & Set 3 \\
\hline \multirow{2}{*}{ Co9 } & $545 C 011$ & $0.0-0.5$ & Soil & Environmental & Set 3 \\
\hline & $545 C 013$ & $3.5-4.0$ & Soil & Environmental & Set 3 \\
\hline $\mathrm{C} 10$ & $545 C 010$ & $0.0-0.5$ & Soil & Environmental, Full Lab QC & Set 3 \\
\hline \multirow{2}{*}{ C11 } & $545 C 008$ & $0.0-0.5$ & Soil & Environmental & Set 3 \\
\hline & $545 C 009$ & $0.0-0.5$ & Soil & Field Duplicate of \#545C008 & Set 3 \\
\hline C12 & $545 \mathrm{C007}$ & $0.0-0.5$ & Soil & Environmental & Set 3 \\
\hline C13 & $545 C 006$ & $0.0-0.5$ & Soil & Environmental & Set 3 \\
\hline $\mathrm{N} / \mathrm{A}$ & $545 C 301$ & $\mathrm{~N} / \mathrm{A}$ & Water & Trip Blank & VOCs \\
\hline $\mathrm{N} / \mathrm{A}$ & $545 C 302$ & $\mathrm{~N} / \mathrm{A}$ & Water & Trip Blank & VOCs \\
\hline $\mathrm{N} / \mathrm{A}$ & $545 C 303$ & $\mathrm{~N} / \mathrm{A}$ & Water & Equipment Rinsate & Set 3 \\
\hline $\mathrm{N} / \mathrm{A}$ & $545 C 304$ & $\mathrm{~N} / \mathrm{A}$ & Water & Field Blank & Set 3 \\
\hline $\mathrm{N} / \mathrm{A}$ & $545 C 305$ & $\mathrm{~N} / \mathrm{A}$ & Water & Trip Blank & VOCs \\
\hline $\mathrm{N} / \mathrm{A}$ & $545 C 306$ & $\mathrm{~N} / \mathrm{A}$ & Water & Trip Blank & VOCs \\
\hline N/A & $545 C 307$ & $\mathrm{~N} / \mathrm{A}$ & Liquid & Source Blank & Set 3 \\
\hline$N / A$ & $545 C 501$ & $N / A$ & Liquid & Waste Management & $\begin{array}{c}\text { Set 3, Gross } \\
\text { Alpha/Beta, Tritium }\end{array}$ \\
\hline
\end{tabular}

Set 1 = Gamma Spectroscopy, Isotopic Uranium, Isotopic Plutonium, Strontium-90

Set 3 = VOCs, SVOCs, TPH-DRO, PCBs, RCRA Metals, Gamma Spectroscopy, Isotopic Uranium, Isotopic Plutonium, Strontium-90

bgs = Below ground surface

$\mathrm{DRO}=$ Diesel-range organic

$\mathrm{ft}=$ Foot

N/A = Not applicable

$\mathrm{PCB}=$ Polychlorinated biphenyl
$\mathrm{QC}=$ Quality control

RCRA = Resource Conservation and Recovery Act

SVOC $=$ Semivolatile organic compound

$\mathrm{TPH}=$ Total petroleum hydrocarbon

VOC $=$ Volatile organic compound 


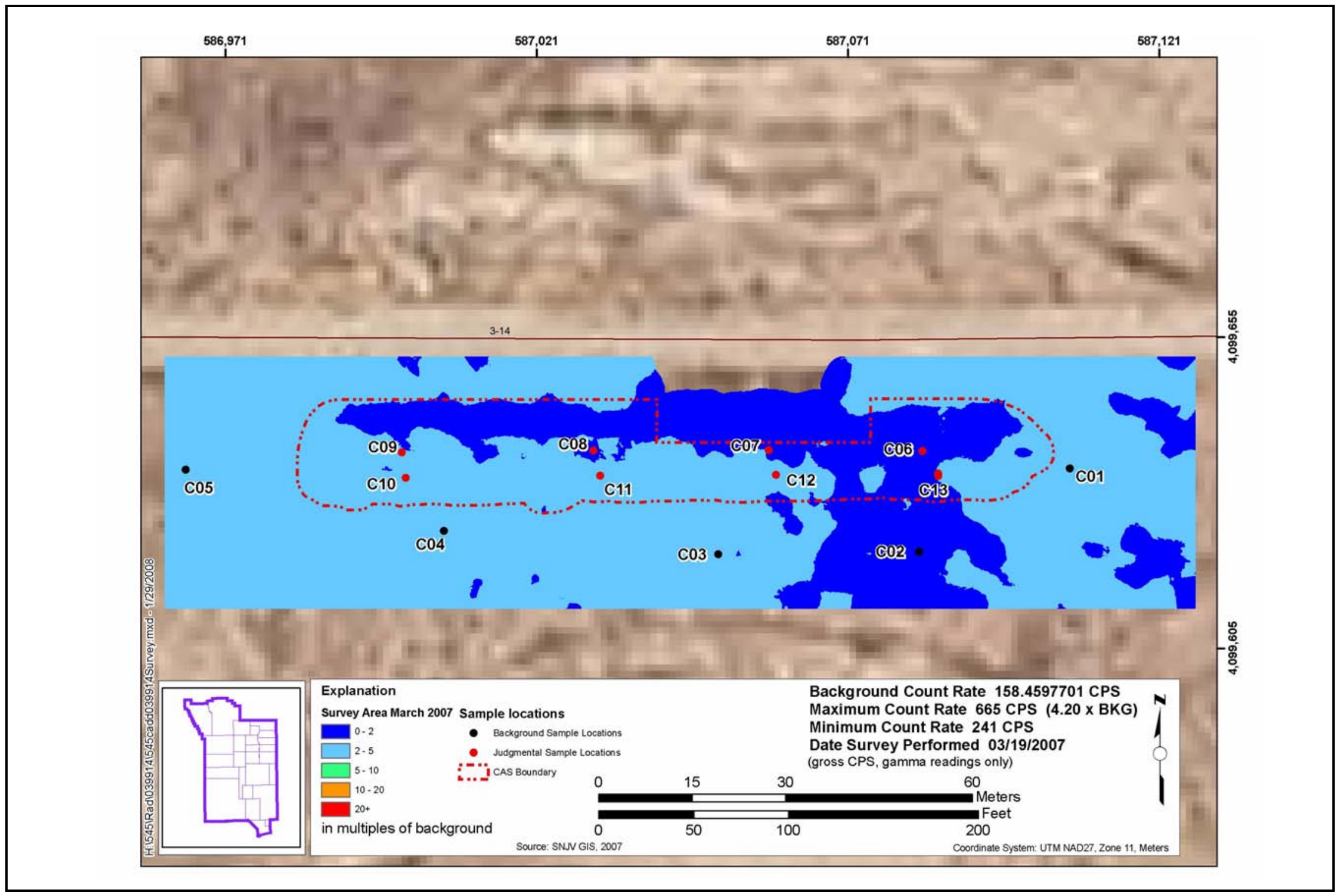

Figure A.5-2

Radiological Survey for CAS 03-99-14

\section{UNCONTROLLED When Printed}




\section{A.5.1.3 Geophysical Survey}

A geophysical walkover survey was conducted at the CAS. Small surface and subsurface anomalies were detected, but no linear or significant subsurface features were found (Figure A.5-3). The geophysical survey was not used in the selection of sample locations.

\section{A.5.1.4 Visual Inspections}

No distinguishing features were visible in the trench or on the berm. The surface features for both components were uniform throughout the CAS.

\section{A.5.1.5 Sample Collection}

Decision I environmental sampling activities included the collection of biased surface and subsurface soil samples from both components (Figure A.5-1) at this CAS. Four transects were established across the trench and berm, and one location each was established on trench and on the berm. Results from the radiological survey were employed to guide three transects across general areas of elevated radioactivity while keeping the transects evenly spaced (approximately) apart across each quarter of the site. The fourth transect, encompassing locations C06 and C13, was an approximate equal distance between the third transect and the east end of the trench and berm.

Surface samples (0.0 to $0.5 \mathrm{ft}$ bgs) were collected from locations C01 through C05 outside the eastern, southern, and western perimeters of the CAS to measure the contribution of radiological contamination from sources other than the CAS. The two exceedences of the FSL for alpha, and the three for beta, were all from these background samples.

Surface samples were also collected at each of the eight locations (C06 through C13) in the four transects across the trench and berm. Neither the alpha nor the beta FSL were exceeded in any samples. Consequently, subsurface samples were not collected at the four locations in the trench, and just one shallow subsurface sample per location was collected from the berm/native soil interface at the four berm locations.

No staining or other biasing factors were found within the soil profile at any of the berm locations. 


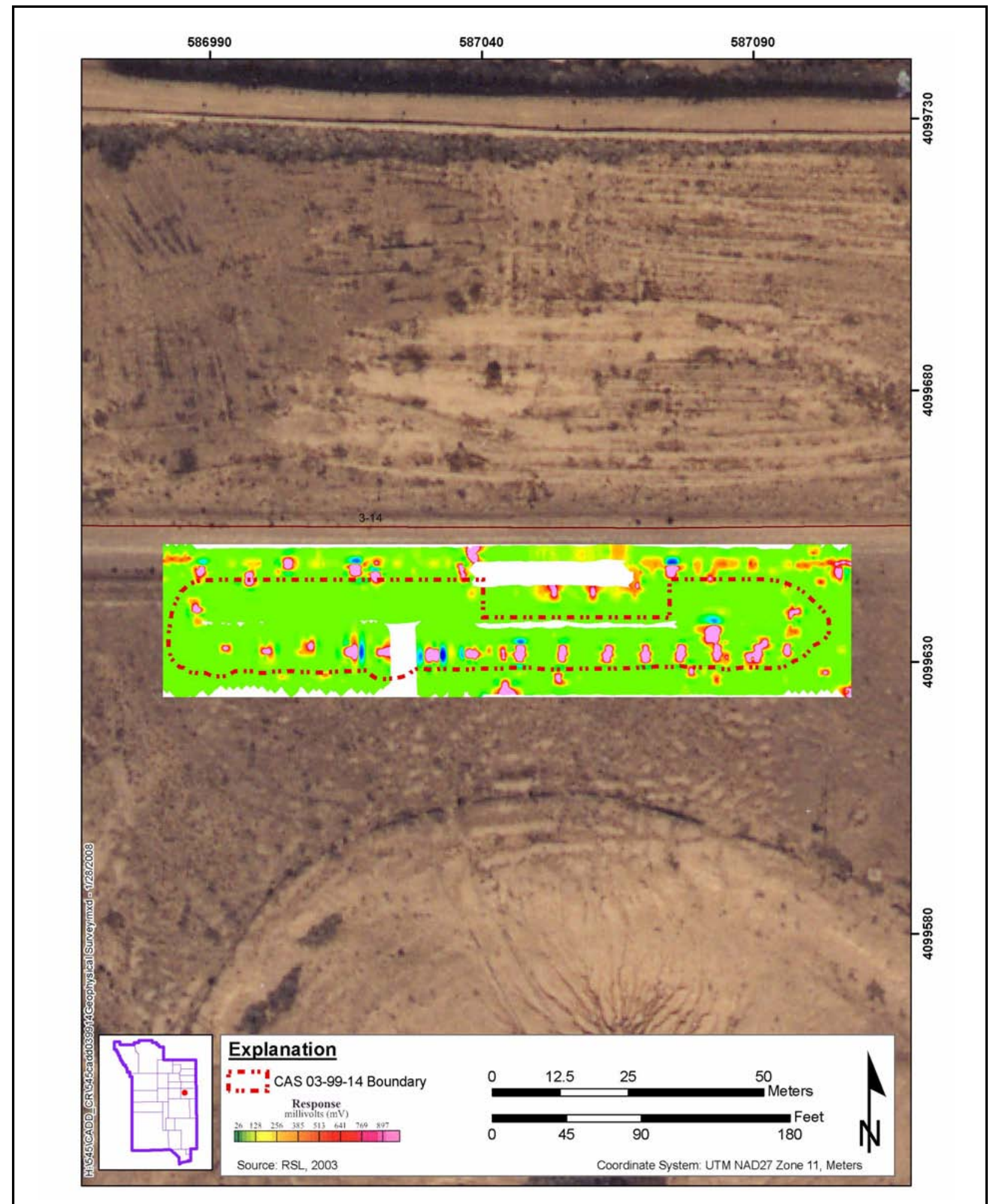

Figure A.5-3

Geophysical Survey for CAS 03-99-14 


\section{A.5.1.6 Deviations}

Investigation samples were collected as outlined in the CAIP for CAU 545 (NNSA/NSO, 2007) and submitted for laboratory analysis. There were no deviations from the planned sampling. All sample locations were accessible.

\section{A.5.2 Investigation Results}

The following sections provide analytical results from the samples collected to complete investigation activities as outlined in the CAIP for CAU 545 (NNSA/NSO, 2007). Investigation samples were analyzed for the CAIP-specified COPCs, which included VOCs, semivolatile organic compounds (SVOCs), TPH-DRO, RCRA metals, polychlorinated biphenyls (PCBs), gamma-emitting radionuclides, isotopic $\mathrm{Pu}, \mathrm{Sr}-90$, and isotopic $\mathrm{U}$. The analytical parameters and laboratory methods used to analyze the investigation samples are listed in Table A.2-2. Table A.5-1 lists the sample-specific analytical suite for CAS 03-99-14. The waste characterization analytical results are discussed in Section A.8.0.

Analytical results from the soil samples with concentrations exceeding MDCs are summarized in the following sections. An evaluation was conducted on all contaminants detected above MDCs by comparing individual concentration or activity results against the FALs. Establishment of the FALs is presented in Appendix C. The FALs were established as the corresponding PAL concentrations or activities if the contaminant concentrations were below their respective PALs.

\section{A.5.2.1 Volatile Organic Compounds}

Analytical results for VOC environmental samples collected at this CAS that were detected above MDCs are presented in Table A.5-2. No VOCs were detected at concentrations exceeding their respective PALs. The FALs were established at the PAL concentrations.

\section{A.5.2.2 Semivolatile Organic Compounds}

Analytical results for SVOC environmental samples collected at this CAS did not exceed the MDCs. 
Table A.5-2

Soil Sample Results for Total VOCs Detected above Minimum Detectable Concentrations at CAS 03-99-14, Radioactive Material Disposal Area

\begin{tabular}{|c|c|c|c|c|c|}
\hline \multirow{2}{*}{$\begin{array}{l}\text { Sample } \\
\text { Location }\end{array}$} & \multirow{2}{*}{$\begin{array}{l}\text { Sample } \\
\text { Number }\end{array}$} & \multirow{2}{*}{$\begin{array}{l}\text { Depth } \\
\text { (ft bgs) }\end{array}$} & \multicolumn{3}{|c|}{ Contaminants of Potential Concern (mg/kg) } \\
\hline & & & Acetone & Methylene Chloride & Styrene \\
\hline \multicolumn{3}{|c|}{ Final Action Levels ${ }^{a}$} & 54,000 & 21 & 1,700 \\
\hline$\overline{C 06}$ & $545 C 015$ & $0.0-0.5$ & $0.00369(\mathrm{~J})$ & $0.00284(\mathrm{~J})$ & $0.000549(\mathrm{~J})$ \\
\hline $\mathrm{C} 07$ & $545 C 014$ & $0.0-0.5$ & -- & 0.00513 & 0.00106 \\
\hline \multirow{2}{*}{ C08 } & $545 \mathrm{C} 012$ & $0.0-0.5$ & -- & -- & $0.000602(\mathrm{~J})$ \\
\hline & $545 C 016$ & $3.5-4.0$ & $0.00368(\mathrm{~J})$ & $0.00415(\mathrm{~J})$ & $0.000855(\mathrm{~J})$ \\
\hline \multirow{2}{*}{ Co9 } & $545 C 011$ & $0.0-0.5$ & -- & -- & $0.000384(\mathrm{~J})$ \\
\hline & $545 C 013$ & $3.5-4.0$ & -- & -- & $0.000212(\mathrm{~J})$ \\
\hline C12 & $545 \mathrm{C} 007$ & $0.0-0.5$ & -- & -- & $0.000248(\mathrm{~J})$ \\
\hline
\end{tabular}

aBased on U.S. Environmental Protection Agency, Region 9 Preliminary Remediation Goals (PRGs) (EPA, 2004).

bgs $=$ Below ground surface

$\mathrm{ft}=$ Foot

$\mathrm{mg} / \mathrm{kg}=$ Milligrams per kilogram

$\mathrm{J}=$ Estimated value

-- = Not detected above minimum detectable concentrations.

\section{A.5.2.3 Total Petroleum Hydrocarbons}

The TPH-DRO analytical results for soil samples collected at this CAS that were detected above MDCs are presented in Table A.5-3. Total petroleum hydrocarbons-DRO was not detected at concentrations exceeding the PAL. The FAL was established at the PAL concentration.

\section{A.5.2.4 RCRA Metals}

The RCRA metals analytical results for environmental samples collected at this CAS that were detected above MDCs are presented in Table A.5-4. No result exceeded the respective PAL. The FALs were established at the PAL concentrations.

\section{A.5.2.5 Polychlorinated Biphenyls}

The PCBs detected above MDCs are presented in Table A.5-5. No PCBs were detected at concentrations exceeding the PAL. The FAL was established at the PAL concentration. 
Table A.5-3

Soil Sample Results for TPH-DRO Detected above Minimum Detectable Concentrations at CAS 03-99-14, Radioactive Material Disposal Area

\begin{tabular}{|c|c|c|c||}
\hline \multirow{2}{*}{$\begin{array}{c}\text { Sample } \\
\text { Location }\end{array}$} & \multirow{2}{*}{$\begin{array}{c}\text { Sample } \\
\text { Number }\end{array}$} & \multirow{2}{*}{$\begin{array}{c}\text { Depth } \\
\text { (ft bgs) }\end{array}$} & Contaminants of Potential Concern (mg/kg) \\
\cline { 3 - 4 } & & & Diesel-Range Organics \\
\hline \multicolumn{2}{|c|}{ Preliminary Action Levels ${ }^{\mathbf{a}}$} & $\mathbf{1 0 0}$ \\
\hline \hline C09 & $545 \mathrm{C} 011$ & $0.0-0.5$ & $1.85(\mathrm{~J})$ \\
\hline C10 & $545 C 010$ & $0.0-0.5$ & $2.21(\mathrm{~J})$ \\
\hline C11 & $545 C 008$ & $0.0-0.5$ & $1.9(\mathrm{~J})$ \\
\hline C12 & $545 C 007$ & $0.0-0.5$ & $2.53(\mathrm{~J})$ \\
\hline
\end{tabular}

${ }^{a}$ Established in the CAIP for CAU 545 (NNSA/NSO, 2007).

bgs $=$ Below ground surface

CAIP $=$ Corrective Action Investigation Plan

$\mathrm{ft}=$ Foot

$\mathrm{mg} / \mathrm{kg}=$ Milligrams per kilogram

$\mathrm{J}=$ Estimated value

Table A.5-4

Soil Sample Results for RCRA Metals Detected above Minimum

Detectable Concentrations at CAS 03-99-14, Radioactive Material Disposal Area

(Page 1 of 2)

\begin{tabular}{|c|c|c|c|c|c|c|c|c|c|}
\hline \multirow[b]{2}{*}{$\begin{array}{l}\text { Sample } \\
\text { Location }\end{array}$} & \multirow[b]{2}{*}{$\begin{array}{l}\text { Sample } \\
\text { Number }\end{array}$} & \multirow[b]{2}{*}{$\begin{array}{c}\text { Depth } \\
\text { (ft bgs) }\end{array}$} & \multicolumn{7}{|c|}{ Contaminants of Potential Concern (mg/kg) } \\
\hline & & & 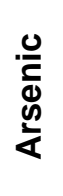 & 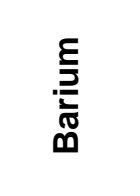 & 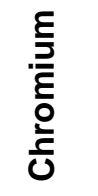 & వ్త & 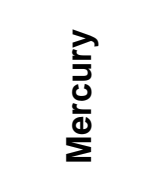 & $\frac{\xi}{\frac{\Sigma}{D}}$ & $\frac{\grave{D}}{\bar{\vdots}}$ \\
\hline \multicolumn{3}{|c|}{ Final Action Levels } & $23^{\mathrm{a}}$ & $67,000^{b}$ & $450^{b}$ & $800^{b}$ & $310^{b}$ & $5,100^{b}$ & $5,100^{b}$ \\
\hline \multirow{2}{*}{ C06 } & $545 C 015$ & $0.0-0.5$ & 5.6 & 126 & 7.1 & $10.5(\mathrm{~J})$ & $0.011(\mathrm{~J}-)$ & 1.6 & -- \\
\hline & $545 C 018$ & $2.0-2.5$ & 4.1 & $169(\mathrm{~J}-)$ & 7.4 & 10.2 & 0.0069 (J-) & -- & -- \\
\hline \multirow{2}{*}{$\mathrm{C} 07$} & $545 C 014$ & $0.0-0.5$ & 4.4 & 113 & 6.3 & $9.5(\mathrm{~J})$ & $0.01(\mathrm{~J}-)$ & 1.7 & -- \\
\hline & $545 C 017$ & $3.0-3.5$ & 3.9 & $135(\mathrm{~J}-)$ & 5.6 & 8.8 & $0.008(\mathrm{~J}-)$ & -- & -- \\
\hline \multirow{2}{*}{ C08 } & $545 \mathrm{C} 012$ & $0.0-0.5$ & 5.2 & 124 & 6.3 & $10.6(\mathrm{~J})$ & $0.009(\mathrm{~J}-)$ & 1.8 & $0.33(\mathrm{~J})$ \\
\hline & $545 \mathrm{C} 016$ & $3.5-4.0$ & 5.6 & 137 & 6.7 & $12.1(\mathrm{~J})$ & $0.012(\mathrm{~J}-)$ & 1.9 & -- \\
\hline \multirow{2}{*}{ C09 } & $545 C 011$ & $0.0-0.5$ & 4.9 & 173 & 5.8 & $19.2(\mathrm{~J})$ & $0.0083(\mathrm{~J}-)$ & 1.8 & -- \\
\hline & $545 C 013$ & $3.5-4.0$ & 3.5 & 147 & 5.1 & $9(\mathrm{~J})$ & 0.0042 (J-) & 1.6 & -- \\
\hline
\end{tabular}


Table A.5-4

Soil Sample Results for RCRA Metals Detected above Minimum Detectable Concentrations at CAS 03-99-14, Radioactive Material Disposal Area (Page 2 of 2)

\begin{tabular}{|c|c|c|c|c|c|c|c|c|c|}
\hline \multirow[b]{2}{*}{$\begin{array}{l}\text { Sample } \\
\text { Location }\end{array}$} & \multirow[b]{2}{*}{$\begin{array}{l}\text { Sample } \\
\text { Number }\end{array}$} & \multirow[b]{2}{*}{$\begin{array}{l}\text { Depth } \\
\text { (ft bgs) }\end{array}$} & \multicolumn{7}{|c|}{ Contaminants of Potential Concern (mg/kg) } \\
\hline & & & 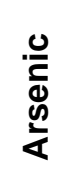 & 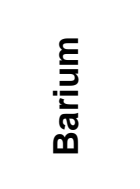 & 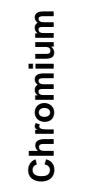 & $\begin{array}{l}\text { వ్త } \\
\text { త్ }\end{array}$ & 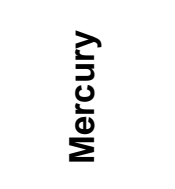 & 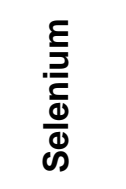 & $\frac{\bar{\Xi}}{\bar{\omega}}$ \\
\hline \multicolumn{3}{|c|}{ Final Action Levels } & $23^{a}$ & $67,000^{b}$ & $450^{b}$ & $800^{b}$ & $310^{b}$ & $5,100^{b}$ & $5,100^{b}$ \\
\hline C10 & $545 C 010$ & $0.0-0.5$ & 3.6 & 179 & 3.9 & $9.9(\mathrm{~J})$ & $0.0078(\mathrm{~J}-)$ & $1.4(\mathrm{~J})$ & -- \\
\hline \multirow{2}{*}{ C11 } & $545 \mathrm{C} 008$ & $0.0-0.5$ & 4.7 & 168 & 4.8 & $11.8(\mathrm{~J})$ & $0.012(\mathrm{~J}-)$ & 1.9 & -- \\
\hline & $545 C 009$ & $0.0-0.5$ & 3.8 & 169 & 4.9 & $11.9(\mathrm{~J})$ & $0.011(\mathrm{~J}-)$ & $1.3(\mathrm{~J})$ & -- \\
\hline C12 & $545 C 007$ & $0.0-0.5$ & 3.8 & 155 & 4.3 & $17.3(\mathrm{~J})$ & $0.01(\mathrm{~J}-)$ & $1.5(\mathrm{~J})$ & -- \\
\hline C13 & $545 C 006$ & $0.0-0.5$ & 4.7 & 153 & 5 & $11.5(\mathrm{~J})$ & $0.0099(\mathrm{~J}-)$ & 1.9 & -- \\
\hline
\end{tabular}

${ }^{a}$ Based on the background concentrations for metals. Background is considered the mean plus two times the standard deviation for sediment samples collected by the Nevada Bureau of Mines and Geology throughout the Nevada Test and Training Range (NBMG, 1998; Moore, 1999).

${ }^{\mathrm{b} B a s e d}$ on U.S. Environmental Protection Agency, Region 9 Preliminary Remediation Goals (PRGs) (EPA, 2004).

bgs $=$ Below ground surface

$\mathrm{ft}=$ Foot

$\mathrm{mg} / \mathrm{kg}=$ Milligrams per kilogram

$\mathrm{J}=$ Estimated value

$\mathrm{J}-=$ The result is an estimated quantity, but the result may be biased low.

$--=$ Not detected above minimum detectable concentrations.

Table A.5-5

Soil Sample Results for PCBs Detected above Minimum Detectable Concentrations at CAS 03-99-14, Radioactive Material Disposal Area

\begin{tabular}{|c|c|c|c||}
\hline Sample & Sample & \multirow{2}{*}{$\begin{array}{c}\text { Depth } \\
\text { Location }\end{array}$} & Contaminants of Potential Concern (mg/kg) \\
\cline { 3 - 4 } & Number & ft bgs) & Aroclor 1260 \\
\hline \multicolumn{3}{|c|}{ Final Action Levels ${ }^{\mathrm{a}}$} & $\mathbf{0 . 7 4}$ \\
\hline \hline C11 & 545 C009 & $0-0.5$ & $0.0024(\mathrm{~J})$ \\
\hline
\end{tabular}

${ }^{a}$ Based on U.S. Environmental Protection Agency, Region 9 Preliminary Remediation Goals (PRGs) (EPA, 2004).

bgs $=$ Below ground surface

$\mathrm{ft}=$ Foot

$\mathrm{mg} / \mathrm{kg}=$ Milligrams per kilogram

$\mathrm{J}=$ Estimated value 


\section{A.5.2.6 Gamma-Emitting Radionuclides}

Gamma-emitting radionuclides analytical results for environmental samples collected at this CAS that were detected above MDCs are presented in Table A.5-6. No gamma-emitting radionuclides were detected at concentrations exceeding the respective PALs. The FALs were established at the PAL concentrations.

\section{A.5.2.7 Plutonium, Strontium-90, and Uranium Isotopes}

Isotopic Pu and isotopic $\mathrm{U}$ analytical results for environmental samples collected at this CAS that were detected above MDCs are presented in Table A.5-7. The only exceedence of a PAL was for $\mathrm{Pu}-239$ for the background sample from location C03 outside of the CAS. This result is likely due to the aboveground testing conducted west of the site. No isotopic Pu, isotopic U, or Sr-90 were detected at concentrations exceeding the respective PALs within the CAS. The FALs were established at the PAL concentrations.

\section{A.5.2.8 Nature and Extent of Contamination}

Based on the analytical results for soil samples collected within CAS 03-99-14, no COCs were identified at this CAS.

\section{A.5.3 Revised Conceptual Site Model}

The CAIP requirements were met at this CAS (NNSA/NSO, 2007), and no revisions were necessary to the CSM. 
Table A.5-6

Soil Sample Results for Gamma-Emitting Radionuclides Detected above Minimum Detectable Concentrations at CAS 03-99-14, Radioactive Material Disposal Area

\begin{tabular}{|c|c|c|c|c|c|c|c|c|c|}
\hline \multirow[b]{2}{*}{ 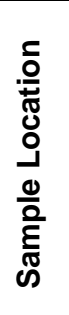 } & \multirow[b]{2}{*}{ 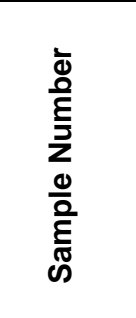 } & \multirow[b]{2}{*}{ 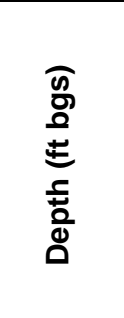 } & \multicolumn{7}{|c|}{ Contaminants of Potential Concern (pCi/g) } \\
\hline & & & 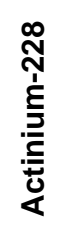 & 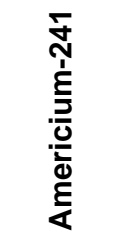 & 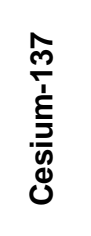 & 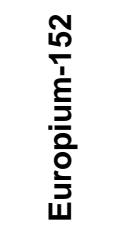 & 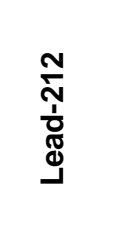 & 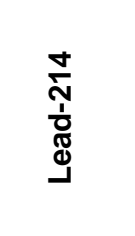 & 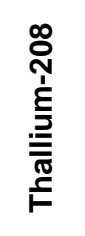 \\
\hline \multicolumn{3}{|c|}{ Final Actions Levels } & $5^{a}$ & $12.7^{b}$ & $12.2^{b}$ & $5.67^{b}$ & $5^{\mathrm{a}}$ & $5^{\mathrm{a}}$ & $5^{a}$ \\
\hline $\mathrm{C01}$ & $545 \mathrm{C001}$ & $0.0-0.5$ & 1.78 & -- & 10.3 & $0.826(\mathrm{~J})$ & $1.58(\mathrm{~J})$ & $1.07(\mathrm{~J})$ & 0.555 \\
\hline $\mathrm{CO} 2$ & $545 \mathrm{C} 002$ & $0.0-0.5$ & 1.78 & -- & 3.82 & $1.2(\mathrm{~J})$ & $1.69(\mathrm{~J})$ & $0.925(\mathrm{~J})$ & 0.495 \\
\hline $\mathrm{C03}$ & $545 \mathrm{C} 003$ & $0.0-0.5$ & 1.39 & $1.05(\mathrm{~J})$ & 5.1 & $3.05(\mathrm{~J})$ & $1.59(\mathrm{~J})$ & $1.12(\mathrm{~J})$ & 0.489 \\
\hline $\mathrm{CO4}$ & $545 C 004$ & $0.0-0.5$ & 1.73 & -- & 5.23 & $3.57(\mathrm{~J})$ & $1.81(\mathrm{~J})$ & $0.956(\mathrm{~J})$ & 0.483 \\
\hline $\mathrm{C} 05$ & $545 \mathrm{C} 005$ & $0.0-0.5$ & 1.51 & -- & 6.74 & $4.62(\mathrm{~J})$ & $1.55(\mathrm{~J})$ & $0.951(\mathrm{~J})$ & 0.442 \\
\hline \multirow{2}{*}{$\mathrm{C} 06$} & $545 \mathrm{C} 015$ & $0.0-0.5$ & 1.73 & -- & -- & -- & $1.78(\mathrm{~J})$ & $1.2(\mathrm{~J})$ & 0.61 \\
\hline & $545 \mathrm{C} 018$ & $2.0-2.5$ & 1.63 & -- & 5 & 0.806 & $1.94(\mathrm{~J})$ & $1.18(\mathrm{~J})$ & 0.491 \\
\hline \multirow{2}{*}{$\mathrm{C07}$} & $545 \mathrm{C} 014$ & $0.0-0.5$ & 1.49 & -- & 0.55 & -- & $1.61(\mathrm{~J})$ & $0.991(\mathrm{~J})$ & 0.539 \\
\hline & $545 C 017$ & $3.0-3.5$ & 1.83 & -- & 2.62 & -- & $1.66(\mathrm{~J})$ & $1.35(\mathrm{~J})$ & 0.546 \\
\hline \multirow{2}{*}{$\mathrm{C08}$} & $545 \mathrm{C} 012$ & $0.0-0.5$ & 1.82 & -- & -- & -- & $1.62(\mathrm{~J})$ & $1.13(\mathrm{~J})$ & 0.578 \\
\hline & $545 \mathrm{C} 016$ & $3.5-4.0$ & 1.93 & -- & -- & -- & $1.89(\mathrm{~J})$ & $1.14(\mathrm{~J})$ & 0.585 \\
\hline \multirow{2}{*}{$\mathrm{C} 09$} & $545 \mathrm{C} 011$ & $0.0-0.5$ & 1.91 & -- & -- & -- & $1.91(\mathrm{~J})$ & $1.06(\mathrm{~J})$ & 0.53 \\
\hline & $545 \mathrm{C} 013$ & $3.5-4.0$ & 1.96 & -- & -- & -- & $1.74(\mathrm{~J})$ & $1.06(\mathrm{~J})$ & 0.485 \\
\hline C10 & $545 \mathrm{C} 010$ & $0.0-0.5$ & 1.42 & -- & 4.82 & $2.91(\mathrm{~J})$ & $1.64(\mathrm{~J})$ & $1.17(\mathrm{~J})$ & 0.464 \\
\hline \multirow{2}{*}{ C11 } & $545 \mathrm{C008}$ & $0.0-0.5$ & 1.52 & -- & 6.25 & $2.11(\mathrm{~J})$ & $1.69(\mathrm{~J})$ & $1.06(\mathrm{~J})$ & 0.539 \\
\hline & $545 C 009$ & $0.0-0.5$ & 1.62 & -- & 5.41 & $2.23(\mathrm{~J})$ & $1.42(\mathrm{~J})$ & $0.866(\mathrm{~J})$ & 0.56 \\
\hline C12 & $545 \mathrm{C} 007$ & $0.0-0.5$ & 1.69 & $0.472(\mathrm{~J})$ & 6.34 & $1.57(\mathrm{~J})$ & $1.5(\mathrm{~J})$ & $1.08(\mathrm{~J})$ & 0.59 \\
\hline C13 & $545 C 006$ & $0.0-0.5$ & 1.75 & -- & 7.73 & $1.17(\mathrm{~J})$ & $1.72(\mathrm{~J})$ & $1.2(\mathrm{~J})$ & 0.53 \\
\hline
\end{tabular}

${ }^{a}$ Taken from the generic guidelines for residual concentrations of actinium-228, bismuth-214, lead-212, lead-214, thallium-208, and thorium-232, as found in Chapter IV of DOE Order 5400.5, Change 2, "Radiation Protection of the Public and Environment" (DOE, 1993). The PALs for these isotopes are specified as $5 \mathrm{pCi} / \mathrm{g}$ averaged over the first $15 \mathrm{~cm}$ of soil and $15 \mathrm{pCi} / \mathrm{g}$ for deeper soils (DOE, 1993). For purposes of this document, $15 \mathrm{~cm}$ is assumed to be equivalent to $0.5 \mathrm{ft}$ ( 6 inches); therefore, $5 \mathrm{pCi} / \mathrm{g}$ represents the PALs for these radionuclides in the surface soil (0 to $0.5 \mathrm{ft}$ depth).

${ }^{\mathrm{b}}$ Taken from the construction, commercial, industrial land-use scenario in Table 2.1 of the NCRP Report No. 129, Recommended Screening Limits for Contaminated Surface Soil and Review Factors Relevant to Site-Specific Studies (NCRP, 1999). The values provided in this source document were scaled to a 25-millirem-per-year dose.

bgs $=$ Below ground surface

$\mathrm{cm}=$ Centimeter

DOE = U.S. Department of Energy $\mathrm{ft}=$ Foot

NCRP $=$ National Council on Radiation Protection and Measurements

$\mathrm{pCi} / \mathrm{g}=$ Picocuries per gram

$\mathrm{J}=$ Estimated value

-- = Not detected above minimum detectable concentrations. 
Table A.5-7

Soil Sample Results for Isotopes Detected above Minimum Detectable Concentrations at CAS 03-99-14, Radioactive Material Disposal Area

\begin{tabular}{|c|c|c|c|c|c|c|c|c|}
\hline \multirow[b]{2}{*}{$\begin{array}{c}\text { Sample } \\
\text { Location }\end{array}$} & \multirow[b]{2}{*}{$\begin{array}{l}\text { Sample } \\
\text { Number }\end{array}$} & \multirow[b]{2}{*}{$\begin{array}{c}\text { Depth } \\
\text { (ft bgs) }\end{array}$} & \multicolumn{6}{|c|}{ Contaminants of Potential Concern (pCi/g) } \\
\hline & & & 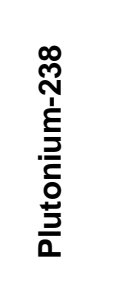 & 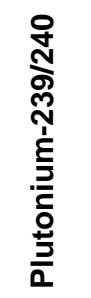 & 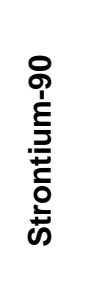 & 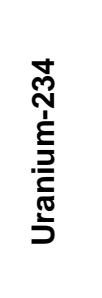 & 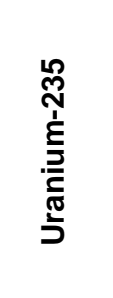 & 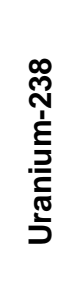 \\
\hline \multicolumn{3}{|c|}{ Final Actions Levels ${ }^{a}$} & 13 & 12.7 & 838 & 143 & 17.6 & 105 \\
\hline $\mathrm{C01}$ & $545 C 001$ & $0.0-0.5$ & -- & 0.49 & 5.17 & 0.75 & -- & 0.728 \\
\hline $\mathrm{CO2}$ & $545 C 002$ & $0.0-0.5$ & -- & 0.468 & 1.97 & 0.746 & -- & 0.846 \\
\hline $\mathrm{C03}$ & $545 C 003$ & $0.0-0.5$ & 2.18 & 15.1 & 1.4 & 0.785 & 0.0891 & 0.796 \\
\hline $\mathrm{CO4}$ & $545 C 004$ & $0.0-0.5$ & 0.199 & 2.35 & 2.64 & 0.691 & -- & 0.65 \\
\hline $\mathrm{C05}$ & $545 C 005$ & $0.0-0.5$ & -- & 1.27 & 4.32 & 1.02 & -- & 0.841 \\
\hline \multirow{2}{*}{$\mathrm{C} 06$} & $545 \mathrm{C} 015$ & $0.0-0.5$ & -- & -- & -- & 0.942 & 0.097 & 0.971 \\
\hline & $545 \mathrm{C} 018$ & $2.0-2.5$ & -- & -- & 2.65 & 0.829 & -- & 0.814 \\
\hline \multirow{2}{*}{$\mathrm{C} 07$} & $545 C 014$ & $0.0-0.5$ & -- & -- & -- & 0.85 & -- & 0.899 \\
\hline & $545 C 017$ & $3.0-3.5$ & -- & 1.39 & 0.589 & 1.27 & -- & 1.09 \\
\hline \multirow{2}{*}{$\mathrm{C08}$} & $545 C 012$ & $0.0-0.5$ & -- & -- & -- & 0.91 & 0.108 & 0.848 \\
\hline & $545 \mathrm{C} 016$ & $3.5-4.0$ & 0.0551 & -- & -- & 0.81 & -- & 0.822 \\
\hline \multirow{2}{*}{ C09 } & $545 \mathrm{C} 011$ & $0.0-0.5$ & -- & -- & -- & 1.02 & -- & 1.15 \\
\hline & $545 C 013$ & $3.5-4.0$ & -- & -- & -- & 0.717 & -- & 0.786 \\
\hline C10 & $545 C 010$ & $0.0-0.5$ & 0.117 & 1.08 & 4.88 & 0.684 & -- & 0.682 \\
\hline \multirow{2}{*}{ C11 } & $545 C 008$ & $0.0-0.5$ & 0.188 & 1.2 & 4.02 & 0.61 & -- & 0.754 \\
\hline & $545 C 009$ & $0.0-0.5$ & -- & 1.01 & 3.3 & 0.869 & -- & 0.673 \\
\hline C12 & $545 C 007$ & $0.0-0.5$ & 0.57 & 2.88 & 4.65 & 0.757 & -- & 0.866 \\
\hline C13 & $545 \mathrm{C} 006$ & $0.0-0.5$ & 0.367 & 2.18 & 5.67 & 0.683 & -- & 0.807 \\
\hline
\end{tabular}

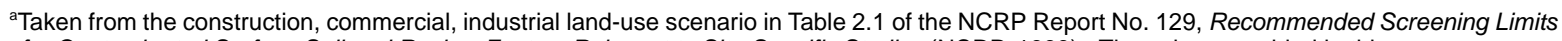
for Contaminated Surface Soil and Review Factors Relevant to Site-Specific Studies (NCRP, 1999). The values provided in this source document were scaled to a 25-millirem-per-year dose.

bgs $=$ Below ground surface

$\mathrm{ft}=$ Foot

NCRP $=$ National Council on Radiation Protection and Measurements

$\mathrm{pCi} / \mathrm{g}=$ Picocuries per gram

$--=$ Not detected above minimum detectable concentrations. 


\section{A.6.0 Corrective Action Site 09-23-02, U-9y Drilling Mud Disposal Crater}

Corrective Action Site 09-23-02 is located at the U-9y drilling mud disposal crater in Area 9 approximately $600 \mathrm{ft}$ southeast of the 9-01 and Circle Roads intersection (Figure A.1-1). The U-9y crater was used for the disposal of radiologically contaminated drilling fluids and decontamination wastewater. At some point in 1979 or 1980, the crater overflowed into the wash to the east. Because the crater presently cannot be entered due to safety concerns, the wash component was the focus of this investigation. Additional detail is provided in the CAIP for CAU 545 (NNSA/NSO, 2007).

\section{A.6.1 Corrective Action Investigation}

A total of 18 characterization samples (including one FD) were collected during investigation activities at CAS 09-23-02. The sample locations are shown on Figure A.6-1. The sample locations, IDs, types, and analyses are listed in Table A.6-1. The specific CAI activities conducted to satisfy the CAIP requirements at this CAS (NNSA/NSO, 2007) are described in the following sections.

\section{A.6.1.1 Field Screening}

Investigation samples were field screened for alpha and beta/gamma radiation. The FSRs were compared to FSLs to guide subsequent sampling decisions where appropriate. Gross alpha radiation FSLs were not exceeded, but beta/gamma radiation FSLs were exceeded in four samples (and one duplicate) at CAS 09-23-02. All samples exceeding FSLs were analyzed.

\section{A.6.1.2 Radiological Survey}

A radiological walkover survey was conducted over the wash component of CAS 09-23-02. No areas of elevated radiological readings were found. Therefore, the radiological survey was not used in the selection of sample locations (Figure A.6-2). 


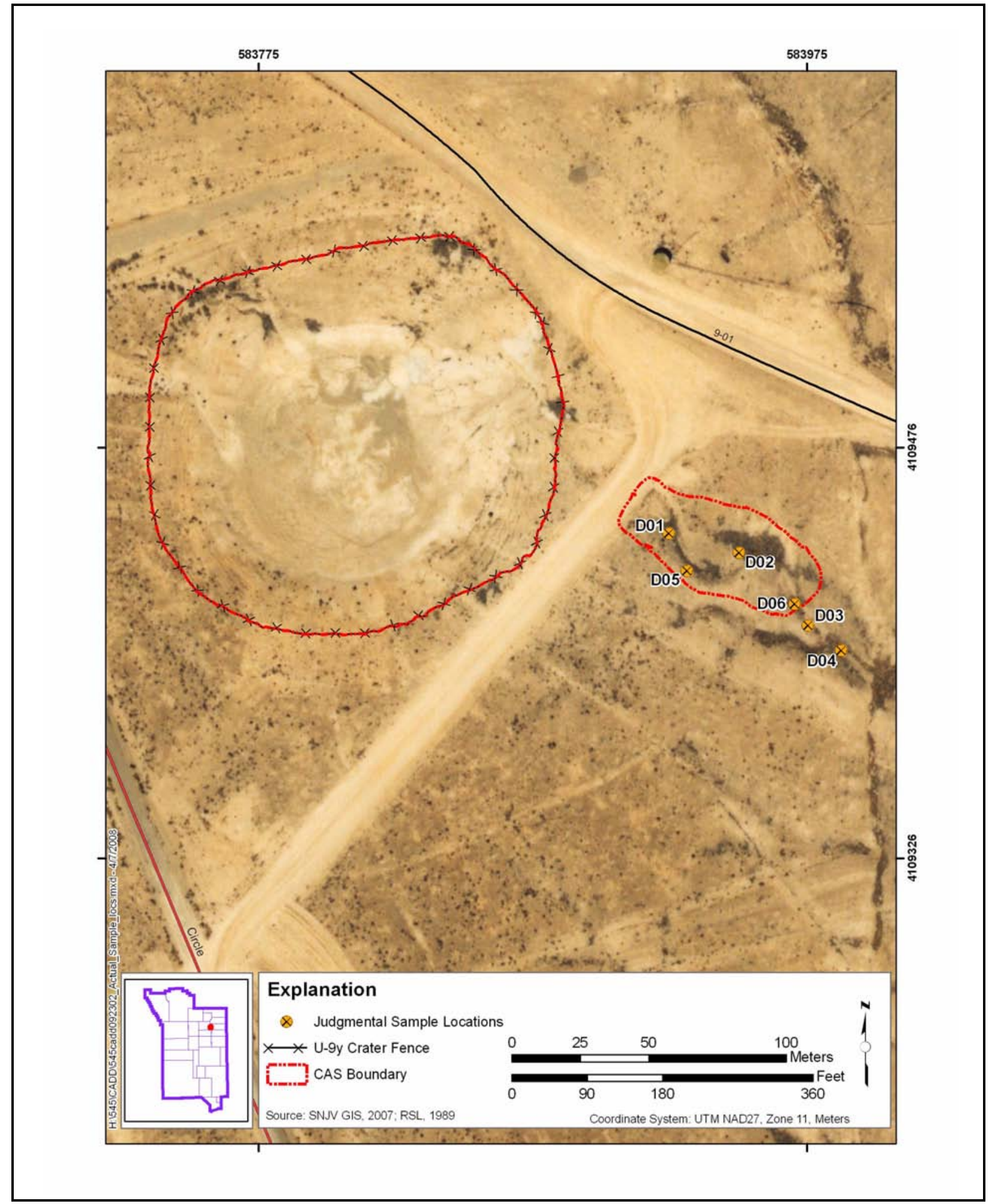

Figure A.6-1

Sample Locations at CAS 09-23-02, U-9y Drilling Mud Disposal Crater 
Table A.6-1

Samples Collected at CAS 09-23-02, U-9y Drilling Mud Disposal Crater

\begin{tabular}{|c|c|c|c|c|c|}
\hline $\begin{array}{l}\text { Sample } \\
\text { Location }\end{array}$ & $\begin{array}{l}\text { Sample } \\
\text { Number }\end{array}$ & $\begin{array}{c}\text { Depth } \\
\text { (ft bgs) }\end{array}$ & Matrix & Purpose & Analyses \\
\hline \multirow{4}{*}{ D01 } & 545D001 & $0.0-0.5$ & $\overline{\overline{\text { Soil }}}$ & "Environmental, Full Lab QC & $\overline{\text { Set } 4}$ \\
\hline & 545D009 & $0.5-1.0$ & Soil & Environmental & Set 4 \\
\hline & 545D010 & $2.0-2.5$ & Soil & Environmental & Set 4 \\
\hline & 545D011 & $4.0-4.5$ & Soil & Environmental & Set 4 \\
\hline \multirow{3}{*}{ D02 } & 545D002 & $0.0-0.5$ & Soil & Environmental & Set 4 \\
\hline & 545D013 & $2.0-2.5$ & Soil & Environmental & Set 4 \\
\hline & 545D014 & $3.0-3.5$ & Soil & Environmental & Set 4 \\
\hline \multirow{2}{*}{ D03 } & 545D003 & $0.0-0.5$ & Soil & Environmental & Set 4 \\
\hline & 545D017 & $1.5-2.0$ & Soil & Environmental & Set 4 \\
\hline \multirow{4}{*}{ D04 } & 545D004 & $0.0-0.5$ & Soil & Environmental & Set 4 \\
\hline & 545D005 & $0.0-0.5$ & Soil & Field Duplicate of \#545D004 & Set 4 \\
\hline & 545D006 & $0.5-1.0$ & Soil & Environmental & Set 4 \\
\hline & 545D018 & $1.0-1.17$ & Soil & Environmental & Set 4 \\
\hline \multirow{2}{*}{ D05 } & 545D007 & $0.0-0.5$ & Soil & Environmental & Set 4 \\
\hline & $545 \mathrm{D} 012$ & $1.5-2.0$ & Soil & Environmental & Set 4 \\
\hline \multirow{3}{*}{ D06 } & 545D008 & $0.0-0.5$ & Soil & Environmental & Set 4 \\
\hline & 545D015 & $1.5-2.0$ & Soil & Environmental & Set 4 \\
\hline & 545D016 & $3.0-3.5$ & Soil & Environmental & Set 4 \\
\hline N/A & 545D301 & $\mathrm{N} / \mathrm{A}$ & Water & Trip Blank & VOCs \\
\hline $\mathrm{N} / \mathrm{A}$ & 545D302 & $\mathrm{N} / \mathrm{A}$ & Water & Field Blank & Set 4 \\
\hline $\mathrm{N} / \mathrm{A}$ & 545D303 & $\mathrm{N} / \mathrm{A}$ & Water & Source Blank & Set 5 \\
\hline $\mathrm{N} / \mathrm{A}$ & 545D304 & N/A & Water & Trip Blank & VOCs \\
\hline $\mathrm{N} / \mathrm{A}$ & 545D305 & $\mathrm{N} / \mathrm{A}$ & Water & Trip Blanks & VOCs \\
\hline $\mathrm{N} / \mathrm{A}$ & 545D306 & $\mathrm{N} / \mathrm{A}$ & Water & Trip Blank & VOCs \\
\hline $\mathrm{N} / \mathrm{A}$ & 545D307 & $\mathrm{N} / \mathrm{A}$ & Water & Trip Blanks & VOCs \\
\hline $\mathrm{N} / \mathrm{A}$ & 545D308 & N/A & Water & Trip Blank & VOCs \\
\hline $\mathrm{N} / \mathrm{A}$ & 545D309 & $\mathrm{N} / \mathrm{A}$ & Water & Equipment Rinsate & Set 4 \\
\hline $\mathrm{N} / \mathrm{A}$ & 545D310 & N/A & Water & Source Blank & Gross Alpha/Beta \\
\hline$N / A$ & 545D501 & N/A & Liquid & Waste Management & $\begin{array}{c}\text { Set 4, Gross } \\
\text { Alpha/Beta, Tritium }\end{array}$ \\
\hline
\end{tabular}

Set 4 = VOCs, SVOCs, TPH-DRO, RCRA Metals, Gamma Spectroscopy, Isotopic Uranium, Isotopic Plutonium, Strontium-90 Set 5 = VOCs, SVOCs, TPH-DRO and GRO, RCRA Metals, Beryllium, PCBs, Gamma Spectroscopy, Isotopic Uranium, Isotopic Plutonium, Strontium-90, Gross Alpha/Beta, Tritium

DRO = Diesel-range organics bgs $=$ Below ground surface $\mathrm{GRO}=$ Gasoline-range organics N/A = Not applicable $\mathrm{QC}=$ Quality control
PCB = Polychlorinated biphenyl

RCRA = Resource Conservation and Recovery Act

$S V O C=$ Semivolatile organic compound

$\mathrm{TPH}=$ Total petroleum hydrocarbons

VOC $=$ Volatile organic compound 


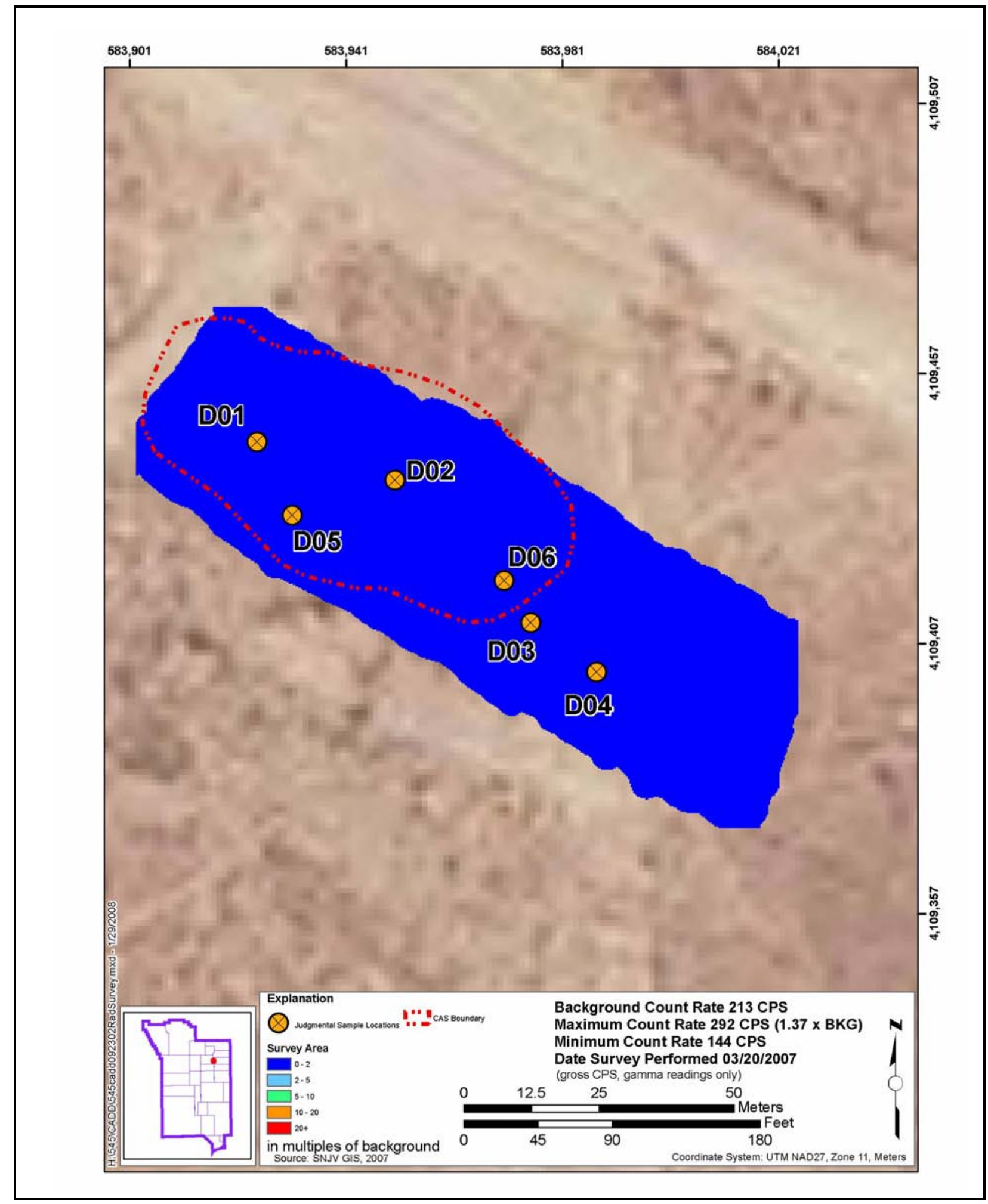

Figure A.6-2

Radiological Survey at CAS 09-23-02 


\section{A.6.1.3 Geophysical Survey}

A geophysical walkover survey was conducted at the CAS. No linear or significant subsurface features were found (Figure A.6-3). Two anomalies, one along the south shoulder of the wash, and one along the east boundary of the CAS, were interpreted to possibly indicate areas of different soil type. One sample location was placed over each anomaly.

\section{A.6.1.4 Visual Inspections}

Visible features that were used to establish biased locations were limited to areas where suspended solids (i.e., silts and clays) settled out of water moving through the wash (i.e., settling areas). Two locations within the CAS, and two locations down stream from the CAS, were established at these areas. Other visible biasing factors were not present at the CAS.

\section{A.6.1.5 Sample Collection}

Decision I environmental sampling activities included the collection of biased surface and subsurface soil samples within the wash and in two settling areas immediately down gradient (Figure A.6-1) at this CAS.

Within the CAS, two locations were selected based upon the geophysical survey, and two locations were selected in areas where fine sediment settled out from flowing runoff. Location D01 was selected at the settling area in the wash closest to the U-9y crater. Sample 545D001 was collected from the surface interval ( 0.0 to $0.5 \mathrm{ft}$ bgs), but did not exceed FSLs. A shallow subsurface sample (545D009) was collected from 0.5 to $1.0 \mathrm{ft}$ bgs, which exceeded the FSL for beta. Further down the soil profile at location D01; a layer of light-colored, fine material that may have been drilling mud, was encountered at 2.0 to $2.5 \mathrm{ft}$ bgs. Sample 545D010 was collected from this layer, but did not exceed FSLs. The interface of the wash material with the native soil was encountered at the interval of 4.0 to $4.5 \mathrm{ft}$ bgs. Sample 545D011 was collected at this interface, but also did not exceed FSLs.

Location D02 was selected in the lower third of the wash within the CAS (Figure A.6-1), at an obvious settling area. A sample (545D002) was collected from the surface interval (0.0 to $0.5 \mathrm{ft}$ bgs), which did not exceed FSLs. Sample 545D013, collected from the shallow subsurface interval 


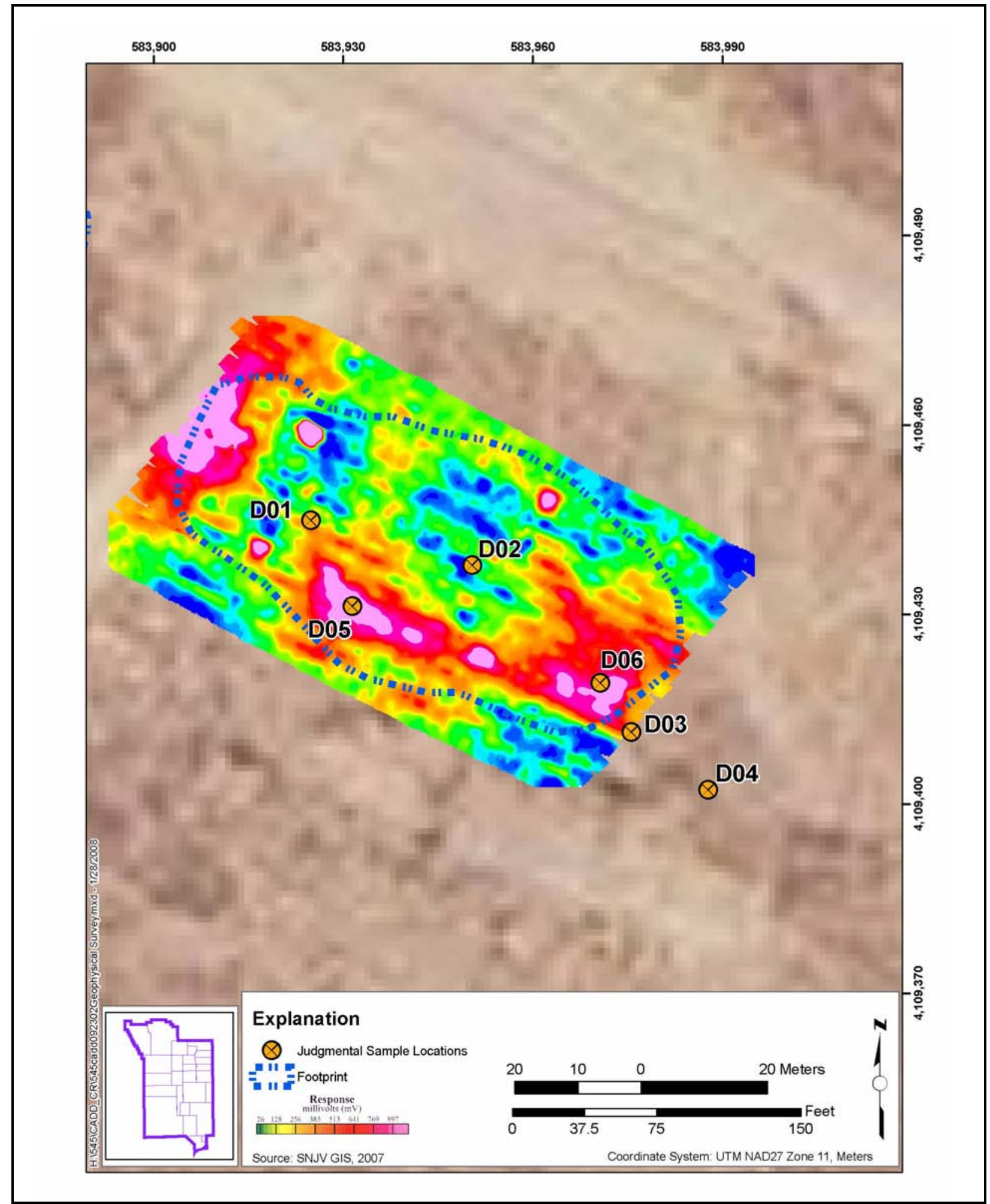

Figure A.6-3

Geophysical Survey at CAS 09-23-02 
between 2.0 and $2.5 \mathrm{ft}$ bgs exceeded the FSL for beta. Sample 545D014 at this location was collected immediately below the wash/native soil interface between 3.0 and $3.5 \mathrm{ft}$ bgs, and was below FSLs.

Location D03 was selected at a settling area just down gradient from the CAS. A sample (545D003) was collected from the surface interval (0.0 to $0.5 \mathrm{ft}$ bgs), and did not exceed FSLs. A sample (545D017) was collected from wash material between 1.5 and $2.0 \mathrm{ft} \mathrm{bgs,} \mathrm{and} \mathrm{did} \mathrm{not} \mathrm{exceed} \mathrm{FSLs.}$

Location D04 was also selected at a settling area, approximately $60 \mathrm{ft}$ down stream from the CAS boundary. A sample (545D004) and duplicate (545D005) was collected from the interval 0.0 to $0.5 \mathrm{ft}$ bgs, and exceeded the FSL for beta. Sample (545D006) was collected from wash material (immediately above native soil) from the interval 0.5 to $1.0 \mathrm{ft}$ bgs, and did not exceed FSLs. An additional shallow subsurface sample (545D018) was collected from the interval 1.0 to $1.17 \mathrm{ft}$ bgs in native soil, which included an approximately 3/8-in. thick layer of black, decomposed natural organic matter. The sample screening results were below FSLs.

Location D05 was selected approximately midway through the CAS and partially up the south bank of the wash, at a geophysical anomaly that was identified as likely being local soil changes, fill material, or buried nonmetallic material. Sample 545D007 was collected from the surface interval ( 0.0 to $0.5 \mathrm{ft}$ bgs) and was below FSLs. The location was excavated to native soil at $3.5 \mathrm{ft}$ bgs, which consisted of a compact sandy silt. No evidence of drilling mud was observed. A shallow subsurface sample (545D012) was collected from wash material in the interval of 1.5 to $2.0 \mathrm{ft}$ bgs and exceeded FSL for beta.

Location D06 was selected at the east boundary of the CAS, along the wash bottom, also at a geophysical anomaly that indicated either local soil changes, buried nonmetallic debris, or fill material. Sample 545D008 was collected from the interval 0.0 to $0.5 \mathrm{ft}$ bgs and did not exceed FSLs. A second sample (545D015) was collected from wash material from 1.5 to $2.0 \mathrm{ft}$ bgs and did not exceed FSLs. A third sample (545D016) at this location was collected just below the wash material/native soil interface at 3.0 to $3.5 \mathrm{ft}$ bgs, and did not exceed FSLs.

No staining, debris, or biasing factors other than elevated radiological readings, were found in any of the sample location profiles. 


\section{A.6.1.6 Deviations}

Investigation samples were collected as outlined in the CAIP for CAU 545 (NNSA/NSO, 2007) and submitted for laboratory analysis. There were no deviations from the planned sampling. All sample locations were accessible.

\section{A.6.2 Investigation Results}

The following sections provide analytical results from the samples collected to complete investigation activities as outlined in the CAIP for CAU 545 (NNSA/NSO, 2007). Investigation samples were analyzed for the CAIP-specified COPCs, which included VOCs, SVOCs, TPH-DRO, RCRA metals, gamma-emitting radionuclides, isotopic Pu, Sr-90, and isotopic U. The analytical parameters and laboratory methods used to analyze the investigation samples are listed in Table A.2-2. Table A.6-1 lists the sample-specific analytical suite for CAS 09-23-02. The waste characterization analytical results are discussed in Section A.8.0.

Analytical results from the soil samples with concentrations exceeding MDCs are summarized in the following sections. An evaluation was conducted on all contaminants detected above MDCs by comparing individual concentration or activity results against the FALs. Establishment of the FALs is presented in Appendix C. The FALs were established as the corresponding PAL concentrations or activities if the contaminant concentrations were below their respective PALs.

\section{A.6.2.1 Volatile Organic Compounds}

Analytical results for VOC environmental samples collected at this CAS that were detected above MDCs are presented in Table A.6-2. No VOCs were detected at concentrations exceeding the respective PALs. The FALs were established at the PAL concentrations.

\section{A.6.2.2 Semivolatile Organic Compounds}

Analytical results for SVOC environmental samples collected at this CAS did not exceed the MDCs. 
Table A.6-2

Soil Sample Results for Total VOCs Detected above Minimum Detectable Concentrations at CAS 09-23-02, U-9y Drilling Mud Disposal Crater

\begin{tabular}{|c|c|c|c|c|c|c|c|c|}
\hline \multirow[b]{2}{*}{ 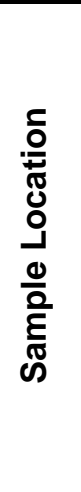 } & \multirow[b]{2}{*}{ 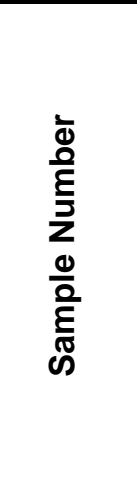 } & \multirow[b]{2}{*}{ 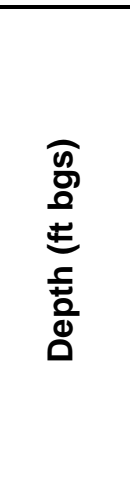 } & \multicolumn{6}{|c|}{ Contaminants of Potential Concern (mg/kg) } \\
\hline & & & 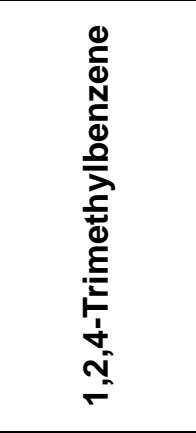 & 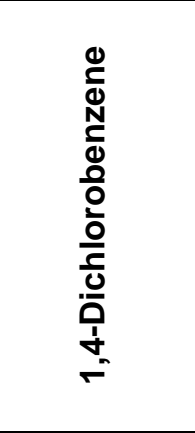 & 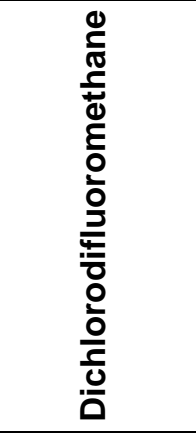 & 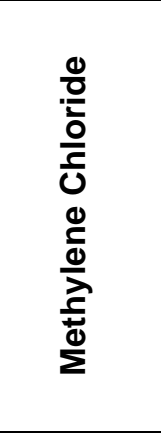 & 离 & 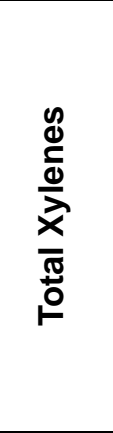 \\
\hline \multicolumn{3}{|c|}{ Final Action Levels ${ }^{a}$} & 170 & 7.9 & 310 & 21 & 1,700 & 420 \\
\hline$\overline{\mathrm{D} 02}$ & 545D002 & $0.0-0.5$ & $\overline{---}$ & $\overline{---}$ & $0.000951(\mathrm{~J})$ & $\overline{---}$ & $\overline{---}$ & $\overline{---}$ \\
\hline D03 & 545D017 & $1.5-2.0$ & -- & -- & -- & -- & $0.000552(\mathrm{~J})$ & -- \\
\hline D05 & 545D007 & $0.0-0.5$ & 0.00151 & $0.000282(\mathrm{~J})$ & -- & $0.0023(\mathrm{~J})$ & 0.00251 & 0.0055 \\
\hline D06 & 545D008 & $0.0-0.5$ & $0.000449(\mathrm{~J})$ & $0.000281(\mathrm{~J})$ & -- & -- & -- & -- \\
\hline
\end{tabular}

${ }^{a}$ Based on U.S. Environmental Protection Agency, Region 9 Preliminary Remediation Goals (PRGs) (EPA, 2004).

bgs $=$ Below ground surface

$\mathrm{ft}=$ Foot

$\mathrm{mg} / \mathrm{kg}=$ Milligrams per kilogram

$\mathrm{J}=$ Estimated value

-- = Not detected above minimum detectable concentrations.

\section{A.6.2.3 Total Petroleum Hydrocarbons}

The TPH-DRO analytical results for soil samples collected at this CAS that were detected above MDCs are presented in Table A.6-3. Total petroleum hydrocarbons-DRO was not detected at concentrations exceeding the PAL of 100 milligrams per kilogram (mg/kg). The FAL was established at the PAL concentration.

\section{A.6.2.4 RCRA Metals}

The RCRA metals analytical results for environmental samples collected at this CAS that were detected above MDCs are presented in Table A.6-4. No results exceeded the PALs. The FALs were established at the PAL concentrations. 
Table A.6-3

Soil Sample Results for TPH-DRO Detected above Minimum Detectable Concentrations at CAS 09-23-02, U-9y Drilling Mud Disposal Crater

\begin{tabular}{|c|c|c|c|}
\hline \multirow{2}{*}{$\begin{array}{c}\text { Sample } \\
\text { Location }\end{array}$} & \multirow{2}{*}{$\begin{array}{l}\text { Sample } \\
\text { Number }\end{array}$} & \multirow{2}{*}{$\begin{array}{l}\text { Depth } \\
\text { (ft bgs) }\end{array}$} & \multirow{2}{*}{$\begin{array}{c}\text { Contaminants of Potential Concern }(\mathrm{mg} / \mathrm{kg}) \\
\text { Diesel-Range Organics }\end{array}$} \\
\hline & & & \\
\hline \multicolumn{3}{|c|}{ Preliminary Action Levels ${ }^{a}$} & 100 \\
\hline$\overline{\overline{\text { D01 }}}$ & 545D001 & $\overline{0.0-0.5}$ & 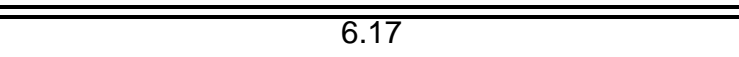 \\
\hline D02 & 545D002 & $0.0-0.5$ & 9.07 \\
\hline \multirow{2}{*}{ D03 } & 545D003 & $0.0-0.5$ & 11.4 \\
\hline & 545D017 & $1.5-2.0$ & $2.44(\mathrm{~J})$ \\
\hline \multirow{4}{*}{ D04 } & 545D004 & $0.0-0.5$ & 4.91 \\
\hline & 545D005 & $0.0-0.5$ & 5.65 \\
\hline & 545D006 & $0.5-1.0$ & 4.51 \\
\hline & 545D018 & $1.0-1.2$ & $1.65(\mathrm{~J})$ \\
\hline \multirow{3}{*}{ D06 } & 545D008 & $0.0-0.5$ & $1.6(\mathrm{~J})$ \\
\hline & 545D015 & $1.5-2.0$ & 5.76 \\
\hline & 545D016 & $3.0-3.5$ & $3.63(\mathrm{~J})$ \\
\hline
\end{tabular}

${ }^{a}$ Established in the CAIP for CAU 545 (NNSA/NSO, 2007).

bgs $=$ Below ground surface

CAIP = Corrective Action Investigation Plan

$\mathrm{ft}=$ Foot

$\mathrm{mg} / \mathrm{kg}=$ Milligrams per kilogram

$\mathrm{J}=$ Estimated value

\section{A.6.2.5 Gamma-Emitting Radionuclides}

Gamma-emitting radionuclide concentrations in environmental samples collected at this CAS that were detected above MDCs are presented in Table A.6-5. No gamma-emitting radionuclides were detected at concentrations exceeding the respective PALs. The FALs were established at the PAL concentrations.

\section{A.6.2.6 Plutonium, Strontium-90, and Uranium Isotopes}

Isotopic Pu and isotopic U concentrations in environmental samples collected at this CAS that were detected above MDCs are presented in Table A.6-6. No isotopic Pu, isotopic U, or Sr-90 were detected at concentrations exceeding the respective PALs. The FALs were established at the PAL concentrations. 
Table A.6-4

Soil Sample Results for RCRA Metals Detected above Minimum Detectable Concentrations at CAS 09-23-02, U-9y Drilling Mud Disposal Crater

\begin{tabular}{|c|c|c|c|c|c|c|c|c|c|}
\hline \multirow{2}{*}{ 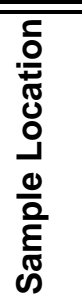 } & \multirow{2}{*}{ 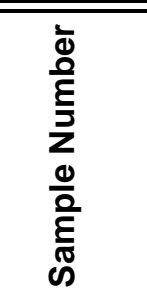 } & \multirow[b]{2}{*}{$\begin{array}{l}0 \\
0 \\
0 \\
\pm \\
5 \\
\vdots \\
0 \\
0\end{array}$} & \multicolumn{7}{|c|}{ Contaminants of Potential Concern (mg/kg) } \\
\hline & & & $\begin{array}{l}\frac{0}{2} \\
\frac{0}{d} \\
\frac{\omega}{\alpha}\end{array}$ & 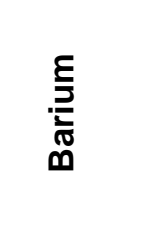 & $\frac{\underline{\Sigma}}{\frac{\Sigma}{\Sigma}}$ & 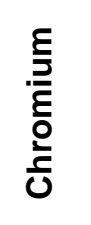 & ర్త్ర & 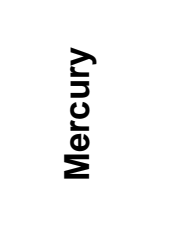 & 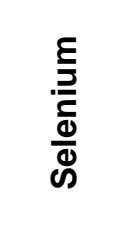 \\
\hline \multicolumn{3}{|c|}{ Final Action Levels } & $23^{a}$ & $67,000^{b}$ & $450^{b}$ & $450^{b}$ & $800^{b}$ & $310^{b}$ & $5,100^{b}$ \\
\hline \multirow{4}{*}{ D01 } & $2545 \mathrm{D001}$ & $0.0-0.5$ & $\overline{3.8}$ & $160(\mathrm{~J})$ & $0.2(\mathrm{~J}-)$ & $\overline{6.9}$ & $13.2(\mathrm{~J})$ & $0.029(\mathrm{~J})$ & $0.83(\mathrm{~J}-)$ \\
\hline & 545D009 & $0.5-1.0$ & 3.3 & $131(\mathrm{~J})$ & -- & 5.9 & 13.3 & $0.005(\mathrm{~J}-)$ & $0.89(\mathrm{~J}-)$ \\
\hline & $545 \mathrm{D} 010$ & $2.0-2.5$ & 3.8 & $130(\mathrm{~J})$ & -- & 5.7 & 13.6 & $0.013(\mathrm{~J}-)$ & $0.97(\mathrm{~J}-)$ \\
\hline & 545D011 & $4.0-4.5$ & 3.4 & $100(\mathrm{~J})$ & -- & 6.3 & 10 & $0.016(\mathrm{~J}-)$ & $0.68(\mathrm{~J}-)$ \\
\hline \multirow{3}{*}{ D02 } & 545D002 & $0.0-0.5$ & -- & $142(\mathrm{~J})$ & $0.12(\mathrm{~J}-)$ & 7.3 & $14.7(\mathrm{~J})$ & $0.025(\mathrm{~J})$ & $1.1(\mathrm{~J}-)$ \\
\hline & 545D013 & $2.0-2.5$ & 3.8 & $97.6(\mathrm{~J})$ & -- & 6.1 & 14.3 & $0.0066(\mathrm{~J}-)$ & $0.55(\mathrm{~J}-)$ \\
\hline & 545D014 & $3.0-3.5$ & 4.3 & $117(\mathrm{~J})$ & -- & 5.3 & 10.7 & $0.027(\mathrm{~J}-)$ & -- \\
\hline \multirow{2}{*}{ D03 } & 545D003 & $0.0-0.5$ & -- & $160(\mathrm{~J})$ & $0.14(\mathrm{~J}-)$ & 5.6 & $15.8(\mathrm{~J})$ & $0.014(\mathrm{~J}-)$ & $0.72(\mathrm{~J}-)$ \\
\hline & 545D017 & $1.5-2.0$ & 3.8 & $89(\mathrm{~J})$ & -- & 5.5 & $9.2(\mathrm{~J})$ & -- & $1.5(\mathrm{~J})$ \\
\hline \multirow{4}{*}{ D04 } & 545D004 & $0.0-0.5$ & -- & $120(\mathrm{~J})$ & $0.19(\mathrm{~J}-)$ & 7.6 & $12.7(\mathrm{~J})$ & $0.013(\mathrm{~J}-)$ & $1.1(\mathrm{~J}-)$ \\
\hline & 545D005 & $0.0-0.5$ & -- & $123(\mathrm{~J})$ & $0.17(\mathrm{~J}-)$ & 7 & $13.3(\mathrm{~J})$ & 0.014 (J-) & $0.65(\mathrm{~J}-)$ \\
\hline & 545D006 & $0.5-1.0$ & -- & $189(\mathrm{~J})$ & $0.17(\mathrm{~J}-)$ & 7.4 & $16.5(\mathrm{~J})$ & $0.013(\mathrm{~J}-)$ & $0.67(\mathrm{~J}-)$ \\
\hline & 545D018 & $1.0-1.17$ & 4.2 & $150(\mathrm{~J})$ & -- & 6.5 & $12(\mathrm{~J})$ & -- & 2 \\
\hline \multirow{2}{*}{ D05 } & 545D007 & $0.0-0.5$ & 3.3 & $138(\mathrm{~J})$ & $0.17(\mathrm{~J})$ & 5.9 & 9.7 & $0.013(\mathrm{~J}-)$ & $0.73(\mathrm{~J}+)$ \\
\hline & 545D012 & $1.5-2.0$ & 7.7 & $90.9(\mathrm{~J})$ & -- & 7.5 & 10.9 & $0.022(\mathrm{~J}-)$ & $1.4(\mathrm{~J}-)$ \\
\hline \multirow{3}{*}{ D06 } & 545D008 & $0.0-0.5$ & 3.2 & $157(\mathrm{~J})$ & $0.18(\mathrm{~J})$ & 5.2 & 11.8 & $0.024(\mathrm{~J}-)$ & $0.63(\mathrm{~J}+)$ \\
\hline & 545D015 & $1.5-2.0$ & 3.3 & $250(\mathrm{~J})$ & -- & 4.9 & $17.8(\mathrm{~J})$ & -- & 2 \\
\hline & 545D016 & $3.0-3.5$ & 4.8 & $110(\mathrm{~J})$ & -- & 7.4 & $13.9(\mathrm{~J})$ & $0.043(\mathrm{~J})$ & 2 \\
\hline
\end{tabular}

${ }^{a}$ Based on the background concentrations for metals. Background is considered the mean plus two times the standard deviation for sediment samples collected by the Nevada Bureau of Mines and Geology throughout the Nevada Test and Training Range (NBMG, 1998; Moore, 1999).

${ }^{\mathrm{b} B a s e d}$ on U.S. Environmental Protection Agency, Region 9 Preliminary Remediation Goals (PRGs) (EPA, 2004).

bgs $=$ Below ground surface

$\mathrm{ft}=$ Foot

$\mathrm{mg} / \mathrm{kg}=$ Milligrams per kilogram

$\mathrm{J}=$ Estimated value

$\mathrm{J}+=$ The result is an estimated quantity, but the result may be biased high.

$\mathrm{J}-=$ The result is an estimated quantity, but the result may be biased low.

-- = Not detected above minimum detectable concentrations. 
Table A.6-5

Soil Sample Results for Gamma-Emitting Radionuclides Detected above Minimum Detectable Concentrations at CAS 09-23-02, U-9y Drilling Mud Disposal Crater

\begin{tabular}{|c|c|c|c|c|c|c|c|c|}
\hline \multirow[b]{2}{*}{ 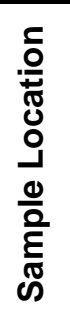 } & \multirow[b]{2}{*}{ 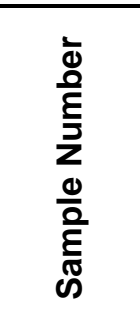 } & \multirow[b]{2}{*}{ 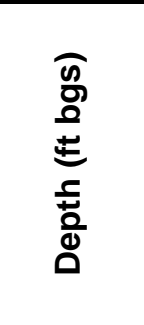 } & \multicolumn{6}{|c|}{ Contaminants of Potential Concern (pCi/g) } \\
\hline & & & 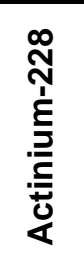 & 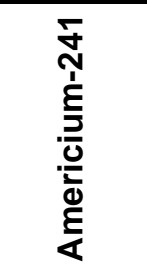 & 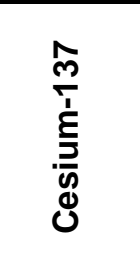 & 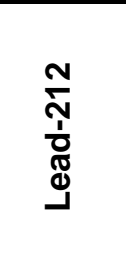 & 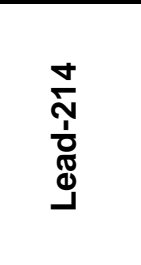 & 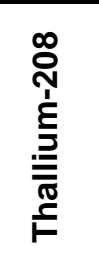 \\
\hline \multicolumn{3}{|c|}{ Final Action Levels } & $5^{\mathrm{a}}$ & $12.7^{b}$ & $12.2^{b}$ & $5^{a}$ & $5^{a}$ & $5^{a}$ \\
\hline \multirow{4}{*}{ D01 } & 545D001 & $0.0-0.5$ & $\overline{2.14}$ & $\overline{---}$ & $\overline{0.832}$ & $1.94(\mathrm{~J})$ & $1.22(\mathrm{~J})$ & 0.597 \\
\hline & $545 D 009$ & $0.5-1.0$ & 1.98 & $\overline{--}$ & 0.552 & $1.58(\mathrm{~J})$ & $1.08(\mathrm{~J})$ & 0.594 \\
\hline & $545 D 010$ & $2.0-2.5$ & 2.36 & -- & -- & 2.04 & 1.11 & 0.573 \\
\hline & 545D011 & $4.0-4.5$ & 1.76 & $\overline{--}$ & $\overline{--}$ & 2.07 & 1.65 & 0.723 \\
\hline \multirow{3}{*}{ D02 } & 545D002 & $0.0-0.5$ & 2.63 & 0.376 & 1.71 & 2.42 & 1.53 & 0.665 \\
\hline & $545 \mathrm{D} 013$ & $2.0-2.5$ & 1.99 & $\overline{--}$ & $\overline{--}$ & $1.87(\mathrm{~J})$ & $1.08(\mathrm{~J})$ & 0.654 \\
\hline & 545D014 & $3.0-3.5$ & 1.99 & -- & -- & 2.07 & 1.52 & 0.565 \\
\hline \multirow{2}{*}{ D03 } & 545D003 & $0.0-0.5$ & 1.17 & $0.376(\mathrm{~J})$ & 1.51 & $1.9(\mathrm{~J})$ & $1.33(\mathrm{~J})$ & 0.581 \\
\hline & 545D017 & $1.5-2.0$ & 1.95 & -- & 0.222 & 1.82 & 0.99 & 0.692 \\
\hline \multirow{4}{*}{ D04 } & 545D004 & $0.0-0.5$ & 2.09 & $0.308(\mathrm{~J})$ & 1.01 & $2.04(\mathrm{~J})$ & $1.09(\mathrm{~J})$ & 0.845 \\
\hline & 545D005 & $0.0-0.5$ & 2.21 & -- & 0.992 & $1.91(\mathrm{~J})$ & $1.22(\mathrm{~J})$ & 0.576 \\
\hline & 545D006 & $0.5-1.0$ & 2.58 & -- & 0.459 & 2.39 & 1.21 & 0.718 \\
\hline & 545D018 & $1.0-1.17$ & 1.87 & $\overline{--}$ & 0.518 & 2.11 & 1.4 & 0.759 \\
\hline \multirow{2}{*}{ D05 } & 545D007 & $0.0-0.5$ & 1.65 & -- & $0.324(\mathrm{~J})$ & $1.69(\mathrm{~J})$ & $0.992(\mathrm{~J})$ & 0.64 \\
\hline & 545D012 & $1.5-2.0$ & 1.82 & -- & 0.162 & $2.06(\mathrm{~J})$ & $1.05(\mathrm{~J})$ & 0.672 \\
\hline \multirow{3}{*}{ D06 } & 545D008 & $0.0-0.5$ & 1.85 & -- & $1.09(\mathrm{~J})$ & $1.92(\mathrm{~J})$ & $1.13(\mathrm{~J})$ & 0.706 \\
\hline & 545D015 & $1.5-2.0$ & 2.06 & -- & -- & 2.13 & 1.22 & 0.775 \\
\hline & 545D016 & $3.0-3.5$ & 2.16 & -- & -- & 2.37 & 1.6 & 0.818 \\
\hline
\end{tabular}

aTaken from the generic guidelines for residual concentrations of actinium-228, bismuth-214, lead-212, lead-214, thallium-208, and thorium-232, as found in Chapter IV of DOE Order 5400.5, Change 2, "Radiation Protection of the Public and Environment" (DOE, 1993). The PALs for these isotopes are specified as $5 \mathrm{pCi} / \mathrm{g}$ averaged over the first $15 \mathrm{~cm}$ of soil and $15 \mathrm{pCi} / \mathrm{g}$ for deeper soils (DOE, 1993). For purposes of this document, $15 \mathrm{~cm}$ is assumed to be equivalent to $0.5 \mathrm{ft}$ (6 inches); therefore, $5 \mathrm{pCi} / \mathrm{g}$ represents the PALs for these radionuclides in the surface soil (0 to $0.5 \mathrm{ft}$ depth).

${ }^{\mathrm{b}}$ Taken from the construction, commercial, industrial land-use scenario in Table 2.1 of the NCRP Report No. 129, Recommended Screening Limits for Contaminated Surface Soil and Review Factors Relevant to Site-Specific Studies (NCRP, 1999). The values provided in this source document were scaled to a 25-millirem-per-year dose.

bgs = Below ground surface

DOE $=$ U.S. Department of Energy

$\mathrm{ft}=$ Foot

$\mathrm{J}=$ Estimated value

-- = Not detected above minimum detectable concentrations.
NCRP = National Council on Radiation Protection and Measurements PAL = Preliminary action level $\mathrm{pCi} / \mathrm{g}=$ Picocuries per gram 
Table A.6-6

Soil Sample Results for Isotopes Detected above Minimum Detectable Concentrations at CAS 09-23-02, U-9y Drilling Mud Disposal Crater

\begin{tabular}{|c|c|c|c|c|c|c|c|}
\hline \multirow[b]{2}{*}{ 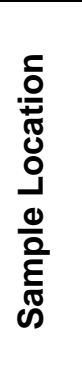 } & \multirow[b]{2}{*}{ 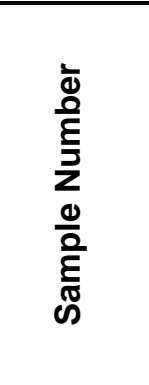 } & \multirow[b]{2}{*}{ 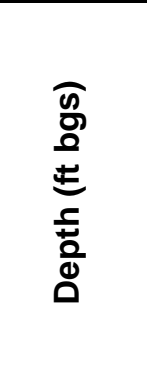 } & \multicolumn{5}{|c|}{ Contaminants of Potential Concern (pCi/g) } \\
\hline & & & 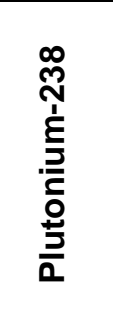 & 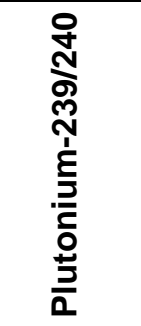 & 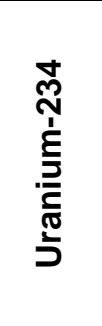 & 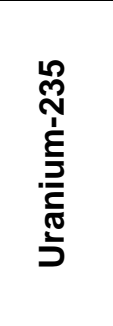 & 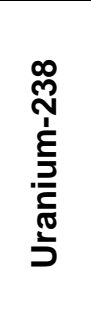 \\
\hline \multicolumn{3}{|c|}{ Final Action Levels ${ }^{a}$} & 13 & 12.7 & 143 & 17.6 & 105 \\
\hline \multirow{4}{*}{ D01 } & 545D001 & $0.0-0.5$ & -- & 0.122 & 1.1 & $\overline{--}$ & 1.04 \\
\hline & 545D009 & $0.5-1.0$ & -- & -- & 0.913 & -- & 0.734 \\
\hline & $545 \mathrm{D} 010$ & $2.0-2.5$ & -- & -- & 1.11 & -- & 1.39 \\
\hline & 545D011 & $4.0-4.5$ & -- & $0.78(\mathrm{~J})$ & 1.52 & 0.111 & 1.65 \\
\hline \multirow{3}{*}{ D02 } & 545D002 & $0.0-0.5$ & -- & 0.708 & 1.08 & -- & 0.935 \\
\hline & 545D013 & $2.0-2.5$ & -- & -- & 0.92 & -- & 0.838 \\
\hline & 545D014 & $3.0-3.5$ & -- & -- & 1.05 & -- & 1.17 \\
\hline \multirow{2}{*}{ D03 } & 545D003 & $0.0-0.5$ & -- & 1.38 & 1.08 & -- & 1.1 \\
\hline & 545D017 & $1.5-2.0$ & -- & - & 0.943 & -- & 0.792 \\
\hline \multirow{4}{*}{ D04 } & 545D004 & $0.0-0.5$ & 0.508 & 6.7 & 0.9 & -- & 0.786 \\
\hline & 545D005 & $0.0-0.5$ & -- & 7.3 & 0.75 & -- & 0.808 \\
\hline & 545D006 & $0.5-1.0$ & -- & 0.182 & 0.845 & -- & 0.824 \\
\hline & 545D018 & $1.0-1.17$ & -- & $0.653(\mathrm{~J})$ & 1.05 & 0.0928 & 0.928 \\
\hline \multirow{2}{*}{ D05 } & 545D007 & $0.0-0.5$ & -- & 0.0874 & 1.05 & -- & 1.13 \\
\hline & 545D012 & $1.5-2.0$ & 0.0618 & 1.45 & 0.798 & 0.0632 & 0.909 \\
\hline \multirow{3}{*}{ D06 } & 545D008 & $0.0-0.5$ & 0.0622 & 1.22 & 0.861 & -- & 1.1 \\
\hline & 545D015 & $1.5-2.0$ & -- & $1.13(\mathrm{~J})$ & 0.945 & -- & 0.882 \\
\hline & 545D016 & $3.0-3.5$ & -- & -- & 1.48 & 0.113 & 1.18 \\
\hline
\end{tabular}

aTaken from the construction, commercial, industrial land-use scenario in Table 2.1 of the NCRP Report No. 129, Recommended Screening Limits for Contaminated Surface Soil and Review Factors Relevant to Site-Specific Studies (NCRP, 1999). The values provided in this source document were scaled to a 25 -millirem-per-year dose.

bgs $=$ Below ground surface

$\mathrm{ft}=$ Foot

NCRP = National Council on Radiation Protection and Measurements

$\mathrm{pCi} / \mathrm{g}=$ Picocuries per gram

$\mathrm{J}=$ Estimated value

$--=$ Not detected above minimum detectable concentrations. 


\section{A.6.3 Nature and Extent of Contamination}

Based on the analytical results for soil samples collected within CAS 09-23-02, no COCs were identified at this CAS.

\section{A.6.4 Revised Conceptual Site Model}

The CAIP requirements were met at this CAS (NNSA/NSO, 2007), and no revisions were necessary to the CSM. 


\section{A.7.0 Corrective Action Site 20-19-01, Waste Disposal Site}

Corrective Action Site 20-19-01 is located northeast of the test hole for U-20p, and encompasses a debris pile that contains mostly construction rubble (i.e., plywood, two-by-fours). Several 55-gal drums that had been at the site were removed in 1991 under the scope of CAS 20-22-03. The remaining debris was placed under the scope of CAS 20-19-01. Additional detail is provided in the CAIP for CAU 545 (NNSA/NSO, 2007).

\section{A.7.1 Corrective Action Investigation}

A total of 11 characterization samples (including one FD) were collected during investigation activities at CAS 20-19-01. The sample locations are shown on Figure A.7-1. The sample locations, IDs, types, and analyses are listed in Table A.7-1. The specific CAI activities conducted to satisfy the CAIP requirements at this CAS (NNSA/NSO, 2007) are described in the following sections.

\section{A.7.1.1 Field Screening}

Investigation samples were field screened for alpha and beta/gamma radiation. The FSRs were compared to FSLs to guide subsequent sampling decisions where appropriate. Gross alpha radiation FSLs was exceeded in one sample, and the beta/gamma radiation FSL was not exceeded at CAS 20-19-01. The sample exceeding the FSL was analyzed.

\section{A.7.1.2 Radiological Survey}

A radiological walkover survey was conducted over CAS 20-19-01. No areas of elevated radiological readings were found. The radiological survey was not used in the selection of sample locations. (Figure A.7-2).

\section{A.7.1.3 Visual Inspections}

Debris assumed to be related to the test conducted at U-20p was scattered throughout the site. Sample locations were established beneath the following visible materials: two locations at used oil filter(s), one location at a canister containing a greasy substance, two locations within the dried drilling mud spill that entered the site from the south, one location along the western edge where the soil was discolored yellowish tan and contained white flakes, one location at a small pile of what appeared to 


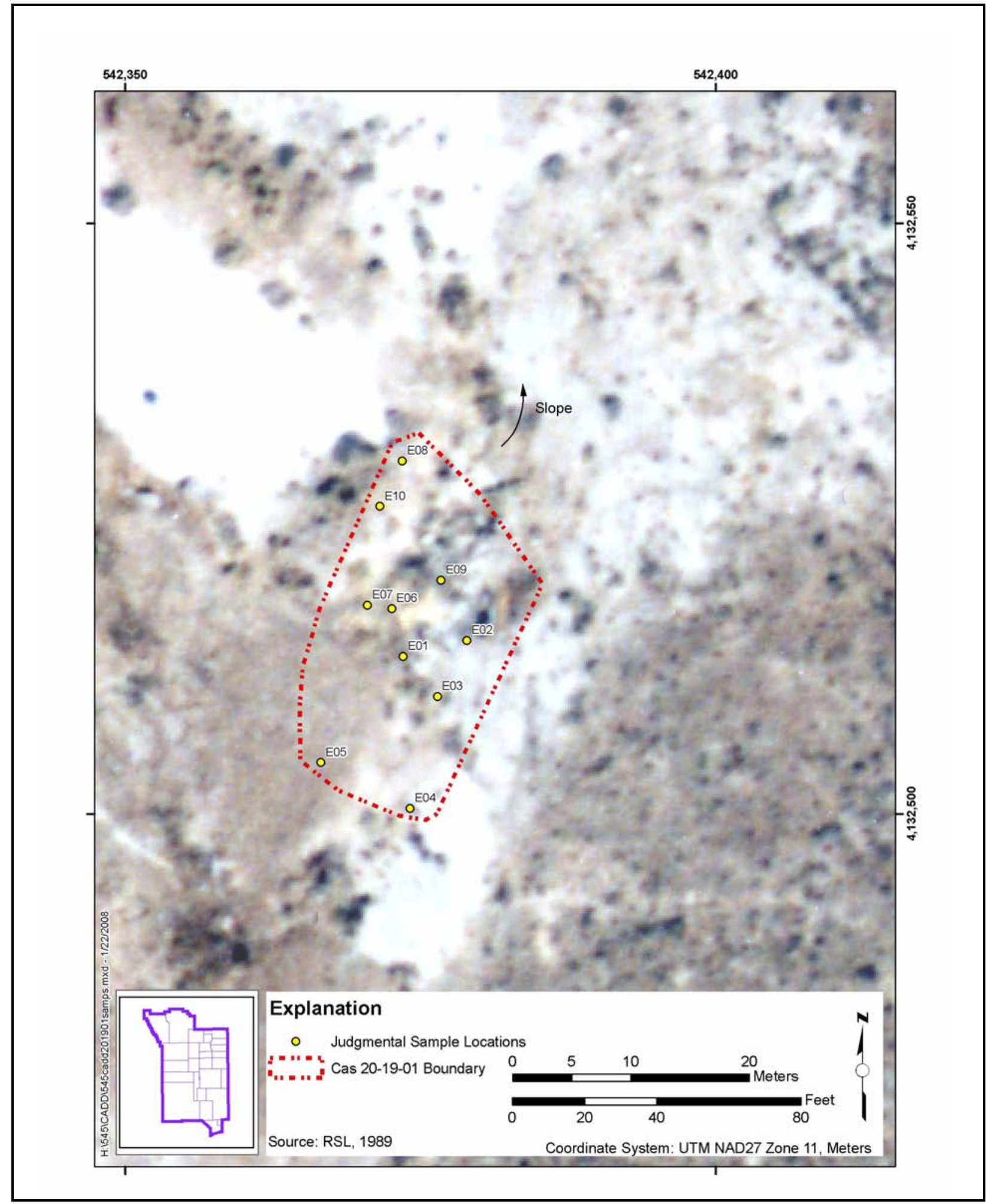

Figure A.7-1

Sample Locations at CAS 20-19-01, Waste Disposal Site 
Table A.7-1

Samples Collected at CAS 20-19-01, Waste Disposal Site

\begin{tabular}{|c|c|c|c|c|c|}
\hline $\begin{array}{c}\text { Sample } \\
\text { Location }\end{array}$ & $\begin{array}{c}\text { Sample } \\
\text { Number }\end{array}$ & $\begin{array}{l}\text { Depth } \\
\text { (ft bgs) }\end{array}$ & Matrix & Purpose & Analyses \\
\hline$\overline{E 01}$ & 545E001 & $0.0-0.5$ & Soll & "Environmental & $\overline{\text { Set } 3}$ \\
\hline E02 & 545E002 & $0.0-0.5$ & Soil & Environmental & Set 3 \\
\hline E03 & 545E003 & $0.0-0.5$ & Soil & Environmental, Full Lab QC & Set 3 \\
\hline E04 & 545E004 & $0.0-0.5$ & Soil & Environmental & Set 3 \\
\hline E05 & 545E005 & $0.0-0.5$ & Soil & Environmental & Set 3 \\
\hline E06 & 545E006 & $0.0-0.5$ & Soil & Environmental & Set 3 \\
\hline E07 & 545E007 & $0.0-0.5$ & Soil & Environmental & Set 3 \\
\hline E08 & 545E008 & $0.0-0.5$ & Soil & Environmental & Set 3 \\
\hline \multirow{2}{*}{ E09 } & 545E009 & $0.0-0.5$ & Soil & Environmental & Set 3 \\
\hline & 545E010 & $0.0-0.5$ & Soil & Field Duplicate of \#545E009 & Set 3 \\
\hline E10 & 545E011 & $0.0-0.5$ & Soil & Environmental & Set 3 \\
\hline $\bar{N} / \mathrm{A}$ & 545E301 & $\mathrm{N} / \mathrm{A}$ & Water & Trip Blank & VOCs \\
\hline $\bar{N} / \mathrm{A}$ & 545E302 & $\bar{N} / \mathrm{A}$ & Water & Trip Blank & VOCs \\
\hline $\mathrm{N} / \mathrm{A}$ & 545E303 & $\mathrm{NA}$ & Water & Field Blank & Set 3 \\
\hline
\end{tabular}

Set 3 = VOCs, SVOCs, TPH-DRO, PCBs, RCRA Metals, Gamma Spectroscopy, Isotopic Uranium, Isotopic Plutonium, Strontium-90

DRO = Diesel-range organics

$\mathrm{ft}=$ Feet below ground surface

$\mathrm{N} / \mathrm{A}=$ Not applicable

$\mathrm{PCB}=$ Polychlorinated biphenyl

\author{
$\mathrm{QC}=$ Quality control \\ RCRA = Resource Conservation and Recovery Act \\ SVOC $=$ Semivolatile organic compound \\ $\mathrm{TPH}=$ Total petroleum hydrocarbons
}

be corroded capacitors or batteries (slightly larger than D-cell size), one location within scattered photograph processing/fixing supplies, one location that was comprised of fine, whitish soil of a lower density than the native soil; and one location that appeared to be stained a darker shade of tan, and that was adjacent to a yellow, solidified mass in the shape of a small (approximately 30-gal) drum. An overall photograph of the debris at the site is shown in Figure A.7-3.

\section{A.7.1.4 Sample Collection}

Decision I environmental sampling activities included the collection of biased surface soil samples at potentially hazardous-containing materials (Figure A.7-1).

Environmental samples were collected from the soil containing the biasing factor (e.g., stained soil, drilling mud spill, oil stains). Sample 545E001 at location E01 was collected from the surface interval ( 0.0 to $0.5 \mathrm{ft}$ bgs) that was impacted by release of used motor oil from several oil filters. The soil beneath this interval did not appear impacted by the oil. Sample 545E002 at location E02 was collected from the surface interval ( 0.0 to $0.5 \mathrm{ft}$ bgs) that was impacted by release of used motor oil 


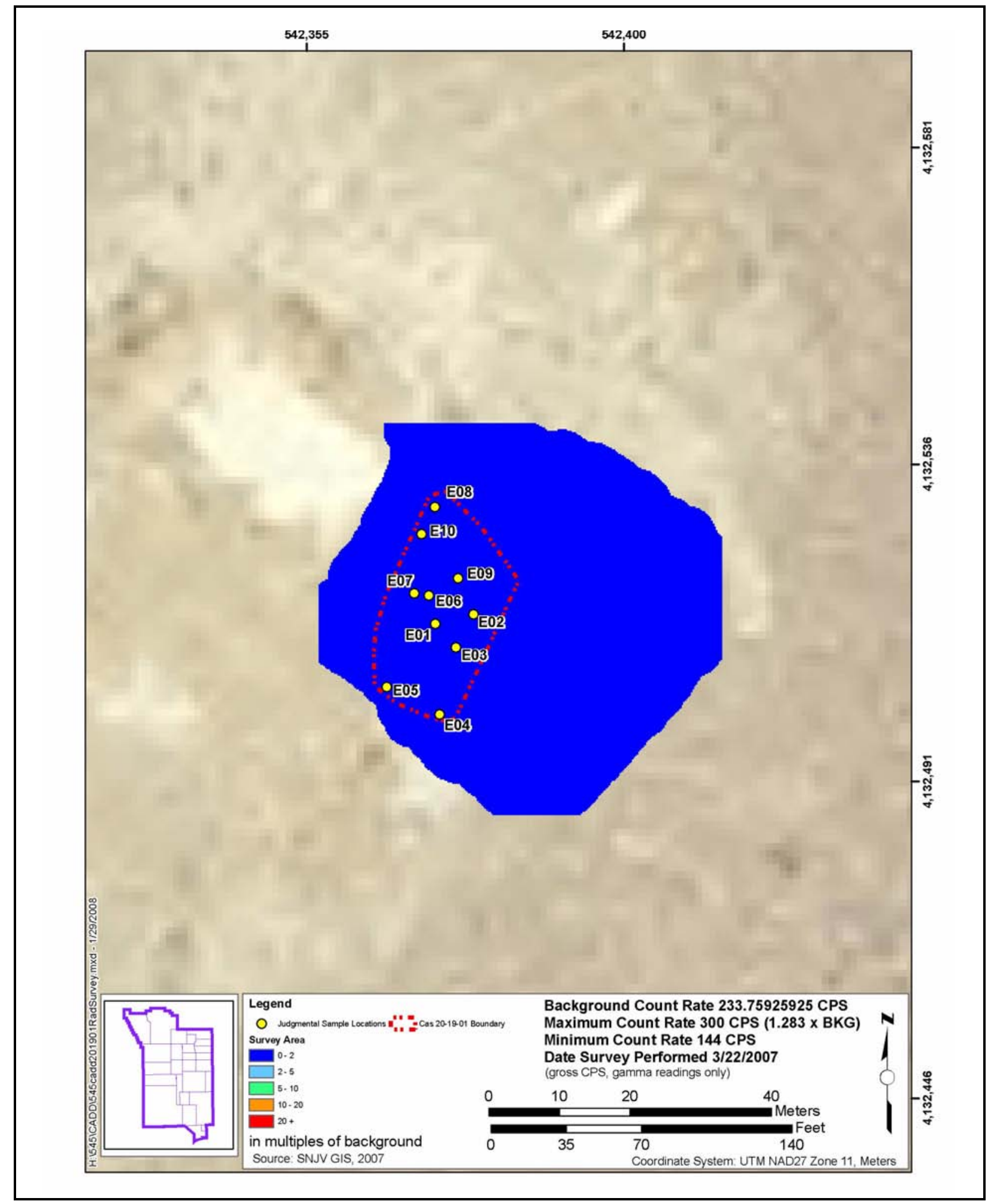

Figure A.7-2

Radiological Survey for CAS 20-19-01 


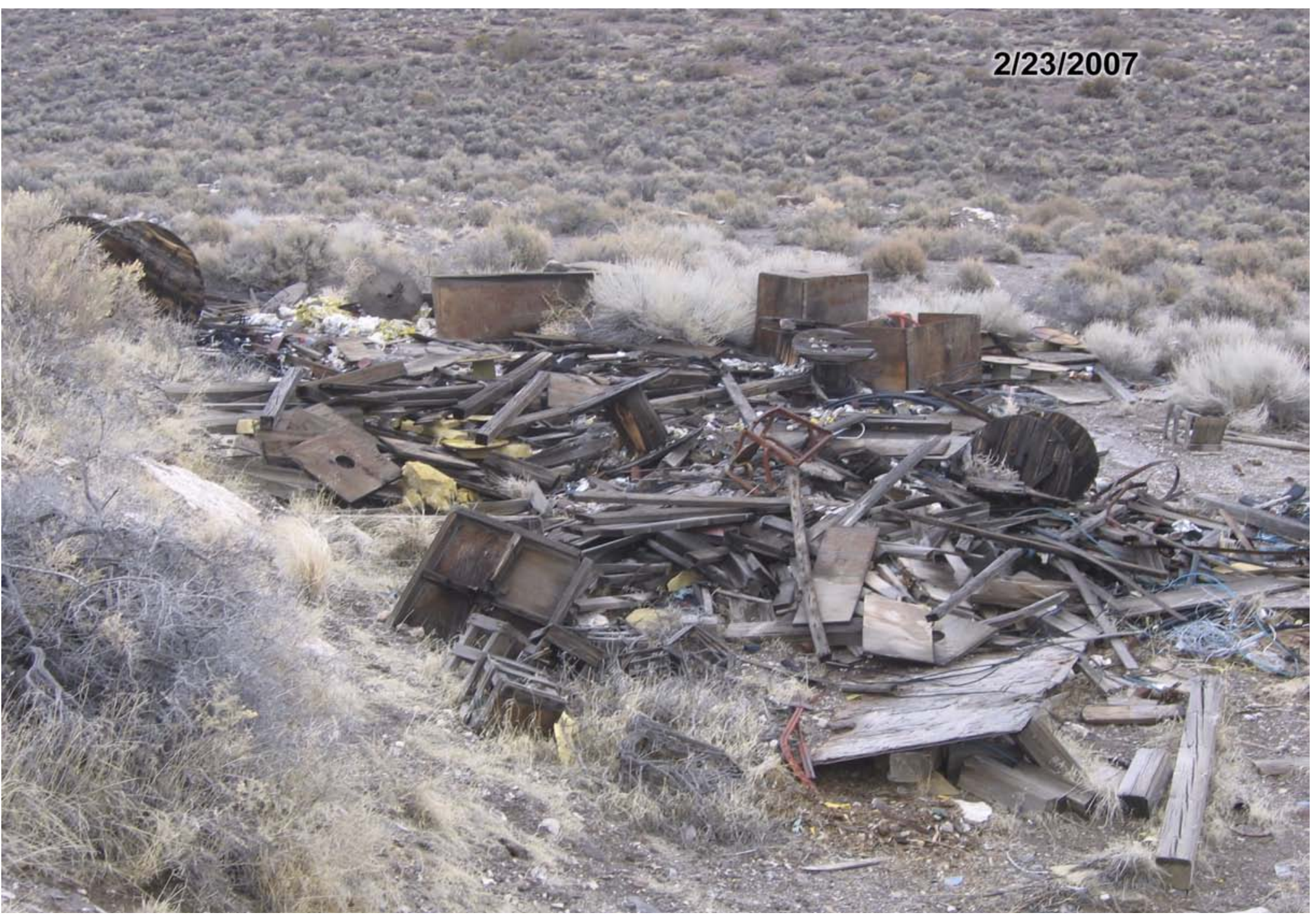

Figure A.7-3

Overall View of Debris at CAS 20-19-01

\section{UNCONTROLLED When Printed}


from a single oil filter. The soil beneath this interval also did not appear impacted by the oil. Sample 545E003 at location E03 was collected from the surface interval (0.0 to $0.5 \mathrm{ft}$ bgs) that was impacted by a spill of drilling mud that entered the site along the southern side. The layer of drilling mud was approximately 1 in. thick and did not appear to impact the underlying soil. Sample 545E004 at location E04 was also collected from the surface interval (0.0 to $0.5 \mathrm{ft}$ bgs) impacted by the release of drilling mud. The layer of drilling mud at this location was approximately 3 in. thick, and also did not appear to impact the underlying soil.

Sample 545E005 at location E05 was collected at the southwest extent of the debris, from the surface interval ( 0.0 to $0.5 \mathrm{ft}$ bgs), beneath a canister in which grease had seeped from a connection. The soil directly beneath this canister was impacted by the grease, but the impact was not visible below $0.5 \mathrm{ft}$ bgs. Sample 545E006 at location E06 was collected from the surface interval (0.0 to $0.5 \mathrm{ft}$ bgs) from soil which had a yellowish hue and contained white flecks of an unknown material. Neither the yellow hue nor the white flecks extended below this interval. Sample 545E007 at location E07 was collected from the surface interval ( 0.0 to $0.5 \mathrm{ft}$ bgs) and impacted by corroded capacitors or batteries. The impact from these materials did not appear to extend below this interval.

Sample 545E008 at location E08 was collected from 0.0 to $0.5 \mathrm{ft}$ bgs in an area impacted by photographic materials. The impact from these materials did not appear to extend below this interval. Samples 545E009 and duplicate 545E010 at location E09 were collected from 0.0 to $0.5 \mathrm{ft}$ bgs in an area of light-hued, loose, low-density material mixed in with soil. The impact of this material was limited to the surface. Sample 545E011 at location E10 was collected from 0.0 to $0.5 \mathrm{ft}$ bgs in an area of stained soil that was adjacent to a yellow, solidified mass in the shape of a small (approximately 30-gal) drum. The soil beneath this interval did not appear to be this darker hue.

\section{A.7.1.5 Deviations}

Investigation samples were collected as outlined in the CAIP for CAU 545 (NNSA/NSO, 2007) and submitted for laboratory analysis. There were no deviations from the planned sampling.

\section{A.7.2 Investigation Results}

The following sections provide analytical results from the samples collected to complete investigation activities as outlined in the CAIP for CAU 545 (NNSA/NSO, 2007). Investigation 
samples were analyzed for the CAIP-specified COPCs, which included VOCs, SVOCs, TPH-DRO, RCRA metals, PCBs, gamma-emitting radionuclides, isotopic Pu, Sr-90, and isotopic U. The analytical parameters and laboratory methods used to analyze the investigation samples are listed in Table A.2-2. Table A.7-1 lists the sample-specific analytical suite for CAS 20-19-01.

Analytical results from the soil samples with concentrations exceeding MDCs are summarized in the following sections. An evaluation was conducted on all contaminants detected above MDCs by comparing individual concentration or activity results against the FALs. Establishment of the FALs is presented in Appendix C. The FALs were established as the corresponding PAL concentrations or activities if the contaminant concentrations were below their respective PALs.

\section{A.7.2.1 Volatile Organic Compounds}

Analytical results for VOC environmental samples collected at this CAS that were detected above MDCs are presented in Table A.7-2. No VOCs were detected at concentrations exceeding their respective PALs. The FALs were established at the PAL concentrations.

\section{A.7.2.2 Semivolatile Organic Compounds}

Analytical results for SVOC environmental samples collected at this CAS that were detected above MDCs are presented in Table A.7-3. No SVOCs were detected at concentrations exceeding the respective PALs. The FALs were established at the PAL concentrations.

\section{A.7.2.3 Total Petroleum Hydrocarbons}

The TPH-DRO analytical results for soil samples collected at this CAS that were detected above MDCs are presented in Table A.7-4. Two surface samples exceeded the PAL of $100 \mathrm{mg} / \mathrm{kg}$ for TPH-DRO. The TPH-DRO was moved on to a Tier 2 evaluation and FALs were established for the hazardous constituents of TPH-DRO. Concentrations of the hazardous constituents of TPH-DRO did not exceed FALs. Therefore, TPH-DRO is not considered a COC. The calculation of FALs for the hazardous constituents of TPH-DRO are presented in Appendix C. 
Table A.7-2

Soil Sample Results for Total VOCs Detected above Minimum Detectable Concentrations at CAS 20-19-01, Waste Disposal Site

\begin{tabular}{|c|c|c|c|c|c|c|c|c|c|}
\hline \multirow[b]{2}{*}{$\begin{array}{c}\text { Sample } \\
\text { Location }\end{array}$} & \multirow[b]{2}{*}{$\begin{array}{l}\text { Sample } \\
\text { Number }\end{array}$} & \multirow[b]{2}{*}{$\begin{array}{c}\text { Depth } \\
\text { (ft bgs) }\end{array}$} & \multicolumn{7}{|c|}{ Contaminants of Potential Concern (mg/kg) } \\
\hline & & & 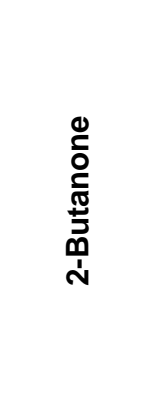 & 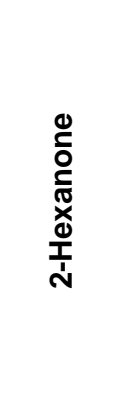 & 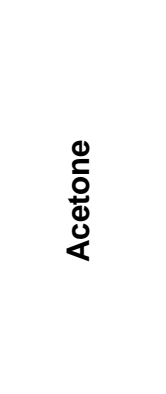 & 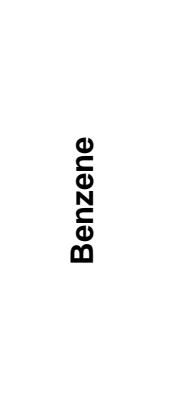 & 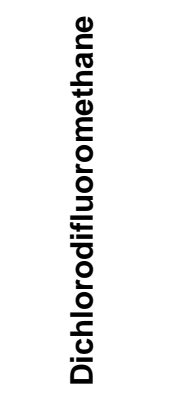 & 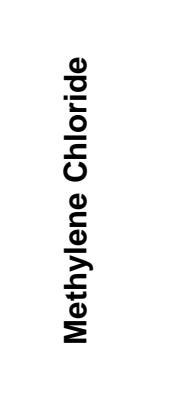 & 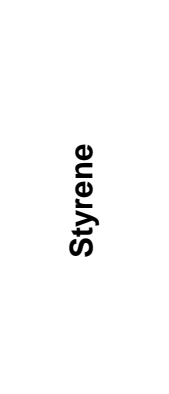 \\
\hline \multicolumn{3}{|c|}{ Final Action Levels ${ }^{a}$} & 110,000 & 110,000 & 54,000 & 1.4 & 310 & 21 & 1,700 \\
\hline E01 & 545E001 & $0.0-0.5$ & $0.00322(\mathrm{~J})$ & -- & 0.0555 & -- & -- & $0.00338(\mathrm{~J})$ & $0.000229(\mathrm{~J})$ \\
\hline E03 & 545E003 & $0.0-0.5$ & -- & -- & -- & -- & -- & 0.00557 & $0.000406(\mathrm{~J})$ \\
\hline E04 & 545E004 & $0.0-0.5$ & -- & -- & -- & -- & 0.00139 & 0.00572 & $0.000209(\mathrm{~J})$ \\
\hline E05 & 545E005 & $0.0-0.5$ & 0.0142 & 0.00935 & 0.0313 & -- & -- & 0.0103 & $0.00049(\mathrm{~J})$ \\
\hline E06 & 545E006 & $0.0-0.5$ & $0.00214(\mathrm{~J})$ & -- & $0.00309(\mathrm{~J})$ & $0.000429(\mathrm{~J})$ & -- & 0.00674 & $0.000315(\mathrm{~J})$ \\
\hline E07 & 545E007 & $0.0-0.5$ & -- & -- & -- & -- & -- & 0.00817 & $0.00028(\mathrm{~J})$ \\
\hline E08 & 545E008 & $0.0-0.5$ & 0.00604 & -- & 0.408 & $0.00041(\mathrm{~J})$ & -- & -- & -- \\
\hline \multirow{2}{*}{ E09 } & 545E009 & $0.0-0.5$ & $0.00416(\mathrm{~J})$ & -- & 0.0173 & -- & 0.00215 & $0.005(\mathrm{~J})$ & -- \\
\hline & 545E010 & $0.0-0.5$ & -- & -- & $0.00358(\mathrm{~J})$ & -- & 0.00205 & $0.00509(\mathrm{~J})$ & -- \\
\hline E10 & 545E011 & $0.0-0.5$ & $0.00231(\mathrm{~J})$ & -- & -- & $0.000375(\mathrm{~J})$ & $0.000803(\mathrm{~J})$ & -- & $0.000276(\mathrm{~J})$ \\
\hline
\end{tabular}

aBased on U.S. Environmental Protection Agency, Region 9 Preliminary Remediation Goals (PRGs) (EPA, 2004).

\footnotetext{
bgs $=$ Below ground surface

$\mathrm{ft}=$ Foot

$\mathrm{mg} / \mathrm{kg}=$ Milligrams per kilogram

$\mathrm{J}=$ Estimated value

-- = Not detected above minimum detectable concentrations.
} 
Table A.7-3

Soil Sample Results for Total SVOCs Detected above Minimum Detectable Concentrations at CAS 20-19-01, Waste Disposal Site

\begin{tabular}{|c|c|c|c|c|c|c|c|}
\hline \multirow[b]{2}{*}{$\begin{array}{l}\text { Sample } \\
\text { Location }\end{array}$} & \multirow[b]{2}{*}{$\begin{array}{l}\text { Sample } \\
\text { Number }\end{array}$} & \multirow[b]{2}{*}{$\begin{array}{c}\text { Depth } \\
\text { (ft bgs) }\end{array}$} & \multicolumn{5}{|c|}{ Contaminants of Potential Concern (mg/kg) } \\
\hline & & & $\begin{array}{l}\frac{0}{0} \\
\frac{8}{4} \\
.0 \\
\frac{0}{0} \\
\frac{1}{d} \\
0 \\
0\end{array}$ & 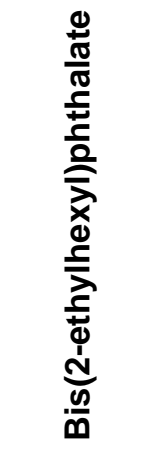 & 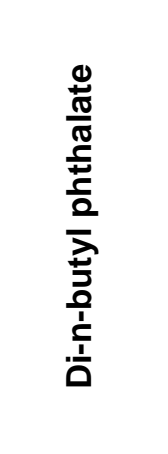 & 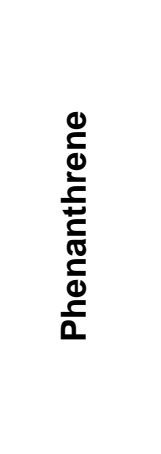 & $\begin{array}{l}\overline{0} \\
\frac{\grave{d}}{0} \\
\frac{\bar{\alpha}}{\alpha}\end{array}$ \\
\hline \multicolumn{3}{|c|}{ Final Action Levels ${ }^{a}$} & 100,000 & 120 & 62,000 & 100,000 & 100,000 \\
\hline$\overline{\mathrm{E} 01}$ & 545E001 & $0.0-0.5$ & $\overline{1.1 .1}$ & $\overline{0.13(\mathrm{~J})}$ & $\overline{0.0906(\mathrm{~J})}$ & $\overline{---}$ & $0.0741(\mathrm{~J})$ \\
\hline E02 & 545E002 & $0.0-0.5$ & $\overline{--}$ & -- & 0.936 & -- & -- \\
\hline E05 & 545E005 & $0.0-0.5$ & -- & $0.0767(\mathrm{~J})$ & -- & $\overline{--}$ & -- \\
\hline E06 & 545E006 & $0.0-0.5$ & 8.53 & -- & $0.107(\mathrm{~J})$ & $0.0157(\mathrm{~J})$ & 0.358 \\
\hline E07 & 545E007 & $0.0-0.5$ & 41.3 & -- & -- & -- & $\overline{--}$ \\
\hline E08 & 545E008 & $0.0-0.5$ & 15.2 & 3.99 & -- & -- & -- \\
\hline \multirow{2}{*}{ E09 } & 545E009 & $0.0-0.5$ & 0.81 & $\overline{--}$ & $0.0405(\mathrm{~J})$ & - & $\overline{--}$ \\
\hline & 545E010 & $0.0-0.5$ & 0.821 & $0.0949(\mathrm{~J})$ & -- & -- & -- \\
\hline E10 & 545E011 & $0.0-0.5$ & 7.2 & -- & $0.0838(\mathrm{~J})$ & $0.0134(\mathrm{~J})$ & $0.286(\mathrm{~J})$ \\
\hline
\end{tabular}

aBased on U.S. Environmental Protection Agency, Region 9 Preliminary Remediation Goals (PRGs) (EPA, 2004).

bgs = Below ground surface

$\mathrm{ft}=$ Foot

$\mathrm{mg} / \mathrm{kg}=$ Milligrams per kilogram

$\mathrm{J}=$ Estimated value

-- = Not detected above minimum detectable concentrations. 
Table A.7-4

Soil Sample Results for TPH-DRO Detected above Minimum Detectable Concentrations at CAS 20-19-01, Waste Disposal Site

\begin{tabular}{|c|c|c|c|}
\hline \multirow{2}{*}{$\begin{array}{l}\text { Sample } \\
\text { Location }\end{array}$} & \multirow{2}{*}{$\begin{array}{l}\text { Sample } \\
\text { Number }\end{array}$} & \multirow{2}{*}{$\begin{array}{l}\text { Depth } \\
\text { (ft bgs) }\end{array}$} & \multirow{2}{*}{$\frac{\text { Contaminants of Potential Concern }(\mathrm{mg} / \mathrm{kg})}{\text { Diesel-Range Organics }}$} \\
\hline & & & \\
\hline \multicolumn{3}{|c|}{ Preliminary Action Levels ${ }^{\mathrm{a}}$} & 100 \\
\hline E01 & 545E001 & $0.0-0.5$ & 51.3 \\
\hline E02 & 545E002 & $0.0-0.5$ & 35.2 \\
\hline E03 & 545E003 & $0.0-0.5$ & 16.9 \\
\hline E04 & 545E004 & $0.0-0.5$ & 4.1 \\
\hline E05 & 545E005 & $0.0-0.5$ & 88.2 \\
\hline E06 & 545E006 & $0.0-0.5$ & 93.7 \\
\hline E07 & 545E007 & $0.0-0.5$ & 157 \\
\hline E08 & 545E008 & $0.0-0.5$ & 123 \\
\hline \multirow{2}{*}{ E09 } & 545E009 & $0.0-0.5$ & 49.1 \\
\hline & 545E010 & $0.0-0.5$ & 24.3 \\
\hline E10 & 545E011 & $0.0-0.5$ & 63.4 \\
\hline
\end{tabular}

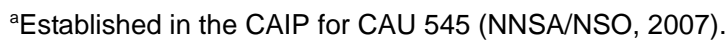

bgs $=$ Below ground surface

CAIP = Corrective Action Investigation Plan

$\mathrm{ft}=$ Foot

$\mathrm{mg} / \mathrm{kg}=$ Milligrams per kilogram

\section{A.7.2.4 RCRA Metals}

The RCRA metals analytical results for environmental samples collected at this CAS that were detected above MDCs are presented in Table A.7-5. No results exceeded the FALs. The FALs were established at the PAL concentrations.

\section{A.7.2.5 Polychlorinated Biphenyls}

The PCBs detected above MDCs are presented in Table A.7-6. No PCBs were detected at concentrations exceeding the PAL. The FAL was established at the PAL concentration. 
Table A.7-5

Soil Sample Results for RCRA Metals Detected above Minimum Detectable Concentrations at CAS 20-19-01, Waste Disposal Site

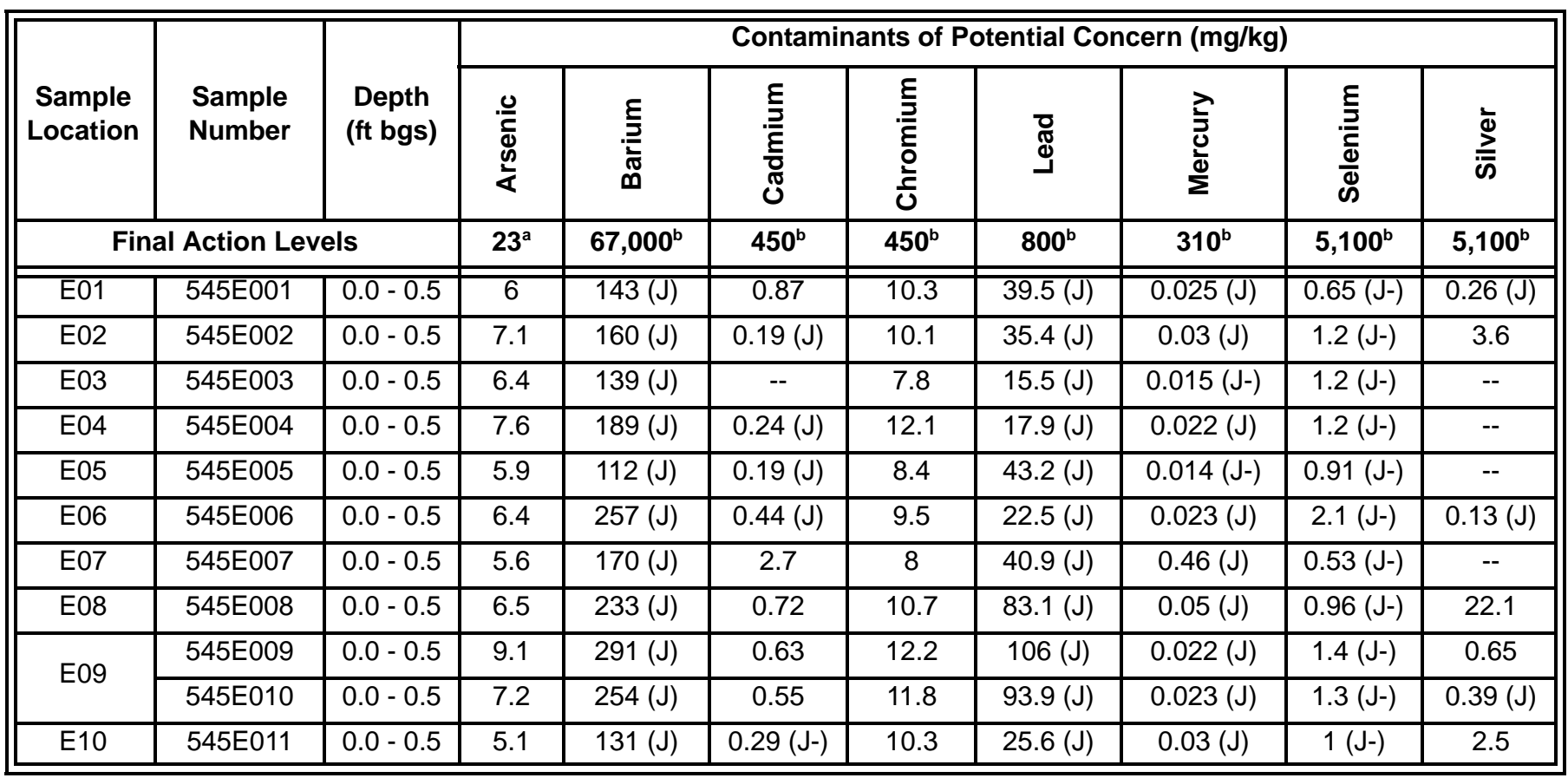

${ }^{a}$ Based on the background concentrations for metals. Background is considered the mean plus two times the standard deviation for sediment samples collected by the Nevada Bureau of Mines and Geology throughout the Nevada Test and Training Range (NBMG, 1998; Moore, 1999).

${ }^{\mathrm{b} B a s e d}$ on U.S. Environmental Protection Agency, Region 9 Preliminary Remediation Goals (PRGs) (EPA, 2004).

bgs $=$ Below ground surface

$\mathrm{ft}=$ Foot

$\mathrm{mg} / \mathrm{kg}=$ Milligrams per kilogram

$\mathrm{J}=$ Estimated value

$\mathrm{J}-=$ The result is an estimated quantity, but the result may be biased low.

-- = Not detected above minimum detectable concentrations. 
Table A.7-6

Soil Sample Results for PCBs Detected above Minimum Detectable Concentrations at CAS 20-19-01, Waste Disposal Site

\begin{tabular}{|c|c|c|c|c|}
\hline \multirow{2}{*}{$\begin{array}{l}\text { Sample } \\
\text { Location }\end{array}$} & \multirow{2}{*}{$\begin{array}{l}\text { Sample } \\
\text { Number }\end{array}$} & \multirow{2}{*}{$\begin{array}{c}\text { Depth } \\
\text { (ft bgs) }\end{array}$} & \multicolumn{2}{|c|}{ Contaminants of Potential Concern (mg/kg) } \\
\hline & & & Aroclor 1254 & Aroclor 1268 \\
\hline \multicolumn{3}{|c|}{ Final Action Levels ${ }^{a}$} & 0.74 & 0.74 \\
\hline E02 & 545E002 & $0.0-0.5$ & $0.0066(\mathrm{~J})$ & -- \\
\hline E06 & 545E006 & $0.0-0.5$ & -- & 0.0437 \\
\hline
\end{tabular}

a'Based on U.S. Environmental Protection Agency, Region 9 Preliminary Remediation Goals (PRGs) (EPA, 2004).

bgs $=$ Below ground surface

$\mathrm{ft}=$ Foot

$\mathrm{mg} / \mathrm{kg}=$ Milligrams per kilogram

$\mathrm{J}=$ Estimated value

-- = Not detected above minimum detectable concentrations.

\section{A.7.2.6 Gamma-Emitting Radionuclides}

Gamma-emitting radionuclide concentrations in environmental samples collected at this CAS that were detected above MDCs are presented in Table A.7-7. No gamma-emitting radionuclides were detected at concentrations exceeding the respective PALs. The FALs were established at the PAL concentrations.

\section{A.7.2.7 Plutonium and Uranium Isotopes}

Isotopic Pu and isotopic U concentrations in environmental samples collected at this CAS that were detected above MDCs are presented in Table A.7-8. No isotopic Pu or isotopic U exceeded the PALs. The FALs were established at the PAL concentrations.

\section{A.7.3 Nature and Extent of Contamination}

Based on the analytical results for soil samples collected within CAS 20-19-01, no COCs were identified at this CAS.

\section{A.7.4 Revised Conceptual Site Model}

The CAIP requirements (NNSA/NSO, 2007) were met at this CAS, and no revisions were necessary to the CSM. 
Table A.7-7

Soil Sample Results for Gamma-Emitting Radionuclides Detected above Minimum Detectable Concentrations at CAS 20-19-01, Waste Disposal Site

\begin{tabular}{|c|c|c|c|c|c|c|c|c|}
\hline \multirow[b]{2}{*}{$\begin{array}{l}\text { Sample } \\
\text { Location }\end{array}$} & \multirow[b]{2}{*}{$\begin{array}{l}\text { Sample } \\
\text { Number }\end{array}$} & \multirow[b]{2}{*}{$\begin{array}{l}\text { Depth } \\
\text { (ft bgs) }\end{array}$} & \multicolumn{6}{|c|}{ Contaminants of Potential Concern (pCi/g) } \\
\hline & & & 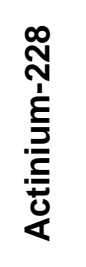 & 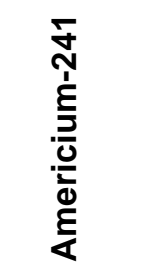 & 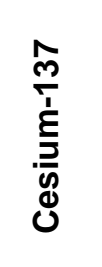 & 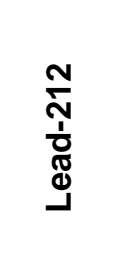 & 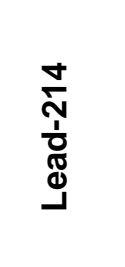 & 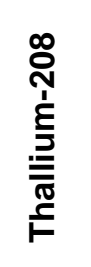 \\
\hline \multicolumn{3}{|c|}{ Final Action Levels } & $5^{a}$ & $12.7^{b}$ & $12.2^{b}$ & $5^{a}$ & $5^{a}$ & $5^{a}$ \\
\hline E01 & 545E001 & $0.0-0.5$ & 1.83 & $0.676(\mathrm{~J})$ & 0.662 & $1.86(\mathrm{~J})$ & $1.8(\mathrm{~J})$ & 0.561 \\
\hline E02 & 545E002 & $0.0-0.5$ & 2.01 & 1.19 & 1 & 1.95 & 1.55 & 0.639 \\
\hline E03 & 545E003 & $0.0-0.5$ & 1.9 & $0.885(\mathrm{~J})$ & 0.655 & $1.79(\mathrm{~J})$ & $1.54(\mathrm{~J})$ & 0.55 \\
\hline E04 & 545E004 & $0.0-0.5$ & 1.85 & -- & -- & $1.89(\mathrm{~J})$ & $1.69(\mathrm{~J})$ & 0.627 \\
\hline E05 & 545E005 & $0.0-0.5$ & 2.33 & -- & -- & 2.18 & 1.65 & 0.634 \\
\hline E06 & 545E006 & $0.0-0.5$ & 1.68 & -- & -- & 1.7 & 1.01 & 0.489 \\
\hline E07 & 545E007 & $0.0-0.5$ & 1.85 & -- & 0.542 & 1.73 & 1.48 & 0.504 \\
\hline E08 & 545E008 & $0.0-0.5$ & 1.79 & 0.466 & 0.415 & 1.69 & 1.45 & 0.574 \\
\hline \multirow{2}{*}{ E09 } & 545E009 & $0.0-0.5$ & 1.76 & 0.568 & 0.567 & 2.3 & 2.07 & 0.778 \\
\hline & 545E010 & $0.0-0.5$ & 1.57 & -- & 0.507 & 1.87 & 2.09 & 0.552 \\
\hline E10 & 545E011 & $0.0-0.5$ & 1.99 & -- & 0.386 & 2.02 & 1.45 & 0.76 \\
\hline
\end{tabular}

aTaken from the generic guidelines for residual concentrations of actinium-228, bismuth-214, lead-212, lead-214, thallium-208, and thorium-232, as found in Chapter IV of DOE Order 5400.5, Change 2, "Radiation Protection of the Public and Environment" (DOE, 1993). The PALs for these isotopes are specified as $5 \mathrm{pCi} / \mathrm{g}$ averaged over the first $15 \mathrm{~cm}$ of soil and $15 \mathrm{pCi} / \mathrm{g}$ for deeper soils (DOE, 1993). For purposes of this document, $15 \mathrm{~cm}$ is assumed to be equivalent to $0.5 \mathrm{ft}$ (6 inches); therefore, $5 \mathrm{pCi} / \mathrm{g}$ represents the PALs for these radionuclides in the surface soil ( 0 to $0.5 \mathrm{ft}$ depth).

${ }^{\mathrm{b}}$ Taken from the construction, commercial, industrial land-use scenario in Table 2.1 of the NCRP Report No. 129, Recommended Screening Limits for Contaminated Surface Soil and Review Factors Relevant to Site-Specific Studies (NCRP, 1999). The values provided in this source document were scaled to a 25-millirem-per-year dose.

bgs $=$ Below ground surface

$\mathrm{cm}=$ Centimeter

DOE $=$ U.S. Department of Energy

$\mathrm{ft}=\mathrm{Foot}$

NCRP $=$ National Council on Radiation Protection and Measurements

$\mathrm{pCi} / \mathrm{g}=$ Picocuries per gram

$\mathrm{J}=$ Estimated value

-- = Not detected above minimum detectable concentrations. 
Table A.7-8

Soil Sample Results for Isotopes Detected above Minimum Detectable Concentrations at CAS 20-19-01, Waste Disposal Site

\begin{tabular}{|c|c|c|c|c|c|c|c|}
\hline \multirow[b]{2}{*}{$\begin{array}{c}\text { Sample } \\
\text { Location }\end{array}$} & \multirow[b]{2}{*}{$\begin{array}{l}\text { Sample } \\
\text { Number }\end{array}$} & \multirow[b]{2}{*}{$\begin{array}{l}\text { Depth } \\
\text { (ft bgs) }\end{array}$} & \multicolumn{5}{|c|}{ Contaminants of Potential Concern (pCi/g) } \\
\hline & & & 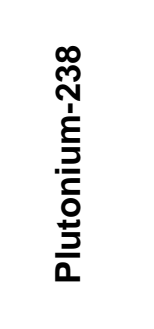 & 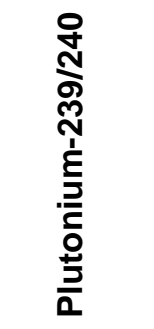 & 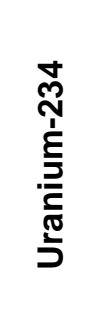 & 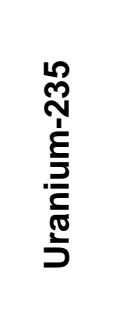 & 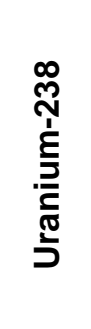 \\
\hline \multicolumn{3}{|c|}{ Final Action Levels ${ }^{a}$} & 13 & 12.7 & 143 & 17.6 & 105 \\
\hline E01 & 545E001 & $0.0-0.5$ & $1.18(\mathrm{~J})$ & $2.29(\mathrm{~J})$ & 1.38 & -- & 1.2 \\
\hline E02 & 545E002 & $0.0-0.5$ & $1.09(\mathrm{~J})$ & $2.59(\mathrm{~J})$ & 0.829 & -- & 0.647 \\
\hline E03 & 545E003 & $0.0-0.5$ & $0.317(\mathrm{~J})$ & $1.68(\mathrm{~J})$ & 0.771 & -- & 0.779 \\
\hline E04 & 545E004 & $0.0-0.5$ & -- & $0.107(\mathrm{~J})$ & 1.04 & -- & 1.2 \\
\hline E05 & 545E005 & $0.0-0.5$ & -- & -- & 0.772 & -- & 0.733 \\
\hline E06 & 545E006 & $0.0-0.5$ & -- & -- & 1 & -- & 1.06 \\
\hline E07 & 545E007 & $0.0-0.5$ & $0.801(\mathrm{~J})$ & $2.73(\mathrm{~J})$ & 1.23 & -- & 1 \\
\hline E08 & 545E008 & $0.0-0.5$ & $0.224(\mathrm{~J})$ & $1.52(\mathrm{~J})$ & 0.992 & -- & 1.03 \\
\hline \multirow{2}{*}{ E09 } & 545E009 & $0.0-0.5$ & $0.267(\mathrm{~J})$ & $1.86(\mathrm{~J})$ & 1.25 & -- & 1.37 \\
\hline & 545E010 & $0.0-0.5$ & $1.09(\mathrm{~J})$ & $1.67(\mathrm{~J})$ & 1.33 & 0.0908 & 1.43 \\
\hline E10 & 545E011 & $0.0-0.5$ & $1.04(\mathrm{~J})$ & $0.85(\mathrm{~J})$ & 0.73 & -- & 0.901 \\
\hline
\end{tabular}

aTaken from the construction, commercial, industrial land-use scenario in Table 2.1 of the NCRP Report No. 129, Recommended Screening Limits for Contaminated Surface Soil and Review Factors Relevant to Site-Specific Studies (NCRP, 1999). The values provided in this source document were scaled to a 25-millirem-per-year dose.

bgs $=$ Below ground surface

$\mathrm{ft}=$ Foot

NCRP = National Council on Radiation Protection and Measurements

$\mathrm{pCi} / \mathrm{g}=$ Picocuries per gram

$\mathrm{J}=$ Estimated value

-- = Not detected above minimum detectable concentrations. 


\section{A.8.0 Waste Management}

Waste management areas were established and managed as specified in the CAIP for CAU 545 (NNSA/NSO, 2007). For regulated waste, the amount, type, and source of the waste placed into each waste container was recorded in a log at the time of generation. Characterization and disposal were completed within regulatory requirements and acceptance criteria.

\section{A.8.1 Sanitary Waste}

Personal protective equipment (PPE) and disposable sampling equipment generated during the site activities were determined to be sanitary based on observation and process knowledge. The waste not containerized (Section A.2.1) was bagged, marked, and placed in a roll-off box for disposition at the industrial landfill. Office and lunch waste was placed in a dumpster as sanitary trash.

\section{A.8.2 Waste Minimization}

Investigation-derived waste (IDW) was generated during the field activities. In an effort to reduce the amount of waste generated, waste minimization techniques were integrated into the field activities and waste was segregated to the greatest extent possible. Controls were in place to minimize the use of hazardous materials and the unnecessary generation of hazardous and/or mixed waste.

Decontamination activities were planned and executed to minimize the volume of rinsate generated.

\section{A.8.2.1 Waste Streams/Disposal}

All waste dispositions were based on process knowledge, radiological surveys, site samples, and direct samples of the waste, when necessary (Table A.8-1). The characterization and disposition was based on federal and state regulations, permit limitations, and acceptance criteria. The load verification and shipping documentation for CAU 545 are in Appendix D. The wastes at CAU 545 are being managed and disposed of as follows:

- Solids

- Debris

- Rinsate 
Table A.8-1

Page A-84 of A-95

Waste Summary

\begin{tabular}{|c|c|c|c|c|c|c|c|c|c|c|c|}
\hline CAS & $\begin{array}{l}\text { Waste } \\
\text { Item }\end{array}$ & $\begin{array}{l}\text { Volumel } \\
\text { Capacity }\end{array}$ & $\begin{array}{c}\text { Process } \\
\text { Knowledge }\end{array}$ & $\begin{array}{l}\text { Analytical } \\
\text { Data }\end{array}$ & $\begin{array}{l}\text { Landfill } \\
\text { Limits }\end{array}$ & $\begin{array}{l}\text { NTS } \\
\text { POC }\end{array}$ & $\begin{array}{l}\text { Lagoon } \\
\text { Criteria }\end{array}$ & $\begin{array}{l}\text { Disposal } \\
\text { Pathway }\end{array}$ & Volume & $\begin{array}{l}\text { Disposal } \\
\text { Date }\end{array}$ & $\begin{array}{c}\text { Disposal } \\
\text { Document }\end{array}$ \\
\hline 02-09-01 & $\begin{array}{c}\text { Solids } \\
\text { (Solidified } \\
\text { Rinsate) }\end{array}$ & $\begin{array}{c}(2) \\
55-g a l \\
\text { drums }\end{array}$ & - & $\begin{array}{l}\text { Sanitary } \\
\text { Waste }\end{array}$ & Meets & Meets & Exceeds & $\begin{array}{c}\text { Area } 9-\mathrm{U} 10 \mathrm{c} \\
\mathrm{LF}\end{array}$ & $\begin{array}{c}\text { (2) } \\
55-\text { gal } \\
\text { drums }\end{array}$ & March 2008 & $\begin{array}{l}\text { Pending } \\
\text { LVF }\end{array}$ \\
\hline 03-08-03 & \multicolumn{11}{|c|}{ No waste was generated at CAS 03-08-03 } \\
\hline \multirow{2}{*}{ 03-17-01 } & $\begin{array}{c}\text { Debris } \\
\text { (Sampling } \\
\text { Debris and PPE) }\end{array}$ & $\begin{array}{l}(1) \\
55-g a l \\
\text { drum }\end{array}$ & - & $\begin{array}{l}\text { Sanitary } \\
\text { Waste }\end{array}$ & Meets & Meets & - & $\begin{array}{c}\text { Area } 9-\text { U10c } \\
\text { LF }\end{array}$ & $\begin{array}{l}(1) \\
55-g a l \\
\text { drum }\end{array}$ & March 2008 & $\begin{array}{l}\text { Pending } \\
\text { LVF }\end{array}$ \\
\hline & Rinsate & $\begin{array}{c}(2) \\
10-g a l \\
\text { drums }\end{array}$ & - & $\begin{array}{l}\text { Sanitary } \\
\text { Waste }\end{array}$ & Meets & Meets & Meets & $\begin{array}{l}\text { Area } 23- \\
\text { Lagoon }\end{array}$ & $5.5 \mathrm{gal}$ & March 2008 & $\begin{array}{l}\text { Pending } \\
\text { BOL }\end{array}$ \\
\hline 03-23-02 & \multicolumn{11}{|c|}{ No waste was generated at CAS 03-23-02 } \\
\hline 03-23-05 & \multicolumn{11}{|c|}{ No waste was generated at CAS 03-23-05 } \\
\hline 03-99-14 & Rinsate & $\begin{array}{l}(1) \\
10-g a l \\
\text { drum }\end{array}$ & - & $\begin{array}{l}\text { Sanitary } \\
\text { Waste }\end{array}$ & Meets & Meets & Meets & $\begin{array}{l}\text { Area } 23- \\
\text { Lagoon }\end{array}$ & $3 \mathrm{gal}$ & March 2008 & $\begin{array}{l}\text { Pending } \\
\text { BOL }\end{array}$ \\
\hline 09-23-02 & Rinsate & $\begin{array}{l}(1) \\
10-g a l \\
\text { drum }\end{array}$ & - & $\begin{array}{l}\text { Sanitary } \\
\text { Waste }\end{array}$ & Meets & Meets & Meets & $\begin{array}{l}\text { Area } 23- \\
\text { Lagoon }\end{array}$ & $5 \mathrm{gal}$ & March 2008 & $\begin{array}{l}\text { Pending } \\
\text { BOL }\end{array}$ \\
\hline 20-19-01 & $\begin{array}{c}\text { Debris } \\
\text { (Oil Filters and } \\
\text { Grease Canister) }\end{array}$ & $\begin{array}{l}(1) \\
\text { 10-gal } \\
\text { drum }\end{array}$ & $\begin{array}{l}\text { Hydrocarbon } \\
\text { Waste }\end{array}$ & - & Meets & Meets & - & $\begin{array}{c}\text { Area } 6- \\
\text { hydrocarbon } \\
\text { LF }\end{array}$ & $\begin{array}{c}(1) \\
10-g a l \\
\text { drum }\end{array}$ & March 2008 & Pending LVF \\
\hline
\end{tabular}

$\mathrm{BOL}=$ Bill of Lading

gal $=$ Gallon
$\mathrm{LF}=$ Landfill

LVF = Load Verification Form

- = Unitless
NTS = Nevada Test Site

POC $=$ Performance objective criteria $\mathrm{PPE}=$ Personal protective equipment 


\section{Corrective Action Site 02-09-01}

Due to the investigation activities at CAS 02-09-01, two drums of IDW were generated. These two (rinsate) drums of IDW were solidified and are recommended for disposal at the NTS U10c Industrial Landfill.

\section{Corrective Action Site 03-17-01}

Due to the investigation activities at CAS 03-17-01, three drums of IDW were generated. One drum of IDW, debris, is recommended for disposal at the NTS U10c Industrial Waste Landfill; and two (rinsate) drums of IDW are recommended for disposal in the NTS A23 Lagoon.

\section{Corrective Action Site 03-99-14}

Due to the investigation activities at CAS 03-99-04, one drum of IDW was generated. This (rinsate) drum of IDW is recommended for disposal in the NTS A23 Lagoon.

\section{Corrective Action Site 09-23-02}

Due to the investigation activities at CAS 09-23-02, one drum of IDW was generated. This (rinsate) drum of IDW is recommended for disposal in the NTS A23 Lagoon.

\section{Corrective Action Site 20-19-01}

Due to the investigation activities at CAS 20-19-01, one drum of IDW was generated. This debris (oil filter and grease container) drum of IDW is recommended for disposal at the NTS Area 6 Hydrocarbon Waste Landfill.

\section{A.8.2.2 Waste Streams}

Investigation-derived waste managed at CAU 545 includes:

- One drum of hydrocarbon impacted soil/debris for disposal as hydrocarbon waste.

- Three drums of solid waste for disposal as industrial waste.

- Four drums of rinsate for disposal at the A23 Lagoon.

Waste disposal documents are located in Appendix D. 


\section{A.9.0 Quality Assurance}

This section contains a summary of QA/QC measures implemented during the sampling and analysis activities conducted in support of the CAU 545 CAI. The following sections discuss the data validation process, QC samples, and nonconformances. A detailed evaluation of the DQIs is presented in Appendix B.

Laboratory analyses were conducted for samples used in the decision-making process to provide a quantitative measurement of any COPCs present. Rigorous QA/QC was implemented for all laboratory samples including documentation, verification and validation of analytical results, and affirmation of DQI requirements related to laboratory analysis. Detailed information regarding the QA program is contained in the QAPP (NNSA/NV, 2002).

\section{A.9.1 Data Validation}

Data validation was performed in accordance with the QAPP and approved protocols and procedures. All laboratory data from samples collected and analyzed for CAU 545 were evaluated for data quality in a tiered process and are presented in Sections A.9.1.1 through A.9.1.3. Data were reviewed to ensure that samples were appropriately processed and analyzed, and the results were evaluated using validation criteria. Documentation of the data qualifications resulting from these reviews is retained in project files as a hard copy and electronic media.

One hundred percent of the data analyzed as part of this investigation were subjected to Tier I and Tier II evaluations. A Tier III evaluation was performed on approximately 5 percent of the data analyzed.

\section{A.9.1.1 Tier I Evaluation}

Tier I evaluation for chemical and radiochemical analysis examines, but is not limited to:

- Sample count/type consistent with chain of custody.

- Analysis count/type consistent with chain of custody.

- Correct sample matrix.

- Significant problems and/or nonconformances stated in cover letter or case narrative.

- Completeness of certificates of analysis. 
- Completeness of Contract Laboratory Program (CLP) or CLP-like packages.

- Completeness of signatures, dates, and times on chain of custody.

- Condition-upon-receipt variance form included.

- Requested analyses performed on all samples.

- Date received/analyzed given for each sample.

- Correct concentration units indicated.

- Electronic data transfer supplied.

- Results reported for field and laboratory QC samples.

- Whether or not the deliverable met the overall objectives of the project.

\section{A.9.1.2 Tier II Evaluation}

Tier II evaluation for chemical analysis examines, but is not limited to:

- Correct detection limits achieved.

- Sample date, preparation date, and analysis date for each sample.

- Holding time criteria met.

- Quality control batch association for each sample.

- Cooler temperature upon receipt.

- Sample pH for aqueous samples, as required.

- Detection limits properly adjusted for dilution, as required.

- Blank contamination evaluated and applied to sample results/qualifiers.

- Matrix spike (MS)/matrix spike duplicate (MSD) percent recoveries (\%R) and relative percent differences (RPDs) evaluated and qualifiers applied to laboratory results, as necessary.

- Field duplicate RPDs evaluated using professional judgment and qualifiers applied to laboratory results, as necessary.

- Laboratory duplicate RPDs evaluated and qualifiers applied to laboratory results, as necessary.

- Surrogate \%R evaluated and qualifiers applied to laboratory results, as necessary.

- Laboratory control sample (LCS) \%R evaluated and qualifiers applied to laboratory results, as necessary.

- Initial and continuing calibration evaluated and qualifiers applied to laboratory results, as necessary.

- Internal standard evaluation.

- Mass spectrometer tuning criteria.

- Organic compound quantitation. 
- Inductively coupled plasma interference check sample evaluation.

- Graphite furnace atomic absorption QC.

- Inductively coupled plasma serial dilution effects.

- Recalculation of 10 percent of laboratory results from raw data.

Tier II evaluation for radiochemical analysis examines, but is not limited to:

- Correct detection limits achieved.

- Blank contamination evaluated and, if significant, qualifiers are applied to sample results.

- Certificate of Analysis consistent with data package documentation.

- Quality control sample results (duplicates, LCSs, laboratory blanks) evaluated and used to determine laboratory result qualifiers.

- Sample results, uncertainty, and MDC evaluated.

- Detector system calibrated with National Institute for Standards and Technology (NIST)traceable sources.

- Calibration sources preparation was documented, demonstrating proper preparation and appropriateness for sample matrix, emission energies, and concentrations.

- Detector system response to daily or weekly background and calibration checks for peak energy, peak centroid, peak full-width half-maximum, and peak efficiency, depending on the detection system.

- Tracers NIST-traceable, appropriate for the analysis performed, and recoveries that met QC requirements.

- Documentation of all QC sample preparation complete and properly performed.

- Spectra lines, photon emissions, particle energies, peak areas, and background peak areas support the identified radionuclide and its concentration.

\section{A.9.1.3 Tier III Evaluation}

A Tier III review is an independent examination of the Tier II evaluation. A Tier III review of 5 percent of the sample analytical data was performed by TLI Solutions of Lakewood, Colorado.

Tier II and Tier III results were compared and where differences are noted, data were reviewed and changes were made accordingly. This review included the following additional evaluations:

- Case narrative, chain of custody, and sample receipt forms

- Lab qualifiers (applied appropriately) 
- Method of analyses performed as dictated by the chain of custody

- Raw data, including chromatograms, instrument printouts, preparation logs, and analytical logs

- Manual integrations to determine whether the response is appropriate

- Data package for completeness

Determine sample results qualifiers through the evaluation of (but not limited to):

- Tracers and QC sample results (e.g., duplicates, LCSs, blanks, MSs) evaluated and used to determine sample results qualifiers.

- Sample preservation, sample preparation/extraction and run logs, sample storage, and holding time.

- Instrument and detector tuning.

- Initial and continuing calibrations.

- Calibration verification (initial, continuing, second source).

- Retention times.

- Second column and/or second detector confirmation.

- Mass spectra interpretation.

- Interference check samples and serial dilutions.

- Post digestion spikes and method of standard additions.

- Breakdown evaluations.

Calculation checks of:

- At least one analyte per QC sample and its recovery.

- At least one analyte per initial calibration curve, continuing calibration verification, and second source recovery.

- At least one analyte per sample that contains positive results (hits); radiochemical results only require calculation checks on activity concentrations (not error).

Verify that target compound detects identified in the raw data are reported on the results form. Document any anomalies for the laboratory to clarify or rectify. The contractor should be notified of any anomalies. 


\section{A.9.2 Field Quality Control Samples}

Field QC samples consisted of 12 trip blanks, 4 equipment rinsate blanks, 5 field blanks, 2 source blanks, 8 full laboratory QCs, and 8 FDs collected and submitted for analysis by the laboratory analytical methods and applicable parameters shown in Table A.2-2. Trip blanks were analyzed for VOCs only. The QC samples were assigned individual sample numbers and sent to the laboratory “blind.” Additional samples were selected by the laboratory to be analyzed as laboratory duplicates.

Review of the source blank analytical data resulted in possible gross alpha/beta contamination of one sample. A second source blank sample was submitted for gross alpha/beta analysis, and no contamination was detected. Results for a source blank of the Well 3 water showed contamination by arsenic, barium, acetone, di-n-butylphthalate, TPH-DRO, and isotopic U. Results for the source blank taken from water used for field blanks showed contamination by acetone and chloroform. However, none of the field blank analyses showed a detection of acetone or chloroform.

During the CAI, eight FDs were sent as blind samples to the laboratory to be analyzed for the investigation parameters listed in Table A.2-2. For these samples, the duplicate results precision (i.e., RPDs between the environmental sample results and their corresponding FD sample results) were evaluated. The results of this evaluation are provided in Section B.1.1.1.1, Criterion 3, Precision, of Appendix B.

\section{A.9.2.1 Laboratory Quality Control Samples}

Analysis of preparation QC blanks were performed on each sample delivery group (SDG) for inorganics. Analysis for surrogate spikes and method blanks were performed on each SDG for organics only. Initial and continuing calibration and LCSs were performed for each SDG. The results of these analyses were used to qualify associated environmental sample results. Documentation of data qualifications resulting from the application of these guidelines is retained in project files as both hard copy and electronic media.

The laboratory included a preparation blank, LCS, and a laboratory duplicate sample with each batch of field samples analyzed for radionuclides. 


\section{A.9.2.2 Field Nonconformances}

There were no field nonconformances identified for the CAI.

\section{A.9.3 Laboratory Nonconformances}

Laboratory nonconformances are generally due to inconsistencies in the analytical instrumentation operation, sample preparations, extractions, missed holding times, and fluctuations in internal standard and calibration results. The laboratories issued 42 nonconformances that may or may not have resulted in qualifying data. These laboratory nonconformances have been accounted for and resolved during the data qualification process. 


\section{A.10.0 Summary}

Organic, inorganics, and radionuclide contaminants detected in environmental samples during the CAI were evaluated against FALs to determine the nature and extent of COCs for CAU 545.

Assessment of the data generated from investigation activities indicates the FALs were not exceeded at any of the five CASs investigated. The following summarizes the results for each CAS.

\section{CAS 02-09-01, Mud Disposal Area}

Suspected releases at this site were potentially radiological contamination of the drilling mud disposed on the soil surface. The radiological survey did not identify any area of elevated radioactivity on the drilling mud. The analytical results for surface and shallow subsurface samples collected at eight locations were below the PALs for the site. The FALs for all analytes were established at the PAL concentrations. No COCs were identified at CAS 02-09-01. Therefore, no further action is required at this CAS.

\section{CAS 03-17-01, Waste Consolidation Site 3B}

Suspected releases at this site were potentially RCRA metal and/or radiological contamination of the soil from debris and contaminated soil previously stored and the site. Several biased locations were determined using the highest values from the radiological survey. The site was sampled following a probabilistic sampling approach, with some judgmental sampling conducted at biasing locations identified during the radiological and geophysical surveys. The analytical results for surface and shallow subsurface samples collected at 31 locations in the CAS and 15 locations outside the CAS fence line identified several areas of Am-241 and/or Pu-239/240 above the PALs. The radiological results for the site were moved on to a Tier 2 evaluation. All individual results were below the FALs. For the probabilistic results that were statistically analyzed, the 95 percent UCLs for Am-241 and $\mathrm{Pu}-239 / 240$ were also below the industrial scenario FALs. No COCs were identified at CAS 03-17-01. Therefore, no further action is required at this CAS.

\section{CAS 03-99-14, Radioactive Material Disposal Area}

Suspected releases at this site were potentially chemical and/or radiological contamination of material disposed at the site. Radiological contamination in the form of trinity glass was present, and 
attributed to nearby aboveground nuclear testing. The radiological survey did identify areas of elevated radioactivity, from two to five times background, most likely due to the presence of the Trinity glass. The analytical results for surface and shallow subsurface samples collected at eight locations were below the PALs for the site. The FALs for all analytes were established at the PAL concentrations. One background sample taken from outside the south border of the site exceeded the PAL for Pu-239/240, most likely due to the nearby aboveground testing, but no COCs were identified at CAS 03-19-14. Therefore, no further action is required at this CAS.

\section{CAS 09-23-02, U-9y Drilling Mud Disposal Crater}

Suspected releases at this site were potentially chemical and/or radiological contamination of drilling mud disposed in the crater component of the site, and the overflow of the mud into the wash. The radiological survey did not identify any area of elevated radioactivity. The analytical results for surface and shallow subsurface samples (collected at four locations in the wash at the CAS and two in the wash downstream from the site) were below the PALs. The FALs for all analytes were established at the PAL concentrations. No COCs were identified at CAS 09-23-02. Therefore, no further action is required at this CAS.

\section{CAS 20-19-01, Waste Disposal Site}

Suspected releases at this site were potentially chemical and/or radiological contamination of debris disposed on the soil surface. The radiological survey did not identify any area of elevated radioactivity on the drilling mud. The analytical results for surface and shallow subsurface samples collected at 10 locations were below the PALs for the site with the exception of TPH-DRO in two samples. No hazardous constituents of TPH-DRO exceeded FALS in the Tier 2 evaluation, thus TPH-DRO is not a COC for this site. The FALs for all analytes were established at the PAL concentrations. No COCs were identified at CAS 20-19-01. Potential source material, in the form of used oil filters, were staged in containers and removed from the site. Therefore, no further action is required at this CAS. 


\section{A.11.0 References}

BN, see Bechtel Nevada.

Bechtel Nevada. 1995. Nevada Test Site Performance Objective for Certification of Nonradioactive Hazardous Waste, Rev. 0, G-E11/96.01. Las Vegas, NV.

DOE, see U.S. Department of Energy.

EMSL/ORD, see Environmental Monitoring and Support Laboratory Office.

EPA, see U.S. Environmental Protection Agency.

Environmental Monitoring and Support Laboratory Office of Research and Development. 1980.

Prescribed Procedures for Measurement of Radioactivity in Drinking Water, EPA-600/4-80-032. August. Cincinnati, OH: U.S. Environmental Protection Agency.

Moore, J., Science Applications International Corporation. 1999. Memorandum to M. Todd (SAIC), “Background Concentrations for NTS and TTR Soil Samples,” 3 February. Las Vegas, NV.

NBMG, see Nevada Bureau of Mines and Geology.

NCRP, see National Council on Radiation Protection and Measurements.

NNSA/NSO, see U.S. Department of Energy, National Nuclear Security Administration Nevada Site Office.

NNSA/NV, see U.S. Department of Energy, National Nuclear Security Administration Nevada Operations Office.

National Council on Radiation Protection and Measurements. 1999. Recommended Screening Limits for Contaminated Surface Soil and Review of Factors Relevant to Site-Specific Studies, Report No. 129. Bethesda, MD.

Nevada Bureau of Mines and Geology. 1998. Mineral and Energy Resource Assessment of the Nellis Air Force Range, Open-File Report 98-1. Reno, NV.

PNNL, see Pacific Northwest National Laboratory.

Pacific Northwest National Laboratory. 2002. Visual Sample Plan, Version 2.0, User's Guide, PNNL-14002. Richland, WA.

RSL, see Remote Sensing Laboratory.

Remote Sensing Laboratory. 1989. Aerial photograph “6612-035,” 23 September. Las Vegas, NV: EG\&G Energy Measurements, Inc. 
Remote Sensing Laboratory. 1998. Aerial photograph “6613-019,” 23 September. Las Vegas, NV: EG\&G Energy Measurements, Inc.

Remote Sensing Laboratory. 2003. Aerial photograph “11189-35,” 4 December. Las Vegas, NV: U.S. Department of Energy, National Nuclear Security Administration, Nevada Site Office.

SNJV, see Stoller-Navarro Joint Venture.

SNJV GIS, see Stoller-Navarro Joint Venture Geographic Information Systems.

Stoller-Navarro Joint Venture. 2006. Model Statement of Work for Analytical Laboratories. Revision 0. February. Las Vegas, NV.

Stoller-Navarro Joint Venture Geographic Information Systems. 2007. ESRI ArcGIS Software.

U.S. Department of Energy. 1993. Radiation Protection of the Public and the Environment, DOE Order 5400.5, Change 2. Washington, DC.

U.S. Department of Energy. 1997. The Procedures Manual of the Environmental Measurements Laboratory, HASL-300. Vol. 1 Ed. 28, HASL-300 (Revised 1997). February. New York, NY.

U.S. Department of Energy, National Nuclear Security Administration Nevada Operations Office. 2002. Industrial Sites Quality Assurance Project Plan, Nevada Test Site, Nevada, Rev. 3, DOE/NV--372. Las Vegas, NV.

U.S. Department of Energy, National Nuclear Security Administration Nevada Site Office. 2006. Industrial Sites Project Establishment of Final Action Levels, Rev. 0, DOE/NV--1107. Las Vegas, NV.

U.S. Department of Energy, National Nuclear Security Administration Nevada Site Office. 2007. Corrective Action Investigation Plan for Corrective Action Unit 545: Dumps, Waste Disposal Sites, and Buried Radioactive Materials, Nevada Test Site, Nevada, DOE/NV--1210, Rev. 0. Las Vegas, NV.

U.S. Environmental Protection Agency. 1996. Test Methods for Evaluating Solid Waste, Physical/Chemical Methods, SW-846, 3rd Edition, CD-ROM PB97-501928GEI. Washington, DC.

U.S. Environmental Protection Agency. 2004 (as revised). Region 9 Preliminary Remediation Goals (PRGs). As accessed at www.epa.gov/region09/waste/sfund/prg/htm on 20 March 2007. 


\section{Appendix B}

\section{Data Assessment}




\section{B.1.0 Data Assessment}

The DQA process is the scientific evaluation of the actual investigation results to determine whether the DQO criteria established in the CAU 545 CAIP (NNSA/NSO, 2007) were met and whether DQO decisions can be resolved at the desired level of confidence. The DQO process ensures that the right type, quality, and quantity of data will be available to support the resolution of those decisions at an appropriate level of confidence. Using both the DQO and DQA processes helps to ensure that DQO decisions are sound and defensible.

The DQA involves five steps that begin with a review of the DQOs and end with an answer to the DQO decisions. The five steps are briefly summarized as follows:

Step 1: Review DQOs and Sampling Design - Review the DQO Process to provide context for analyzing the data. State the primary statistical hypotheses; confirm the limits on decision errors for committing false negative (Type I) or false positive (Type II) decision errors; and review any special features, potential problems, or deviations to the sampling design.

Step 2: Conduct a Preliminary Data Review - Perform a preliminary data review by reviewing QA reports and inspecting the data both numerically and graphically, validating and verifying the data to ensure that the measurement systems performed in accordance with the criteria specified, and using the validated dataset to determine whether the quality of the data is satisfactory.

Step 3: Select the Test - Select the test based on the population of interest, population parameter, and hypotheses. Identify the key underlying assumptions that could cause a change in one of the DQO decisions.

Step 4: Verify the Assumptions - Perform tests of assumptions. If data are missing or censored, determine the impact on DQO decision error.

Step 5: Draw Conclusions from the Data - Perform the calculations required for the test. 


\section{B.1.1 Review DQOs and Sampling Design}

This section contains a review of the DQO process presented in Appendix A of the CAIP for CAU 545 (NNSA/NSO, 2007). The DQO decisions are presented with the DQO provisions to limit false negative or false positive decision errors. Special features, potential problems, and deviations to the sampling design are also presented.

\section{B.1.1.1 Decision I}

The Decision I statement as presented in the CAIP: “Is any COC present in the environmental media within the CAS?” (NNSA/NSO, 2007).

\section{Decision I Rules:}

- If the population parameter of any COPC in the Decision I population of interest (defined in step 4 of the DQOs) exceeds the corresponding FAL, then that contaminant is identified as a COC.

- If a COC is detected, then Decision II samples will be collected.

- If COCs are not identified, then the investigation is complete.

- If COC contamination is inconsistent with the CSM or extends beyond the spatial boundaries identified in Section A.6.2 of the CAIP (NNSA/NSO, 2007), then work will be suspended and the investigation strategy will be reconsidered, else the decision will be to continue sampling to define the extent.

- If a waste is present that, if released, has the potential to cause the further contamination of site environmental media, then a corrective action will be determined, else no further action will be necessary.

\section{B.1.1.1.1 DQO Provisions To Limit False Negative Decision Error}

The investigation conducted at CAU 545 used the judgmental and probabilistic sampling approaches to collect the data required to assess the site. A false negative decision error (where consequences are more severe) was controlled by meeting the following criteria:

1a. Having a high degree of confidence that sample locations selected will identify COCs if present anywhere within the CAS (judgment sampling). 
1.b Having a high degree of confidence that the average sample contaminant concentrations represent the true average contaminant concentrations (probabilistic).

2. Having a high degree of confidence that analyses conducted will be sufficient to detect any COCs present in the samples at an acceptable level of sensitivity.

3. Having a high degree of confidence that the dataset is of sufficient quality and completeness.

\section{Criterion 1:}

Improper selection of sampling locations and number of locations could result in not identifying one or more COCs that may be present at a CAS. Along with proper management and transportation of samples, the judicious collection of samples (i.e., sufficient number of sample locations and proper selection of those locations) at a CAS, as specified in approved DQOs, can avoid sampling error and result in a high degree of confidence that any COCs present in the CAS were identified.

For judgmental sampling designs (i.e., CASs 02-09-01, 03-99-14, 09-23-02, 20-19-01, and part of 03-17-01), the number of locations to sample were specified in the DQOs (NNSA/NSO, 2007).

Selecting locations for judgmental sampling designs, that are representative of the populations of interest, involve the use of biasing factors. To identify COCs at a CAS using a judgmental sampling design, the following methods (stipulated in the DQOs) were used in selecting sample locations.

1. Selection of sampling locations associated with the results of the radiological walkover and geophysical surveys.

2. Selection of sampling locations associated with staining, mounds, trenches, presence of debris, and other items was accomplished by visual field observations.

3. Selection of sampling locations associated with surface drainage (e.g., washes).

4. Selection of sampling locations associated with professional judgment based on acceptable knowledge was accomplished by:

- Source and location of release.

- Chemical nature and fate properties.

- Physical transport pathways and properties.

- Transport drivers. 
Selection of sample locations at CAS 02-09-01 varied slightly from planned activities. Sample locations at CAS 02-09-01 were selected based on site features (i.e., mounds and low-lying areas).

For probabilistic sampling designs (i.e., most of CAS 03-17-01) the minimum number of sample locations required was calculated from the field investigation sample results for each significant COPC at each CAS (CAU 545 CAIP). For the purposes of determining sample size requirements, significant COPCs are considered to be the analytes detected above the PALs, as defined in Section A.5.2.1.2 of the CAIP (NNSA/NSO, 2007). The VSP software was used to calculate final minimum sample sizes using the following inputs (PNNL, 2002):

- A two-sided 95 percent confidence interval (e.g., the false rejection rate equals 5 percent).

- A false acceptance rate of 15 percent.

- The maximum acceptable half-width of confidence interval for each population-specific significant COPC set to half the FAL value (gray region).

- The calculated standard deviation for each population-specific significant COPC.

The input values and VSP determined minimum number of samples to be taken for each significant COPC at CAS 03-17-01 are listed in Table B.1-1.

Table B.1-1

Input Values and VSP Determined Minimum Number of Samples for CAU 545, CAS 03-17-01

\begin{tabular}{|c|c|c|c|c|c|c||}
\hline CAS & Constituent & $\begin{array}{c}\text { Actual } \\
\text { Standard } \\
\text { Deviation }\end{array}$ & FAL $^{\mathrm{a}}$ & Gray Region & $\begin{array}{c}\text { Initial } \\
\text { Estimate of } \\
\text { Minimum } \\
\text { Number of } \\
\text { Samples }\end{array}$ & $\begin{array}{c}\text { Actual } \\
\text { Required } \\
\text { Minimum } \\
\text { Number of } \\
\text { Samples }\end{array}$ \\
\hline \hline $03-17-01$ & Americium-241 & 5.46 & $1,501 \mathrm{pCi} / \mathrm{g}$ & 750.5 & 24 & 8 \\
\cline { 2 - 5 } & Plutonium-239 & 11.25 & $1,890 \mathrm{pCi} / \mathrm{g}$ & 945 & \\
\hline
\end{tabular}

aSite-specific FALs determined with RESRAD for radionuclides under an industrial scenario (Appendix C).

$\mathrm{FAL}=$ Final action level $\mathrm{pCi} / \mathrm{g}=$ Picocuries per gram RESRAD = Residual Radioactive 
For the Am-241 and Pu-239 results at CAS 03-17-01, the variability of the results was less than initial estimates (Table B.1-1), thus the 95 percent UCL for these significant COPCs was used to make DQO decisions.

\section{Criterion 2:}

All samples were analyzed for the chemical and radiological constituents listed in Table A.3-2 of Section A.3.2.2 of the CAIP (NNSA/NSO, 2007). Table B.1-2 provides a reconciliation of samples analyzed to the planned analytical program.

Table B.1-2

CAU 545 Analyses Performed

\begin{tabular}{|c|c|c|c|c|c|c|c|c|c|}
\hline CAS & 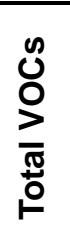 & 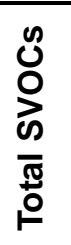 & $\begin{array}{l}\mathscr{n} \\
\text { U్ }\end{array}$ & 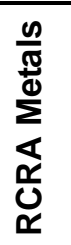 & 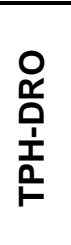 & 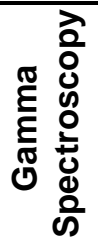 & 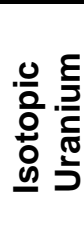 & 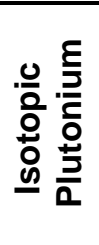 & 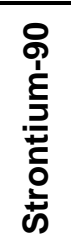 \\
\hline 02-09-01 & $\mathrm{N} / \mathrm{A}$ & $\overline{N / A}$ & $\bar{N} / \mathrm{A}$ & $\overline{\mathrm{N} / \mathrm{A}}$ & $\bar{N} / \mathrm{A}$ & $\overline{\overline{R S}}$ & $\overline{\mathrm{RS}}$ & $\overline{\overline{R S}}$ & $\overline{\mathrm{RS}}$ \\
\hline 03-17-01 & N/A & N/A & N/A & $\mathrm{RS}$ & N/A & $\mathrm{RS}$ & $\mathrm{RS}$ & RS & $\mathrm{RS}$ \\
\hline 03-99-14 & RS & RS & RS & RS & RS & RS & RS & RS & $\mathrm{RS}$ \\
\hline 09-23-02 & RS & $\mathrm{RS}$ & NA & $\mathrm{RS}$ & RS & RS & RS & RS & $\mathrm{RS}$ \\
\hline $20-19-01$ & RS & RS & RS & RS & RS & RS & RS & RS & $\mathrm{RS}$ \\
\hline
\end{tabular}

DRO $=$ Diesel-range organics N/A = Not applicable

RS = Required and submitted

$\mathrm{PCB}=$ Polychlorinated biphenyl

RCRA = Resource Conservation and Recovery Act

SVOC $=$ Semivolatile organic compound

$\mathrm{TPH}=$ Total petroleum hydrocarbons

VOC $=$ Volatile organic compound

Sample results were assessed against the acceptance criterion for the DQI of sensitivity as defined in the Industrial Sites QAPP (NNSA/NV, 2002). The sensitivity acceptance criterion defined in the CAIP is that analytical detection limits will be less than the corresponding action level

(NNSA/NSO, 2007). This criterion was not achieved for the analytical results listed in Table B.1-3. Results not meeting the sensitivity acceptance criterion will not be used in making DQO decisions and, therefore, be considered rejected data. The impact on DQO decisions is addressed in the assessment of completeness. 
Table B.1-3

Analytes Failing Sensitivity Criteria

\begin{tabular}{|c|c|c|c|}
\hline $\begin{array}{c}\text { Sample } \\
\text { Number }\end{array}$ & Constituent & $\begin{array}{c}\text { Minimum } \\
\text { Detection } \\
\text { Concentration } \\
\text { (mg/kg) }\end{array}$ & $\begin{array}{c}\text { Final Action Level } \\
\text { (mg/kg) }\end{array}$ \\
\hline \hline \multirow{2}{*}{$545 \mathrm{E} 007$} & Hexachlorobenzene & 1.35 & 1.1 \\
\cline { 2 - 4 } & N-Nitroso-Di-N-Propylamine & 1.35 & 0.25 \\
\hline 545E008 & N-Nitroso-Di-N-Propylamine & 0.68 & 0.25 \\
\hline
\end{tabular}

$\mathrm{mg} / \mathrm{kg}=$ Milligrams per kilogram

\section{Criterion 3:}

To satisfy the third criterion, the entire dataset, as well as individual sample results, were assessed against the acceptance criteria for the DQIs of precision, accuracy, comparability, completeness, and representativeness, as defined in the QAPP (NNSA/NV, 2002). The DQI acceptance criteria are presented in Table 6-1 of the CAIP (NNSA/NSO, 2007). As presented in Tables B.1-3 through B.1-6, the acceptance criteria for the DQIs are discussed under the following sections.

\section{$\underline{\text { Precision }}$}

Precision was evaluated as described in Section 6.2 of the CAIP (NNSA/NSO, 2007). Table B.1-4 provides the chemical and radiological precision analysis results for all constituents that were qualified for precision. The chemical constituents qualified for precision were barium and lead. The radionuclides qualified for precision were $\mathrm{Pu}-238$ and -239/240 and cesium (Cs)-137.

Table B.1-4

Precision Measurements

\begin{tabular}{|c|c|c|c|c|}
\hline Constituent & User Test Panel & $\begin{array}{c}\text { Number of } \\
\text { Measurements } \\
\text { Qualified }\end{array}$ & $\begin{array}{c}\text { Number of } \\
\text { Measurements } \\
\text { Performed }\end{array}$ & $\begin{array}{c}\text { Percent } \\
\text { within } \\
\text { Criteria }\end{array}$ \\
\hline \hline Barium & Metals & 11 & 78 & 85.9 \\
\hline Lead & Metals & 22 & 78 & 71.8 \\
\hline Cesium-137 & Gamma & 16 & 127 & 87.4 \\
\hline Plutonium-238 & Plutonium & 11 & 127 & 91.3 \\
\hline Plutonium-239/240 & Plutonium & 34 & 127 & 73.2 \\
\hline
\end{tabular}


As shown in Table B.1-4, the precision rates for all chemical and radionuclides were above the CAIP acceptance criterion of 80 percent except for Pu-239/240 and lead. The precision rates for all other constituents is 100 percent. The samples qualified for $\mathrm{Pu}-239 / 240$ precision were based on differences in laboratory duplicate sample results. High variability in the sampled matrix may indicate the potential that discrete particles of contamination are present within the sample. Therefore, mixing will not produce homogeneity. This does not mean the precision of the measurement is poor but that activities are variable within the sample. This is commonly observed in isotopic Pu results, as a single particle of plutonium within a sample can result in detectable activities attributed to the entire sample. There are no obvious reasons (e.g., matrix interference) for the discrepancies; however, the potential for a false negative DQO decision error is negligible because the highest reported concentration (455 mg/kg) is significantly less than the FAL (1,890 pCi/g). Therefore, when a duplicate sample is analyzed for isotopic $\mathrm{Pu}$, the results can be significantly different depending on how many discrete particles are contained in each sample.

The samples qualified for lead precision were estimated based on the duplicate precision failures on laboratory quality control samples. There are no obvious reasons (e.g., matrix interference) for the discrepancies; however, the potential for a false negative DQO decision error is negligible because the highest reported concentration $(19.2 \mathrm{mg} / \mathrm{kg})$ is significantly less than the FAL (800 mg/kg).

Therefore, Pu-239/240 and lead results that were qualified for reasons of precision can be confidently used confidently to support DQO decisions. As the precision rates for all other constituents met the acceptance criteria for precision, the dataset is determined to be acceptable for the DQI of precision.

\section{Accuracy}

Accuracy was evaluated as described in Section 6.2 of the CAIP (NNSA/NSO, 2007) Table B.1-5 provides the chemical accuracy analysis results for all constituents qualified for accuracy. Accuracy rates are above the CAIP criterion of 80 percent, except for barium, which has a rate of 28.2 percent. There were no radiological data qualified for accuracy.

The 56 barium results qualified for accuracy were associated with an MS recovery outside control limits, which could be biased high or low. Because the FAL for barium $(67,000 \mathrm{mg} / \mathrm{kg})$ is orders of 
Table B.1-5

Accuracy Measurements

\begin{tabular}{|c|c|c|c|c|}
\hline Constituent & $\begin{array}{c}\text { User Test } \\
\text { Panel }\end{array}$ & $\begin{array}{c}\text { Number of } \\
\text { Measurements } \\
\text { Qualified }\end{array}$ & $\begin{array}{c}\text { Number of } \\
\text { Measurements } \\
\text { Performed }\end{array}$ & $\begin{array}{c}\text { Percent } \\
\text { within } \\
\text { Criteria }\end{array}$ \\
\hline Barium & Metals & 56 & 78 & 28.2 \\
\hline Benzene & VOCs & 1 & 42 & 97.6 \\
\hline Chlorobenzene & VOCs & 1 & 42 & 97.6 \\
\hline Toluene & VOCs & 1 & 42 & 97.6 \\
\hline Aroclor 1221 & PCBs & 2 & 24 & 91.7 \\
\hline Aroclor 1232 & PCBs & 2 & 24 & 91.7 \\
\hline Aroclor 1242 & PCBs & 2 & 24 & 91.7 \\
\hline Aroclor 1248 & PCBs & 2 & 24 & 91.7 \\
\hline Aroclor 1254 & PCBs & 2 & 24 & 91.7 \\
\hline Aroclor 1260 & PCBs & 2 & 24 & 91.7 \\
\hline Aroclor 1268 & PCBs & 2 & 24 & 91.7 \\
\hline Aroclors (low risk) & PCBs & 2 & 24 & 91.7 \\
\hline
\end{tabular}

$\mathrm{PCB}=$ Polychlorinated biphenyl

VOC $=$ Volatile organic compound

magnitude higher than the reporting limit, these results did not affect the decision-making process. Therefore, the dataset is acceptable for the DQI of accuracy.

\section{$\underline{\text { Representativeness }}$}

The DQO process as identified in Appendix A of the CAIP (NNSA/NSO, 2007) was used to address sampling and analytical requirements for this CAU. During this process, appropriate locations were selected that enabled the samples collected to be representative of the population parameters identified in the DQO (the most likely locations to contain contamination or represent contamination of the CAS [probabilistic approach] and locations that bound COCs). The sampling locations identified in the Criterion 1 discussion meet this criterion. Therefore, the analytical data acquired during the CAU 545 CAI are considered representative of the population parameters. 


\section{Comparability}

Field sampling, as described in the CAIP (NNSA/NSO, 2007), was performed and documented in accordance with approved procedures that are comparable to standard industry practices. Approved analytical methods and procedures per DOE were used to analyze, report, and validate the data. These are comparable to other methods used not only in industry and government practices, but most importantly are comparable to other investigations conducted for the NTS. Therefore, project datasets are considered comparable to other datasets generated using these same standardized DOE procedures, thereby meeting DQO requirements.

Also, standard, approved field and analytical methods ensured that data were appropriate for comparison to the investigation action levels specified in the CAIP (NNSA/NSO, 2007).

\section{Completeness}

The CAIP defines acceptable criteria for completeness to be that the dataset is sufficiently complete to be able to make the DQO decisions (NNSA/NSO, 2007). This is initially evaluated as 80 percent of CAS-specific noncritical constituents identified in the CAIP having valid results and 100 percent of critical constituents (including Decision II samples) having valid results. Critical constituents for CAU 545 are CAS-specific and limited to the following radiological contaminants:

- CAS 03-17-01: Am-241, Cs-137, europium (Eu)-152, Pu-238, and Pu-239/240

- CAS 09-23-02: Am-241, Cs-137, Pu-238, and Pu-239/240

- CAS 20-19-01: The hazardous constituent of diesel because TPH detected greater than $100 \mathrm{ppm}$

Rejected data (either qualified as rejected or data that failed the criterion of sensitivity) were not used in the resolution of DQO decisions and are not counted toward meeting the completeness acceptance criterion. Table B.1-6 provides the rejected data for the site, and Table B.1-3 provides the data that failed sensitivity criteria.

Hexachlorobenzene and N-Nitroso-Di-N-Propylamine failed the criterion for sensitivity (see Table B.1-3) in specific samples while Am-241 and mercury were qualified as rejected due to analytical quality issues. All critical analytes met the 100 percent criteria for completeness, because no Am-241 data were rejected for CASs 03-17-01 and 09-23-02. All other data met the 80 percent completeness criteria. Therefore, all data for critical constituents were within the acceptable criteria. 
Table B.1-6

Rejected Measurements

\begin{tabular}{|c|c|c|c|c|}
\hline Constituent & $\begin{array}{c}\text { User Test } \\
\text { Panel }\end{array}$ & $\begin{array}{c}\text { Number of } \\
\text { Measurements } \\
\text { Rejected }\end{array}$ & $\begin{array}{c}\text { Number of } \\
\text { Measurements } \\
\text { Performed }\end{array}$ & $\begin{array}{c}\text { Percent } \\
\text { within } \\
\text { Criteria }\end{array}$ \\
\hline \hline Americium-241 & Gamma & 1 & 127 & 99.2 \\
\hline Mercury & Metals & 9 & 78 & 88.5 \\
\hline
\end{tabular}

\section{B.1.1.1.2 DQO Provisions To Limit False Positive Decision Error}

The false positive decision error was controlled by assessing the potential for false positive analytical results. Quality assurance/QC samples such as field blanks, trip blanks, LCSs, and method blanks were used to determine whether a false positive analytical result may have occurred. Of all QA/QC samples submitted, no samples detected potential cross-contamination that could cause a false positive determination.

Proper decontamination of sampling equipment and the use of certified clean sampling equipment and containers also minimized the potential for cross contamination that could lead to a false positive analytical result.

\section{B.1.1.2 Decision II}

Decision II was assessed for CASs 03-08-03 and 03-23-05 because COCs were identified for only those sites. The COCs as CAS 03-08-03 are contained within the drilling mud disposed in the craters. Based on previous investigations of mud pits, contaminants have not migrated laterally beyond the mud pit boundaries. The UR boundary was conservatively set at the fence line, which is approximately $30 \mathrm{ft}$ from the craters.

The COCs at CAS 03-23-05 are entombed in grout and are not expected to have migrated. The UR boundary was conservatively set at the fence line, which varies from 10 to $20 \mathrm{ft}$ from the buried material. 


\section{B.1.1.3 Sampling Design}

The CAIP (NNSA/NSO, 2007) made the following commitments for sampling:

1. A probabilistic sampling design was developed for CAS 03-17-01 with six additional judgmental locations selected at the most prominent anomalies detected in the geophysical and radiological surveys. Some randomly chosen locations were specified at CASs 09-23-02 and 20-19-01 because biasing factors appeared to be absent.

Result: All random sample locations were designated by the VSP and collected at CAS 03-17-01. Random sample locations were not required for CASs 09-23-02 and 20-19-01 due to the presence of biasing factors (e.g., used oil filters, photographic supplies, drilling mud spill, soil staining, geophysical surveys, sediment setting areas).

2. A judgmental sampling design was employed for CASs 02-09-01, 03-99-14, 09-23-02, and 20-19-01 due to the presence and significance of biasing factors.

Result: Sample locations were determined at CASs 02-09-01, 03-99-14, 09-23-02, and 20-19-01 based on the presence of biasing factors (e.g., soil staining, radiological/geophysical survey results).

\section{B.1.2 Conduct a Preliminary Data Review}

A preliminary data review was conducted by reviewing QA reports and inspecting the data. The contract analytical laboratories generate a QA nonconformance report when data quality does not meet contractual requirements. All data received from the analytical laboratories met contractual requirements, and a QA nonconformance report was not generated. Data were validated and verified to ensure that the measurement systems performed were in accordance with the criteria specified. The validated dataset quality was found to be satisfactory.

\section{B.1.3 Select the Test and Identify Key Assumptions}

The test for making DQO Decision I was the comparison of the maximum analyte result from each CAS to the corresponding FAL. The test for making DQO Decision II was the comparison of all COC analyte results from each bounding sample to the corresponding FALs.

The key assumptions that could impact a DQO decision are listed in Table B.1-7. 


\begin{tabular}{|c|c|}
\hline Exposure Scenario & $\begin{array}{l}\text { Industrial and construction workers, and military personnel conducting training in an } \\
\text { Occasional Use Area, may be exposed to contaminants of potential concern through } \\
\text { oral ingestion, inhalation, dermal contact (absorption) of soil and/or debris due to } \\
\text { inadvertent disturbance of these materials, or through irradiation by radioactive } \\
\text { materials. }\end{array}$ \\
\hline Affected Media & $\begin{array}{l}\text { Surface soil and shallow subsurface soil. } \\
\text { Deep groundwater contamination is not a concern, and contaminants migrating to } \\
\text { regional aquifers are not considered. }\end{array}$ \\
\hline $\begin{array}{l}\text { Location of Contamination/ } \\
\text { Release Points }\end{array}$ & $\begin{array}{l}\text { Drilling mud (CAS 02-09-01). } \\
\text { Debris at location(s) of disposed/stored waste or materials (CASs 03-17-01, 03-99-14, } \\
\text { and 20-19-01). } \\
\text { Drilling mud or possible buried materials (CAS 09-23-02). } \\
\text { The conceptual site model accounts for potential releases resulting from migration of } \\
\text { contaminants from the source outward to the contiguous environment. } \\
\text { The extent of contaminant of concern concentration decreases with increased } \\
\text { distance from the area of contamination. }\end{array}$ \\
\hline Transport Mechanisms & $\begin{array}{l}\text { Surfacewater runoff of dissolved or suspended contaminants is the most likely } \\
\text { potential transport mechanism for waste materials placed on and in soils at the } \\
\text { Nevada Test Site (NTS). The potential for overland migration of contaminants } \\
\text { increases with slope gradient and precipitation. Infiltration and percolation of } \\
\text { precipitation through subsurface media could serve as a major driving force for } \\
\text { migration of contaminants. However, due to the arid environment of the NTS, } \\
\text { percolation of precipitation is limited and migration of contaminants is limited. } \\
\text { Evapotranspiration potentials significantly exceed available soil moisture from } \\
\text { precipitation (i.e., } 6 \text { to } 10 \text { inches) (Winograd and Thordarson, 1975). }\end{array}$ \\
\hline Preferential Pathways & $\begin{array}{l}\text { Lateral transport expected to dominate over vertical transport, except for subsurface } \\
\text { releases and within craters. }\end{array}$ \\
\hline $\begin{array}{l}\text { Lateral and Vertical Extent } \\
\quad \text { of Contamination }\end{array}$ & $\begin{array}{l}\text { Contamination, where present, is contiguous to the release points, and decreases with } \\
\text { distance from the source. Lateral and vertical extent of COC contamination is within } \\
\text { the spatial boundaries. }\end{array}$ \\
\hline Groundwater Impacts & None \\
\hline Future Land Use & Occasional Use Area \\
\hline $\begin{array}{l}\text { Other Data Quality Objective } \\
\text { Assumptions }\end{array}$ & $\begin{array}{l}\text { The grout surrounding the buried lead pig and protactinium- } 233 \text { would fail at some } \\
\text { point, and lead and radionuclides would be released to the surrounding media. } \\
\text { Waste or debris containing materials that are comprised of contaminants (e.g., lead } \\
\text { batteries, fluorescent light bulbs and ballasts, floor tiles, preserved wood) would } \\
\text { decompose at some point and release the contaminant(s) to the surrounding media. } \\
\text { The resulting concentration of contaminants in the surrounding media would be } \\
\text { greater than applicable action levels. }\end{array}$ \\
\hline
\end{tabular}




\section{B.1.4 Verify the Assumptions}

The results of the investigation support the key assumptions identified in the CAU 545 DQOs (NNSA/NSO, 2007) and Table B.1-7 and no revisions to the CSMs were required.

\section{B.1.4.1 Other DQO Commitments}

The CAIP (NNSA/NSO, 2007) made the following commitments for sampling:

The presence of a COC would require a corrective action. A corrective action may also be necessary if there is a potential for wastes that are present at a site to impose COCs into site environmental media if the wastes were to be released. To evaluate the potential for a future release from source material, introducing a COC to the surrounding environmental media, the following conservative assumptions were made:

- The contaminant surrounding both the Eu-152 source and the buried lead pig and protactinium-233 source at CAS 03-23-05 would fail at some point, and lead and radionuclides would be released to the surrounding media.

- Waste or debris containing materials that are comprised of contaminants (e.g., lead batteries, fluorescent light bulbs and ballasts, floor tiles, preserved wood) would decompose at some point and release the contaminant(s) to the surrounding media.

- The resulting concentration of contaminants in the surrounding media would exceed applicable action levels.

Result: It was determined that the buried radioactive sources (i.e., Pa-233 and Eu-152) at CAS 03-23-05 were PSM and require a corrective action.

Result: Several used oil filters discarded at CAS 20-19-01 are potential source material and require corrective action.

- The CAIP (NNSA/NSO, 2007) assumed that COCs are present at CAS 03-08-03.

Result: This contamination is a PSM and requires a corrective action.

\section{B.1.5 Draw Conclusions from the Data}

This section resolves the two DQO decisions for each of the CAU 545 CASs. 


\section{B.1.5.1 Decision Rules for Decision I}

Decision Rule: If the population parameter of any COPC in the Decision I population of interest (defined in Step 4) exceeds the corresponding FAL, then that contaminant is identified as a COC, and Decision II sampling will be resolved, else no further investigation is needed for that COPC in that population.

Result: No COCs were identified in samples collected from CASs 02-09-01, 03-17-01, 03-99-14, 09-23-02, and 20-19-01, therefore, no further action was identified as the corrective action for these CASs.

Potential source material was identified at CASs 03-23-05 and 20-19-01; therefore, corrective actions were required at these CASs.

Radiological COCs are assumed to exist at CAS 03-08-03, therefore, requiring corrective action. 


\section{B.2.0 References}

NNSA/NSO, see U.S. Department of Energy, National Nuclear Security Administration Nevada Site Office.

NNSA/NV, see U.S. Department of Energy, National Nuclear Security Administration Nevada Operations Office.

PNNL, see Pacific Northwest National Laboratory.

Pacific Northwest National Laboratory. 2002. Visual Sample Plan, Version 2.0, User’s Guide, PNNL-14002. Richland, WA.

U.S. Department of Energy, National Nuclear Security Administration Nevada Operations Office. 2002. Industrial Sites Quality Assurance Project Plan, Nevada Test Site, Nevada, Rev. 3, DOE/NV--372. Las Vegas, NV.

U.S. Department of Energy, National Nuclear Security Administration Nevada Site Office. 2007. Corrective Action Investigation Plan for Corrective Action Unit 545: Dumps, Waste Disposal Sites, and Buried Radioactive Materials, Nevada Test Site, Nevada, Rev. 0, DOE/NV--1210. Las Vegas, NV.

Winograd, I.J., and W. Thordarson. 1975. Hydrogeologic and Hydrochemical Framework, South-Central Great Basin, Nevada-California, with Special Reference to the Nevada Test Site, Professional Paper 712-C. Denver, CO: U.S. Geological Survey. 


\section{Appendix C}

\section{Risk Assessment}




\section{C.1.0 Evaluation of Risk}

The RBCA process used to establish FALs is described in the Industrial Sites Project Establishment of Final Action Levels (NNSA/NSO, 2006). This process conforms with NAC Section 445A.227 (NAC, 2006a), which lists the requirements for sites with soil contamination. For the evaluation of corrective actions, NAC Section 445A.22705 (NAC, 2006b) recommends the use of ASTM Method E 1739-95 (ASTM, 1995) to “conduct an evaluation of the site, based on the risk it poses to public health and the environment, to determine the necessary remediation standards (i.e., FALs) or to establish that corrective action is not necessary.”

The evaluation of the need for corrective action will include the potential for wastes that are present at a site to cause the future contamination of site environmental media if the wastes were to be released.

This section contains documentation of the RBCA process used to establish FALs described in the Industrial Sites Project Establishment of FALs (NNSA/NSO, 2006). This process defines three tiers (or levels) to establish FALs used to evaluate DQO decisions:

- $\quad$ Tier 1 - Sample results from source areas (highest concentrations) compared to RBSLs (i.e., PALs) based on generic (nonsite-specific) conditions.

- $\quad$ Tier 2 - Sample results from exposure points compared to SSTLs calculated using site-specific inputs and Tier 1 formulas.

- $\quad$ Tier 3 - Sample results from exposure points compared to SSTLs and points of compliance calculated using chemical fate/transport and probabilistic modeling.

The RBCA decision process stipulated in the Industrial Sites Project Establishment of FALs (NNSA/NSO, 2006) is summarized in Figure C.1-1. 


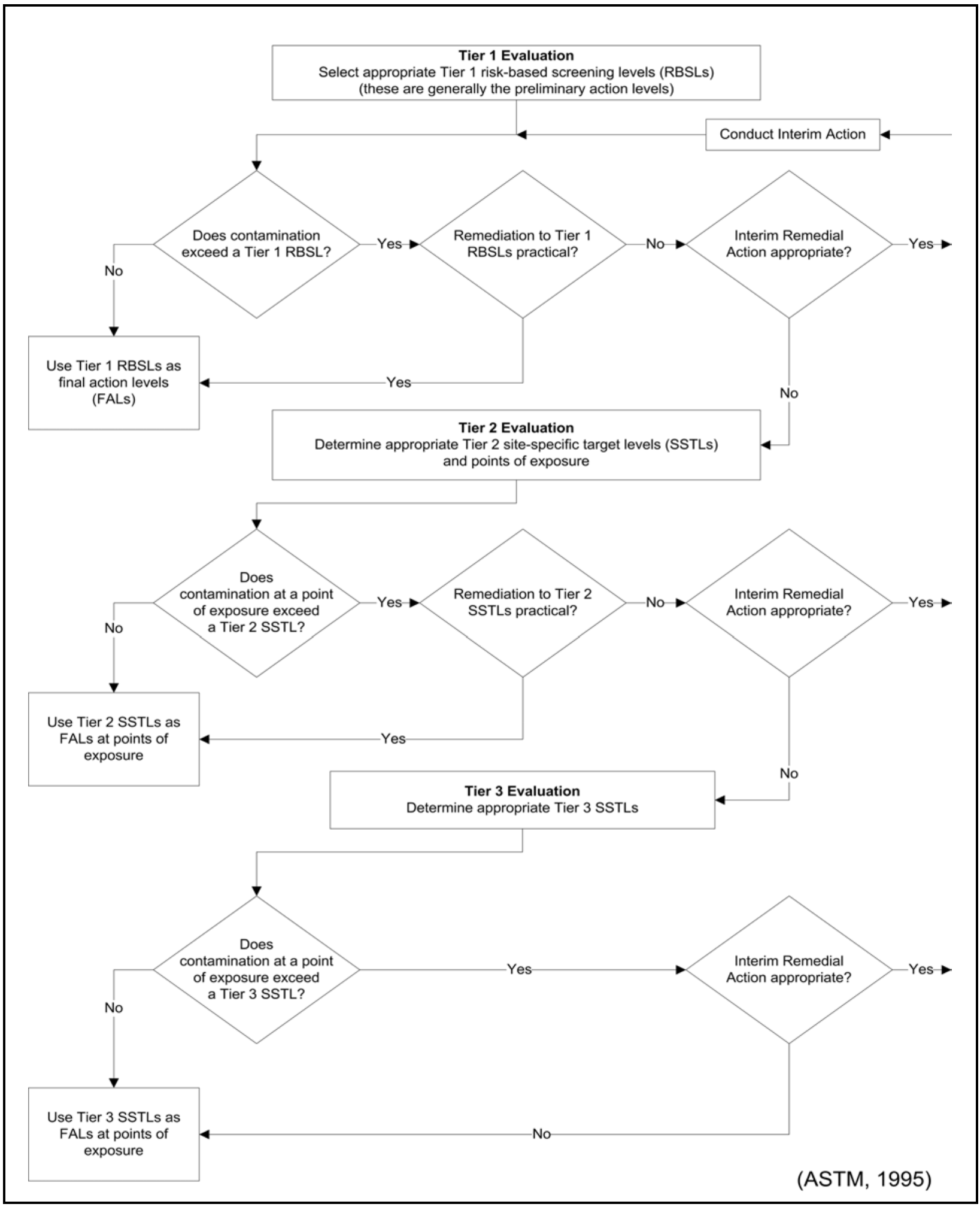

Figure C.1-1

Risk-Based Corrective Action Decision Process 


\section{C.1.1 A. Scenario}

Corrective Action Unit 545, Dumps, Waste Disposal Sites, and Buried Radioactive Materials consists of the following eight inactive CASs within Areas 2, 3, 9, and 20 of the NTS:

- 02-09-01, Mud Disposal Area

- 03-08-03, Mud Disposal Site

- 03-17-01, Waste Consolidation Site 3B

- 03-23-02, Waste Disposal Site

- 03-23-05, Europium Disposal Site

- 03-99-14, Radioactive Material Disposal Area

- 09-23-02, U-9y Drilling Mud Disposal Crater

- 20-19-01, Waste Disposal Site

Corrective Action Site 02-09-01, Mud Disposal Area, is located immediately to the west of the 2-05 Road and Circle Road intersection in Area 2 of the NTS. The CAS consists of potentially contaminated drilling mud released within and outside of the U-2ei crater, which formed as a result of the Coulommiers underground nuclear test conducted on September 27, 1977. The specific history of mud disposal activities at the U-2ei crater is unknown; however aerial photography indicates mud was disposed at the site between 1977 and 1984. The mud released at CAS 02-09-01 is assumed to be associated with NTS drilling operations, and therefore may either be pre-use material or else used pre-test and/or post-test drilling mud.

Corrective Action Site 03-08-03 consists of two adjacent craters (U-3ai and U-3be test holes) that were used for the disposal of drilling mud. The site is located southeast of the intersection of the 3-03 and 3-12 Roads. The CAS consists of the releases associated with the two craters. Disposal of drilling mud at CAS 03-08-03 occurred at a ramp located at the north end of the site. Records indicate radioactively contaminated drilling mud was disposed at CAS 03-08-03. The craters are posted as an RMA. A contamination area is adjacent to the craters to the east. For CAS 03-08-03, though the potential for subsidence of the craters was judged to be extremely unlikely, the DQO meeting participants agreed that sufficient information existed about disposal and releases at the site and that a corrective action of close in place with a UR for isotopic $\mathrm{U}$, isotopic $\mathrm{Pu}$, fission products and decay products is recommended. Sampling in the craters was not considered necessary.

For CASs 03-23-02 no documentation was identified for the storage or disposal of materials at the site. Corrective Action Site 03-23-02 consists of the uncollapsed crater at the U-3gi test hole. The 
site was originally posted as an underground RMA, but is now posted as a contamination area. For CAS 03-23-02, there were no potential releases of hazardous or radioactive contaminants identified. Therefore, no additional information was needed to recommend a no further action corrective action decision, and DQOs were not developed for this CAS. This CAS is closed with no further action.

Corrective Action Site 03-23-05 consists of the crater area formed from the Pommard underground nuclear test. The CAS consists of the releases associated with two radioactive sources, one contained in a lead "pig" at a the northwest portion of the site, and the contaminated third floor of a tower used at the site during the underground testing; along with the other source within the uncollapsed U-3ee crater. For CAS 03-23-05, existing information about the two buried sources and lead pig was considered to be sufficient, and safety concerns existed about the stability of the crater component. Therefore, a corrective action of close in place with a use restriction is recommended, and sampling at the site was not considered necessary.

Corrective Action Site 03-17-01, Waste Consolidation Site 3B, is located 1.0 mi east of the Area 3 RWMS at the NTS. The CAS consists of an area used for storage of suspected radioactive materials associated with nearby atmospheric tests, which was cleaned up in the 1980s. Two components comprise the site: a rectangular area measuring 950 by $750 \mathrm{ft}$, posted as a contamination area; and an unposted, circular area measuring $145 \mathrm{ft}$ in diameter. Some metallic debris, including the remnants of an ecology study, remain at the site.

Corrective Action Site 03-99-14, Radioactive Materials Disposal Area, is located approximately $1.0 \mathrm{mi}$ southeast of the Area 3 RWMS. The CAS consists of potential soil contamination associated with a soil berm and an associated trench approximately $350 \mathrm{ft}$ long. The volume of soil on the berm appears to be equivalent to that missing from the trench. The original purpose for the berm and trench is unknown. The site, along with adjoining lands, is posted as an RMA. The posting is likely due to atmospheric testing that was conducted just to the west of the site. The area encompassing the RMA will be investigated by the Soils Project for CAU 104.

Corrective Action Site 09-23-02, U-9y Drilling Mud Disposal Crater, is located approximately $600 \mathrm{ft}$ southeast of the 9-01 and Circle Roads intersection. The CAS consists of potentially radiologically contaminated drilling fluids and decontamination wastewater disposed of in the U-9y crater. This crater formed as a result of the Wichita underground nuclear test conducted on July 27, 1962. At 
some time between 1979 and 1980, the fluids inside the crater overflowed into the wash to the east, and use of the crater for disposal was discontinued. The wash is posted as a buried RMA, but it is not known if the posting is related to the overflow of the crater.

Corrective Action Site 20-19-01, Waste Disposal Site, is located to the east-northeast of the U-20p test hole, within the potential crater area, in the northwestern portion of Area 20. The CAS consists of the debris pile to the east-northeast of the test hole. The history of the debris is not known, but the contents are consistent with general construction debris. Several used oil filters were identified at the site. A drilling mud spill entering the site from the south was also identified at the site.

\section{C.1.2 B. Site Assessment}

The CAI at CAS 02-09-01, Mud Disposal Area, involved conducting visual inspection, radiological survey, and soil sampling activities at the CAS. Surface and subsurface soil samples were collected from biased locations identified as potential sources or release points (i.e., mounds or low lying areas). Based on investigation results, no COPCs were identified at concentrations exceeding the PALs.

The CAI at CAS 03-17-01, Waste Consolidation Site 3B, involved conducting visual inspection, radiological survey, geophysical survey, and soil sampling activities at the CAS. Surface and subsurface soil samples were collected from randomly selected locations (probabilistic sampling approach) and biased locations identified as potential sources or release points (i.e., subsurface anomalies, areas of elevated radioactivity). Americium-241 and Pu-239/240 were detected at concentrations that exceeded their PALs of $12.7 \mathrm{pCi} / \mathrm{g}$ at multiple locations.

The CAI at CAS 03-99-14, Radioactive Material Disposal Area, involved conducting visual inspection, radiological survey, geophysical survey, and soil sampling activities at the CAS. Surface and subsurface soil samples were collected from biased locations identified as potential sources or release points (i.e., the trench and berm). Based on the results of the investigation, no COPCs were identified at concentrations exceeding the PALs.

The CAI at CAS 09-23-02, U-9y Drilling Mud Disposal Crater, involved conducting visual inspection, radiological survey, geophysical survey, and soil sampling activities at the CAS. Surface 
and subsurface soil samples were collected from biased locations identified as potential sources or release points (i.e., the wash and low-lying areas). Based on the results of the investigation, no COPCs were identified at concentrations exceeding the PALs.

The CAI at CAS 20-19-01, Waste Disposal Site, involved conducting visual inspection, radiological survey, and soil sampling activities at the CAS. Surface and subsurface soil samples were collected from biased locations identified as potential sources or release points (i.e., debris piles, discolored soil). The only COPC identified at concentrations exceeding the PALs was TPH-DRO. No hazardous constituents of TPH-DRO exceeded PALs. The source, release point, and nature and extent of the COCs are consistent with the CSM presented in the CAIP for CAU 545 (NNSA/NSO, 2007).

Corrective Action Sites 03-08-03, 03-23-02, and 03-23-05 were not investigated because sufficient data existed to support the decisions necessary for site closure (NNSA/NSO, 2007).

The maximum concentration of contaminant identified at each CAS, and their corresponding PALs, are presented in Table C.1-1.

\section{C.1.3 C. Site Classification and Initial Response Action}

The four major site classifications listed in Table 3 of the ASTM Standard are: (1) immediate threat to human health, safety, and the environment; (2) short-term (0 to 2 years) threat to human health, safety, and the environment; (3) long-term (more than 2 years) threat to human health, safety, or the environment; and (4) no demonstrated long-term threats.

Based on the CAI, none of the CASs present an immediate threat to human health, safety, and the environment; therefore, no interim response actions are necessary at these sites. Based on this information, five of the eight CASs are determined to be Classification 4 sites as defined by ASTM Method E 1739-95 (ASTM-1995) and pose no demonstrated near- or long-term threats. At CASs 03-08-03, 03-23-05, and 20-19-01, PSM existed that may pose long-term threats to human health, safety, or the environment and have been determined to be Classification 3 sites as defined by ASTM Method E 1739-95. 


\section{C.1.4 D. Development of Tier 1 Lookup Table of Risk-Based Screening Levels}

Tier 1 action levels have been defined as the PALs established during the DQO process. The PALs are a tabulation of chemical-specific (but not site-specific) screening levels based on the type of media (soil) and potential exposure scenarios (industrial). These are very conservative estimates of risk, are preliminary in nature, and are used as action levels for site screening purposes. Although the PALs are not intended to be used as FALs, a FAL may be defined as the Tier 1 action level (i.e., PAL) value if individual contaminant analytical results are below the corresponding Tier 1 action level value. The FAL may also be established as the Tier 1 action level value if individual contaminant analytical results exceed the corresponding Tier 1 action level value and implementing a corrective action based on the FAL is practical. The PALs are defined as:

- The EPA Region 9 Risk-Based PRGs for Industrial Soils (2004).

- Background concentrations for RCRA metals will be evaluated when natural background exceeds the PAL, as is often the case with arsenic. Background is considered the mean plus two times the standard deviation based on data published in Mineral and Energy Resource Assessment of the Nellis Air Force Range (NBMG, 1998; Moore, 1999).

- The TPH concentrations above the action level of $100 \mathrm{mg} / \mathrm{kg}$ per NAC 445A.2272 (NAC, 2006a).

- For COPCs without established PRGs, a protocol similar to EPA Region 9 will be used to establish an action level; otherwise, an established PRG from another EPA region may be chosen.

- The PALs for material, equipment, and structures with residual surface contamination are the allowable total residual surface contamination values for unrestricted release of material and equipment listed in the DOE Order 5400.5 (DOE, 1993), which is also Table 4-2 of the NV/YMP Radiological Control Manual (NNSA/NSO, 2004).

- The PALs for radioactive contaminants are based on the NCRP Report No. 129 recommended screening limits for construction, commercial, industrial land-use scenarios (NCRP, 1999) scaled to 25-mrem/yr-dose constraint (Appenzeller-Wing, 2004) and the generic guidelines for residual concentration of radionuclides in DOE Order 5400.5 (DOE, 1993).

The PALs were developed based on an industrial scenario. Because the CAU 545 CASs are not assigned work stations, and considered to be in remote or occasional use areas, industrial scenario based PALs are used conservatively. The Tier 1 lookup table is defined as the PAL concentrations or activities defined in the CAIP (NNSA/NSO, 2007). 
Table C.1-1

Page C-8 of C-19

Maximum Reported Value for Tier 1 Comparison

(Page 1 of 3 )

\begin{tabular}{|c|c|c|c|c|c|c|c|c|}
\hline \multirow{2}{*}{ CAS No. } & \multirow{2}{*}{ Constituent } & \multirow{2}{*}{$\begin{array}{l}\text { Preliminary } \\
\text { Action Level }\end{array}$} & \multirow{2}{*}{ Units } & \multicolumn{5}{|c|}{ Maximum Reported Value } \\
\hline & & & & 02-09-01 & 03-17-01 & $03-99-14$ & 09-23-02 & 20-19-01 \\
\hline $95-63-6$ & 1,2,4-Trimethylbenzene & 170 & $\mathrm{mg} / \mathrm{kg}$ & $\mathrm{N} / \mathrm{A}$ & $\mathrm{N} / \mathrm{A}$ & -- & 0.002 & -- \\
\hline $106-46-7$ & 1,4-Dichlorobenzene & 7.9 & $\mathrm{mg} / \mathrm{kg}$ & N/A & N/A & -- & $0.0003(\mathrm{~J})$ & -- \\
\hline $78-93-3$ & 2-Butanone & 110,000 & $\mathrm{mg} / \mathrm{kg}$ & $\mathrm{N} / \mathrm{A}$ & N/A & -- & -- & 0.01 \\
\hline $591-78-6$ & 2-Hexanone & 110,000 & $\mathrm{mg} / \mathrm{kg}$ & N/A & N/A & -- & -- & 0.009 \\
\hline $67-64-1$ & Acetone & 54,000 & $\mathrm{mg} / \mathrm{kg}$ & $\mathrm{N} / \mathrm{A}$ & N/A & $0.004(\mathrm{~J})$ & -- & 0.41 \\
\hline $71-43-2$ & Benzene & 1.4 & $\mathrm{mg} / \mathrm{kg}$ & $\mathrm{N} / \mathrm{A}$ & N/A & -- & -- & $0.0004(\mathrm{~J})$ \\
\hline $75-71-8$ & Dichlorodifluoromethane & 310 & $\mathrm{mg} / \mathrm{kg}$ & $\mathrm{N} / \mathrm{A}$ & N/A & -- & $0.001(\mathrm{~J})$ & 0.002 \\
\hline $75-09-2$ & Methylene Chloride & 21 & $\mathrm{mg} / \mathrm{kg}$ & $N / A$ & $\mathrm{~N} / \mathrm{A}$ & 0.005 & $0.002(\mathrm{~J})$ & 0.01 \\
\hline $100-42-5$ & Styrene & 1,700 & $\mathrm{mg} / \mathrm{kg}$ & $\mathrm{N} / \mathrm{A}$ & N/A & 0.001 & 0.003 & $0.0005(\mathrm{~J})$ \\
\hline $1330-20-7$ & Total Xylenes & 420 & $\mathrm{mg} / \mathrm{kg}$ & $\mathrm{N} / \mathrm{A}$ & N/A & -- & 0.006 & -- \\
\hline $65-85-0$ & Benzoic Acid & 100,000 & $\mathrm{mg} / \mathrm{kg}$ & $\mathrm{N} / \mathrm{A}$ & N/A & -- & -- & 41.3 \\
\hline $117-81-7$ & Bis(2-ethylhexyl)phthalate & 120 & $\mathrm{mg} / \mathrm{kg}$ & $\mathrm{N} / \mathrm{A}$ & $\mathrm{N} / \mathrm{A}$ & -- & -- & 3.99 \\
\hline $84-74-2$ & Di-n-butyl phthalate & 62,000 & $\mathrm{mg} / \mathrm{kg}$ & $\mathrm{N} / \mathrm{A}$ & N/A & -- & -- & 0.94 \\
\hline $85-01-8$ & Phenanthrene & 100,000 & $\mathrm{mg} / \mathrm{kg}$ & $\mathrm{N} / \mathrm{A}$ & N/A & -- & -- & $0.02(\mathrm{~J})$ \\
\hline $108-95-2$ & Phenol & 100,000 & $\mathrm{mg} / \mathrm{kg}$ & N/A & N/A & -- & -- & 0.36 \\
\hline $68334-30-5$ & Diesel-Range Organics & 100 & $\mathrm{mg} / \mathrm{kg}$ & $\mathrm{N} / \mathrm{A}$ & N/A & $2.53(\mathrm{~J})$ & 11.4 & 157 \\
\hline 11097-69-1 & Aroclor 1254 & 0.74 & $\mathrm{mg} / \mathrm{kg}$ & $\mathrm{N} / \mathrm{A}$ & N/A & -- & -- & $0.007(\mathrm{~J})$ \\
\hline $11096-82-5$ & Aroclor 1260 & 0.74 & $\mathrm{mg} / \mathrm{kg}$ & $\mathrm{N} / \mathrm{A}$ & $\mathrm{N} / \mathrm{A}$ & $0.002(\mathrm{~J})$ & -- & -- \\
\hline $11100-14-4$ & Aroclor 1268 & 0.74 & $\mathrm{mg} / \mathrm{kg}$ & $N / A$ & $\mathrm{~N} / \mathrm{A}$ & -- & -- & 0.04 \\
\hline
\end{tabular}

\section{UNCONTROLLED When Printed}


Table C.1-1

Page C-9 of C-19

Maximum Reported Value for Tier 1 Comparison

(Page 2 of 3 )

\begin{tabular}{|c|c|c|c|c|c|c|c|c|}
\hline \multirow{2}{*}{ CAS No. } & \multirow{2}{*}{ Constituent } & \multirow{2}{*}{$\begin{array}{l}\text { Preliminary } \\
\text { Action Level }\end{array}$} & \multirow{2}{*}{ Units } & \multicolumn{5}{|c|}{ Maximum Reported Value } \\
\hline & & & & 02-09-01 & 03-17-01 & 03-99-14 & $09-23-02$ & 20-19-01 \\
\hline $7440-38-2$ & Arsenic & 23 & $\mathrm{mg} / \mathrm{kg}$ & $\mathrm{N} / \mathrm{A}$ & 7.6 & 5.6 & 7.7 & 9.1 \\
\hline $7440-39-3$ & Barium & 67,000 & $\mathrm{mg} / \mathrm{kg}$ & $\mathrm{N} / \mathrm{A}$ & $235(\mathrm{~J})$ & 179 & $250(\mathrm{~J})$ & $291(\mathrm{~J})$ \\
\hline $7440-43-9$ & Cadmium & 450 & $\mathrm{mg} / \mathrm{kg}$ & $\mathrm{N} / \mathrm{A}$ & $0.37(\mathrm{~J})$ & -- & $0.2(\mathrm{~J}-)$ & 2.7 \\
\hline $7440-47-3$ & Chromium & 450 & $\mathrm{mg} / \mathrm{kg}$ & $N / A$ & 9.6 & 7.4 & 7.6 & 12.2 \\
\hline $7439-92-1$ & Lead & 800 & $\mathrm{mg} / \mathrm{kg}$ & $\mathrm{N} / \mathrm{A}$ & 13.3 & $19.2(\mathrm{~J})$ & $17.8(\mathrm{~J})$ & $106(\mathrm{~J})$ \\
\hline $7439-97-6$ & Mercury & 310 & $\mathrm{mg} / \mathrm{kg}$ & N/A & $0.04(\mathrm{~J}-)$ & $0.01(\mathrm{~J}-)$ & $0.04(\mathrm{~J})$ & $0.46(\mathrm{~J})$ \\
\hline $7782-49-2$ & Selenium & 5,100 & $\mathrm{mg} / \mathrm{kg}$ & $\mathrm{N} / \mathrm{A}$ & $2.6(\mathrm{~J})$ & 1.9 & 2 & $2.1(\mathrm{~J}-)$ \\
\hline $7440-22-4$ & Silver & 5,100 & $\mathrm{mg} / \mathrm{kg}$ & $N / A$ & $0.24(\mathrm{~J})$ & $0.33(\mathrm{~J})$ & -- & 22.1 \\
\hline 14331-83-0 & Actinium-228 & 5 & $\mathrm{pCi} / \mathrm{g}$ & 2.67 & 2.18 & 1.96 & 2.63 & 2.33 \\
\hline $14596-10-2$ & Americium-241 & 12.7 & $\mathrm{pCi} / \mathrm{g}$ & -- & 284 & $1.05(\mathrm{~J})$ & 0.38 & 1.19 \\
\hline $10045-97-3$ & Cesium-137 & 12.2 & $\mathrm{pCi} / \mathrm{g}$ & 2.04 & 5.14 & 10.3 & 1.71 & 1 \\
\hline 14683-23-9 & Europium-152 & 5.7 & $\mathrm{pCi} / \mathrm{g}$ & -- & 2.17 & $4.62(\mathrm{~J})$ & -- & -- \\
\hline 15092-94-1 & Lead-212 & 5 & $\mathrm{pCi} / \mathrm{g}$ & 2.4 & 1.98 & $1.94(\mathrm{~J})$ & 2.42 & 2.3 \\
\hline $15067-28-4$ & Lead-214 & 5 & $\mathrm{pCi} / \mathrm{g}$ & 1.44 & 1.35 & $1.35(\mathrm{~J})$ & 1.65 & 2.09 \\
\hline $14913-50-9$ & Thallium-208 & 5 & $\mathrm{pCi} / \mathrm{g}$ & 0.86 & 0.78 & 0.61 & 0.85 & 0.78 \\
\hline $13981-16-3$ & Plutonium-238 & 13 & $\mathrm{pCi} / \mathrm{g}$ & 0.06 & 5.14 & 2.18 & 0.51 & $1.18(\mathrm{~J})$ \\
\hline $15117-48-3$ & Plutonium-239/240 & 12.7 & $\mathrm{pCi} / \mathrm{g}$ & 0.82 & 455 & $15.1^{a}$ & 7.3 & $2.73(\mathrm{~J})$ \\
\hline $10098-97-2$ & Strontium-90 & 838 & $\mathrm{pCi} / \mathrm{g}$ & 0.29 & 1.1 & 5.67 & -- & -- \\
\hline $13966-29-5$ & Uranium-234 & 143 & $\mathrm{pCi} / \mathrm{g}$ & 1.27 & 2.42 & 1.27 & 1.52 & 1.38 \\
\hline
\end{tabular}


Table C.1-1

Maximum Reported Value for Tier 1 Comparison

(Page 3 of 3 )

\begin{tabular}{|c|c|c|c|c|c|c|c|c|}
\hline \multirow{2}{*}{ CAS No. } & \multirow{2}{*}{ Constituent } & \multirow{2}{*}{$\begin{array}{l}\text { Preliminary } \\
\text { Action Level }\end{array}$} & \multirow{2}{*}{ Units } & \multicolumn{5}{|c|}{ Maximum Reported Value } \\
\hline & & & & 02-09-01 & 03-17-01 & 03-99-14 & 09-23-02 & $20-19-01$ \\
\hline 15117-96-1 & Uranium-235 & 17.6 & $\mathrm{pCi} / \mathrm{g}$ & -- & 0.12 & 0.11 & 0.11 & 0.09 \\
\hline $7440-61-1$ & Uranium-238 & 105 & $\mathrm{pCi} / \mathrm{g}$ & 1.18 & 1.1 & 1.15 & 1.65 & 1.43 \\
\hline
\end{tabular}

${ }^{\mathrm{a} V a l u e ~ o f ~} 15.1 \mathrm{pCi} / \mathrm{g}$ for Pu-239/240 is for background sample collected outside Corrective Action Site 03-99-14.

CAS $=$ Chemical Abstracts Service

$\mathrm{mg} / \mathrm{kg}=$ Milligrams per kilogram

$\mathrm{N} / \mathrm{A}=$ Not applicable

$\mathrm{pCi} / \mathrm{g}=$ Picocuries per gram

$\mathrm{Pu}=$ Plutonium

$\mathrm{J}=$ Estimated value

$\mathrm{J}-=$ The result is an estimated quantity, but the result may be biased low.

-- = Not detected above minimum detectable concentrations.

Bold indicates the value exceeds the preliminary action level. 


\section{C.1.5 E. Exposure Pathway Evaluation}

The DQOs stated that site workers would be exposed to COCs only through oral ingestion, inhalation, or dermal contact (absorption) due to exposure to potentially contaminated media (i.e., soil) at the CASs. The results of the CAI showed that no COCs were identified within CAU 545, except at CASs 03-08-03 and 03-23-05. The radiological contamination, in the form of drilling mud, at CAS 03-08-03 does not have a pathway to a receptor, as it is within the craters where access is restricted. The contamination at CAS 03-23-05, in the form of PSM (lead pig and radiological sources) does not have a pathway to a receptor, as both sources within are buried and are in blocks of grout, with one encapsulated source buried within the potential crater area. Access is restricted to these two components of CAS 03-23-05. The limited migration demonstrated by the analytical results, elapsed time since the suspected release, and depth to groundwater, supports the selection and evaluation only surface and shallow subsurface contact as the complete exposure pathways. Groundwater is not considered to be a significant exposure pathway.

The oil filters, as surface PSM, at CAS 20-19-01, were subject to a direct contact pathway.

\section{C.1.6 F. Comparison of Site Conditions with Tier 1 Risk-Based Screening Levels}

All analytical results from CAU 545 samples were less than corresponding Tier 1 action levels (i.e., PALs) except for those listed in Table C.1-2.

Additionally, PSM, in the form of the lead pig and radioactive sources, exists at CAS 03-23-05; PSM in the form of the used oil filters existed at CAS 20-19-01; and radiologically contaminated drilling mud exists at CAS 03-08-03.

\section{C.1.7 G. Evaluation of Tier 1 Results}

For all contaminants at all CASs not listed in Table C.1-2, the FALs were established as the Tier 1 RBSLs. It was determined that no further action is required for these contaminants at these CASs.

\section{C.1.8 H. Tier 1 Remedial Action Evaluation}

It was determined by NNSA/NSO that corrective actions for the contaminants listed in Table C.1-2 were not practical. Therefore, a Tier 2 SSTL will be calculated for these contaminants. 
Table C.1-2

Contaminants of Potential Concern Detected above Preliminary Action Levels $(\mu \mathrm{g} / \mathrm{kg})$

\begin{tabular}{|c|c|c|c|}
\hline CAS & 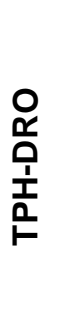 & 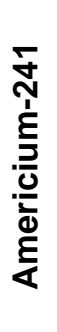 & 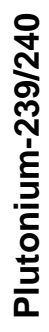 \\
\hline 02-09-01 & -- & -- & -- \\
\hline 03-17-01 & -- & $X$ & $X$ \\
\hline 03-99-14 & -- & -- & -- \\
\hline 09-23-02 & -- & -- & -- \\
\hline 20-19-01 & $x$ & -- & -- \\
\hline
\end{tabular}

DRO $=$ Diesel-range organics

$\mathrm{TPH}=$ Total petroleum hydrocarbons

$\mu \mathrm{g} / \mathrm{kg}=$ Micrograms per kilogram

-- = Not applicable

\section{TPH-DRO Evaluation}

Corrective actions for TPH-DRO at CAS 20-19-01 to Tier 1 action levels are not practical; therefore, TPH-DRO was moved to a Tier 2 evaluation.

\section{Radionuclide Evaluation}

Corrective actions to remediate Am-241 and Pu-239/240 at CAS 03-17-01 to Tier 1 action levels are not practical; therefore, these radionuclides at this CAS were moved to a Tier 2 evaluation.

Also, PSM, in the form of the lead pig and radioactive sources, exists at CAS 03-23-05; and radiologically contaminated drilling mud exists at CAS 03-08-03.

\section{C.1.9 I. Tier 2 Evaluation}

No additional data were needed to complete a Tier 2 evaluation. 


\section{C.1.10J. Development of Tier 2 Table of Site-Specific Target Levels}

\section{Evaluation of TPH-DRO SSTLS}

Method E 1739-95 stipulates that risk evaluations for TPH contamination be calculated and evaluated based on the risk posed by the potentially hazardous constituents of TPH. Section 6.4.3 ("Use of Total Petroleum Hydrocarbon Measurements”) of ASTM Method E 1739-95 states: “TPHs should not be used for risk assessment because the general measure of TPH provides insufficient information about the amounts of individual chemical(s) of concern present” (see also Sections X1.5.4 and X1.42 of Method E 1739-95 in ASTM [1995]). Therefore, the individual potentially hazardous constituents will be evaluated for risk in place of TPH-DRO. The PAL for TPH-DRO was exceeded at CAS 20-19-01. The SSTLs were established for the individual potentially hazardous constituents in TPH-DRO at the corresponding PAL concentrations. (Note: The PALs were based on an industrial use scenario in the CAIP [NNSA/NSO, 2007]). These SSTLs and the maximum reported level for each diesel constituent are presented in Table C.1-3.

\section{Evaluation of Radiological Contaminant SSTLS}

The Tier 2 evaluation consisted of evaluating the mixture of all radionuclides detected at each CAS to develop Tier 2 action levels for the two radionuclides that exceeded Tier 1 levels. The CAS-specific Tier 2 action levels for CAS 03-17-01 were calculated using the RESRAD computer code (version 6.3) and site-specific parameters. The RESRAD calculations were based on continued industrial use of the site assuming that a worker will be on the site for 250 days per year, 8 hours per day, for 25 years. A more detailed discussion of the RESRAD code, site-specific parameters used, and the printed RESRAD outputs is provided in Attachment A of this appendix. 
Table C.1-3

Tier 2 SSTLs and CAU 545 Results for Hazardous Constituents of Diesel

\begin{tabular}{|c|c|c|}
\hline \multirow[t]{2}{*}{ Common Name } & \multirow{2}{*}{$\begin{array}{c}\text { SSTL } \\
\text { (mg/kg) }\end{array}$} & $\begin{array}{c}\text { Maximum Reported } \\
\text { Value (mg/kg) }\end{array}$ \\
\hline & & CAS 20-19-01 \\
\hline Benzo(a)pyrene & 0.21 & ND \\
\hline Benzene & 1.4 & $0.0004(\mathrm{~J})$ \\
\hline Benzo(a)anthracene & 2.1 & ND \\
\hline Benzo(b)fluoranthene & 2.1 & ND \\
\hline Benzo(k)fluoranthene & 21 & ND \\
\hline 1,3,5-Trimethylbenzene & 70 & ND \\
\hline Naphthalene & 190 & ND \\
\hline 2-Methylnaphthalene & 190 & ND \\
\hline Chrysene & 210 & ND \\
\hline n-Propylbenzene & 240 & ND \\
\hline n-Butylbenzene & 240 & ND \\
\hline Ethylbenzene & 400 & ND \\
\hline Total Xylenes $^{a}$ & 420 & ND \\
\hline Toluene & 520 & ND \\
\hline Fluoranthene & 22,000 & ND \\
\hline Fluorene & 26,000 & ND \\
\hline Benzo(g,h,i)perylene & 29,000 & ND \\
\hline Pyrene & 29,000 & ND \\
\hline Anthracene & 100,000 & ND \\
\hline Phenanthrene & 100,000 & $0.02(\mathrm{~J})$ \\
\hline
\end{tabular}

${ }^{\mathrm{a} C}$ Combination of o-, m-, and p-xylenes

$\mathrm{mg} / \mathrm{kg}=$ Milligrams per kilogram

ND = Nondetect

SSTL $=$ Site-specific target level

$\mathrm{J}=$ Estimated value 
All detected radionuclides at a CAS are used in the sum-of-fractions calculation, and a unique Tier 2 SSTL was developed for the two radionuclides that initially exceeded Tier 1 RBSLs. Table C.1-4 provides the CAS-specific FALs established for the two radionuclides specific to CAS 03-17-01.

Table C.1-4

Final Action Levels for Radionuclides

\begin{tabular}{|c|c|c|c|c|}
\hline \multirow{2}{*}{ CAS } & \multicolumn{2}{|c|}{$\begin{array}{c}\text { Americium-241 } \\
\text { (pCi/g) }\end{array}$} & \multicolumn{2}{c|}{$\begin{array}{c}\text { Plutonium-239/240 } \\
\text { (pCi/g) }\end{array}$} \\
\hline \hline \multirow{2}{*}{$03-17-01$} & $\begin{array}{c}\text { Maximum } \\
\text { Reported Value }\end{array}$ & FAL & $\begin{array}{c}\text { Maximum } \\
\text { Reported Value }\end{array}$ & FAL \\
\cline { 2 - 5 } & 284 & $1,501^{\mathrm{a}}$ & 455 & $1,890^{\mathrm{a}}$ \\
\hline
\end{tabular}

aTier 2 action level (site-specific target level)

$\mathrm{FAL}=$ Final action level

$\mathrm{pCi} / \mathrm{g}=$ Picocuries per gram

\section{C.1.11 K. Comparison of Site Conditions with Tier 2 Table Site-Specific Target Levels}

The Tier 2 action levels are typically compared to individual sample results from reasonable points of exposure (as opposed to the source areas as is done in Tier 1) on a point-by-point basis. Points of exposure are defined as those locations or areas at which an individual or population may come in contact with a contaminant of concern originating from a CAS. For CAU 545, the Tier 2 action levels were compared to maximum contaminant concentrations from each sample location.

A comparison was conducted between the maximum concentration of the two radionuclides identified above Tier 1 action levels (i.e., Am-241 and Pu-239/240), as shown in Table C.1-1, against the CAS-specific Tier 2-based FALs listed in Table C.1-4. No radionuclides are identified above the Tier 2 action levels. The Tier 2 action levels were established as the FALs for Am-241 and $\mathrm{Pu}-239 / 240$ at CAS 03-17-01.

\section{C.1.12 L. Tier 2 Remedial Action Evaluation}

Based on the Tier 2 evaluation of the TPH-DRO hazardous constituents, the TPH-DRO contamination at CAS 20-19-01 does not pose an unacceptable risk to human health and the environment. Therefore, no further action is required concerning TPH-DRO at CAS 20-19-01. 
Based on the Tier 2 evaluation of the radiological contaminants (Am-241 and Pu-239/240), the radiological contamination at CAS 03-17-01 does not pose an unacceptable risk to human health and the environment. Therefore, no further action is required at CAS 03-17-01.

As all contaminant FALs were established as Tier 1 or Tier 2 action levels, a Tier 3 evaluation was not considered necessary. 


\section{C.2.0 Recommendations}

All of the site contaminant concentrations in soils from the analysis of CAU 545 samples were less than the corresponding FALs at all locations. It was determined that contamination at these locations does not pose a significant risk to human health or the environment and, therefore, do not warrant corrective actions.

The radiologically contaminated drilling mud (i.e., assumed to be contaminated with isotopic U, isotopic Pu, fission products, and decay products) at CAS 03-08-03 remains in place. The site was closed with a UR.

The PSM (i.e., lead pig and radiological sources) at CAS 03-23-05 were left in place; buried in blocks of grout. The site was closed with a UR.

The PSM (i.e., used oil filters) at CAS 20-19-01 were removed from the site and managed as hydrocarbon waste. 


\section{C.3.0 References}

ASTM, see American Society for Testing and Materials.

American Society for Testing and Materials. 1995. Standard Guide for Risk-Based Corrective Action Applied at Petroleum Release Sites, ASTM E 1739-95 (Reapproved 2002). Philadelphia, PA.

Appenzeller-Wing, J., U.S. Department of Energy, National Nuclear Security Administration Nevada Site Office. 2004. Letter to T.A. Maize (NDEP) entitled, "Submittal of Proposed Radiological Preliminary Action Levels (PALs) for the Industrial Sites Project,” 15 January. Las Vegas, NV.

DOE, see U.S. Department of Energy.

EPA, see U.S. Environmental Protection Agency.

Moore, J., Science Applications International Corporation. 1999. Memorandum to M. Todd (SAIC), “Background Concentrations for NTS and TTR Soil Samples,” 3 February. Las Vegas, NV.

NAC, see Nevada Administrative Code.

NBMG, see Nevada Bureau of Mines and Geology.

NCRP, see National Council on Radiation Protection and Measurements.

NNSA/NSO, see U.S. Department of Energy, National Nuclear Security Administration Nevada Site Office

National Council on Radiation Protection and Measurements. 1999. Recommended Screening Limits for Contaminated Surface Soil and Review of Factors Relevant to Site-Specific Studies/National Council on Radiation Protection and Measurements, NCRP Report No. 129. Bethesda, MD.

Nevada Administrative Code. 2006a. NAC 445A, “Water Controls.” Carson City, NV. As accessed at http://www.leg.state.nv.us/nac on 20 March 2007.

Nevada Administrative Code. 2006b. NAC 445A.227, “Contamination of Soil: Order by Director for Corrective Action; Factors To Be Considered in Determining Whether Corrective Action Required.” Carson City, NV. As accessed at http://www.leg.state.nv.us/nac on 20 March 2007.

Nevada Bureau of Mines and Geology. 1998. Mineral and Energy Resource Assessment of the Nellis Air Force Range, Open-File Report 98-1. Reno, NV.

U.S. Department of Energy. 1993. Radiation Protection of the Public and the Environment, DOE Order 5400.5, Change 2. Washington, DC: U.S. Government Printing Office. 
U.S. Department of Energy, National Nuclear Security Administration Nevada Site Office. 2004. NV/YMP Radiological Control Manual, DOE/NV--11718-079, Rev. 5. Las Vegas, NV.

U.S. Department of Energy, National Nuclear Security Administration Nevada Site Office. 2006. Industrial Sites Project Establishment of Final Action Levels, Rev. 0, DOE/NV--1107. Las Vegas, NV.

U.S. Department of Energy, National Nuclear Security Administration Nevada Site Office. 2007. Corrective Action Investigation Plan for Corrective Action Unit 545: Dumps, Waste Disposal Sites, and Buried Radioactive Materials, Nevada Test Site, Nevada, Rev. 0, DOE/NV--1210. Las Vegas, NV.

U.S. Environmental Protection Agency. 2004. Region 9 Preliminary Remediation Goals (PRGs). As accessed at http://www.epa.gov/region09/waste/sfund/prg/index.htm on 20 March 2007. 


\section{Attachment A}

\section{RESRAD Report}




\section{Attachment 1}

Derivation of Residual Radioactive Material Guidelines for Radionuclides in Soil at Corrective Action Unit (CAU) 545, CAS 03-17-01, Waste Consolidation Site 3B, Nevada Test Site, Nevada 
Derivation of Residual Radioactive Material Guidelines for Radionuclides in Soil at Corrective Action Unit (CAU) 545, Corrective Action Site (CAS) 03-17-01, Waste Consolidation Site 3B, Nevada Test Site, Nevada

January 2008

Prepared by:

Stoller-Navarro Joint Venture,

7710 W. Cheyenne, Las Vegas, Nevada 89129

Work sponsored by United States Department of Energy, National Nuclear Security Administration Nevada Site Office, Environmental Restoration Division, Las Vegas, Nevada 


\section{Derivation of Residual Radioactive Material Guidelines for Radionuclides in Soil at Corrective Action Unit (CAU) 545, Corrective Action Site (CAS) 03-17-01, Waste Consolidation Site 3B, Nevada Test Site, Nevada}

\subsection{Introduction}

The U.S. Department of Energy (DOE), the U.S. and the National Nuclear Security Administration Nevada Site Office (NNSA/NSO) Environmental Restoration Division have numerous sites impacted from the development, testing, and production of nuclear weapons. These impacts can take the form of chemical and/or radiological contaminants. Similar to its approach for chemical contamination, the NNSA/NSO is committed to properly evaluating, radiologically characterizing, and where appropriate, managing these sites to ensure the doses to radiation workers and members of the public are maintained as-low-as-reasonably achievable; at a minimum, below the primary dose limits as stated in DOE Order 5400.5 (DOE, 1993).

To accomplish this, the potential for residual radioactive contamination in soils must be evaluated to determine the status of compliance with the requirements of DOE Order 5400.5 (DOE, 1993). The DOE Order 5400.5 requires that: “The Authorized Limits shall be established to (1) provide that, at a minimum, the basic dose limits ... will not be exceeded, or (2) be consistent with applicable generic guidelines.” Because generic guidelines have not been established for volumetric residual radioactivity for the radionuclides of concern at CAU 545 CAS 03-17-01, Authorized Limits or final action levels (FALs), were derived using the Residual Radioactive (RESRAD) model and computer code (Yu et al., 2001). The goal of this effort was to produce Authorized Limits, in units of picocuries per gram (pCi/g) in soil above background, for CAU 545 CAS 03-17-01 that would result in radiation doses less than 25 mrem per year (mrem/yr) to an industrial worker at the site.

To develop the FALs, a "realistic" yet conservative radiation dose analysis was conducted using approved exposure scenarios and site-specific data to determine the translation between surface soil concentrations and individual radiation doses. For this analysis, site-specific data included soil sampling results obtained during site investigation activities at CAU 545 CAS 03-17-01, and meteorological data obtained from the Air Resources Laboratory/Special Operations and Research Division. This report provides the radiation dose modeling analysis supporting the technical derivation of the Authorized Limits for CAU 545 CAS 03-17-01, Waste Consolidation Site $3 B$. This report also defines the radionuclides considered and approved exposure scenarios for the NTS, identifies the applicable exposure pathways and key input data or assumptions, presents the radiation doses for unit concentrations of radionuclides in soil, and establishes the FALs for CAU 545 CAS 03-17-01 (ARL/SORD, 2007). 


\subsection{Site Closure Activities and Sample Results}

Radionuclides were found in the soil samples. The RESRAD calculations are based on validated analytical sample results obtained during site investigation activities and other applicable information specified in the CAU 545 Corrective Action Investigation Plan (NNSA/NSO, 2007). Because the sampling plan was a mixture of randomized and biased sampling, RESRAD calculation is based on the maximum value of the radionuclide found in the samples. Appendix A of the CAU 545 Corrective Action Decision Document/Closure Report contains a detailed description of the sample results, analytical parameters, and laboratory methods used to analyze the soil samples. The maximum concentrations (including background) found at CAS 03-17-01 are listed in Table 2-1.

Table 2-1

Maximum Radionuclide Results Found in CAU 545, CAS 03-17-01, Soil Samples

\begin{tabular}{||c|c|c||}
\hline Radionuclide & $\begin{array}{c}\text { Sample } \\
\text { Number }\end{array}$ & $\begin{array}{c}\text { Concentration } \\
\text { (pCi/g) }\end{array}$ \\
\hline \hline Americium-241 & $545 \mathrm{~B} 030$ & 284 \\
\hline Cesium-137 & $545 \mathrm{~B} 032$ & 5.14 \\
\hline Europium-152 & $545 \mathrm{~B} 032$ & 2.17 \\
\hline Plutonium-238 & $545 \mathrm{~B} 033$ & 5.14 \\
\hline Plutonium-239/240 & $545 \mathrm{~B} 035$ & 455 \\
\hline Strontium-90 & $545 \mathrm{~B} 032$ & 1.1 \\
\hline Uranium-233 & $545 \mathrm{~B} 035$ & 2.42 \\
\hline Uranium-235 & $545 \mathrm{~B} 032$ & 1.16 \\
\hline Uranium-238 & $545 \mathrm{~B} 045$ & 1.10 \\
\hline
\end{tabular}

$\mathrm{pCi} / \mathrm{g}=$ Picocuries per gram 


\subsection{Initial Concentrations for Principal Radionuclides}

Principal radionuclides are defined as radionuclides with a half-life greater than six months. The decay products of any principal radionuclide down to, but not including, the next principal radionuclide in its decay chain are defined as associated radionuclides. The RESRAD assumes that a principal radionuclide is in secular equilibrium with its associated radionuclides at the point of exposure. Therefore, associated radionuclides and radionuclides with half-lives less than six months are not input into the RESRAD calculations.

\subsection{Authorized Values for Initial Concentrations of Principal Radionuclides}

The authorized exposure scenarios specify that value of the arithmetic mean plus the 95 percent upper confidence level (UCL) obtained from site-specific sampling results are entered as the principal radionuclide concentrations for RESRAD calculates. The sample results for all samples with radionuclide concentrations above the minimum detectable concentration within the land parcels are entered into the EPA software application ProUCL version 4.0. The ProUCL software is used to calculate the 95 percent UCL for principal radionuclide concentrations based on the distribution of the unknown mean.

For instances where the ProUCL software determined that there was not enough data to calculate the 95 percent UCL for a specific radionuclide, the maximum concentration from the sample dataset was used as the initial concentration for that radionuclide.

\subsection{Authorized Values Initial Concentrations of Principal Radionuclides for Area Averaging/Location Specific Scenarios}

The DOE Order 5400.5 (DOE, 1993) states: "Residual concentrations of radioactive material in soil are defined as those in excess of background concentrations averaged over an area of

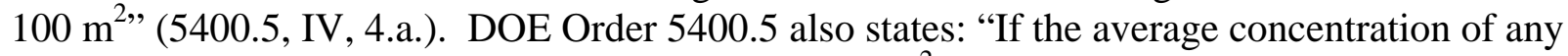
surface or below-surface area less than or equal to $25 \mathrm{~m}^{2}$, exceeds the limit or guideline by a factor of $(100 / \mathrm{A})^{0.5}$, [where $\mathrm{A}$ is the area (in square meters) of the region in which concentrations are elevated], limits for "hot-spots" shall also be developed and applied" (5400.5, IV, 4.a.(1)). DOE Order 5400.5, IV, 4.a.(1) indicates that criterion for these location-specific analysis is discussed in DOE G 441.1-XX (DOE, 2002) Section 5.2.2.

The purpose of the location-specific analysis criterion is to ensure that applying the homogeneous criteria, in which the concentrations of residual radioactive material are averaged over a 100-square meter $\left(\mathrm{m}^{2}\right)$ area, does not result in the release of small areas that, because of averaging, contain unacceptably high concentrations of residual radioactive material. The location-specific criterion is used to supplement Authorized Limits for larger areas and is intended to prevent excessive exposures from a small, contaminated area that is within a larger area that meets the basic Authorized Limits. Thus, it is intended for use in areas where the residual radioactive material concentrations are not uniform. Also, the above criterion was derived conservatively, assuming the Authorized Limits were based on a dose constraint of $25 \mathrm{mrem} / \mathrm{yr}$, and selected to ensure unlikely exposure conditions would not cause the primary dose limit (100 mrem/yr) to be exceeded. The authorized exposure scenarios specify that the value of the maximum concentration of principal radionuclides obtained from site-specific 
sampling results be entered as the principal radionuclide concentrations for RESRAD location-specific calculations. The authorized area parameters for RESRAD location-specific calculations are $1 \mathrm{~m}^{2}, 10 \mathrm{~m}^{2}$, and $100 \mathrm{~m}^{2}$ contamination areas.

\subsection{Inhomogeneous Contamination and Initial Radionuclide Concentrations}

A contaminated zone is inhomogeneous if it contains a contaminated region within which the concentration of a radionuclide exceeds three times the average for the contaminated zone. The RESRAD uses a mathematical construct that assumes uniform distribution of radionuclides within a volume. However, RESRAD recognizes that radiological contamination is inhomogeneous in nature and provides detailed guidance for applying inhomogeneous criteria (e.g., location-specific criteria, sum of fractions rule). The RESRAD User's Manual states that the inhomogeneous release criteria are generally more realistic and hence less restrictive than the homogeneous release criteria (Yu, et.al, 2001). This shows that the approved initial radionuclide concentration values (i.e., arithmetic mean plus 95 percent UCL or the maximum radionuclide concentration from the sample dataset) will result in more restrictive release criteria. The arithmetic mean plus the 95 percent UCL are used for the initial concentrations of principal radionuclides when the sample results are obtained using a random sampling method. The maximum radionuclide concentration values are used for the initial concentrations of principal radionuclides when the sample results are obtained using a nonrandom (e.g., bias or judgmental sampling) sampling method.

The RESRAD states that a statistical approach should always be considered as a first priority regarding the estimation of soil concentrations, as cited in the Data Collection Handbook to Support Modeling Impacts of Radioactive Material in Soil (Yu et al., 1993). The 95 percent UCL represents a value that has a 5 percent chance that the actual mean of the dataset would exceed it. The 95 percent UCL is computed using the EPA code ProUCL. The code calculates the 95 percent UCL based on the distribution of the dataset (e.g., normal, log-normal, gamma, nonparametric).

The ProUCL software has been developed to compute an appropriate 95 percent UCL of the unknown population mean to support exposure assessment and cleanup decisions for EPA projects. A 95 percent UCL of the unknown population arithmetic mean is often used to:

- Estimate the exposure point concentration (EPC) term.

- Determine the attainment of cleanup standards.

- Estimate background level mean contaminant concentrations, or

- Compare the soil concentrations with site-specific soil screening levels.

It is important to compute a reliable, conservative, and stable 95 percent UCL of the population mean using the available data. The 95 percent UCL should approximately provide the 95 percent coverage for the unknown population mean.

The EPA has recommended that the maximum value of the dataset be used for the initial EPC term when the 95 percent UCL exceeds the maximum (EPA, 1992). However, if the maximum value of the dataset is used, then most of the statistical data associated with the distribution of the dataset are ignored (except for the maximum). Therefore, by using the mean plus the 95 percent 
UCL, the statistical data associated with the dataset are retained, and the value approaches or exceeds the maximum value of the dataset as recommended by EPA.

\subsection{Initial Concentrations of Principal Radionuclide for CAU 545, CAS 03-17-01}

The initial radionuclide concentrations used for the RESRAD calculations are those listed in Table 2-1. Because the sampling plan was a mixture of randomized and biased sampling, the maximum value of the radionuclide found in the samples is used for RESRAD analysis. 


\subsection{Authorized RESRAD Exposure Pathways and Scenarios}

This section describes the input parameters, exposures scenarios, and guidance for calculating site-specific radiological remediation levels for projects using the RESRAD computer code, as agreed to by NNSA/NSO and Nevada Division of Environmental Protection (NDEP).

\subsection{Guidance for RESRAD Calculations}

The guidance in this section was developed by NNSA/NSO and NDEP and is only applicable to soils containing residual radioactive material. This guidance does not apply to structures, facilities, equipment, and building materials containing contaminated surfaces or volume contamination. The primary dose limit for any member of the public is 100-millirem (mrem) total effective dose equivalent in a year. This limit applies to the sum of internal and external doses resulting from all modes of exposure to all radiation sources other than background radiation and doses received as a patient from medical sources as required by DOE 5400.5, II.1.a.(3)(a) (DOE, 1993). The dose constraint is defined as one quarter of the dose limit (i.e., 25-mrem) and will be applied to ensure that, in a 1,000-year period, the maximally exposed individual does not exceed the dose constraint in any single year. The requirements of Chapter IV of DOE 5400.5 Chapter IV will not specifically apply if NNSA/NSO chooses to continue to own and actively control access or use of the site. However, the radiation protection requirements in the other sections of DOE 5400.5 will apply to NNSA/NSO owned and maintained sites.

Due to the large spatial variability in background amongst sites, the "above background criterion" will be defined as the concentration of a specific radionuclide in soil that equals or exceeds its corresponding preliminary action level (PAL). The source data for these radionuclide specific PALs are taken directly from National Council on Radiation Protection and Measurements Report No. 129 Table 2.1, Construction, Commercial, Industrial land-use scenario column for a 25-mrem dose constraint (NCRP, 1999). The generic guidelines for residual concentrations of radium (Ra)-226, Ra-228, thorium (Th)-230, and Th-232 are found in Chapter IV of DOE Order 5400.5, Change 2, Radiation Protection of the Public and Environment (DOE, 1993).

Background radiation refers to the local area and includes:

- Concentration of naturally occurring radionuclides.

- Cosmic radiation.

- Radionuclides of anthropogenic origin that have been globally dispersed and are present at low concentrations such as fallout from nuclear weapons. (Note: This is not the case at the NTS because the historical aspects of the NTS [e.g., above and underground testing, and other operations resulted in dispersion of radionuclides locally].)

Due to the impracticality of determining "true" background, a dose constraint with no background subtraction will be used (i.e., a dose constraint not in excess of background). The 
use of the dose constraint with no background subtraction is a far more conservative and sensitive approach because it does not deal with the uncertainty of natural background.

\subsection{Description of Approved Scenarios}

Detailed description for each scenario can be found in the Industrial Sites Project Establishment of Final Action Levels (NNSA/NV, 2006).

\subsection{Residual Radioactive Material Guideline}

The residual radioactive material guideline represents the concentration of residual radioactive material that can remain in place and still allow use of that area without radiological restrictions. Using site-specific parameters and sample analysis results, the radioactive material guideline, $\mathrm{G}$, can be calculated for a given dose limit of $\mathrm{H}_{\mathrm{EL}}$ for an individual as follows;

$$
\mathrm{G}=\mathrm{H}_{\mathrm{EL}} / \mathrm{DSR}
$$

where DSR is the total dose/source concentration ratio. The dose limit $\mathrm{H}_{\mathrm{EL}}$, used to derive the residual radioactive material guideline is $25 \mathrm{mrem} / \mathrm{yr}$.

Single radionuclide guidelines are calculated for individual radionuclides such that the annual dose to industrial/construction workers at the site should not exceed an annual dose limitation of $25 \mathrm{mrem} / \mathrm{yr}$. Sites contaminated with two or more radionuclides (i.e., a mixture of radionuclides) require further evaluation to ensure that collective exposures from individual radionuclides do not exceed the $25 \mathrm{mrem} / \mathrm{yr}$ annual dose constraint. This evaluation is performed using a sum of the fractions method. The initial soil concentration of each radionuclide is divided by the single radionuclide guideline for that radionuclide to produce a ratio. These ratios are then summed. If the sum is less than or equal to unity, then the collective annual dose from all radionuclides at the site should not exceed the $25 \mathrm{mrem} / \mathrm{yr}$ annual dose constraint. If the sum does exceed unity, the annual dose to industrial/construction workers could exceed the $25 \mathrm{mrem} / \mathrm{yr}$ dose constraint, even if the concentrations of residual radionuclides at the site are below the single radionuclide guideline values. For sites where the sum of the ratios exceeds unity, residual radioactive material guidelines for mixtures of radionuclides are calculated such that the following equation is satisfied;

$$
\overline{\mathrm{M}}=\sum_{\mathrm{i}} \overline{\mathrm{S}}_{\mathrm{i}}\left(\mathrm{t}_{\mathrm{o}}\right) / \mathrm{G}_{\mathrm{i}}\left(\mathrm{t}_{\mathrm{m}}\right) \leq 1
$$

Where: $\quad \overline{\mathrm{M}} \quad=\quad$ average mixture sum (dimensionless)

$\overline{\mathrm{S}}_{\mathrm{i}}\left(\mathrm{t}_{\mathrm{o}}\right) \quad=\quad$ initial concentration of the $i$ th principal radionuclide averaged over an area determined by scenario activities 


$$
\mathrm{G}_{\mathrm{i}}\left(\mathrm{t}_{\mathrm{m}}\right)=\quad \begin{aligned}
& \text { single radionuclide soil concentration guideline for the } i \text { th } \\
& \text { principal radionuclide at time t maximum. }
\end{aligned}
$$

For a site where the sum of the ratios does not exceed unity, the residual radioactive guidelines for single radionuclides are the radionuclide concentrations to be used as the FAL. For sites where the sum of the ratios exceeds unity, the residual radioactive guidelines for mixtures of radionuclides are mathematically adjusted so that the above equation is satisfied. Those adjusted values are then used as the FAL. 


\subsection{RESRAD Calculations for CAU 545 CAS 03-17-01, Waste Consolidation Site $3 B$}

This section discuses the RESRAD calculations and results for CAU 545 CAS 03-17-01. Industrial Worker scenario is selected as the exposure scenario because the operational history of the CAS and to demonstrate conservatism for the final action levels.

\subsection{User Input Parameters}

The RESRAD default parameters that were modified for the calculations performed for CAU 545 CAS 03-17-01 in this report and the site-specific values entered are presented in Table 5-1, RESRAD Parameter Input Values for CAU 545 CAS 03-17-01. The initial radionuclide concentrations used for analyses are those listed in Table 2-1.

\subsection{Radionuclide Concentrations and Dose Estimates}

The maximum dose results from RESRAD calculations for the CAU 545 CAS 03-17-01 is $12.76 \mathrm{mrem} / \mathrm{yr}$ (Table 5-2) occurring at year zero (current year) and the dose will decrease to zero year 300. The detailed RESRAD results for this CAS are provided in Exhibit 1, RESRAD Summary Report: CAU 545 CAS 03-17-01.

Uncertainty in the derivation of dose estimates and dose/source contribution ratios comes from the distribution of possible input parameter values, as well as uncertainty in the conceptual model used to represent the site. The pathway contributing to the total annual dose at the time of maximum dose occurs are inhalation (58.72 percent), external exposure (22.13 percent), and soil ingestion (19.16 percent). Therefore, uncertainties in the following parameters: soil disturbance (e.g., erosion rates), thickness of contaminated zone, and occupancy factors have the greatest significance on the model predictions.

Because the radionuclide concentrations found at this site pose a dose level below the $25 \mathrm{mrem} / \mathrm{yr}$ constraint under the current site conditions, remediation alternative is not necessary for the site.

\subsection{Residual Radioactive Material Guidelines for CAU 545 CAS 03-17-01}

The sum of the ratios for CAU 545 CAS 03-17-01 does not exceed unity. Table 5-3, presents the calculations results for deriving guidelines for radionuclides for this CAS. The FAL for the CAU 545 CAS 03-17-01 scenario is the residual radioactive material guideline values for single radionuclide. 
Table 5-1

RESRAD Parameters Input Values for CAU 545 CAS 03-17-01

\begin{tabular}{|c|c|c|c|c|}
\hline Parameter & Units & $\begin{array}{c}\text { CAU } 545 \text { CAS } \\
03-17-01\end{array}$ & Defaults & Reference/Rationale \\
\hline Area of $\mathrm{CZ}$ & $\mathrm{m}^{2}$ & $1.000 \mathrm{E}+02$ & $1.000 \mathrm{E}+04$ & Estimated using the sampling boundary \\
\hline Thickness of CZ & $\mathrm{m}$ & $1.500 \mathrm{E}-01$ & $2.000 \mathrm{E}+00$ & Top layer of the contamination soil \\
\hline Principal radionuclides & $\mathrm{pCi} / \mathrm{g}$ & See Table 2-1 & 0.0 & $\begin{array}{l}\text { Initial concentrations are the maximum concentrations from sample } \\
\text { results. }\end{array}$ \\
\hline Average Annual Wind Speed & $\mathrm{m} / \mathrm{sec}$ & 4.07 & $2.000 \mathrm{E}+00$ & NNSA/NSO, 2007 \\
\hline Precipitation & $\mathrm{m} / \mathrm{yr}$ & 1.626E-01 & $1.000 \mathrm{E}+00$ & Data from Air Resources Laboratory \\
\hline Runoff Coefficient & - & 4.000E-01 & 2.000E-01 & Open Sandy Loam 30\% impervious Table 10.1 (Yu, et al., 1993) \\
\hline Mass Loading for Inhalation & $\mathrm{g} / \mathrm{m}^{3}$ & $6.00 \mathrm{E}-04$ & $1 \mathrm{E}-04$ & $\begin{array}{l}\text { The estimated mass loading for construction activities. (Yu, et al., } \\
\text { 1993) }\end{array}$ \\
\hline Exposure Duration & $\mathrm{yr}$ & 25 & 30 & Standard for Industrial/Commercial Scenario \\
\hline Shielding Factor Inhalation & - & 1.0 & 0.4 & Assumes no indoor time fraction \\
\hline Shielding Factor External Gamma & - & 1.0 & 0.7 & Assumes no indoor time fraction \\
\hline Fraction of Time Spent Indoors & - & 0.0 & 0.5 & Assumes no indoor time fraction \\
\hline Fraction of Time Spent Outdoors & - & 8.55E-02 & 0.25 & NNSA/NSO, 2007 \\
\hline Soil Ingestion Rate & $g / y r$ & 108 & 36.5 & NNSA/NSO, 2007 \\
\hline $\begin{array}{l}\mathrm{CZ}=\text { Contaminated Zone } \\
\mathrm{g} / \mathrm{m}^{3}=\text { Grams per cubic meter } \\
\mathrm{g} / \mathrm{yr}=\text { Grams per year } \\
\mathrm{m}=\text { Meter } \\
\mathrm{m}^{2}=\text { Square meter }\end{array}$ & & & \multicolumn{2}{|c|}{$\begin{array}{l}\mathrm{m} / \mathrm{sec}=\text { Meters per second } \\
\mathrm{m} / \mathrm{yr}=\text { Meters per year } \mathrm{pCi} / \mathrm{g}=\text { Picocuries per gram } \\
\mathrm{RESRAD}=\text { Residual Radioactive } \\
\mathrm{yr}=\text { Year } \\
-=\text { Unitless }\end{array}$} \\
\hline
\end{tabular}


Table 5-2

Maximum Dose Contributions for CAU 545 CAS 03-17-01 Using Industrial Worker Scenario (dose as mrem/yr)

\begin{tabular}{|c|c|c|c|c|c|c|c|c|}
\hline \multirow{2}{*}{ Radionuclide } & \multicolumn{2}{|c|}{ Ground } & \multicolumn{2}{|c|}{ Inhalation } & \multicolumn{2}{|c|}{ Soil Ingestion } & \multicolumn{2}{|c|}{ Total } \\
\hline & $\begin{array}{c}\text { Annual } \\
\text { Dose }\end{array}$ & Fraction & $\begin{array}{c}\text { Annual } \\
\text { Dose }\end{array}$ & Fraction & $\begin{array}{c}\text { Annual } \\
\text { Dose }\end{array}$ & Fraction & $\begin{array}{c}\text { Annual } \\
\text { Dose }\end{array}$ & Fraction \\
\hline Americium-241 & 8.778E-01 & 0.0688 & $2.906 \mathrm{E}+00$ & 0.2278 & 9.455E-01 & 0.0741 & $4.730 \mathrm{E}+00$ & 0.3707 \\
\hline Cesium-137 & $1.050 E+00$ & 0.0823 & 3.759E-06 & 0.0000 & 2.338E-04 & 0.0000 & $1.051 \mathrm{E}+00$ & 0.0823 \\
\hline Europium-152 & 8.671E-01 & 0.0680 & $1.084 \mathrm{E}-05$ & 0.0000 & 1.261E-05 & 0.0000 & 8.671E-01 & 0.0680 \\
\hline Plutonium-238 & 5.991E-05 & 0.0000 & 4.654E-02 & 0.0036 & 1.508E-02 & 0.0012 & 6.168E-02 & 0.0048 \\
\hline Plutonium-239/240 & 9.196E-03 & 0.0007 & $4.527 E+00$ & 0.3548 & $1.482 \mathrm{E}+00$ & 0.1162 & $6.018 \mathrm{E}+00$ & 0.4717 \\
\hline Strontium-90 & 1.703E-03 & 0.0001 & 3.287E-05 & 0.0000 & 1.523E-04 & 0.0000 & 1.888E-03 & 0.0001 \\
\hline Uranium-233 & 2.412E-04 & 0.0000 & 7.566E-03 & 0.0006 & 6.427E-04 & 0.0001 & 8.450E-03 & 0.0007 \\
\hline Uranium-235 & 5.932E-03 & 0.0005 & 3.302E-04 & 0.0000 & 2.849E-05 & 0.0000 & 6.291E-03 & 0.0005 \\
\hline Uranium-238 & 1.026E-02 & 0.0008 & 3.005E-03 & 0.0002 & 2.714E-04 & 0.0000 & 1.354E-02 & 0.0011 \\
\hline Total & $2.823 E+00$ & 0.2213 & $7.490 \mathrm{E}+00$ & 0.5872 & $2.444 \mathrm{E}+00$ & 0.1916 & $1.276 \mathrm{E}+01$ & 1.0000 \\
\hline
\end{tabular}

$\mathrm{mrem} / \mathrm{yr}=$ Millirem per year 
Table 5-3

CAU 545, CAS 03-17-01, Final Action Level

\begin{tabular}{||c|c|c||}
\hline Radionuclide & $\begin{array}{c}\text { Initial Radionuclide } \\
\text { Concentration } \\
\text { (pCi/g) }\end{array}$ & $\begin{array}{c}\text { Final Action Level } \\
\text { (pCi/g) }\end{array}$ \\
\hline \hline Americium-241 & $2.840 \mathrm{E}+02$ & $1.501 \mathrm{E}+03$ \\
\hline Cesium-137 & $5.140 \mathrm{E}+00$ & $1.223 \mathrm{E}+02$ \\
\hline Europium-152 & $2.170 \mathrm{E}+00$ & $6.256 \mathrm{E}+01$ \\
\hline Plutonium-238 & $5.140 \mathrm{E}+00$ & $2.083 \mathrm{E}+03$ \\
\hline Plutonium-239/240 & $4.550 \mathrm{E}+02$ & $1.890 \mathrm{E}+03$ \\
\hline Strontium-90 & $1.100 \mathrm{E}+00$ & $1.457 \mathrm{E}+04$ \\
\hline Uranium-233 & $2.420 \mathrm{E}+00$ & $7.160 \mathrm{E}+03$ \\
\hline Uranium-235 & $1.160 \mathrm{E}+01$ & $4.610 \mathrm{E}+02$ \\
\hline Uranium-238 & $1.100 \mathrm{E}+00$ & $2.031 \mathrm{E}+03$ \\
\hline
\end{tabular}

$\mathrm{pCi} / \mathrm{g}=$ Picocuries per gram 


\subsection{References}

ARL, see Air Resources Laboratory.

Air Resources Laboratory. 2007. "Climatological Information and Data.” As accessed at http://www.sord.nv.doe.gov on 28 November.

DOE, see U.S. Department of Energy.

EPA, see U.S. Environmental Protection Agency.

NCRP, see National Council on Radiation Protection and Measurements.

National Council on Radiation Protection and Measurements. 1999. Recommended Screening Limits for Contaminated Surface Soil and Review of Factors Relevant to Site-Specific Studies/National Council on Radiation Protection and Measurements, NCRP Report No. 129. Bethesda, MD.

U.S. Department of Energy. 1993. Radiation Protection of the Public and the Environment, DOE 5400.5. Change 2. Washington, DC.

U.S. Department of Energy. 2002. Draft Implementation Guide, Control and Release of Property with Residual Radioactive Material, for use with DOE 5400.5, Radiation Protection of the Public and the Environment, DOE G 441.1-XX. Washington, DC.

U.S. Department of Energy, National Nuclear Security Administration Nevada Site Office. 2006. Industrial Sites Project Establishment of Final Action Levels. Rev. 0, DOE/NV1107, Las Vegas, NV.

U.S. Department of Energy, National Nuclear Security Administration Nevada Site Office. 2007. Corrective Action Investigation Plan for CAU 545, Waste Disposal Sites, and Buried Radioactive Materials, Nevada Test Site, Nevada, Rev 0, DOE/NV-1210, Las Vegas, NV.

U.S. Environmental Protection Agency. 1992. Memorandum from F. Habicht (EPA), entitled “Guidance on Risk Managers and Risk Assessor.” Washington, DC.

Yu C., Loureiro C., Cheng C. C., Jones L. G., Wang Y. Y., Chia Y. P., and Faillace E. 1993. Data Collection Handbook to Support Modeling the Impacts of Radioactive Material in Soil, ANL/EAIS-8. Environmental Assessment Division, Argonne National Laboratory. Chicago, IL:

Yu C., A.J. Zielen, J.J Cheng, D.J. LePoire., E. Gnanapragasam, S. Kamboj, J. Arnish, A. Wallo III, W.A. Williams, and H. Peterson. 2001. User's Manual for RESRAD Version 6, ANL/EAD-4, Argonne National Laboratory, Environmental Assessment Division, Argonne, IL. 


\section{Exhibit 1}

\section{RESRAD Summary Report: CAU 545 CAS 03-17-01 \\ (27 pages)}


1RESRAD, Version 6.3 T« Limit $=180$ days

Summary : CAU 545 CAS 03-17-01 Biasd

11/28/2007 23:08 Page 1

File: CAU 545_ind_Biased.RAD

Table of Contents

ÄÄÄÄÄÄÄÄÄÄÄÄÄÄÄ

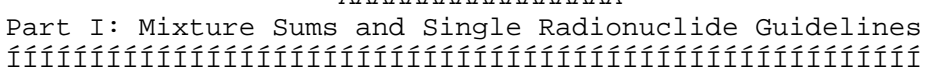

Dose Conversion Factor (and Related) Parameter Summary ... Site-Specific Parameter Summary .................. 6

Summary of Pathway Selections $\ldots \ldots \ldots \ldots \ldots \ldots \ldots \ldots \ldots \ldots, 12$

Contaminated Zone and Total Dose Summary $\ldots \ldots \ldots \ldots \ldots \ldots .13$

Total Dose Components

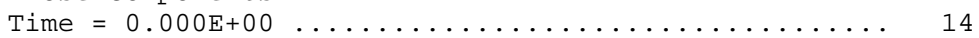

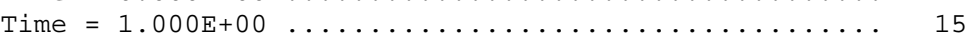

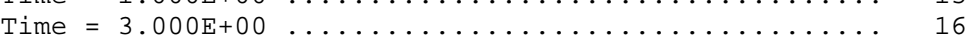

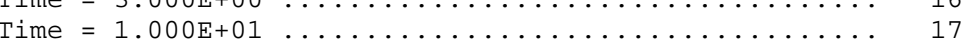

Time $=3.000 \mathrm{E}+01 \ldots \ldots \ldots \ldots \ldots \ldots \ldots \ldots \ldots \ldots \ldots \ldots, 18$

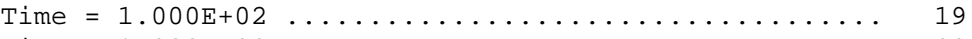

Time $=3.000 \mathrm{E}+02 \ldots \ldots \ldots \ldots \ldots \ldots \ldots \ldots \ldots \ldots \ldots \ldots, 20$

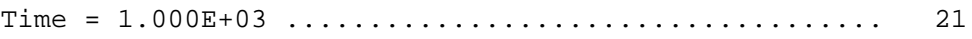

Dose/Source Ratios Summed Over All Pathways .......... 22

Single Radionuclide Soil Guidelines ................. 23

Single Radionuclide Soil Guidelines $\ldots \ldots \ldots \ldots \ldots \ldots \ldots \ldots$
Dose Per Nuclide Summed over All Pathways $\ldots \ldots \ldots \ldots \ldots \ldots$

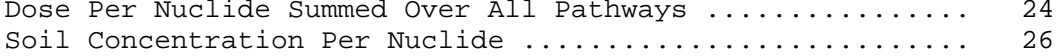




$\begin{array}{ll}\text { 1RESRAD, Version 6.3 T« Limit }=180 \text { days } & \text { 11/28/2007 23:08 Page } 2 \\ \text { Summary : CAU 545 CAS } 03-17-01 \text { Biasd } & \text { File: CAU 545_ind_Biased.RAD }\end{array}$

Dose Conversion Factor (and Related) Parameter Summary

File: FGR 13 MORBIDITY

$\odot$

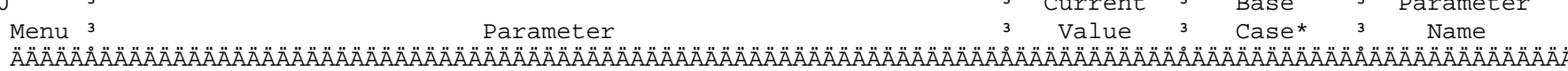

3 Current 3 Base 3 Parameter

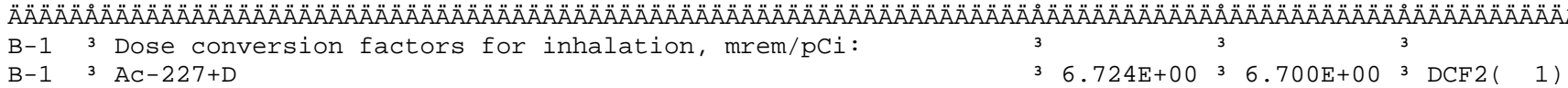

$\mathrm{B}-1 \quad 3 \mathrm{Am}-241$

B-1 3 Cs $-137+D$

B-1 3 Eu-152

B-1 3 Gd-152

$\mathrm{B}-1 \quad 3 \mathrm{~Np}-237+\mathrm{D}$

B-1 $3 \mathrm{~Pa}-231$

B-1 3 Pb-210+D

$\mathrm{B}-1 \quad 3 \mathrm{Pu}-238$

$\mathrm{B}-1 \quad 3 \mathrm{Pu}-239$

B-1 3 Ra-226+D

B-1 3 Sr $-90+\mathrm{D}$

B-1 3 Th-229+D

B-1 3 Th-230

B-1 3 U-233

B-1 3 U-234

B-1 3 U-235+D

$B-1 \quad 3 \quad U-238$

B-1 3 U-238+D

D-1 3 Dose conversion factors for ingestion, $\mathrm{mrem} / \mathrm{pCi}$ :

D-1 3 AC-227+D

D-1 3 Am-241

D-1 $3 \mathrm{Cs}-137+\mathrm{D}$

D-1 3 Eu-152

D-1 3 Gd-152

$\mathrm{D}-1 \quad 3 \quad \mathrm{~Np}-237+\mathrm{D}$

$\mathrm{D}-1 \quad 3 \mathrm{~Pa}-231$

D-1 3 Pb-210+D

D-1 3 Pu-238

D-1 3 Pu-239

D-1 3 Ra-226+D

D-1 3 Sr -90+D

D-1 3 Th-229+D

D-1 3 Th -230

$\mathrm{D}-1 \quad 3 \quad \mathrm{U}-233$

$\mathrm{D}-1 \quad 3 \quad \mathrm{U}-234$

D-1 3 U-235+D

$\mathrm{D}-1 \quad 3 \quad \mathrm{U}-238$

D-1 3 U-238+D

D-34 3 Food transfer factors

D-34 3 AC-227+D, plant/soil concentration ratio, dimensionless $\mathrm{D}-343 \mathrm{AC}-227+\mathrm{D}$, beef/livestock-intake ratio, $(\mathrm{pCi} / \mathrm{kg}) /(\mathrm{pCi} / \mathrm{d})$ $\mathrm{D}-343 \mathrm{AC}-227+\mathrm{D}$, milk/livestock-intake ratio, $(\mathrm{pCi} / \mathrm{L}) /(\mathrm{pCi} / \mathrm{d})$

$\mathrm{D}-344^{3}$

D-34 3 Am-241, plant/soil concentration ratio, dimensionless

$\mathrm{D}-343 \mathrm{Am}-241$, beef/livestock-intake ratio, $(\mathrm{pCi} / \mathrm{kg}) /(\mathrm{pCi} / \mathrm{d})$

D-34 3 Am-241

, milk/livestock-intake ratio, $(\mathrm{pCi} / \mathrm{L}) /(\mathrm{pCi} / \mathrm{d})$

$\left.\begin{array}{llll}6.724 E+\odot \odot & 6.700 E+\odot \odot & \text { DCF2( } & 1\end{array}\right)$

$3.190 \mathrm{E}-05$ 3 $3.190 \mathrm{E}-05$ 3 DCF2 ( 3$)$

$32.210 E-04{ }^{3}$ 2.210E-04 3 DCF2( 4$)$

3 2.430E-01 3 2.430E-01 3 DCF2( 6)

3 5.400E-01 3 5.400E-01 3 DCF2( 7)

$1.280 \mathrm{E}+00 \quad 3 \quad 1.280 \mathrm{E}+00$ 3 DCF2 ( 8)

3 2.320E-02 3 1.360E-02 3 DCF2( 9$)$

3 3.920E-01 3 $3.920 \mathrm{E}-01$ 3 DCF2( 10$)$

4.290E-01 3 4.290E-01 3 DCF2( 12 )

3 8.594E-03 3 8.580E-03 3 DCF2( 13$)$

$1.308 \mathrm{E}-03$ 3 $1.300 \mathrm{E}-03$ 3 DCF2( 14$)$

$2.169 \mathrm{E}+00 \quad 3 \quad 2.150 \mathrm{E}+00 \quad 3 \quad \mathrm{DCF} 2(\mathrm{15})$

3.260E-01 3 3.260E-01 3 DCF2( 16$)$

$1.350 E-01$ 3 $1.350 E-01$ 3 DCF2( 17$)$

1.320E-01 3 1.320E-01 3 DCF2( 18$)$

1.230E-01 3 1.230E-01 3 DCF2( 19$)$

3 1.180E-01 3 1.180E-01 3 DCF2( 20 )

$31.180 E-01{ }^{3} 1.180 E-01{ }^{3}$ DCF2( 21$)$

3 1.480E-02 3 1.410E-02 3 DCF3( 1$)$

$3.640 \mathrm{E}-03$ 3 $3.640 \mathrm{E}-03$ 3 DCF3( 2$)$

3 5.000E-05 3 5.000E-05 3 DCF3( 3$)$

6.480E-06 3 6.480E-06 3 DCF3( 4$)$

$1.610 \mathrm{E}-044^{3} 1.610 \mathrm{E}-04{ }^{3}$ DCF3( 6$)$

3 4.444E-03 3 4.440E-03 3 DCF3( 7$)$

$31.060 \mathrm{E}-02{ }^{3}$ 1.060E-02 3 DCF3( 8)

3 7.276E-03 3 5.370E-03 3 DCF3(9)

3 3.200E-03 3 3.200E-03 3 DCF3( 10)

3 3.540E-03 3 3.540E-03 3 DCF3( 12)

1.321E-03 3 1.320E-03 3 DCF3( 13$)$

3 1.528E-04 3 1.420E- $04{ }^{3}$ DCF3( 14$)$

4.027E-03 3 3.530E-03 3 DCF3( 15$)$

5.480E-04 3 5.480E-04 3 DCF3( 16$)$

3 2.890E-04 3 2.890E-04 3 DCF3( 17$)$

$2.830 \mathrm{E}-04 \quad 3 \quad 2.830 \mathrm{E}-04 \quad 3$ DCF3( 18$)$

$32.673 \mathrm{E}-04{ }^{3}$ 2.660E- $04{ }^{3}$ DCF3( 19$)$

$2.550 \mathrm{E}-04 \quad 3 \quad 2.550 \mathrm{E}-04{ }^{3}$ DCF3( 20$)$

3 2.687E-๑4 3 2.550E-๑4 3 DCF3( 21)

3 2.500E-03 3 2.500E-03 3 RTF( 1,1$)$

2. $000 \mathrm{E}-05 \quad 3 \quad 2.000 \mathrm{E}-053 \mathrm{RTF}(1,2)$

2. 000E-05 3 2.000E-05 $3 \operatorname{RTF}(1,3)$

1. $000 \mathrm{E}-03 \quad 3 \quad 1.000 \mathrm{E}-03 \quad 3 \operatorname{RTF}(2,1)$

5. $000 \mathrm{E}-05$ 3 $5.000 \mathrm{E}-053 \operatorname{RTF}(2,2)$

$32.000 \mathrm{E}-06$ 3 2.000E-06 $3 \operatorname{RTF}(2,3)$

UNCONTROLLED When Printed 

1RESRAD, Version 6.3
T $\ll$ Limit $=180$ days
11/28/2007 23:08 Page 3
Summary : CAU 545 CAS $03-17-01$ Biasd
File: CAU 545 ind Biased. RAD

Dose Conversion Factor (and Related) Parameter Summary (continued) File: FGR 13 MORBIDITY

$\odot^{0}$ Menu ${ }^{3}$

Menu 3 Parameter

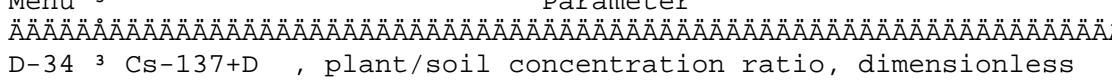
plant/soil concentration ratio, dimensionless Current ${ }^{3}$ Base ${ }^{3}$ Parameter $\mathrm{D}-34{ }^{3} \mathrm{Cs}-137+\mathrm{D}$, beef/livestock-intake ratio, $(\mathrm{pCi} / \mathrm{kg}) /(\mathrm{pCi} / \mathrm{d})$ $\mathrm{D}-343 \mathrm{Cs}-137+\mathrm{D}$, milk/livestock-intake ratio, (pCi/L)/(pCi/d) $\mathrm{D}-343$

$\mathrm{D}-344^{3} \mathrm{Eu}-152$

D-34 3 Eu-152

D-34 3 Eu-152

D-34 3

D-34 3 Gd -152

D-34 3 Gd-152

D-34 $3 \mathrm{Gd}-152$

$\mathrm{D}-344^{3}$

$\mathrm{D}-343 \mathrm{~Np}-237+\mathrm{D}$

plant/soil concentration ratio, dimensionless beef/livestock-intake ratio, $(\mathrm{pCi} / \mathrm{kg}) /(\mathrm{pCi} / \mathrm{d})$ , milk/livestock-intake ratio, $(\mathrm{pCi} / \mathrm{L}) /(\mathrm{pCi} / \mathrm{d})$

plant/soil concentration ratio, dimensionless beef/livestock-intake ratio, $(\mathrm{pCi} / \mathrm{kg}) /(\mathrm{pCi} / \mathrm{d})$ , milk/livestock-intake ratio, $(\mathrm{pCi} / \mathrm{L}) /(\mathrm{pCi} / \mathrm{d})$ $\mathrm{D}-343 \mathrm{~Np}-237+\mathrm{D}$, beef/livestock-intake ratio, $(\mathrm{pCi} / \mathrm{kg}) /(\mathrm{pCi} / \mathrm{d})$ $\mathrm{D}-343 \mathrm{~Np}-237+\mathrm{D}$, milk/livestock-intake ratio, $(\mathrm{pCi} / \mathrm{L}) /(\mathrm{pCi} / \mathrm{d})$ $\mathrm{D}-344^{3}$

$\mathrm{D}-34 \quad \mathrm{~Pa}-231$

$\mathrm{D}-34 \quad \mathrm{~Pa}-231$

$\mathrm{D}-34 \quad 3 \mathrm{~Pa}-231$

$\mathrm{D}-343$

$\mathrm{D}-344^{3} \mathrm{~Pb}-210+\mathrm{D}$ beef/livestock-intake ratio, $(\mathrm{pCi} / \mathrm{kg}) /(\mathrm{pCi} / \mathrm{d})$ , milk/livestock-intake ratio, $(\mathrm{pCi} / \mathrm{L}) /(\mathrm{pCi} / \mathrm{d})$ $\mathrm{D}-343 \mathrm{~Pb}-210+\mathrm{D}$, beef/livestock-intake ratio, $(\mathrm{pCi} / \mathrm{kg}) /(\mathrm{pCi} / \mathrm{d})$

$\mathrm{D}-343 \mathrm{~Pb}-210+\mathrm{D}$, milk/livestock-intake ratio, (pCi/L)/(pCi/d)

D-34 3

$\mathrm{D}-34{ }^{3} \mathrm{Pu}-238$

$\mathrm{D}-344^{3} \mathrm{Pu}-238$

$\mathrm{D}-34 \quad 3 \mathrm{Pu}-238$

D-34 3

D-34 3 Pu-239

$\mathrm{D}-34$ 3 $\mathrm{Pu}-239$

D -34 -

D-34 3 Ra-226+D

D-34 3 Ra-226+D

D-34 3 Ra-226+D

D-34 3

D-34 $3 \mathrm{Sr}-90+\mathrm{D}$

D-34 $3 \mathrm{Sr}-90+\mathrm{D}$

D-34 3 Sr $-90+D$

D $-344^{3}$

D-34 3 Th-229+D

D-34 3 Th-229+D

D-34 3 Th-229+D

D-34 3

D-34 3 Th -230

D-34 3 Th-230

D 34 Th -230

$\begin{array}{ll}D-34 & 3 \\ D-34 & 3\end{array}$

$\mathrm{D}-34 \quad 3 \quad \mathrm{U}-233$

$\mathrm{D}-34 \quad 3 \quad \mathrm{U}-233$

D-34 3 U-233

, plant/soil concentration ratio, dimensionless beef/livestock-intake ratio, $(\mathrm{pCi} / \mathrm{kg}) /(\mathrm{pCi} / \mathrm{d})$ $\mathrm{milk} /$ livestock-intake ratio, $(\mathrm{pCi} / \mathrm{L}) /(\mathrm{pCi} / \mathrm{d})$

plant/soil concentration ratio, dimensionless beef/livestock-intake ratio, $(\mathrm{pCi} / \mathrm{kg}) /(\mathrm{pCi} / \mathrm{d})$ $\mathrm{milk} /$ livestock-intake ratio, $(\mathrm{pCi} / \mathrm{L}) /(\mathrm{pCi} / \mathrm{d})$

plant/soil concentration ratio, dimensionless beef/livestock-intake ratio, $(\mathrm{pCi} / \mathrm{kg}) /(\mathrm{pCi} / \mathrm{d})$ milk/livestock-intake ratio, $(\mathrm{pCi} / \mathrm{L}) /(\mathrm{pCi} / \mathrm{d})$

plant/soil concentration ratio, dimensionless beef/livestock-intake ratio, $(\mathrm{pCi} / \mathrm{kg}) /(\mathrm{pCi} / \mathrm{d})$

milk/livestock-intake ratio, $(\mathrm{pCi} / \mathrm{L}) /(\mathrm{pCi} / \mathrm{d})$

plant/soil concentration ratio, dimensionless beef/livestock-intake ratio, $(\mathrm{pCi} / \mathrm{kg}) /(\mathrm{pCi} / \mathrm{d})$ $\mathrm{milk} /$ livestock-intake ratio, $(\mathrm{pCi} / \mathrm{L}) /(\mathrm{pCi} / \mathrm{d})$

plant/soil concentration ratio, dimensionless beef/livestock-intake ratio, $(\mathrm{pCi} / \mathrm{kg}) /(\mathrm{pCi} / \mathrm{d})$

milk/livestock-intake ratio, $(\mathrm{pCi} / \mathrm{L}) /(\mathrm{pCi} / \mathrm{d})$

, plant/soil concentration ratio, dimensionless beef/livestock-intake ratio, $(\mathrm{pCi} / \mathrm{kg}) /(\mathrm{pCi} / \mathrm{d})$ Value 3 Case* 3 Name

34.00002

3 4.000E-02 3 4.000E-02 $3 \operatorname{RTF}(3,1)$

3.000E-02 3 3. $3.000 \mathrm{E}-02$ 2 3 RTF $(3,2)$

2.500E-03 $332.500 \mathrm{E}-03 \quad 3$ RTF $(4,1)$

$5.000 \mathrm{E}-05 \quad 3 \quad 5.000 \mathrm{E}-053 \operatorname{RTF}(4,3)$

$2.500 \mathrm{E}-03 \quad 3 \quad 2.500 \mathrm{E}-03 \quad 3 \operatorname{RTF}(6,1)$

2.000E-03 $32.000 \mathrm{E}-033^{3} \operatorname{RTF}(6,2)$

$2.000 \mathrm{E}-05$ 3 $2.000 \mathrm{E}-05$ 3 $\operatorname{RTF}(6,3)$

3 2. $000 \mathrm{E}-02 \quad 3 \quad 2.000 \mathrm{E}-02 \quad 3 \operatorname{RTF}(7,1)$

1. $000 \mathrm{E}-03 \quad 3 \quad 1.000 \mathrm{E}-03$ 3 $\operatorname{RTF}(7,2)$

5. $000 \mathrm{E}-06$ 3 5. $3000 \mathrm{E}-06{ }^{3} \operatorname{RTF}(7,3)$

1.000E-02 3 1.000E-02 $3 \operatorname{RTF}(8,1)$

5.000E-03 3 5. 000E-03 $3 \operatorname{RTF}(8,2)$

5. $000 \mathrm{E}-06$ 3 $5.000 \mathrm{E}-06$ 3 $\operatorname{RTF}(8,3)$

1. $000 \mathrm{E}-023$ 1. $3000 \mathrm{E}-023 \operatorname{RTF}(9,1)$

$8,000 \mathrm{-O} 43 \mathrm{3}, 000 \mathrm{C}-043 \mathrm{RTF}(2,1)$

3.

1.000E-03 3 1.000E-03 $3 \operatorname{RTF}(10,1)$

$31.000 \mathrm{E}-043$ 1. 3 . $100 \mathrm{E}-043 \operatorname{RTF}(10,2)$

1.000E-06 3 1.000E-06 $3 \operatorname{RTF}(10,3)$

1. $000 \mathrm{E}-03 \quad 3 \quad 1.000 \mathrm{E}-033 \operatorname{RTF}(12,1)$

$1.000 \mathrm{O}-043 \mathrm{1}, 000 \mathrm{E}-04{ }^{3} \mathrm{RTF}(12,2)$

$1.000 \mathrm{E}-06 \quad 3 \quad 1.000 \mathrm{E}-06{ }^{3} \mathrm{RTF}(12,3)$

4.000E-02 3 4.000E-02 $3 \operatorname{RTF}(13,1)$

3 1. $000 \mathrm{E}-03 \quad 3 \quad 1.000 \mathrm{E}-033 \operatorname{RTF}(13,2)$

1.000E-03 3 1.000E-03 $3 \operatorname{RTF}(13,3)$

3. $000 \mathrm{E}-01 \quad 3 \quad 3.000 \mathrm{H}-013 \operatorname{RTF}(14,1)$

$8.000 \mathrm{E}-03 \quad 3 \quad 8,000 \mathrm{~B}-03 \quad 3 \mathrm{RTF}(14,2)$

3 2. 000E-03 3 2. $000 \mathrm{E}-033 \operatorname{RTF}(14,3)$

1. $1.000-03 \quad 3 \quad 1.000 \mathrm{E}-033 \operatorname{RTF}(15,1)$

1. $000 \mathrm{E}-044^{3} 1.000 \mathrm{E}-04{ }^{3} \operatorname{RTF}(15,2)$

5. $000 \mathrm{E}-06^{3}$ 5. 000E-06 $3 \operatorname{RTF}(15,3)$

1. $000 \mathrm{E}-03 \quad 3 \quad 1.000 \mathrm{E}-033 \operatorname{RTF}(16,1)$

$1.000 \mathrm{E}-04 \quad 3 \quad 1,000 \mathrm{E}-04 \quad 3 \operatorname{RTF}(16,2)$

5. ๑00E-06 3 5.

3 . 3

2.500E-03 3 2.500E-03 $3 \operatorname{RTF}(17,1)$

3. $400 \mathrm{E}-04$ 3 $3.400 \mathrm{E}-043 \operatorname{RTF}(17,2)$

3 6. $000 \mathrm{E}-044^{3} 6.000 \mathrm{E}-04{ }^{3} \operatorname{RTF}(17,3)$

UNCONTROLLED When Printed 

1RESRAD, Version 6.3
T« Limit $=180$ days
11/28/2007 23:08 Page 4
Summary : CAU 545 CAS $03-17-01$ Biasd
File: CAU 545 ind Biased. RAD

Dose Conversion Factor (and Related) Parameter Summary (continued)

File: FGR 13 MORBIDITY

$0_{\text {Menu }}^{3}{ }^{3}$

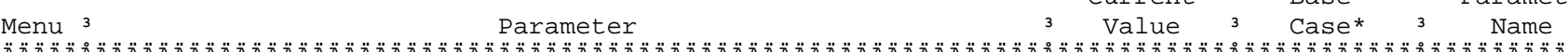

3 Current 3 Base 3 Parameter

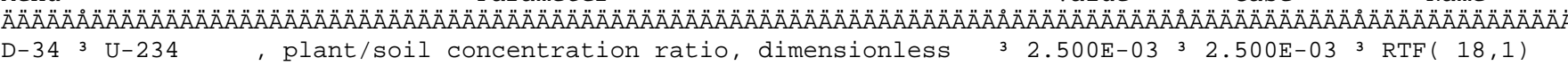

, plant/soil concentration ratio, dimensionless

$3.500 \mathrm{E}-03$ 3 $2.500 \mathrm{E}-03 \quad 3 \operatorname{RTF}(18,1)$

$\mathrm{D}-34 \quad 3 \mathrm{U}-234$

, beef/livestock-intake ratio, ( $\mathrm{pCi} / \mathrm{kg}) /(\mathrm{pCi} / \mathrm{d})$

$3.400 \mathrm{E}-04 \quad 3 \quad 3.400 \mathrm{E}-04$ 3 $\operatorname{RTF}(18,2)$

D- 34 3

$D-34 \quad 3 \quad U-235+D$

milk/livestock-intake ratio, $(\mathrm{pCi} / \mathrm{L}) /(\mathrm{pCi} / \mathrm{d})$

plant/soil concentration ratio, dimensionless beef/livestock-intake ratio, $(\mathrm{pCi} / \mathrm{kg}) /(\mathrm{pCi} / \mathrm{d})$

$\mathrm{D}-34{ }^{3} \mathrm{U}-235+\mathrm{D}$

$D-34 \quad 3 \quad U-235+D$

D-34 3

$\mathrm{D}-34$ - 3 U-238

$\mathrm{D}-34 \quad 3 \quad \mathrm{U}-238$

D-34 3 U-238

D -343

$D-34{ }^{3} \quad U-238+D$

, milk/livestock-intake ratio, $(\mathrm{pCi} / \mathrm{L}) /(\mathrm{pCi} / \mathrm{d})$

plant/soil concentration ratio, dimensionless

, beef/livestock-intake ratio, $(\mathrm{pCi} / \mathrm{kg}) /(\mathrm{pCi} / \mathrm{d})$

, milk/livestock-intake ratio, $(\mathrm{pCi} / \mathrm{L}) /(\mathrm{pCi} / \mathrm{d})$

2.500E-03 $3 \quad 2.500 \mathrm{E}-03 \quad 3 \operatorname{RTF}(19,1)$

3. $400 \mathrm{E}-\Theta 4 \quad 3 \quad 3,400 \mathrm{~B}-\Theta 4 \quad 3 \operatorname{RTF}(19,2)$

6. $000 \mathrm{E}-044^{3}$ 6. $600 \mathrm{E}-04{ }^{3} \operatorname{RTF}(19,3)$

2.500E-03 $3 \quad 2.500 \mathrm{E}-03 \quad 3 \operatorname{RTF}(20,1)$

$3.400 \mathrm{E}-044^{3}$ 3.400E-04 $3 \operatorname{RTF}(20,2)$

$6.000 \mathrm{E}-044^{3} \quad 6.0000 \mathrm{E}-04{ }^{3} \operatorname{RTF}(20,3)$

plant/soil concentration ratio, dimensionless

, beef/livestock-intake ratio, ( $\mathrm{pCi} / \mathrm{kg}) /(\mathrm{pCi} / \mathrm{d})$

2.500E-03 3 2.500E-03 3 RTF $(21,1)$

$3,400 \mathrm{E}-04 \quad 3 \quad 3,400 \mathrm{H}-04 \quad 3 \operatorname{RTF}(21,2)$

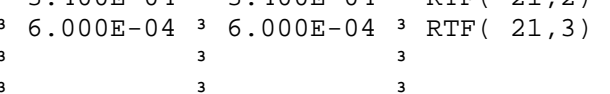

$D-34 \quad 3 \quad U-238+D$

, milk/livestock-intake ratio, $(\mathrm{pCi} / \mathrm{L}) /(\mathrm{pCi} / \mathrm{d})$

D-5 3 Bioaccumulation factors, fresh water, $\mathrm{L} / \mathrm{kg}$ :

D-5 3 AC-227+D, fish

D-5 3 AC-227+D, crustacea and mollusks

D-5 3

D-5 3 Am-241, fish

D-5 3 Am-241, crustacea and mollusks

D-5 3

D-5 3 Cs $-137+D$, fish

D-5 3 Cs $-137+D$,' crustacea and mollusks

D-5 3

D-5 3 Eu-152, fish

D-5 3 Eu-152, crustacea and mollusks

D-5 3

D-5 3 Gd-152 fish

D-5 3 Gd-152, crustacea and mollusks

D-5 3

$\begin{array}{llll}\mathrm{D}-5 & 3 & \mathrm{~Np}-237+\mathrm{D} & \text {, fish } \\ \mathrm{D}-5 & 3 & \mathrm{~Np}-237+\mathrm{D} & \text {, crustacea and mollusks }\end{array}$

D- -5 - 3

$\mathrm{D}-5$ 3 $\mathrm{Pa}-231$, fish

D-5 3 Pa-231, crustacea and mollusks

D -53

D -5

$\begin{array}{llll}\mathrm{D}-5 & 3 & \mathrm{~Pb}-210+\mathrm{D}, & \text { fish } \\ \mathrm{D}-5 & 3 & \mathrm{~Pb}-210+\mathrm{D}, \text { crustacea and mollusks }\end{array}$

D-5

D-5 3 Pu-238, fish

D-5 3 Pu-238, crustacea and mollusks

D-5 3 Pu-239, fish

D-5 3 Pu-239, crustacea and mollusks

D- 53

D-5 3 Ra-226+D, fish

D-5 3 Ra-226+D ', crustacea and mollusks

$31.500 \mathrm{E}+0131.500 \mathrm{E}+013 \operatorname{BIOFAC}(1,1)$

1. $000 \mathrm{E}+03 \quad 3 \quad 1.000 \mathrm{E}+03{ }^{3} \operatorname{BIOFAC}(1,2)$

$3.000 \mathrm{E}+0133.000 \mathrm{E}+013 \operatorname{BIOFAC}(2,1)$

1. $000 \mathrm{E}+033$ 1. $300 \mathrm{E}+033^{3} \operatorname{BIOFAC}(2,2)$

$\begin{array}{lllll}2.000 \mathrm{E}+03 & 3 & 2.00 \odot \mathrm{E}+03 & 3 & \operatorname{BIOFAC}(3,1) \\ 1.000 \mathrm{E}+02 & 3 & 1.000 \mathrm{E}+02 & 3 & \operatorname{BIOFAC}(3,2)\end{array}$

$5.000 \mathrm{E}+011^{3} 5.000 \mathrm{E}+011^{3} \operatorname{BIOFAC}(4,1)$

$31.000 \mathrm{E}+03 \quad 3 \quad 1.000 \mathrm{E}+03 \quad 3 \operatorname{BIOFAC}(4,2)$

$2.500 \mathrm{E}+013 \quad 2.500 \mathrm{E}+01 \quad 3 \quad \operatorname{BIOFAC}(6,1)$

1. $000 \mathrm{E}+03 \quad 3 \quad 1.000 \mathrm{E}+033 \operatorname{BIOFAC}(6,2)$

3. $000 \mathrm{E}+011^{3} 3.000 \mathrm{E}+01 \quad 3 \operatorname{BIOFAC}(7,1)$

3 4. $000 \mathrm{E}+02$ 3 $4.000 \mathrm{E}+02$ 3 $\operatorname{BIOFAC}(7,2)$

$31.000 \mathrm{E}+01^{3} 1.000 \mathrm{E}+013 \operatorname{BIOFAC}(8,1)$

$1.100 \mathrm{E}+022^{3} 1.100 \mathrm{E}+02{ }^{3} \operatorname{BIOFAC}(8,2)$

$3.000 \mathrm{E}+02 \quad 3 \quad 3.000 \mathrm{E}+02 \quad 3 \quad \operatorname{BIOFAC}(9,1)$

1. $000 \mathrm{E}+022^{3} 1.000 \mathrm{E}+023 \operatorname{BIOFAC}(9,2)$

$3.000 \mathrm{E}+0133.000 \mathrm{E}+013 \operatorname{BIOFAC}(10,1)$

3 1. $00 \odot E+\odot 231.000 \mathrm{E}+\odot 23 \operatorname{BIOFAC}(10,2)$

$3 \quad 3.000 \mathrm{E}+0133.000 \mathrm{E}+013 \operatorname{BIOFAC}(12,1)$

1. $000 \mathrm{E}+\odot 231.000 \mathrm{2}+\Theta 2{ }^{3} \operatorname{BIOFAC}(12,2)$

$5.000 \mathrm{E}+01^{3} 5.000 \mathrm{E}+01^{3}$ BTOFAC $(13,1)$

$2.500 \mathrm{E}+02$ 3 $2.500 \mathrm{E}+02$ 3 $\operatorname{BIOFAC}(13,2)$

UNCONTROLLED When Printed 

1RESRAD, Version 6.3
T« Limit $=180$ days
11/28/2007 23:08 Page 5
Summary : CAU 545 CAS $03-17-01$ Biasd
File: CAU 545_ind Biased.RAD

Dose Conversion Factor (and Related) Parameter Summary (continued)

File: FGR 13 MORBIDITY

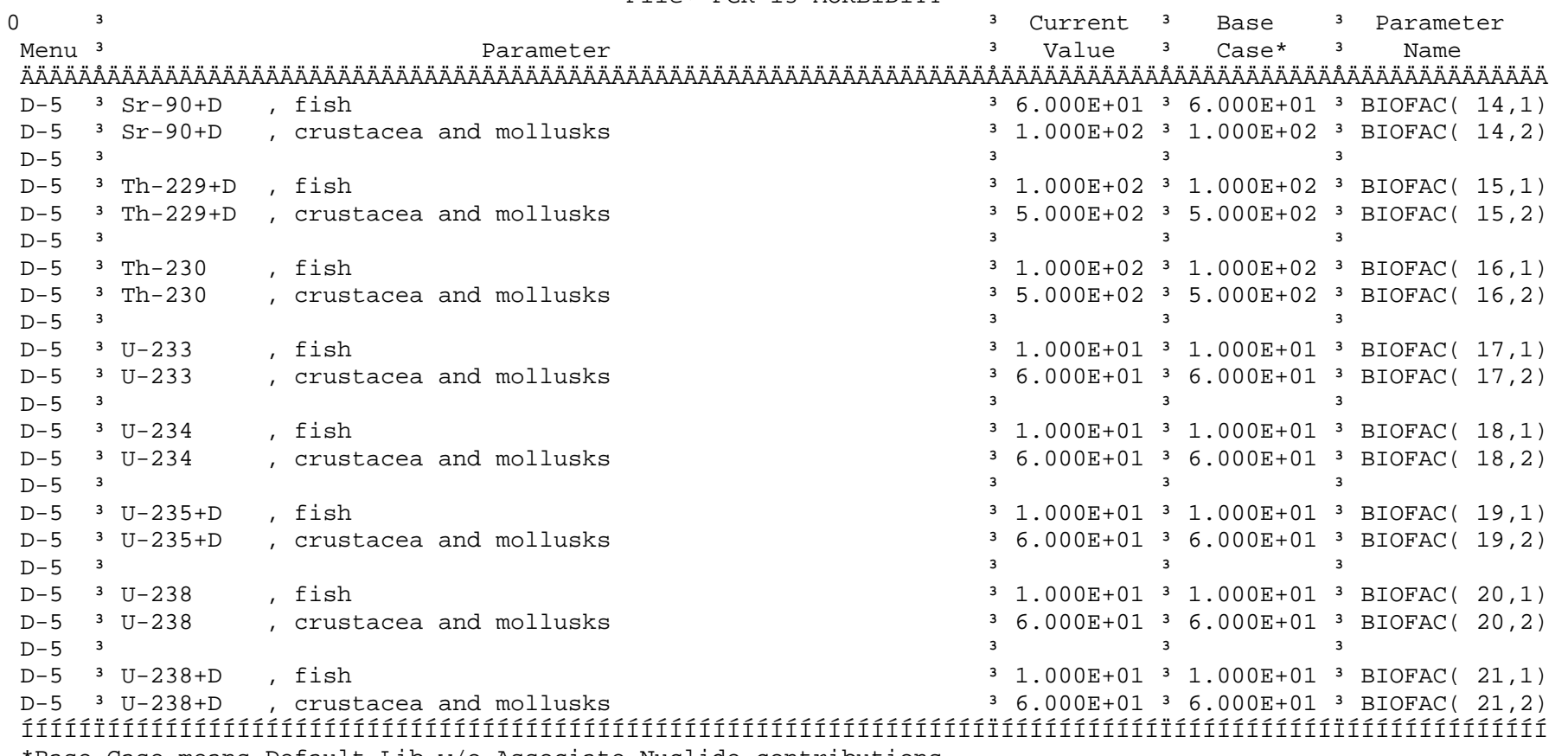

*Base Case means Default. Lib W/o Associate Nuclide contributions. 
RO11 3 Area of contaminated zone $\left(m^{* *} 2\right)$

R011 3 Thickness of contaminated zone $(\mathrm{m})$

R011 3 Length parallel to aquifer flow $(\mathrm{m})$

R011 3 Basic radiation dose limit (mrem/yr)

R011 3 Time since placement of material (yr)

R011 3 Times for calculations $(y r)$

R011 3 Times for calculations ( $\mathrm{yr}$ )

R011 3 Times for calculations ( $\mathrm{yr}$ )

R011 3 Times for calculations ( $y r$ )

R011 3 Times for calculations ( $\mathrm{yr}$ )

R011 3 Times for calculations ( $\mathrm{yr}$ )

R011 3 Times for calculations ( $y r$ )

Times for calculations ( $y r$ )

3

R012 3 Initial principal radionuclide ( $\mathrm{pCi} / \mathrm{g}$ ):

R012 3 Initial principal radionuclide (pCi/g): Am-241

R012 3 Initial principal radionuclide ( $\mathrm{pCi} / \mathrm{g})$ : Eu-152

R012 3 Initial principal radionuclide (pCi/g): $\mathrm{Pu}-238$

$\mathrm{R} 012$ 3 Initial principal radionuclide ( $\mathrm{pCi} / \mathrm{g}): \quad \mathrm{Pu}-239$

$\mathrm{R} 0123$ Initial principal radionuclide $(\mathrm{pCi} / \mathrm{g}): \mathrm{Sr}-90$

R०12 3 Initial principal radionuclide (pCi/g): $U-233$

$1.500 \mathrm{C}-01$ 3 $1.000 \mathrm{E}+04$

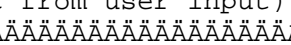

3

$\mathrm{U}-235$

R012 3 Initial principal radionuclide $(\mathrm{pCi} / \mathrm{g})$ :

R012 3 Concentration in groundwater ( $\mathrm{pCi} / \mathrm{L})$ :

R012 3 Concentration in groundwater (pCi/L): Eu-152 3 not used $30.000 \mathrm{E}+\odot 0^{3}$

R012 3 Concentration in groundwater (pCi/L): Pu-238 3 not used $30.000 \mathrm{E}+00$

R012 3 Concentration in groundwater $(\mathrm{pCi} / \mathrm{L}): \mathrm{Pu}-239{ }^{3}$ not used $30.000 \mathrm{E}+00^{3}$

R012 3 Concentration in groundwater (pCi/L): $\mathrm{Sr}-90$ 3 not used $30.000 \mathrm{E}+00^{3}$

$\mathrm{R} 0123$ Concentration in groundwater ( $\mathrm{pCi} / \mathrm{L}): \mathrm{U}-2333$ not used $30.000 \mathrm{E}+00$

R012 3 Concentration in groundwater ( $\mathrm{PCI} / \mathrm{L}): \mathrm{U}-233,3$ not used $30.000 \mathrm{E}+00$

R012 3 Concentration in groundwater (pCi/L): U-235 3 not used $30.000 \mathrm{E}+00$

R012 3 Concentration in groundwater (pCi/L): U-238

R013 3 Cover depth $(\mathrm{m})$

R013 3 Density of cover material $\left(\mathrm{g} / \mathrm{cm}^{* *} 3\right)$

R013 3 Cover depth erosion rate $(\mathrm{m} / \mathrm{yr})$

R013 3 Density of contaminated zone $\left(\mathrm{g} / \mathrm{cm}^{* *} 3\right)$

R013 3 Contaminated zone erosion rate $(\mathrm{m} / \mathrm{yr})$

R013 3 Contaminated zone total porosity

R013 3 Contaminated zone field capacity

3 not used 3 $\quad 0.000 \mathrm{E}+\Theta \Theta_{3}$

$0.000 \mathrm{E}+\odot \odot \quad 3 \quad 0.000 \mathrm{E}+0 \odot$

3 not used $31.500 \mathrm{E}+00$

3 not used $31.000 \mathrm{E}-03$

$3 \quad 1.500 \mathrm{E}+\odot \odot \quad 3 \quad 1.500 \mathrm{E}+\odot \odot^{3}$

$1.000 \mathrm{E}-03$ 3 $1.000 \mathrm{E}-03$

4. $000 \mathrm{E}-013$ 4.000E-01 3

$32.000 \mathrm{E}-01 \quad 3 \quad 2.000 \mathrm{E}-01$

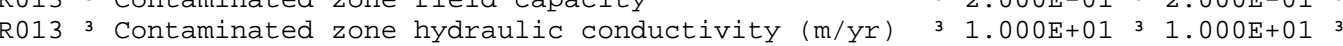

$\mathrm{R} 013$ 3 Contaminated zone b parameter $3 \begin{array}{llll}1.000 \mathrm{E}+00 & 3 & 5.300 \mathrm{E}+00 & 3\end{array}$

R013 3 Average annual wind speed (m/sec) $34.070 \mathrm{E}+003$ 2.000E+00

R013 3 Humidity in air $(\mathrm{g} / \mathrm{m} * * 3)$

R013 3 Evapotranspiration coefficient

not used $38.000 \mathrm{E}+0 \mathrm{O}^{3}$

$35.000 \mathrm{E}-013$ 5. 3 . 000E- 01

R013 3 Precipitation ( $\mathrm{m} / \mathrm{yr}$ )

R013 3 Irrigation ( $\mathrm{m} / \mathrm{yr}$ )

R013 3 Irrigation mode

$1.626 \mathrm{E}-013 \mathrm{1} 3.000 \mathrm{E}+00^{3}$

$\begin{array}{llll}3 & 0.000 \mathrm{E}+00 & 3 & 2.000 \mathrm{E}-01^{3}\end{array}$

3 overhead 3 overhead 3

R013 3 Watershed area for nearby stream or pond $\left(m^{* *} 2\right) \quad 3$ not used $31.000 \mathrm{E}+06^{3}$

\begin{tabular}{|c|c|c|}
\hline- & 3 & THICKO \\
\hline$\ldots$ & 3 & LCZPAQ \\
\hline$\ldots$ & 3 & BRDL \\
\hline$\ldots$ & 3 & $\mathrm{TI}$ \\
\hline- & 3 & $\mathrm{~T}(\mathrm{2})$ \\
\hline & 3 & $\mathrm{~T}(3)$ \\
\hline$\ldots$ & 3 & $\mathrm{~T}(4)$ \\
\hline$\ldots$ & 3 & $\mathrm{~T}(5)$ \\
\hline$\cdots$ & 3 & $T(6)$ \\
\hline$\cdots$ & 3 & $\mathrm{~T}(7)$ \\
\hline$\ldots$ & 3 & $\mathrm{~T}(\mathrm{8})$ \\
\hline- & 3 & $\mathrm{~T}(9)$ \\
\hline- & $\begin{array}{l}3 \\
3\end{array}$ & $\mathrm{~T}(10)$ \\
\hline-- & 3 & $\mathrm{~S} 1(2)$ \\
\hline- & 3 & $\mathrm{~s} 1(3)$ \\
\hline$\cdots$ & 3 & S1( 4) \\
\hline & 3 & $\mathrm{~S} 1(10)$ \\
\hline- & 3 & $\mathrm{~S} 1(12)$ \\
\hline$\cdots$ & 3 & S1(14) \\
\hline 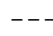 & 3 & S1(17) \\
\hline & 3 & S1(19) \\
\hline- & 3 & $\mathrm{~S} 1(20)$ \\
\hline$\ldots$ & 3 & W1 ( 2) \\
\hline- & 3 & W1( 3$)$ \\
\hline . & 3 & W1 ( 4) \\
\hline- & 3 & W1 (10) \\
\hline - & 3 & W1(12) \\
\hline - & 3 & W1(14) \\
\hline - & 3 & W1(17) \\
\hline & 3 & W1(19) \\
\hline- & $\begin{array}{l}3 \\
3\end{array}$ & W1 $(20)$ \\
\hline- & 3 & COVERO \\
\hline- & 3 & DENSCV \\
\hline$\ldots$ & 3 & VCV \\
\hline . & 3 & DENSCZ \\
\hline - & 3 & VCZ \\
\hline - & 3 & TPCZ \\
\hline 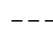 & 3 & FCCZ \\
\hline & 3 & $\mathrm{HCCZ}$ \\
\hline- & 3 & $B C Z$ \\
\hline - & 3 & WIND \\
\hline & 3 & HUMID \\
\hline - & 3 & EVAPTR \\
\hline- & 3 & PRECIP \\
\hline & 3 & RI \\
\hline & 3 & IDITCH \\
\hline - & 3 & RUNOFF \\
\hline & 3 & WAREA \\
\hline
\end{tabular}




1RESRAD, Version 6.3 T« Limit $=180$ days
Summary : CAU 545 CAS $03-17-01$ Biasd

Site-Specific Parameter Summary (continued)

$\odot \quad 3$

Used by RESRAD

3 Parameter

Menu $3 \quad$ Parameter 3 Input 3 Default 3 (If different from user input) 3 Name

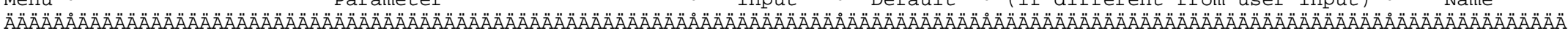
R013 3 Accuracy for water/soil computations 3

R014 3 Density of saturated zone $\left(\mathrm{g} / \mathrm{cm}^{* *} 3\right)$

R014 3 Saturated zone total porosity

R014 3 Saturated zone effective porosity

R014 3 Saturated zone field capacity

R014 3 Saturated zone hydraulic conductivity (m/yr)

R014 3 Saturated zone hydraulic gradient

R014 3 Saturated zone b parameter

R014 3 Water table drop rate (m/yr)

R014 3 Well pump intake depth ( $m$ below water table)

R014 3 Model: Nondispersion (ND) or Mass-Balance (MB)

R014 ${ }^{3}$ Well pumping rate $\left(m^{* *} 3 / \mathrm{yr}\right)$

R015 3 Number of unsaturated zone strata

R015 3 Unsat. zone 1, thickness (m)

R015 3 Unsat. zone 1 , soil density $\left(\mathrm{g} / \mathrm{cm}^{* *} 3\right)$

R015 3 Unsat. zone 1 , total porosity

R015 3 Unsat. zone 1, effective porosity

R015 3 Unsat. zone 1, field capacity

R015 3 Unsat. zone 1 , soil-specific b parameter

R015 3 Unsat. zone 1 , hydraulic conductivity (m/yr)

R016 3 Distribution coefficients for Am-241

R016 3 Contaminated zone $\left(\mathrm{cm}^{* *} 3 / \mathrm{g}\right)$

R016 3 Unsaturated zone $1\left(\mathrm{~cm}^{* *} 3 / \mathrm{g}\right)$

R016 3 Saturated zone $\left(\mathrm{cm}^{* *} 3 / \mathrm{g}\right)$

R016 3 Leach rate (/yr)

R016 3 Solubility constant

R016 3 Distribution coefficients for Cs -137

R016 3 Contaminated zone $\left(\mathrm{cm}^{* *} 3 / \mathrm{g}\right)$

R016 3 Unsaturated zone $1\left(\mathrm{~cm}^{* *} 3 / \mathrm{g}\right)$

R016 3 Saturated zone $\left(\mathrm{cm}^{* *} 3 / \mathrm{g}\right)$

R016 3 Leach rate (/yr)

R016 3 Solubility constant

R016 3 Distribution coefficients for Eu-152

R016 3 Contaminated zone $\left(\mathrm{cm}^{* *} 3 / \mathrm{g}\right)$

R016 3 Unsaturated zone $1\left(\mathrm{~cm}^{* *} 3 / \mathrm{g}\right)$

R016 3 Saturated zone $\left(\mathrm{cm}^{* *} 3 / \mathrm{g}\right)$

R016 3 Leach rate (/yr)

R016 3 Solubility constant

R016 3 Distribution coefficients for $\mathrm{Pu}-238$

R016 3 Contaminated zone $\left(\mathrm{cm}^{* *} 3 / \mathrm{g}\right)$

R016 3 Unsaturated zone $1\left(\mathrm{~cm}^{* *} 3 / \mathrm{g}\right)$

R016 3 Saturated zone $\left(\mathrm{cm}^{* *} 3 / \mathrm{g}\right)$

R016 3 Leach rate (/yr)

R016 3 Solubility constant

\begin{tabular}{|c|c|c|c|}
\hline & not used & $\begin{array}{l}3 \\
3\end{array}$ & 1. $000 \mathrm{E}-03$ \\
\hline & not used & 3 & $1.500 \mathrm{E}+\odot \odot$ \\
\hline & not used & 3 & 4. . $000 E-01$ \\
\hline & not used & 3 & 2. $.00 \mathrm{E}-\odot 1$ \\
\hline & not used & 3 & 2. $00 \odot \mathrm{E}-01$ \\
\hline & not used & 3 & $1.00 \odot \mathrm{E}+\odot 2$ \\
\hline & not used & 3 & $2.000 \mathrm{E}-\odot 2$ \\
\hline & not used & 3 & $5.300 \mathrm{E}+\odot \odot$ \\
\hline & not used & 3 & 1. $000 \mathrm{E}-\odot 3$ \\
\hline & not used & 3 & 1. $000 \mathrm{E}+01$ \\
\hline & not used & 3 & ND \\
\hline & not used & 3 & $2.500 \mathrm{E}+02$ \\
\hline & & 3 & \\
\hline & not used & 3 & 1 \\
\hline & not used & 3 & 4. . $00 \odot E+\odot \odot$ \\
\hline & not used & 3 & $1.500 \mathrm{E}+\odot \odot$ \\
\hline & not used & 3 & 4. . $00 \odot E-01$ \\
\hline & not used & 3 & 2. $00 \odot E-01$ \\
\hline & not used & 3 & 2. $000 \mathrm{E}-01$ \\
\hline & not used & 3 & $5.30 \odot \mathrm{E}+\odot \odot$ \\
\hline & not used & 3 & 1. $00 \odot \mathrm{E}+01$ \\
\hline & & 3 & \\
\hline & & 3 & \\
\hline & 2. $\odot \odot \odot E+\odot 1$ & 3 & $2.00 \odot E+\odot 1$ \\
\hline & not used & 3 & $2.00 \odot \mathrm{E}+01$ \\
\hline & not used & 3 & 2. $000 \mathrm{E}+01$ \\
\hline & $\odot . \odot \odot \odot E+\odot \odot$ & 3 & $\odot . \odot \odot \odot E+\odot \odot$ \\
\hline & $\odot . \odot \odot \odot E+\odot \odot$ & 3 & $\odot . \odot \odot \odot E+\odot \odot$ \\
\hline & & 3 & \\
\hline & & 3 & \\
\hline & $4.600 \mathrm{E}+03$ & 3 & $4.600 \mathrm{E}+03$ \\
\hline & not used & 3 & $4.600 \mathrm{E}+03$ \\
\hline & not used & 3 & $4.600 \mathrm{E}+03$ \\
\hline & $\odot . \odot \odot \odot E+\odot \odot$ & 3 & $\odot . \odot \odot \odot E+\odot \odot$ \\
\hline & ๑.๑०९Е+๑९ & 3 & $\odot . \odot \odot \odot Е+\odot \odot$ \\
\hline & & 3 & \\
\hline & & 3 & \\
\hline & - $1.00 \odot E+\odot \odot$ & & $-1.00 \odot E+\odot \odot$ \\
\hline & not used & & - $1.0 \odot \odot E+\odot \odot$ \\
\hline & not used & & $-1.00 \odot \mathrm{E}+\odot \odot$ \\
\hline & $\odot . \odot \odot \odot E+\odot \odot$ & 3 & $\odot . \odot \odot \odot E+\odot \odot$ \\
\hline & ๑.०००Е+०९ & 3 & ๑.०००E+०० \\
\hline & & 3 & \\
\hline & & 3 & \\
\hline & 2. $.00 \mathrm{E}+\odot 3$ & 3 & 2. $000 \mathrm{E}+03$ \\
\hline & not used & 3 & $2.000 \mathrm{E}+03$ \\
\hline & not used & 3 & $2.000 \mathrm{E}+03$ \\
\hline & $\odot . \odot ० \odot \mathrm{E}+\odot \odot$ & 3 & $\odot . \odot ० \odot E+\odot \odot$ \\
\hline & & & \\
\hline
\end{tabular}

3 not used $31.000 \mathrm{E}-03$

\section{3} 3 EPS

3 DENSAQ

$\begin{array}{ll}3 & \text { TPSZ } \\ 3 & \text { EPSZ }\end{array}$

3 FCSZ

3 HCSZ

3 HGWT

3 BSZ

3 VWT

3 DWIBWT

3 MODEL

3 UW

NS

3 DENSUZ(1)

3 TPUZ (1)

3 EPUZ(1)

3 FCUZ(1)

BUZ(1)

$\operatorname{HCUZ}(1)$

$\operatorname{DCNUCC}(2)$

$\operatorname{DCNUCU}(2,1)$

DCNUCS ( 2)

$\begin{array}{ll}1.074 \mathrm{E}-02 & 3 \mathrm{ALEACH}(2) \\ \text { not used } & 3 \mathrm{SOLUBK}(2)\end{array}$

not used

$\begin{array}{ll}--- & 3 \operatorname{DCNUCC}(3) \\ -- & 3 \operatorname{DCNUCU}(3,1) \\ --- & 3 \operatorname{DCNUCS}(3)\end{array}$

4.713E- $05+3$ ALEACH $(3)$

3 SOLUBK( 3 )

8.249E+02 $3 \operatorname{DCNUCC}(4)$

-.- $3 \operatorname{DCNUCU}(4,1)$

3 DCNUCS ( 4$)$

2.628E-04 3 ALEACH ( 4$)$

not used 3 SOLUBK( 4$)$

-.- $3 \operatorname{DCNUCC}(10)$

$3 \operatorname{DCNUCU}(10,1)$

3 DCNUCS $(10)$

not used $3 \operatorname{SOLUBK}(10)$ 
Site-Specific Parameter Summary (continued)

$\odot \quad 3$

Menu 3 Parameter $\quad 3$ Input 3 Default 3 (If different from user input) 3 Name

Menu $3 \quad$ Parameter 3 Input 3 Default 3 (If different from user input) 3 Name

Menu 3 Parameter 3 Input 3 Default 3 (If different from user input) 3 Name

Used by RESRAD

3 Parameter

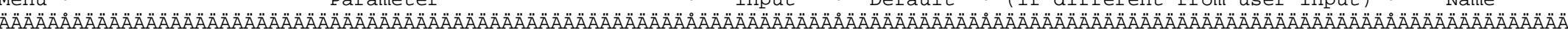

R016 3 Contaminated zone $\left(\mathrm{cm}^{* *} 3 / \mathrm{g}\right)$

R016 3 Saturated zone $\left(\mathrm{cm}^{* *} 3 / \mathrm{g}\right)$

R016 3 Leach rate (/yr)

R016 3 Solubility constant

R016 3 Distribution coefficients for Sr-90

R016 3 Contaminated zone $\left(\mathrm{cm}^{* *} 3 / \mathrm{g}\right)$

R016 3 Unsaturated zone $1\left(\mathrm{~cm}^{* *} 3 / \mathrm{g}\right)$

R016 3 Saturated zone $\left(\mathrm{cm}^{* *} 3 / \mathrm{g}\right)$

R016 3 Leach rate (/yr)

R016 3 Solubility constant

R016 3 Distribution coefficients for U-233

R016 3 Contaminated zone $\left(\mathrm{cm}^{* *} 3 / \mathrm{g}\right)$

R016 3 Unsaturated zone $1\left(\mathrm{~cm}^{* *} 3 / \mathrm{g}\right)$

R016 3 Saturated zone $\left(\mathrm{cm}^{* *} 3 / \mathrm{g}\right)$

R016 3 Leach rate (/yr)

R016 ${ }^{3}$ Solubility constant

R016 3 Distribution coefficients for U-235

R016 3 Contaminated zone $\left(\mathrm{cm}^{* *} 3 / \mathrm{g}\right)$

R016 3 Unsaturated zone $1\left(\mathrm{~cm}^{* *} 3 / \mathrm{g}\right)$

R016 3 Saturated zone $\left(\mathrm{cm}^{* *} 3 / \mathrm{g}\right)$

R016 3 Leach rate (/yr)

R016 3 Solubility constant

R016 3 Distribution coefficients for U-238

R016 3 Contaminated zone $\left(\mathrm{cm}^{* *} 3 / \mathrm{g}\right)$

R016 3 Unsaturated zone $1\left(\mathrm{~cm}^{* *} 3 / \mathrm{g}\right)$

R016 3 Saturated zone $\left(\mathrm{cm}^{* *} 3 / \mathrm{g}\right)$

R016 3 Leach rate (/yr)

R016 3 Solubility constant

R016 3 Distribution coefficients for daughter AC-227

R016 3 Contaminated zone $\left(\mathrm{cm}^{* *} 3 / \mathrm{g}\right)$

R016 3 Unsaturated zone $1\left(\mathrm{~cm}^{* *} 3 / \mathrm{g}\right)$

R016 3 Saturated zone $\left(\mathrm{cm}^{* *} 3 / \mathrm{g}\right)$

R016 3 Leach rate (/yr)

R016 3 Solubility constant

R016 3 Distribution coefficients for daughter Gd-152

R016 3 Contaminated zone $\left(\mathrm{cm}^{* *} 3 / \mathrm{g}\right)$

R016 3 Unsaturated zone $1\left(\mathrm{~cm}^{* *} 3 / \mathrm{g}\right)$

R016 3 Saturated zone $\left(\mathrm{cm}^{* *} 3 / \mathrm{g}\right)$

R016 3 Leach rate (/yr)

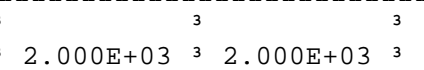

3 not used $32.000 \mathrm{E}+03$

3 not used $32.000 \mathrm{E}+03$

$30.000 E+00 \quad 3 \quad 0.000 E+00$

$\odot .000 E+03^{3} \quad 0.000 E+00^{3}$

$3.000 \mathrm{E}+01 \quad 3 \quad 3.000 \mathrm{E}+01$

not used $33.000 \mathrm{E}+01$

3 not used $33.000 \mathrm{E}+01^{3}$

$\odot .000 E+00 \quad 3 \quad 0.000 \mathrm{E}+0 \odot$

$0.000 \mathrm{E}+0 \mathrm{O}^{3} \quad 0.000 \mathrm{E}+00^{3}$

$5.000 \mathrm{E}+013 \quad 5.000 \mathrm{E}+01$

not used 3 5.000E+01

not used $35.000 \mathrm{E}+01$

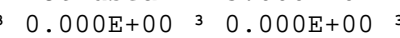

$0.000 \mathrm{E}+0 \odot{ }^{3} \quad 0.000 \mathrm{E}+0 \odot$

$5.000 \mathrm{E}+01 \quad 3 \quad 5.000 \mathrm{E}+01$

not used $3 \quad 5.000 \mathrm{E}+013$

not used $35.000 \mathrm{E}+013$

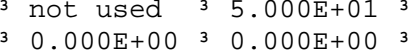

$0.000 \mathrm{E}+0 \mathrm{O}^{3} \quad 0.000 \mathrm{E}+0{ }^{3}$

$5.000 \mathrm{E}+01 \quad 3 \quad 5.000 \mathrm{E}+01$

not used $35.000 \mathrm{E}+013$

not used $35.000 \mathrm{E}+013$

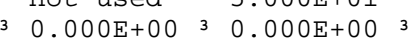

$0.000 \mathrm{E}+0 \mathrm{O}^{3} \quad 0.000 \mathrm{E}+0 \Theta^{3}$

$2.000 \mathrm{E}+01 \quad 3 \quad 2.000 \mathrm{E}+01$

not used $32.000 E+01$

not used $32.000 \mathrm{E}+01$

$0.000 \mathrm{E}+0 \odot \quad 3 \quad 0.000 \mathrm{E}+00 \quad 3$

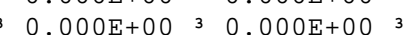

3

$3-1.000 \mathrm{E}+00 \quad 3-1.000 \mathrm{E}+0 \odot$

3 not used $3-1.000 E+00$

3 not used $3-1.000 E+00$

$30.000 \mathrm{E}+00 \quad 3 \quad 0.000 \mathrm{E}+00$

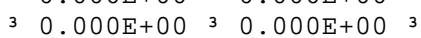

\begin{tabular}{|c|c|c|}
\hline & & \\
\hline-- & 3 & DCNUCC (12) \\
\hline - - - & 3 & $\operatorname{DCNUCU}(12,1)$ \\
\hline-- & 3 & DCNUCS (12) \\
\hline 1. $084 \mathrm{E}-04$ & 3 & ALEACH (12) \\
\hline not used & 3 & SOLUBK (12) \\
\hline & 3 & \\
\hline & 3 & \\
\hline - - - & 3 & DCNUCC (14) \\
\hline - - & 3 & $\operatorname{DCNUCU}(14,1)$ \\
\hline - . & 3 & $\operatorname{DCNUCS}(14)$ \\
\hline $7.183 E-03$ & 3 & ALEACH (14) \\
\hline not used & 3 & SOLUBK(14) \\
\hline & 3 & \\
\hline & 3 & \\
\hline - - - & 3 & DCNUCC (17) \\
\hline$\ldots$ & 3 & $\operatorname{DCNUCU}(17,1)$ \\
\hline-- & 3 & DCNUCS (17) \\
\hline $4.320 E-03$ & 3 & ALEACH (17) \\
\hline not used & 3 & SOLUBK(17) \\
\hline & 3 & \\
\hline & 3 & \\
\hline - - & 3 & DCNUCC (19) \\
\hline-- & 3 & $\operatorname{DCNUCU}(19,1)$ \\
\hline - . - & 3 & DCNUCS (19) \\
\hline $4.320 \mathrm{E}-03$ & 3 & ALEACH (19) \\
\hline not used & 3 & SOLUBK(19) \\
\hline & 3 & \\
\hline & 3 & \\
\hline-- & 3 & $\operatorname{DCNUCC}(20)$ \\
\hline-- & 3 & $\operatorname{DCNUCU}(20,1)$ \\
\hline - - - & 3 & $\operatorname{DCNUCS}(20)$ \\
\hline $4.320 E-03$ & 3 & $\operatorname{ALEACH}(20)$ \\
\hline not used & 3 & SOLUBK (20) \\
\hline & $\begin{array}{l}3 \\
3\end{array}$ & \\
\hline . . - & 3 & $\operatorname{DCNUCC}(1)$ \\
\hline - . - & 3 & DCNUCU $(1,1)$ \\
\hline$-\ldots$ & 3 & DCNUCS $(1)$ \\
\hline 1. $074 \mathrm{E}-02$ & 3 & $\operatorname{ALEACH}(1)$ \\
\hline not used & 3 & SOLUBK( 1$)$ \\
\hline & 3 & \\
\hline & 3 & \\
\hline $8.249 E+02$ & 3 & DCNUCC $(6)$ \\
\hline$\ldots$ & 3 & $\operatorname{DCNUCU}(6,1)$ \\
\hline-- & 3 & DCNUCS( 6$)$ \\
\hline $2.628 \mathrm{E}-04$ & 3 & $\operatorname{ALEACH}(6)$ \\
\hline not used & 3 & $\operatorname{SOLUBK}(6)$ \\
\hline
\end{tabular}




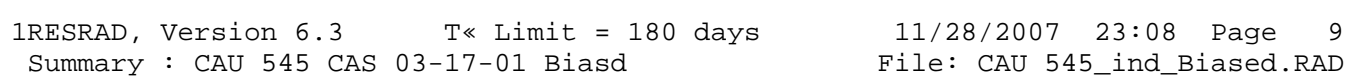

Site-Specific Parameter Summary (continued)

$\odot \quad 3$

Used by RESRAD

3 Parameter

Menu 3 Parameter 3 Input 3 Default 3 (If different from user input) 3 Name

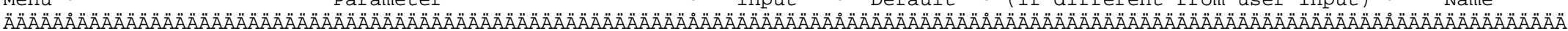

R016 3 Distribution coefficients for daughter Np-237 3

R016 3 Contaminated zone $\left(\mathrm{cm}^{*} 3 / \mathrm{g}\right) \quad 3-1.000 \mathrm{E}+003-1.000 \mathrm{E}+00^{3}$

R016 3 Unsaturated zone $1\left(\mathrm{~cm}^{* *} 3 / \mathrm{g}\right) \quad 3$ not used $3-1.000 \mathrm{E}+00^{3}$

R016 3 Saturated zone $\left(\mathrm{cm}^{* *} 3 / \mathrm{g}\right) \quad 3$ not used $3-1.000 \mathrm{E}+00^{3}$

R016 3 Leach rate (/yr) $30.000 \mathrm{E}+00^{3} 0.000 \mathrm{E}+00^{3}$

R016 3 Solubility constant

R016 3 Distribution coefficients for daughter Pa-231

R016 3 Contaminated zone $\left(\mathrm{cm}^{* *} 3 / \mathrm{g}\right)$

R016 3 Unsaturated zone $1\left(\mathrm{~cm}^{* *} 3 / \mathrm{g}\right)$

R016 3 Saturated zone $\left(\mathrm{cm}^{* *} 3 / \mathrm{g}\right)$

R016 3 Leach rate (/yr)

R016 3 Solubility constant

R016 3 Distribution coefficients for daughter Pb-210

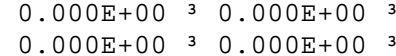

3

3

$5.000 \mathrm{E}+01 \quad 3 \quad 5.000 \mathrm{E}+01$

not used 3 5.000E+01

3 not used $35.000 \mathrm{E}+01$

$\begin{array}{llll}3 & 0.000 \mathrm{E}+00 & 3 & 0.000 \mathrm{E}+00 \\ 3\end{array}$

$0.000 \mathrm{E}+00^{3} \quad 0.000 \mathrm{E}+00^{3}$

R016 3 Contaminated zone $\left(\mathrm{cm}^{* *} 3 / \mathrm{g}\right)$

R016 3 Unsaturated zone $1\left(\mathrm{~cm}^{* *} 3 / \mathrm{g}\right)$

R016 3 Saturated zone $\left(\mathrm{cm}^{* *} 3 / \mathrm{g}\right)$

R016 3 Leach rate (/yr)

R016 ${ }^{3}$ Solubility constant

R016 3 Distribution coefficients for daughter Ra-226

R016 3 Contaminated zone $\left(\mathrm{cm}^{* * 3 / \mathrm{g}}\right)$

R016 3 Unsaturated zone $1\left(\mathrm{~cm}^{* *} 3 / \mathrm{g}\right)$

R016 3 Saturated zone $\left(\mathrm{cm}^{* *} 3 / \mathrm{g}\right)$

R016 3 Leach rate (/yr)

R016 3 Solubility constant

R016 3 Distribution coefficients for daughter Th-229

R016 3 Contaminated zone $\left(\mathrm{cm}^{* *} 3 / \mathrm{g}\right)$

R016 3 Unsaturated zone $1\left(\mathrm{~cm}^{* *} 3 / \mathrm{g}\right)$

R016 3 Saturated zone $\left(\mathrm{cm}^{* *} 3 / \mathrm{g}\right)$

R016 3 Leach rate (/yr)

R016 3 Solubility constant

R016 3 Distribution coefficients for daughter Th-230

$\begin{array}{lll}R 016 & 3 & \text { Contaminated zone }\left(\mathrm{cm}^{* *} 3 / \mathrm{g}\right) \\ \text { R016 } & 3 & \text { Unsaturated zone } 1\left(\mathrm{~cm}^{* *} 3 / \mathrm{g}\right)\end{array}$

R016 3 Saturated zone $\left(\mathrm{cm}^{* *} 3 / \mathrm{g}\right)$

R016 3 Leach rate (/yr)

R016 3 Solubility constant

R016 3 Distribution coefficients for daughter U-234

R016 3 Contaminated zone $\left(\mathrm{cm}^{* *} 3 / \mathrm{g}\right)$

R016 3 Unsaturated zone $1\left(\mathrm{~cm}^{* *} 3 / \mathrm{g}\right)$

R016 3 Saturated zone $\left(\mathrm{cm}^{* *} 3 / \mathrm{g}\right)$

3 $1.000 \mathrm{E}+02 \quad 3 \quad 1.000 \mathrm{E}+02$

not used $31.000 \mathrm{E}+02$

not used $31.000 \mathrm{E}+02$

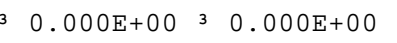

$0.000 \mathrm{E}+00 \quad 3 \quad 0.000 \mathrm{E}+0 \odot$

7. $000 \mathrm{E}+01 \quad 3 \quad 7.000 \mathrm{E}+01$

(1) $7.000 \mathrm{E}+01$

not used $37.000 \mathrm{E}+01$

$\odot .000 \mathrm{E}+0 \odot{ }^{3} \quad 0.000 \mathrm{E}+\odot \odot$

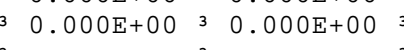

6. $6000 \mathrm{E}+04 \quad 3 \quad 6.000 \mathrm{E}+04$

not used $36.000 \mathrm{E}+04$

not used $36.000 E+04$

not used 3 .

$0.000 \mathrm{E}+00$ 3 $0.00 \odot \mathrm{E}+\odot \odot$

$\odot .00 \odot \mathrm{E}+\odot \odot{ }^{3} \quad 0.000 \mathrm{E}+0 \odot$

$36.000 \mathrm{E}+04 \quad 3 \quad 6.000 \mathrm{E}+04$

not used 3 6.000E+04

not used $36.000 E+04$

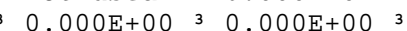

$0.000 \mathrm{E}+00$ 3 $\quad 0.000 \mathrm{E}+003$

$5.000 \mathrm{E}+01 \quad 3 \quad 5.000 \mathrm{E}+01$

3 not used 3 5.000E +01

3 not used 3 5.000E+01

$30.000 \mathrm{E}+0 \odot \quad 3 \quad 0.000 \mathrm{E}+\odot \odot$

$\odot .000 \mathrm{E}+00 \quad 3 \quad 0.000 \mathrm{E}+0{ }^{3}$

Leach rate (/yr)

R016 3 Solubility constant

R017 3 Inhalation rate $\left(m^{* *} 3 / y r\right)$

R017 3 Mass loading for inhalation $(\mathrm{g} / \mathrm{m} * * 3)$

$8.400 \mathrm{E}+03$ 3 $3.400 \mathrm{E}+03$

6.000E- 04 3 $1.000 \mathrm{E}-044^{3}$

\begin{tabular}{|c|c|c|}
\hline $2.574 \mathrm{E}+02$ & 3 & DCNUCC ( 7) \\
\hline-- & 3 & $\operatorname{DCNUCU}(7,1)$ \\
\hline- & 3 & DCNUCS ( 7) \\
\hline $8.416 \mathrm{E}-04$ & 3 & ALEACH $(7)$ \\
\hline \multirow[t]{2}{*}{ not used } & $\begin{array}{l}3 \\
3\end{array}$ & SOLUBK( 7$)$ \\
\hline & 3 & \\
\hline - . - & 3 & DCNUCC ( 8 ) \\
\hline- & 3 & $\operatorname{DCNUCU}(8,1)$ \\
\hline$-\ldots$ & 3 & DCNUCS ( 8) \\
\hline $4.320 E-03$ & 3 & ALEACH ( 8) \\
\hline \multirow{2}{*}{ not used } & 3 & SOLUBK( 8$)$ \\
\hline & 3 & \\
\hline$\ldots$ & 3 & DCNUCC (9) \\
\hline$\ldots$ & 3 & DCNUCU $(9,1)$ \\
\hline - _ - & 3 & DCNUCS $(9)$ \\
\hline $2.164 \mathrm{E}-03$ & 3 & ALEACH ( 9) \\
\hline \multirow[t]{3}{*}{ not used } & 3 & SOLUBK( 9$)$ \\
\hline & 3 & \\
\hline & 3 & \\
\hline - - - & 3 & $\operatorname{DCNUCC}(13)$ \\
\hline - - - & 3 & $\operatorname{DCNUCU}(13,1)$ \\
\hline - - - & 3 & $\operatorname{DCNUCS}(13)$ \\
\hline $3.089 E-03$ & 3 & $\operatorname{ALEACH}(13)$ \\
\hline \multirow[t]{3}{*}{ not used } & 3 & SOLUBK(13) \\
\hline & 3 & \\
\hline & 3 & \\
\hline - . - & 3 & DCNUCC (15) \\
\hline-- & 3 & $\operatorname{DCNUCU}(15,1)$ \\
\hline - - - & 3 & DCNUCS (15) \\
\hline $3.613 \mathrm{E}-06$ & 3 & ALEACH (15) \\
\hline \multirow[t]{3}{*}{ not used } & 3 & SOLUBK(15) \\
\hline & 3 & \\
\hline & 3 & \\
\hline - - - & 3 & $\operatorname{DCNUCC}(16)$ \\
\hline - - - & 3 & $\operatorname{DCNUCU}(16,1)$ \\
\hline-- & 3 & DCNUCS (16) \\
\hline $3.613 \mathrm{E}-06$ & 3 & $\operatorname{ALEACH}(16)$ \\
\hline \multirow[t]{3}{*}{ not used } & 3 & SOLUBK(16) \\
\hline & 3 & \\
\hline & 3 & \\
\hline- & 3 & DCNUCC (18) \\
\hline-- & 3 & $\operatorname{DCNUCU}(18,1)$ \\
\hline - - - & 3 & DCNUCS (18) \\
\hline $4.320 E-03$ & 3 & ALEACH (18) \\
\hline not used & 3 & SOLUBK(18) \\
\hline$\ldots$ & $\begin{array}{l}3 \\
3\end{array}$ & TNHAIP \\
\hline$\ldots$ & 3 & MLINH \\
\hline
\end{tabular}


Site-Specific Parameter Summary (continued)

$\odot \quad 3$

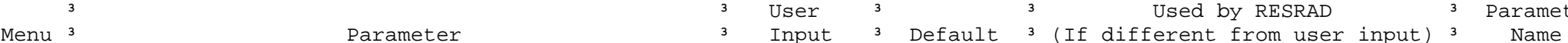

Used by RESRAD

3 Parameter

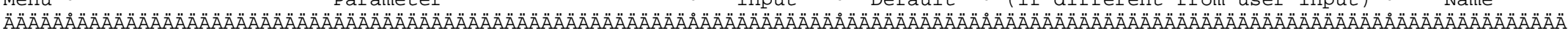

R017 3 Exposure duration

$2.500 \mathrm{E}+01 \quad 3 \quad 3.000 \mathrm{E}+01$

R017 3 Shielding factor, inhalation $\quad 31.000 \mathrm{E}+00^{3} 4.000 \mathrm{E}-011^{3}$

R017 3 Shielding factor, external gamma

R017 3 Fraction of time spent indoors

$1.000 \mathrm{E}+00 \quad 3 \quad 7.000 \mathrm{E}-01$

3 ๑. $000 \mathrm{E}+00$ 3 $5.000 \mathrm{E}-013$

8.550E-02 3 2.500E- 01

R017 3 Fraction of time spent outdoors (on site)

R017 3 Shape factor flag, external gamma

$1.000 \mathrm{E}+\Theta \Theta^{3} 1.000 \mathrm{E}+0 \Theta^{3}$

R017 3 Radii of shape factor array (used if FS = -1):

R017 3 Outer annular radius $(\mathrm{m})$, ring 1:

R017 3 Outer annular radius $(\mathrm{m})$, ring 2:

$\mathrm{R} 017$ Outer annular radius $(\mathrm{m})$, ring 3

$\mathrm{R} 017^{3}$ Outer annular radius $(\mathrm{m})$, ring 4

$\mathrm{R} 017$ 3 $\quad$ Outer annular radius $(\mathrm{m})$, ring 5 :

R017 3 Outer annular radius $(\mathrm{m})$, ring 7 :

R017 3 Outer annular radius $(\mathrm{m})$, ring 8 :

R017 3 Outer annular radius (m), ring 8:

$\begin{array}{llll}\mathrm{R} 017 & 3 & \text { Outer annular radius }(\mathrm{m}) \text {, ring 9: } \\ \mathrm{R} 017 & 3 & \text { Outer annular radius }(\mathrm{m}) \text {, ring 10: }\end{array}$

R017 3 Outer annular radius (m), ring 11:

$\mathrm{R} 017^{3}$ Outer annular radius $(\mathrm{m})$, ring 12:

R017 3 Fractions of annular areas within AREA:

R017 3 Ring 1

$\begin{array}{llll}\mathrm{R} 017 & 3 & \text { Ring } & 1 \\ \mathrm{R} 017 & \mathrm{Ring} & 2\end{array}$

$\begin{array}{llll}R 017 & 3 & \text { Ring } & 2 \\ R 017 & 3 & \text { Ring } & 3\end{array}$

$\begin{array}{llll}\text { R017 } 3 & \text { Ring } 4\end{array}$

R017 3 Ring 5

$\begin{array}{llll}\mathrm{R} 017 & 3 & \text { Ring } & 6 \\ \mathrm{R} 017 & 3 & \text { Ring } & 7\end{array}$

$\begin{array}{llll}\mathrm{R} 017 & 3 & \text { Ring } & 7 \\ \mathrm{R} 017 & 3 & \text { Ring } & 8\end{array}$

R017 3 Ring 9

not used $35.000 \mathrm{E}+01$

not used $3 \quad 7.071 \mathrm{E}+01$

not used $30.000 \mathrm{E}+0 \odot^{3}$

not used $30.000 \mathrm{E}+\Theta \odot$

not used $3 \quad 0.000 \mathrm{E}+0 \odot$

3 not used $30.000 \mathrm{E}+00^{3}$

3 not used $30,00 \odot \mathrm{E}+\odot \odot$

3 not used $30.000 \mathrm{E}+00^{3}$

not used $30.000+00$

not used $3.000 \mathrm{E}+00$

$\begin{array}{lll}3 \text { not used } & & 0.000 \mathrm{E}+0 \odot \\ \text { not used } 3 & 0.000 \mathrm{E}+0 \odot & 3\end{array}$

not used $30.000 \mathrm{E}+00$

3 not used 3 1. $000 \mathrm{E}+\odot \odot$

3 not used $32.732 \mathrm{E}-01^{3}$

3 not used $30.0 \odot \odot \mathrm{E}+\odot{ }^{3}$

3 not used $30.000 \mathrm{E}+0{ }^{3}$

3 not used $30.000 \mathrm{E}+\odot \odot$

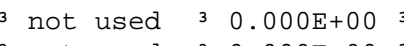

3 not used $30.000 \mathrm{E}+\Theta \odot$

3 not used $30.000 \mathrm{E}+00^{3}$

3 not used $30.000 \mathrm{E}+\Theta \odot_{3}$

3 not used 3 Q $000 \mathrm{E}+00$

3 not used 3 O.

$\mathrm{R} 0177^{3}$ Ring 10

not used $30.000 \mathrm{E}+00$

3

R018 ${ }^{3}$ Fruits, vegetables and grain consumption ( $\mathrm{kg} / \mathrm{yr}$ )

R018 3 Leafy vegetable consumption ( $\mathrm{kg} / \mathrm{yr}$ )

R018 3 Milk consumption ( $\mathrm{L} / \mathrm{yr}$ )

R018 3 Meat and poultry consumption ( $\mathrm{kg} / \mathrm{yr}$ )

R018 3 Fish consumption ( $\mathrm{kg} / \mathrm{yr}$ )

R018 3 other seafood consumption ( $\mathrm{kg} / \mathrm{yr}$ )

R018 3 Soil ingestion rate (g/yr)

R018 3 Drinking water intake (L/yr)

R018 3 Contamination fraction of drinking water

R018 3 Contamination fraction of household water

R018 3 Contamination fraction of livestock water

R018 3 Contamination fraction of irrigation water

R018 3 Contamination fraction of aquatic food

R018 3 Contamination fraction of plant food

R018 3 Contamination fraction of meat

R018 3 Contamination fraction of milk

not used $31.400 \mathrm{E}+01$

3 not used $3 \quad 9.200 \mathrm{E}+01$

not used $36.300 \mathrm{E}+01$

not used $35.400 \mathrm{E}+00$

not used 3 9.000E- 01

1. $080 \mathrm{E}+02 \quad 3 \quad 3.650 \mathrm{E}+01$

not used $3 \quad 5.100 \mathrm{E}+02$

not used $31.000 \mathrm{E}+00^{3}$

not used $31.000 \mathrm{E}+00$

not used $31.000 \mathrm{E}+00$

not used 3 1.000E+0๑

not used 35 . $000 \mathrm{E}-01$

3 not used $3-1$

not used $3-1$

not used $3-1$

3 not used

$\begin{array}{lll}-- & 3 & \text { ED } \\ --- & 3 & \text { SHF3 } \\ --- & 3 & \text { SHF1 } \\ --- & 3 & \text { FIND }\end{array}$

3 FOTD

$>0$ shows circular AREA. 3 FS

RAD_SHAPE ( 1$)$

3 RAD_SHAPE( 2$)$

3 RAD_SHAPE ( 3$)$

3 RAD_SHAPE ( 4$)$

3 RAD_SHAPE ( 5)

3 RAD_SHAPE $(6)$

3 RAD_SHAPE ( 7)

RAD_SHAPE ( 8$)$

3 RAD_SHAPE ( 9)

3 RAD_SHAPE $(10)$

3 RAD_SHAPE (11)

FRACA ( 1)

FRACA( 2)

FRACA ( 3)

FRACA( 4)

FRACA( 5)

FRACA ( 6)

3 FRACA ( 7)

FRACA( 8)

FRACA ( 9)

FRACA (10)

FRACA (11)

3 FRACA (12)

3 DIET(2)

3 DIET(3)

$3 \operatorname{DIET}(4)$

3 DIET (5)

$3 \operatorname{DIET}(6)$

3 SOIL

3 DWI

3 FDW

3 FHHW

$3 \mathrm{FLW}$

3 FIRW

3 FR9

3 FPLANT

3 FMEAT

3 FMILK 
Site-Specific Parameter Summary (continued)

Menu 3 Parameter User 3 sof 3 (If differ

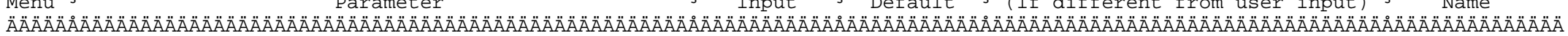

R019 3 Livestock fodder intake for meat ( $\mathrm{kg} /$ day) 3 not used $36.800 \mathrm{E}+013 \mathrm{3}$

R019 3 Livestock fodder intake for milk (kg/day) 3 not used $35.500 \mathrm{E}+013^{3}$

R019 3 Livestock water intake for meat (L/day) 3 not used $35.000 \mathrm{E}+01^{3} \quad{ }_{3}$

R019 3 Livestock water intake for milk (L/day) 3 not used $31.600 \mathrm{E}+02^{3} \quad-$.

R019 3 Livestock soil intake ( $\mathrm{kg} /$ day)

R019 3 Mass loading for foliar deposition $\left(\mathrm{g} / \mathrm{m}^{* *} 3\right) \quad 3$ not used $31.000 \mathrm{E}-044^{3} \quad$---

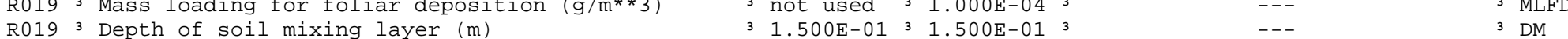

R019 3 Drinking water fraction from ground water

R019

R019 Household water fraction from ground water

3 not used $31.000 \mathrm{E}+00^{3}$

not used $31.000 \mathrm{E}+\odot \odot^{3}$

R019 Livestock water fraction from ground water

not used $31.000 \mathrm{E}+00^{3}$

R019 3 Irrigation fraction from ground water

R19B 3 Wet weight crop yield for Non-Leafy $\left(\mathrm{kg} / \mathrm{m}^{* *} 2\right)$

3 not used 31 1. $3000 \mathrm{E}+\odot \odot_{3}^{3}$

not used $37.000 \mathrm{E}-01^{3}$

R19B 3 wet weight crop yield for Leafy $\left(\mathrm{kg} / \mathrm{m}^{* *} 2\right) \quad 3$ not used $31.500 \mathrm{E}+00^{3}$

R19B 3 wet weight crop yield for Fodder $\left(\mathrm{kg} / \mathrm{m}^{* * 2}\right) \quad 3$ not used $31.100 \mathrm{2}+00^{3}$

R19B 3 Growing Season for Non-Leafy (years) 3 not used $31.700 \mathrm{E}-01^{3}$

R19B 3 Growing Season for Leafy (years) 3 not used $32.500 \mathrm{E}-01^{3}$

R19B 3 Growing Season for Fodder (years) 3 not used $38.000 \mathrm{E}-02^{3}$

R19B 3 Translocation Factor for Non-Leafy 3 not used 3 1.000E-01

R19B 3 Translocation Factor for Leafy 3 not used $31.000 \mathrm{E}+00^{3}$

R19B 3 Translocation Factor for Fodder 3 not used $31.000 \mathrm{E}+00^{3}$

R19B 3 Dry Foliar Interception Fraction for Non-Leafy 3 not used $32.500 \mathrm{E}-01^{3}$

R19B 3 Dry Foliar Interception Fraction for Leafy 3 not used $32.500 \mathrm{E}-013$

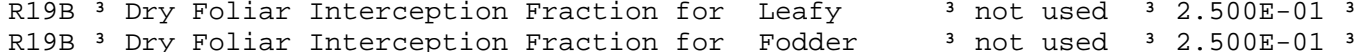

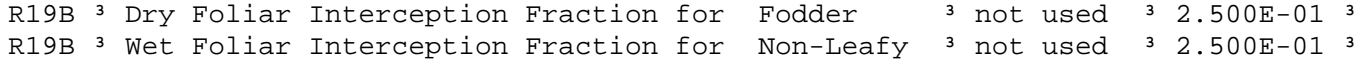

R19B 3 Wet Foliar Interception Fraction for Leafy 3 not used $32.500 \mathrm{E}-013$

R19B 3 Wet Foliar Interception Fraction for Fodder 3 not used $32.500 \mathrm{E}-01$

R19B 3 Weathering Removal Constant for Vegetation 3 not used $32.000 \mathrm{E}+01^{3}$

C14 3 C-12 concentration in water $\left(\mathrm{g} / \mathrm{cm}^{* *} 3\right)$

C14 3 C-12 concentration in contaminated soil $(\mathrm{g} / \mathrm{g})$

C14 3 Fraction of vegetation carbon from soi

C14 3 Fraction of vegetation carbon from air

C14 3 C-14 evasion layer thickness in soil $(\mathrm{m})$

C14 3 C-14 evasion flux rate from soil (1/sec)

C14 3 C-12 evasion flux rate from soil (1/sec)

C14 3 Fraction of grain in beef cattle feed

C14 3 Fraction of grain in milk cow feed

C14 3 DCF correction factor for gaseous forms of $\mathrm{C}_{14}$

3

3 not used $32.000 \mathrm{E}-053$

3 not used $33.000 \mathrm{E}-022^{3}$

3 not used 32 2.000E- -02

3 not used $39.800 \mathrm{E}-01^{3}$

3 not used 3 3.000E-01

3 not used 3 7.000E- 07

3 not used 3 1.000E-10

not used 3 8.000E- $01^{3}$

3 not used 3 2.000E-01

not used 3 ०.

STOR 3 Storage times of contaminated foodstuffs (days): 3

STOR 3 Fruits, non-leafy vegetables, and grain (3)

STOR ${ }^{3}$ Leafy vegetables

STOR ${ }^{3}$ Milk

STOR ${ }^{3}$ Meat and poultry

STOR 3 Fish

$31.400 \mathrm{E}+01^{3} 1.400 \mathrm{E}+01$

$31.000 \mathrm{E}+\odot \odot$ 3 $1.000 \mathrm{E}+\odot \odot$

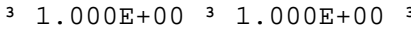

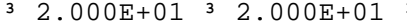

$37.00 \odot E+0 \odot \quad 3 \quad 7.000 \mathrm{E}+0 \odot$

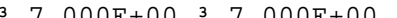

STOR ${ }^{3}$ Crustacea and mollusks

STOR 3 Well water

STOR 3 Surface water

STOR 3 Livestock fodder

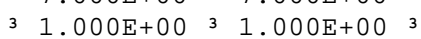

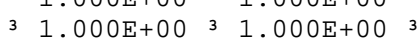

3 4.500E+01 3 4.500E+01 3

$-\cdot-$

- . 3 FGWHH

3 FGWLW

$-\cdot-$

$---3 \mathrm{YV}(1)$

$--13 \mathrm{YV}(2)$

$---3 \mathrm{YV}(3)$

3 TE (1)

$\begin{array}{ll}3 & \operatorname{TE}(3) \\ 3 & \operatorname{TIV}(1)\end{array}$

$3 \operatorname{TIV}(2)$

$3 \operatorname{TIV}(3)$

$--$

-. $3 \operatorname{RDRY}(2)$

- - 3 RDRY (3)

- - $\quad 3 \operatorname{RWET}(1)$

$\begin{array}{ll}-.- & 3 \\ -. & \operatorname{RWET}(2) \\ --- & 3 \\ \operatorname{RWET}(3)\end{array}$

$--$

C12WTR

$-\cdot-$

-- $\quad 3 \mathrm{C} 12 \mathrm{CZ}$

-.- 3 CSOIL

3 CAIR

- - 13 EVSN

3 REVSN

3 AVFG4

- - $3 \mathrm{CO} 2 \mathrm{~F}$

3

3 STOR_T(1)

3 STOR_T(2)

3 STOR_T(3)

3 STOR_T(4)

3 STOR_T(5)

3 STOR_T(6)

3 STOR_T(7)

3 STOR_T(9) 


1RESRAD, Version $6.3 \quad$ T« Limit $=180$ days
Summary : CAU 545 CAS $03-17-01$ Biasd

Site-Specific Parameter Summary (continued)

$0 \quad 3$

Menu 3 Parameter 3 Input 3 Default 3 (If different from user input) 3 Name

3 Used by RESRAD 3 Parameter

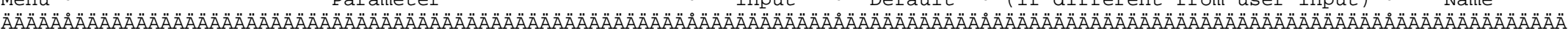

RO21 3 Thickness of building foundation (m)

R021 Bulk density of building foundation $\left(\mathrm{g} / \mathrm{cm}^{* *} 3\right) \quad 3$ not used $32.400 \mathrm{E}+00^{3}$

R021 3 Total porosity of the cover material 3 not used $34.000 \mathrm{E}-01{ }^{3}$

R021 3 Total porosity of the building foundation 3 not used 3 1.000E-01

R021 3 Volumetric water content of the cover material 3 not used $35.000 \mathrm{E}-02^{3}$

R021 3 Volumetric water content of the foundation 3 not used $33.000 \mathrm{E}-02^{3}$

$\mathrm{R} 0211^{3}$ in cover material

$\mathrm{R} \odot 21^{3}$ in foundation material

RO21 3 in contaminated zone soil

R०21 3 Radon vertical dimension of mixing ( $\mathrm{m}$ )

R021 3 Average building air exchange rate $(1 / \mathrm{hr})$

Ro21 3 Height of the building (room) (m)

R021 3 Building interior area factor

not used 3 2.000E-06

not used $32.000 \mathrm{E}-06$

$\begin{array}{lll}\text { not used } & 3 & 3.000 \mathrm{E}-07 \\ \text { not used } & 3 & 2.000 \mathrm{E}-06 \\ \end{array}$

not used $32.000 \mathrm{E}+003$

not used 3 5.000E-01

3 not used $32.500 \mathrm{E}+00^{3}$

3 not used $30.000 \mathrm{E}+00$

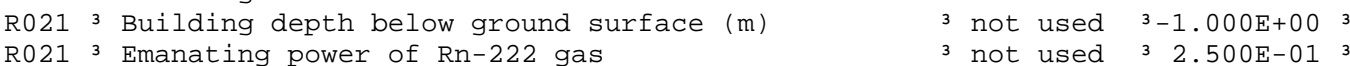

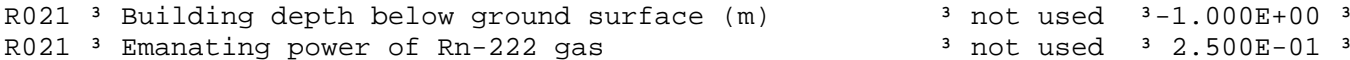

$\mathrm{R} 0213$ Emanating power of $\mathrm{Rn}-222$ gas

not used 3 1.500E- $-11^{3}$ 3

TITL 3 Number of graphical time points

TITL 3 Maximum number of integration points for dose

TITL 3 Maximum number of integration points for risk

$\begin{array}{lcc}3 & 1.500 \mathrm{E}-01 & 3 \\ 3 & & 3 \\ 3 & --- & 3 \\ 3 & --. & 3 \\ 3 & -- & 3\end{array}$

$\begin{array}{lll}--- & 3 & \text { FLOOR1 } \\ --- & 3 & \text { DENSFL } \\ --- & 3 & \text { TPCV } \\ --- & 3 & \text { TPFL } \\ --- & 3 & \text { PH2OCV } \\ --- & 3 & \text { PH2OFL } \\ & 3 & \\ --- & 3 & \text { DIFCV } \\ --- & 3 & \text { DIFFL } \\ --- & 3 & \text { DIFCZ } \\ --- & 3 & \text { HMIX } \\ --- & 3 & \text { REXG } \\ --- & 3 & \text { HRM } \\ --- & 3 & \text { FAI } \\ --- & 3 & \text { DMFL } \\ --- & 3 & \text { EMANA(1) } \\ --- & 3 & \text { EMANA(2) } \\ --- & 3 & \\ --- & 3 & \text { NPTS } \\ --- & 3 & \text { LYMAX } \\ -- & 3 & \text { KYMAX }\end{array}$

Summary of Pathway Selections

Pathway ${ }^{3}$ User Selection

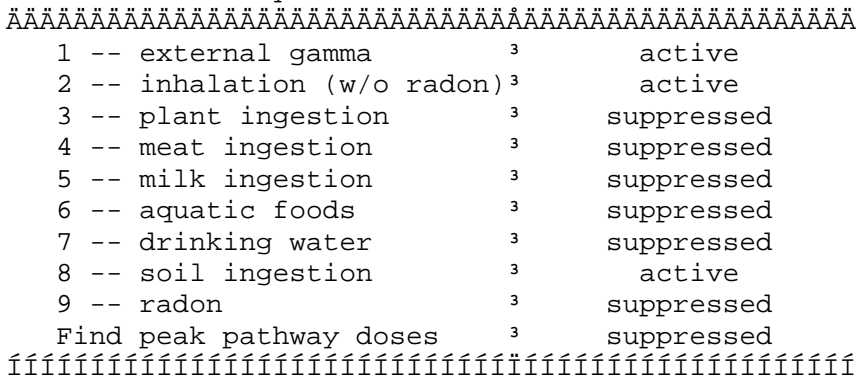

UNCONTROLLED When Printed 
1RESRAD, Version 6.3 T« Limit $=180$ days Summary : CAU 545 CAS 03-17-01 Biasd ÄÄÄÄÄÄÄÄÄÄÄÄÄÄÄÄÄÄÄÄÄÄÄÄÄÄÄÄÄÄ

Area: 100.00 square meters

Thickness: $\quad 0.15$ meters

Cover Depth: 0.00 meters
Contaminated Zone Dimensions

11/28/2007 23:08 Page 13

File: CAU 545_ind_Biased.RAD

Initial Soil Concentrations, pCi/g ÄÄÄÄÄÄÄÄÄÄÄÄÄÄÄÄÄÄÄÄÄÄÄÄÄÄÄÄÄÄÄÄÄÄ

$\mathrm{Am}-241 \quad 2.840 \mathrm{E}+02$

CS-137 $5.140 \mathrm{E}+00$

Eu-152 2.170E+๑๑

$\mathrm{Pu}-238 \quad 5.140 \mathrm{E}+00$

Pu-239 4.550E+०2

$\mathrm{Sr}-90 \quad 1.100 \mathrm{E}+00$

$\mathrm{U}-233 \quad 2.420 \mathrm{E}+00$

$-238-1.100 E+00$

Total Dose TDOSE(t), mrem/yr

Basic Radiation Dose Limit $=2.500 \mathrm{E}+01 \mathrm{mrem} / \mathrm{yr}$

Total Mixture Sum $M(t)=$ Fraction of Basic Dose Limit Received at Time $(t)$

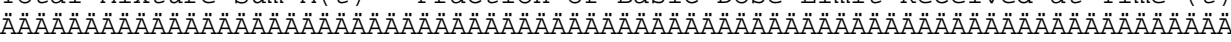

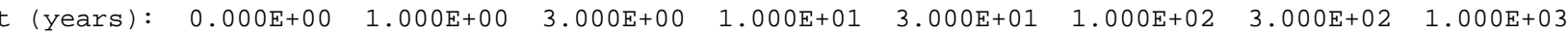

TDOSE $(t): \begin{array}{llllllll}1.276 E+01 & 1.256 \mathrm{E}+01 & 1.217 \mathrm{E}+01 & 1.094 \mathrm{E}+01 & 8.216 \mathrm{E}+00 & 2.651 \mathrm{E}+00 & 0.000 \mathrm{E}+00 & 0.000 \mathrm{E}+00\end{array}$

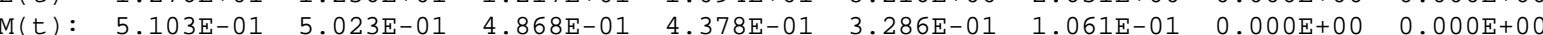

OMaximum TDOSE(t): $1.276 \mathrm{E}+01 \mathrm{mrem} / \mathrm{yr}$ at $\mathrm{t}=0.000 \mathrm{E}+00$ years 


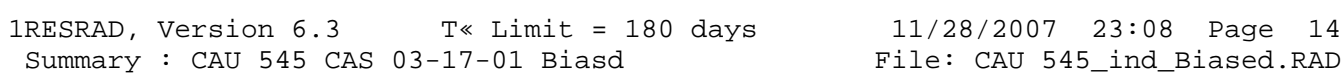

Total Dose Contributions $\operatorname{TdOSE}(i, p, t)$ for Individual Radionuclides (i) and Pathways (p) As $\mathrm{mrem} / \mathrm{yr}$ and Fraction of Total Dose At $t=0.000 \mathrm{E}+00$ years Ground Inhalation
Radon water Independent Pathways (Inhalation excludes radon)

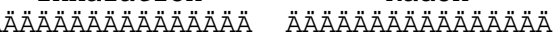
Plant Meat 


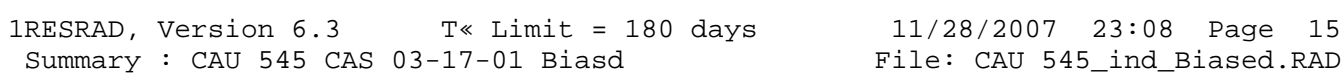

Total Dose Contributions $\operatorname{TDOSE}(i, p, t)$ for Individual Radionuclides (i) and Pathways (p) As $\mathrm{mrem} / \mathrm{yr}$ and Fraction of Total Dose At $t=1.000 \mathrm{E}+00$ years

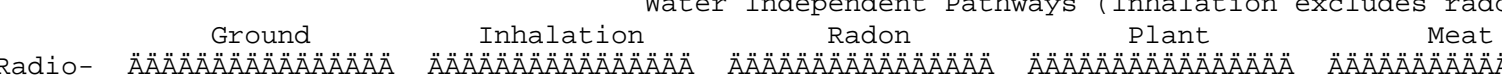
water Independent Pathways (Inhalation excludes radon) vuclide mrem/y r fract. Plant Meat 

1RESRAD, Version 6.3
T« Limit $=180$ days
11/28/2007 23: 08 Page 16
Summary : CAU 545 CAS $03-17-01$ Biasd
File: CAU 545_ind_Biased.RAD

Total Dose Contributions $\operatorname{TDOSE}(i, p, t)$ for Individual Radionuclides (i) and Pathways $(p)$

As mrem/yr and Fraction of Total Dose At $t=3.000 \mathrm{E}+00$ years Water Independent Pathways (Inhalation excludes radon) Nuclide mrem/yr fract.

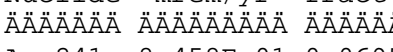
$\begin{array}{lll}\mathrm{Am}-241 & 8.458 \mathrm{E}-01 & 0.0695\end{array}$ Cs-137 9.707E-01 0.0798 $\mathrm{Eu}-152 \quad 7.337 \mathrm{E}-010.0603$ Pu-238 5.847E-05 0.0000 Pu-239 9.143E-03 0.0008 $\mathrm{Sr}-90 \quad 1.540 \mathrm{E}-03 \quad 0.0001$ $\mathrm{U}-233 \quad 3.053 \mathrm{E}-04 \quad 0.0000$ $\mathrm{U}-235 \quad 5.822 \mathrm{E}-03 \quad 0.0005$ $\mathrm{U}-238 \quad 1.004 \mathrm{E}-02 \quad 0.0008$ ííííí ííííííi ííííi Total $2.577 \mathrm{E}+00 \quad 0.2117$
Inhalation Radon Plant

\section{ÄÄÄÄÄÄÄÄÄÄÄÄÄÄÄÄ} mrem/yr fract. ÄÄÄÄÄÄÄÄÄ ÄÄÄÄÄÄ $\begin{array}{ll}2.744 \mathrm{E}+0 \odot & 0.2255 \\ 3.436 \mathrm{E}-06 & 0.0000\end{array}$ $9.078 \mathrm{E}-06 \quad 0.0000$ $4.452 \mathrm{E}-02 \quad 0.0037$ $4.434 \mathrm{E}+00 \quad 0.3643$ $2.935 \mathrm{E}-05 \quad 0.0000$ 7.352E-03 0.0006 $3.197 \mathrm{E}-040.0000$ $2.906 \mathrm{E}-03 \quad 0.0002$

$7.233 E+00$ 0.5943

\section{ÄÄÄÄÄÄÄÄÄÄÄÄÄÄÄÄ} $\mathrm{mrem} / \mathrm{yr}$ fract. Meat mrem/yr fract.
mreaA

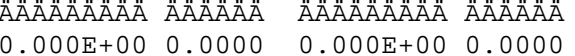

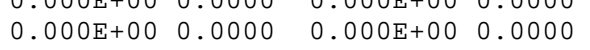
$\odot .000 E+\odot \odot \quad \odot .00 \odot \odot \quad \odot .000 \mathrm{E}+\odot \odot \quad \odot .00 \odot \odot$ $\odot .000 \mathrm{E}+\odot \odot \quad \odot .000 \odot \quad 0.000 \mathrm{E}+\odot \odot \quad \odot .00 \odot \odot$ $\begin{array}{llll}0.000 \mathrm{E}+00 & 0.0000 & 0.000 \mathrm{E}+00 & 0.0000\end{array}$

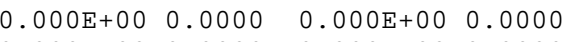
$0.000 \mathrm{E}+00 \quad 0.0000 \quad 0.000 \mathrm{E}+00 \quad 0.0000$ $0.000 \mathrm{E}+00 \quad 0.0000 \quad 0.000 \mathrm{E}+00 \quad 0.0000$

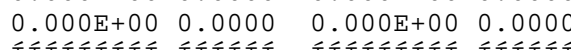
 $0.000 \mathrm{E}+000.0000$
ÄÄÄÄÄÄÄÄÄÄÄÄÄÄÄÄÄ mrem/yr fract. ÄÄÄÄÄÄÄÄÄ ÄÄÄÄÄÄ $0.000 \mathrm{E}+00 \quad 0.0000$ $\odot .000 \mathrm{E}+0 \odot \quad 0.0000$ $0.000 \mathrm{E}+00 \quad 0.0000$ $0.000 \mathrm{E}+00 \quad 0.0000$ $\odot .000 \mathrm{E}+0 \odot \quad 0.0000$ $\odot .000 \mathrm{E}+00 \quad 0.0000$ $0.000 \mathrm{E}+00 \quad 0.0000$ $\odot . \odot \odot \odot E+\odot \odot \odot . ๑ \odot \odot \odot$ Íííííííi ííííi $0.000 \mathrm{E}+00 \quad 0.0000$ m mrem/yr fract. ๑. OOQE+OQ AAAAAA $\odot .000 \mathrm{E}+0 \odot \quad 0.000 \odot$ $\odot .000 \mathrm{E}+00 \quad 0.0000$ $\odot .000 \mathrm{E}+00 \quad 0.0000$ $\odot .000 \mathrm{E}+00 \quad 0.0000$ $\odot .000 \mathrm{E}+00 \quad 0.000 \odot$ $0.000 \mathrm{E}+00 \quad 0.0000$ $\odot .000 \mathrm{E}+00 \quad 0.0000$ $0.000 \mathrm{E}+00 \quad 0.0000$ IIIIifí Iííi $0.000 \mathrm{E}+00 \quad 0.0000$
Soil АลАลАล̈ÄÄÄÄÄÄÄÄÄÄ mrem/yr fract. AAAAAAAAA ÄÄÄÄÄA $8.929 \mathrm{E}-01 \quad 0.0734$ $2.137 \mathrm{E}-04 \quad 0.0000$ $1.056 \mathrm{E}-05 \quad 0.0000$ $1.442 \mathrm{E}-02 \quad 0.0012$ $1.452 \mathrm{E}+00 \quad 0.1193$ $1.360 \mathrm{E}-04 \quad 0.0000$ $6.241 \mathrm{E}-04 \quad 0.0001$ $2.764 \mathrm{E}-05 \quad 0.0000$ $2.626 \mathrm{E}-04 \quad 0.0000$ Íííííííi ííííí $2.361 E+0 \odot \quad 0.1939$

Total Dose Contributions $\operatorname{TDOSE}(i, p, t)$ for Individual Radionuclides (i) and Pathways (p) As $\mathrm{mrem} / \mathrm{yr}$ and Fraction of Total Dose At $t=3.000 \mathrm{E}+\odot \odot$ years

\section{Meat}

ĀÄÄÄÄÄÄÄÄÄÄÄÄÄA mrem/yr fract ÄÄÄÄÄÄÄ ÄÄÄÄÄÄ $0.000 \mathrm{E}+00 \quad 0.0000$ $0.000 \mathrm{E}+00 \quad 0.0000$ $0.000 \mathrm{E}+00 \quad 0.0000$ $0.000 \mathrm{E}+0 \odot \quad 0.0000$ $0.000 \mathrm{E}+0 \odot \quad 0.000 \odot$ $0.000 E+00 \quad 0.0000$ $0.000 \mathrm{E}+00 \quad 0.0000$ $\odot .000 \mathrm{E}+00 \quad \odot .0000$ $0.000 \mathrm{E}+000.0000$ Íííííííí ííííí $\odot .000 \mathrm{E}+0 \odot \quad 0.000 \odot$
Milk

AAAAAAAAAAÄÄÄÄA mrem/yr fract. AAAAAÄÄÄÄ ÄÄÄÄÄÄ $0.000 \mathrm{E}+00 \quad 0.0000$ $0.000 \mathrm{E}+00 \quad 0.0000$ $\odot .000 \mathrm{E}+00 \quad 0.0000$ $\odot .000 \mathrm{E}+00 \quad 0.0000$ $0.000 \mathrm{E}+00 \quad 0.0000$ $0.000 \mathrm{E}+0 \odot \quad 0.000 \odot$ $0.000 \mathrm{E}+00 \quad 0.0000$ $\odot .000 \mathrm{E}+00 \quad 0.0000$ $0.000 \mathrm{E}+00 \quad 0.0000$ Íííííííi ííííí $\odot . \odot \odot \odot \mathrm{E}+\odot \odot \quad \odot . \odot ० ० \odot$
All Pathways* AAAAAAAAAÄÄÄÄÄÄÄ mrem/yr fract. $4.483 \mathrm{E}+00 \quad 0.3683$ $9.709 \mathrm{E}-01 \quad 0.0798$ 7. 337E-01 0.0603 $5.901 \mathrm{E}-02 \quad 0.0048$ $5.895 \mathrm{E}+0 \odot \quad 0.4843$ $1.705 \mathrm{E}-03 \quad 0.0001$ $8.282 \mathrm{E}-03 \quad 0.0007$ $6.169 \mathrm{E}-03 \quad 0.0005$ $1.321 \mathrm{E}-02$ 0. 0011 (1) $\begin{array}{ll}1.217 \mathrm{E}+01 & 1.000 \odot\end{array}$

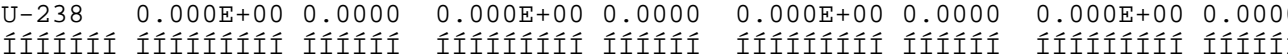

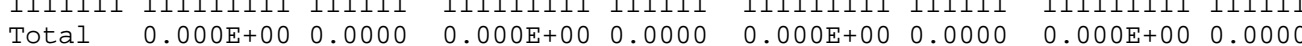
$\odot$ * Sum of all water independent and dependent pathways. 


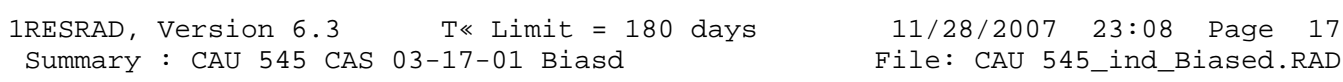

Total Dose Contributions $\operatorname{TDOSE}(i, p, t)$ for Individual Radionuclides (i) and Pathways (p) As $\mathrm{mrem} / \mathrm{yr}$ and Fraction of Total Dose At $t=1.000 \mathrm{E}+01$ years Inhalation water Independent Pathways (Inhalation excludes radon) Radio- ÄÄÄÄÄÄÄÄÄÄÄÄÄÄÄA Radon Plant Meat 


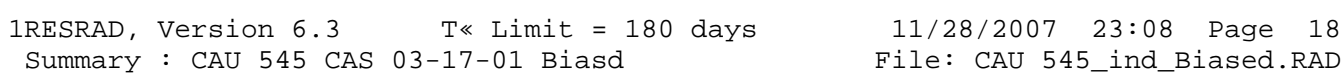

Total Dose Contributions $\operatorname{TDOSE}(i, p, t)$ for Individual Radionuclides (i) and Pathways (p) As $\mathrm{mrem} / \mathrm{yr}$ and Fraction of Total Dose At $t=3.000 \mathrm{E}+01$ years Inhalation water Independent Pathways (Inhalation excludes radon) Radio- ÄÄÄÄÄÄÄÄÄÄÄÄÄÄÄA Radon Plant Meat 


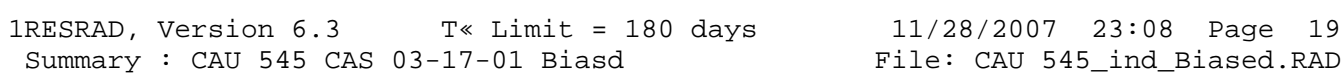

Total Dose Contributions $\operatorname{TDOSE}(i, p, t)$ for Individual Radionuclides (i) and Pathways (p) As $\mathrm{mrem} / \mathrm{yr}$ and Fraction of Total Dose At $t=1.000 \mathrm{E}+02$ years Inhalation water Independent Pathways (Inhalation excludes radon) Radio- ÄÄÄÄÄÄÄÄÄÄÄÄÄÄÄ Radon Plant Meat 


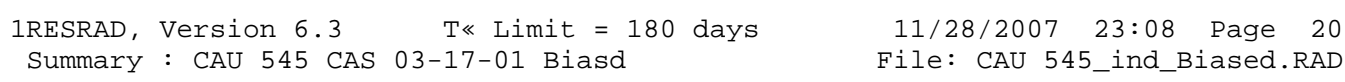

Total Dose Contributions $\operatorname{TDOSE}(i, p, t)$ for Individual Radionuclides (i) and Pathways (p) As $\mathrm{mrem} / \mathrm{yr}$ and Fraction of Total Dose At $t=3.000 \mathrm{E}+02$ years water Independent Pathways (Inhalation excludes radon)

\section{Inhalation Radon Plant Meat}

Radio- ÄÄÄÄÄÄÄÄ̈̈̈̈ÄÄÄ vuclide mrem/yr fract. 


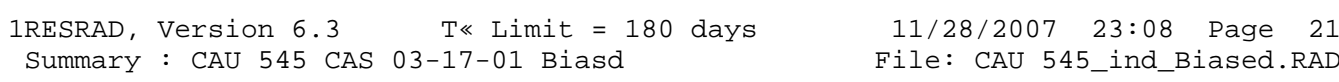

Total Dose Contributions $\operatorname{TDOSE}(i, p, t)$ for Individual Radionuclides (i) and Pathways (p) As $\mathrm{mrem} / \mathrm{yr}$ and Fraction of Total Dose At $t=1.000 \mathrm{E}+03$ years water Independent Pathways (Inhalation excludes radon)

\section{Inhalation Radon Plant Meat}

Radio- ÄÄÄÄÄÄÄÄ̈̈̈̈ÄÄÄ vuclide mrem/yr fract. 
Dose/Source Ratios Summed Over All Pathways

Parent Product Thread DSR $(\mathrm{j}, \mathrm{t})$ At Time in Years (mrem/yr)/(pCi/g)

АA ААAАAАA

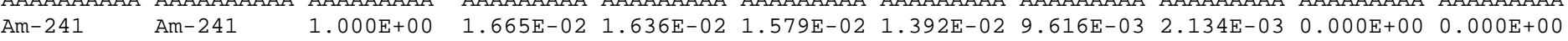
$\begin{array}{lllllllllll}A m-241 & N p-237+D & 1.000 E+00 & 1.432 E-08 & 4.258 E-08 & 9.746 E-08 & 2.730 E-07 & 6.479 E-07 & 8.563 E-07 & 0.000 E+00 & 0.000 E+00\end{array}$

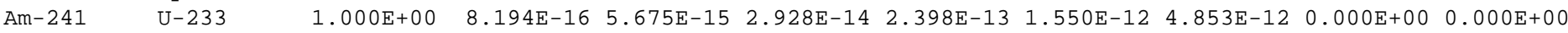

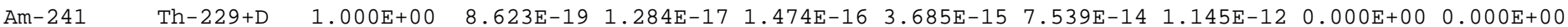
$1.665 \mathrm{E}-02 \quad 1.636 \mathrm{E}-02 \quad 1.579 \mathrm{E}-02 \quad 1.392 \mathrm{E}-02 \quad 9.617 \mathrm{E}-03 \quad 2.135 \mathrm{E}-03 \quad 0.000 \mathrm{E}+000.000 \mathrm{E}+00$

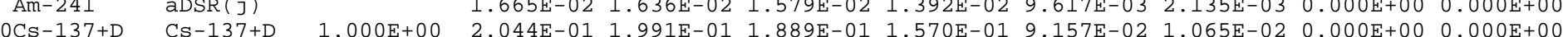

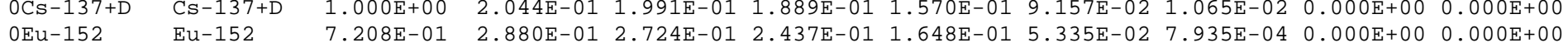

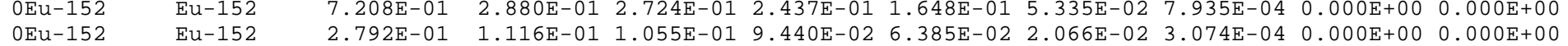

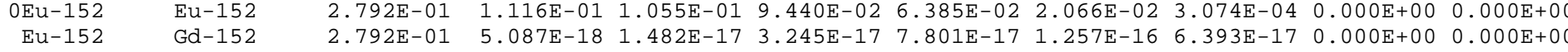
$\operatorname{Eu}-152 \quad$ äDSR $(j)$

OPu-238 Pu-238

OPu-238 Pu-238

$\mathrm{Pu}-238 \quad \mathrm{U}-234$

$\mathrm{Pu}-238 \quad \mathrm{Th}-230$

Pu -238

$\mathrm{Pu}-238$

๑Pu- 239

$\mathrm{Pu}-239$

$\mathrm{Pu}-239$

Pu-239

$\mathrm{Pu}-239$

OSr - 90+D

OU -233

$\mathrm{U}-233$

$\mathrm{U}-233$

$\odot U-235+D$

$\mathrm{U}-235+\mathrm{D}$

$\mathrm{U}-235+\mathrm{D}$

$\mathrm{U}-235+\mathrm{D}$

OU -238

OU $-238+D$

$\mathrm{U}-238+\mathrm{D}$

$\mathrm{U}-238+\mathrm{D}$

$\mathrm{U}-238+\mathrm{D}$

$\mathrm{U}-238+\mathrm{D}$

Th-230

Ra-226+D

äDSR $(j)$

$\mathrm{Pu}-239$

U-235+D

$\mathrm{Pa}-231$

$A C-227+D$

äDSR $(j)$

Sr $-90+\mathrm{D}$

Th-229+D

äDSR $(j)$

$\mathrm{U}-235+\mathrm{D}$

$\mathrm{Pa}-231$

$A C-227+D$

äDSR $(j)$

U- 238

$\mathrm{U}-238+$

$\mathrm{U}-234$

Th-230

$2.208 \mathrm{E}-11$ 1. $255 \mathrm{E}-01 \quad 9.440 \mathrm{E}-02 \quad 6.385 \mathrm{E}-02 \quad 2.066 \mathrm{E}-02 \quad 3.074 \mathrm{E}-\odot 4 \quad 0.0 \odot \odot \mathrm{E}+\odot \odot \odot . \odot \odot \odot \mathrm{E}+\odot \odot$

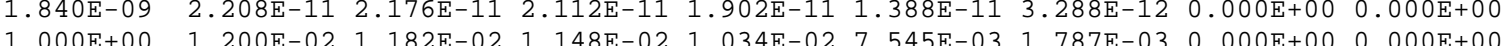

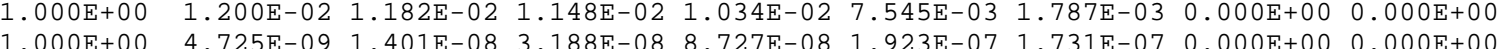

1.000E+00 $3.450 \mathrm{E}-14 \quad 2.401 \mathrm{E}-08$ 3.188E-08 $8.727 \mathrm{E}-08$ 1.923E- 07 1.731E

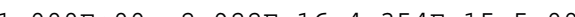

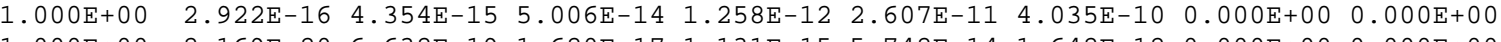

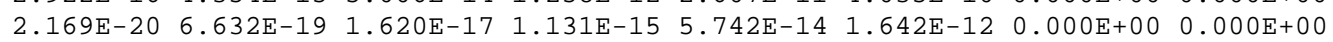

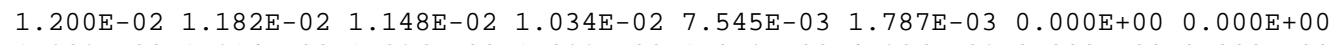

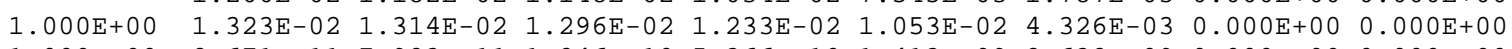

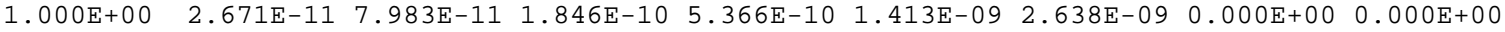

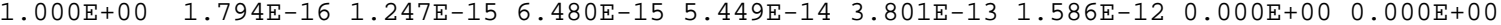

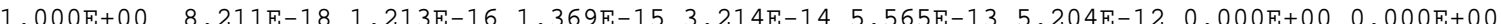

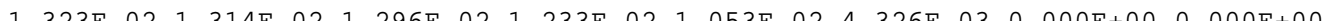

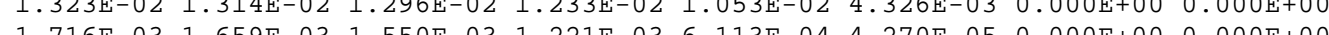

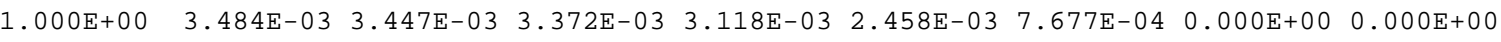

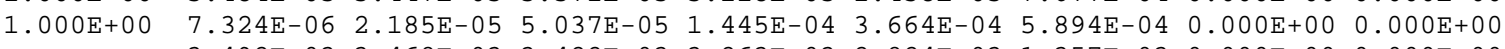

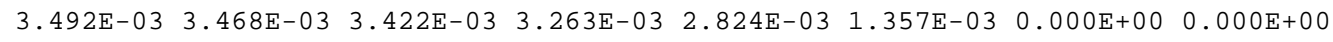

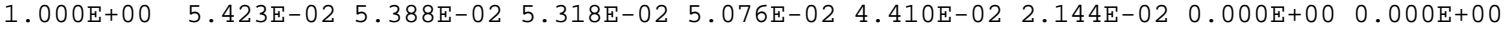

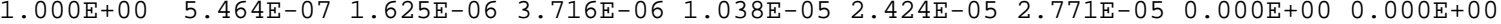
$1.000 \mathrm{E}+00 \quad 3.327 \mathrm{E}-08 \quad 2.286 \mathrm{E}-07 \quad 1.158 \mathrm{E}-06 \quad 8.916 \mathrm{E}-06 \quad 4.932 \mathrm{E}-05 \quad 1.131 \mathrm{E}-04 \quad 0.000 \mathrm{E}+00 \quad 0.000 \mathrm{E}+00$

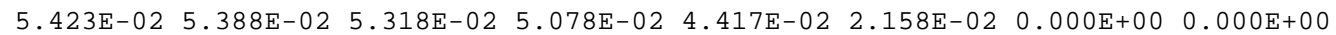
$5.400 \mathrm{E}-05$ 1. $605 \mathrm{E}-07 \quad 1.588 \mathrm{E}-07 \quad 1.553 \mathrm{E}-07 \quad 1.435 \mathrm{E}-07 \quad 1.4128 \mathrm{E}-07 \quad 3.469 \mathrm{E}-08 \quad 0.000 \mathrm{E}+000.000 \mathrm{E}+00$ 9.999E-01 1.231E-02 1.221E-02 1.201E-02 1.134E-02 $9.529 \mathrm{E}-03 \quad 4.079 \mathrm{E}-03 \quad 0.000 \mathrm{E}+00 \quad 0.000 \mathrm{E}+00$ 9.999E-01 4.730E-09 1.405E-08 3.208E-08 8.897E-08 2.033E-07 2.072E-07 $0.000 \mathrm{E}+00 \quad 0.000 \mathrm{E}+00$ $\begin{array}{lllllllll}9.999 \mathrm{E}-01 & 3.453 \mathrm{E}-14 & 2.397 \mathrm{E}-13 & 1.244 \mathrm{E}-12 & 1.039 \mathrm{E}-11 & 7.099 \mathrm{E}-11 & 2.650 \mathrm{E}-10 & 0.000 \mathrm{E}+00 & 0.000 \mathrm{E}+00\end{array}$

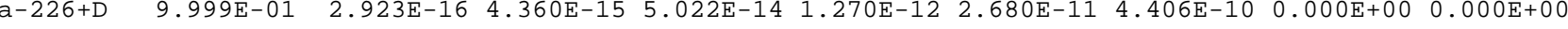
$\begin{array}{llllllllll} & 9.999 \mathrm{E}-01 & 2.171 \mathrm{E}-20 & 6.640 \mathrm{E}-19 & 1.624 \mathrm{E}-17 & 1.139 \mathrm{E}-15 & 5.874 \mathrm{E}-14 & 1.772 \mathrm{E}-12 & 0.000 \mathrm{E}+00 & 0.000 \mathrm{E}+00\end{array}$

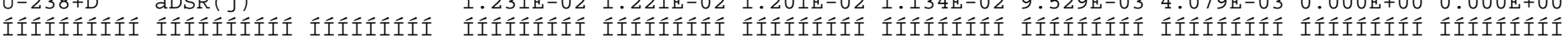

The DSR includes contributions from associated (half-life ó 180 days) daughters. 
Single Radionuclide Soil Guidelines $\mathrm{G}(\mathrm{i}, \mathrm{t})$ in $\mathrm{pCi} / \mathrm{g}$ Basic Radiation Dose Limit $=2.500 \mathrm{E}+01 \mathrm{mrem} / \mathrm{yr}$

\begin{tabular}{|c|c|c|c|c|c|c|c|c|}
\hline $\begin{array}{c}(i) \\
\ddot{A} \ddot{A} A \ddot{A} \ddot{A} A ̈ A ̈\end{array}$ & 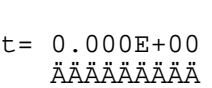 & $\begin{array}{l}1.000 E+\odot \odot \\
\ddot{A} \ddot{A} A \ddot{A} A \ddot{A} A \ddot{A}\end{array}$ & $\begin{array}{l}3.000 E+0 \odot \\
\ddot{A ̈ A ̈ A ̈ A ̈ A ̈ A ̈ A ̈ A ̈ A ̈ A ̈ ~}\end{array}$ & $\begin{array}{l}\text { 1. } 00 \odot E+01 \\
\ddot{A} \ddot{A} A ̈ A ̈ A ̈ A ̈ A ̈ A ̈\end{array}$ & $\begin{array}{l}3.000 E+01 \\
\ddot{A} \ddot{A} A ̈ A ̈ A ̈ A ̈ A ̈ A\end{array}$ & $\begin{array}{l}1.000 E+\odot 2 \\
\ddot{A} A ̈ A ̈ A ̈ A ̈ A ̈ A ̈ A ̈\end{array}$ & $\begin{array}{l}3.000 E+02 \\
\ddot{A} \ddot{A} \ddot{A} \ddot{A} \ddot{A} \ddot{A} \ddot{A} \ddot{A}\end{array}$ & $\begin{array}{l}1.000 E+\odot 3 \\
\ddot{A} \ddot{A ̈ A ̈ A ̈ A ̈ A ̈ A ̈ A ̈ ~}\end{array}$ \\
\hline Am-241 & $1.501 \mathrm{E}+03$ & $1.528 \mathrm{E}+03$ & $1.584 \mathrm{E}+03$ & $1.796 \mathrm{E}+03$ & $2.600 \mathrm{E}+\odot 3$ & $1.171 \mathrm{E}+\odot 4$ & $* 3.431 \mathrm{E}+12$ & $* 3.431 \mathrm{E}+12$ \\
\hline Cs -137 & $1.223 E+02$ & $1.256 \mathrm{E}+02$ & $1.324 \mathrm{E}+02$ & $1.593 \mathrm{E}+02$ & $2.730 E+\Theta 2$ & $2.347 E+\odot 3$ & $* 8.704 \mathrm{E}+13$ & *8. \\
\hline Eu-152 & $6.256 \mathrm{E}+01$ & $6.614 \mathrm{E}+01$ & $7.394 \mathrm{E}+01$ & $3 E+02$ & $E+02$ & $2.271 E+\odot 4$ & $5+14$ & $5 E+14$ \\
\hline Pu-238 & $2.083 E+03$ & $E+03$ & +03 & $E+03$ & +03 & 1. & $E+13$ & $2 E+13$ \\
\hline Pu-239 & $E+03$ & $E+03$ & $E+03$ & $E+03$ & $=+03$ & 5.7 & $E+10$ & $E+10$ \\
\hline $\operatorname{Sr}-90$ & 1. $457 \mathrm{E}+04$ & $1.507 \mathrm{E}+04$ & $1.613 \mathrm{E}+04$ & $2 . \odot 48 \mathrm{E}+\odot 4$ & $4.090 E+\odot 4$ & $5.854 \mathrm{E}+05$ & $* 1.365 E+14$ & $* 1.365 \mathrm{E}+14$ \\
\hline$U-233$ & $7.160 E+03$ & $7.208 \mathrm{E}+03$ & $7.305 \mathrm{E}+03$ & $7.663 \mathrm{E}+03$ & $8.853 E+03$ & 1.842 & $* 9.678 \mathrm{E}+09$ & $* 9.678 \mathrm{E}+09$ \\
\hline$U-235$ & $4.610 E+02$ & $4.640 \mathrm{E}+02$ & $4.701 \mathrm{E}+02$ & 4.9 & $E+\odot 2$ & & $E+06$ & $1 E+06$ \\
\hline$U-238$ & $2.031 E+03$ & $2.048 \mathrm{E}+03$ & 2.0 & $2.205 \mathrm{E}+03$ & $E+03$ & +03 & $L E+05$ & $* 3.361 \mathrm{E}+05$ \\
\hline Ííííííi & Íííííííí & Íííííííí & Íííííííí & Íííííííí́ & Íííííííí & Íííííííí & Íííííííí́ & Ííííí́íí́ \\
\hline
\end{tabular}

Summed Dose/Source Ratios DSR(i,t) in (mrem/yr)/(pCi/g)

and Single Radionuclide Soil Guidelines $\mathrm{G}(\mathrm{i}, \mathrm{t})$ in $\mathrm{pCi} / \mathrm{g}$

at $\mathrm{tmin}=$ time of minimum single radionuclide soil guideline

and at tmax $=$ time of maximum total dose $=0.000 \mathrm{E}+00$ years

\begin{tabular}{|c|c|c|c|c|c|c|}
\hline $\begin{array}{l}\text { ONuclide } \\
\text { (i) }\end{array}$ & $\begin{array}{l}\text { Initial } \\
(\mathrm{pCi} / \mathrm{g})\end{array}$ & $\begin{array}{c}\text { tmin } \\
(\text { years) }\end{array}$ & $\operatorname{DSR}(i, \operatorname{tmin})$ & $\begin{array}{c}\mathrm{G}(\mathrm{i}, \mathrm{tmin}) \\
(\mathrm{pCC} / \mathrm{g})\end{array}$ & $\operatorname{DSR}(i, \operatorname{tmax})$ & $\begin{array}{c}\mathrm{G}(\mathrm{i}, \operatorname{tmax}) \\
(\mathrm{pCi} / \mathrm{g})\end{array}$ \\
\hline ÄÄÄÄÄÄÄ & ÄÄÄÄÄÄÄÄ & ÄÄÄÄÄÄÄÄÄÄÄ̈̈̈̈ & ÄÄÄÄÄÄÄÄÄ & ÄÄÄÄÄÄÄÄ & ÄÄÄÄÄÄÄÄÄÄ & \\
\hline Am- 241 & $2.840 \mathrm{E}+\Theta 2$ & $\odot . \odot \odot \odot E+\odot \odot$ & $1.665 \mathrm{E}-02$ & $1.501 \mathrm{E}+03$ & $1.665 \mathrm{E}-\odot 2$ & 50 \\
\hline Cs -137 & $5.140 \mathrm{E}+00$ & $\odot . \odot \odot \odot E+\odot \odot$ & 2. $044 \mathrm{E}-01$ & 1. $223 \mathrm{E}+02$ & 2. $044 \mathrm{E}-01$ & \\
\hline Eu-152 & $2.170 E+\odot \odot$ & $\odot . \odot \odot \odot E+\odot \odot$ & $3.996 \mathrm{E}-01$ & $6.256 \mathrm{E}+01$ & $3.996 \mathrm{E}-01$ & $6.256 \mathrm{E}$ \\
\hline Pu-238 & $5.140 \mathrm{E}+\odot \odot$ & $\odot . \odot \odot \odot E+\odot \odot$ & $1.200 \mathrm{E}-\odot 2$ & $2.083 E+\odot 3$ & $1.200 \mathrm{E}-\odot 2$ & $2.083 E+$ \\
\hline Pu-239 & $4.550 \mathrm{E}+02$ & $\odot .000 \mathrm{E}+\odot \odot$ & $1.323 \mathrm{E}-02$ & $1.890 \mathrm{E}+03$ & $1.323 E-02$ & $1.890 \mathrm{E}$ \\
\hline $\mathrm{Sr}-90$ & $1.100 \mathrm{E}+00$ & $\odot . \odot \odot \odot E+\odot \odot$ & $1.716 \mathrm{E}-03$ & $1.457 \mathrm{E}+04$ & $1.716 \mathrm{E}-\odot 3$ & $1.457 \mathrm{E}+$ \\
\hline$U-233$ & $2.420 E+\odot \odot$ & $\odot . \odot \odot \odot E+\odot \odot$ & & $7.160 \mathrm{E}+03$ & -03 & $7.160 \mathrm{E}+$ \\
\hline$U-235$ & $1.160 \mathrm{E}-01$ & $\odot . \odot \odot \odot E+\odot \odot$ & $\odot 2$ & $4.610 \mathrm{E}+02$ & -02 & 1810 \\
\hline$U-238$ & $1.100 \mathrm{E}+\odot \odot$ & $\odot . \odot \odot \odot E+\odot \odot$ & $1.231 \mathrm{E}-02$ & $2.031 E+03$ & $1.231 \mathrm{E}-02$ & $2.031 \mathrm{E}+$ \\
\hline Ííííííí & İííííííí & Éííííííííííín & ÍÍííííííí & Íííííííí & Íííííííín & ÍÍÍÍÍÍÍ \\
\hline
\end{tabular}


Individual Nuclide Dose Summed Over All Pathways

Parent Nuclide and Branch Fraction Indicated

oNuclide Parent THF(i)

ÄÄÄÄÄÄÄ ÄÄÄÄÄÄÄ ÄÄÄÄÄÄÄÄÄ

Am-241 Am-241 1.000E+@O

๑Np-237 Am-241 1.000E+०0

OU-233 Am-241 $1.000 \mathrm{E}+00$

$\mathrm{U}-233 \quad \mathrm{U}-233 \quad 1.000 \mathrm{E}+00$

U-233 äDOSE $(j)$

०Th-229 Am-241 $1.000 \mathrm{E}+00$

Th-229 U-233 $1.000 \mathrm{E}+00$

Th-229 äDOSE $(j)$

๑Cs -137 Cs -137 1.000E +00

๑Eu-152 Eu-152 7.208E-01

Eu-152 Eu-152 2.792E-01

Eu-152 äDOSE $(j)$

०Gd-152 Eu-152 2.792E-01

$\odot \mathrm{Pu}-238$ Pu-238 $1.840 \mathrm{E}-09$

$\mathrm{Pu}-238$ Pu-238 $1.000 \mathrm{E}+00$

$\mathrm{Pu}-238$ äDOSE $(j)$

๑U-234 Pu-238 1.000E+००

$\mathrm{U}-234 \quad \mathrm{U}-238 \quad 9.999 \mathrm{E}-01$

$\mathrm{U}-234$ äDOSE $(j)$

๑Th-230 Pu-238 1. $000 \mathrm{E}+0 \odot$

Th-230 U-238 9.999E-01

Th-230 äDOSE $(j)$

ORa-226 Pu-238 $1.000 \mathrm{E}+00$

$\mathrm{Ra}-226 \quad \mathrm{U}-238 \quad 9.999 \mathrm{E}-01$

$\mathrm{Ra}-226$ äDOSE $(\mathrm{j})$

०Pb-210 Pu-238 1. $000 \mathrm{E}+00$

$\mathrm{Pb}-210 \quad \mathrm{U}-238 \quad 9.999 \mathrm{E}-01$

$\mathrm{Pb}-210$ äDOSE $(j)$

๑Pu-239 Pu-239 $1.000 \mathrm{E}+00$

OU -235 PU-239 $1.000 \mathrm{E}+00$

$\mathrm{U}-235 \mathrm{U}-235 \quad 1.000 \mathrm{E}+\odot \circ$

$\mathrm{U}-235$ äDOSE $(\mathrm{j})$

$\odot \mathrm{Pa}-231 \mathrm{Pu}-239 \quad 1.000 \mathrm{E}+\odot 0$

$\mathrm{Pa}-231 \mathrm{U}-235 \quad 1.000 \mathrm{E}+\odot \odot$

Pa-231 äDOSE $(j)$

\section{$\operatorname{DOSE}(j, t)$, mrem/yr}

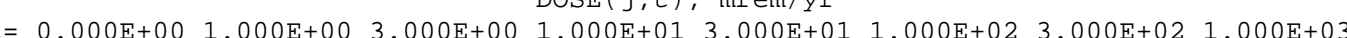
ÄÄÄÄÄÄÄÄ

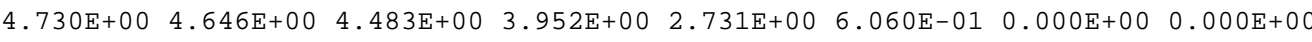
4.066E-06 1.209E-05 2.768E-05 7.753E-05 1.840E-04 2.432E-04 $0.000 \mathrm{E}+00 \quad 0.000 \mathrm{E}+00$

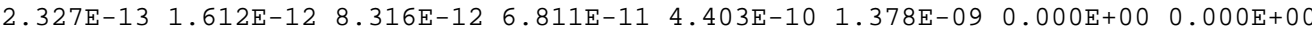

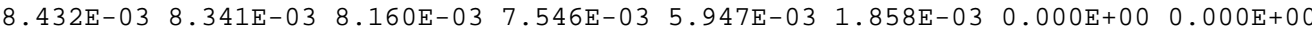

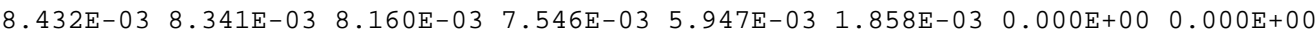
$2.449 \mathrm{E}-16 \quad 3.647 \mathrm{E}-15 \quad 4.187 \mathrm{E}-14 \quad 1.046 \mathrm{E}-12 \quad 2.141 \mathrm{E}-11 \quad 3.251 \mathrm{E}-10 \quad 0.000 \mathrm{E}+0 \odot \quad 0.000 \mathrm{E}+00$

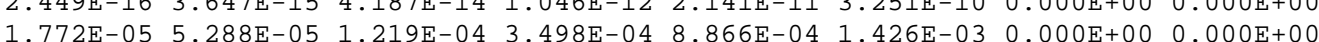

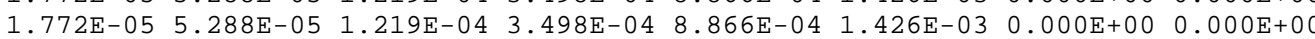

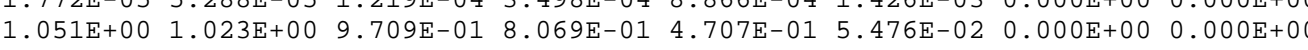

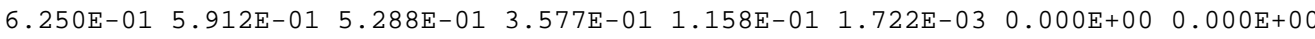

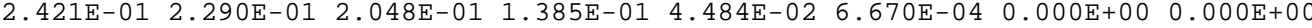

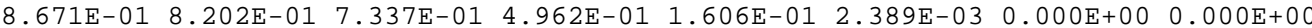
$1.104 \mathrm{E}-17 \quad 3.217 \mathrm{E}-17 \quad 7.041 \mathrm{E}-17 \quad 1.693 \mathrm{E}-16 \quad 2.727 \mathrm{E}-16 \quad 1.387 \mathrm{E}-16 \quad 0.000 \mathrm{E}+00 \quad 0.000 \mathrm{E}+00$

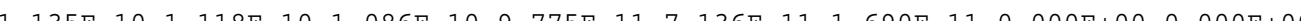
$6.168 \mathrm{E}-02$ 6.078E-02 5.901E-02 5.313E-02 3.878E-02 9.185E-03 $0.000 \mathrm{E}+00$ 0.000E+00

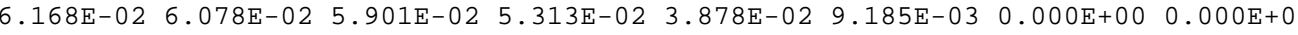

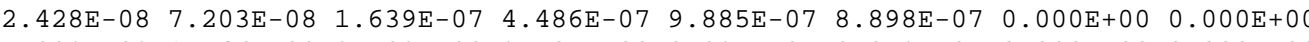

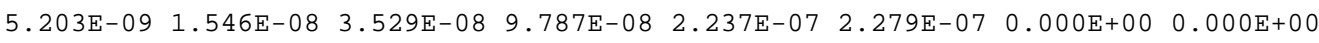

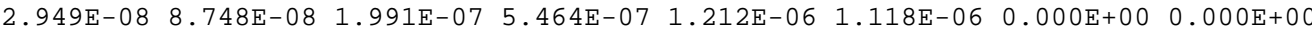

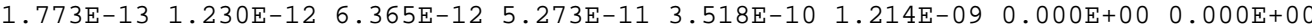
3.798E-14 2.637E-13 1.368E-12 1.143E-11 7.809E-11 2.915E-10 $0.000 \mathrm{E}+00 \quad 0.000 \mathrm{E}+00$ $2.153 \mathrm{E}-13 \quad 1.494 \mathrm{E}-12 \quad 7.734 \mathrm{E}-12 \quad 6.416 \mathrm{E}-11 \quad 4.299 \mathrm{E}-10 \quad 1.506 \mathrm{E}-09 \quad 0.000 \mathrm{E}+00 \quad 0.000 \mathrm{E}+00$

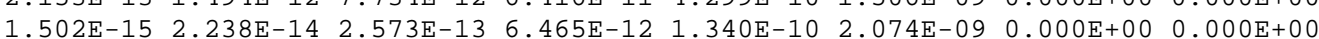
$3.216 \mathrm{E}-16 \quad 4.796 \mathrm{E}-15 \quad 5.524 \mathrm{E}-14 \quad 1.397 \mathrm{E}-12 \quad 2.948 \mathrm{E}-11 \quad 4.846 \mathrm{E}-10 \quad 0.000 \mathrm{E}+00 \quad 0.000 \mathrm{E}+00$

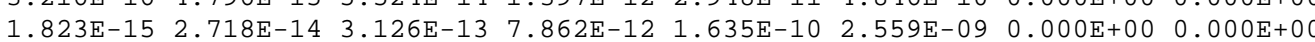

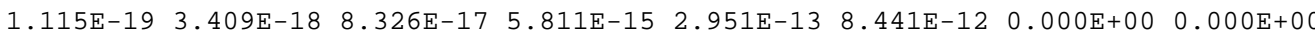

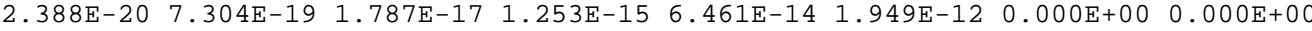
$1.354 \mathrm{E}-19$ 4.139E-18 1.011E-16 $7.065 \mathrm{E}-15$ 3.597E-13 $1.039 \mathrm{E}-11 \quad 0.000 \mathrm{E}+00$ 0.000E+00

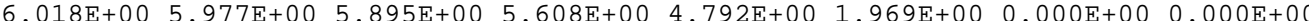
1.216E-08 $3.632 \mathrm{E}-08 \quad 8.401 \mathrm{E}-08 \quad 2.441 \mathrm{E}-07 \quad 6.429 \mathrm{E}-07 \quad 1.200 \mathrm{E}-06$ - $0.000 \mathrm{E}+00$ - $0.000 \mathrm{E}+00$

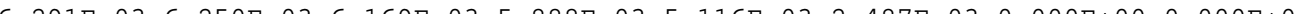
$6.291 \mathrm{E}-03$ 6.250E-03 6.169

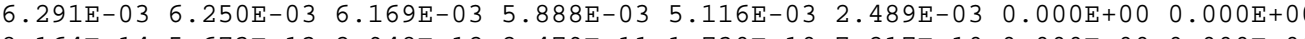
8.164E-14 5.673E-13 $2.948 \mathrm{E}-12 \quad 2.479 \mathrm{E}-11$ 1.730E-10 $7.217 \mathrm{E}-100.00 \odot \mathrm{E}+00 \quad 0.000 \mathrm{E}+\odot$ 6.339E- 08 1.885E- $07 \quad 4.311 \mathrm{E}-07 \quad 1.204 \mathrm{E}-06 \quad 2.812 \mathrm{E}-06 \quad 3.215 \mathrm{E}-06 \quad 0.000 \mathrm{E}+00 \quad 0.000 \mathrm{E}+00$

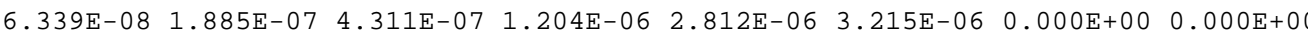


Individual Nuclide Dose Summed Over All Pathways

Parent Nuclide and Branch Fraction Indicated

ONuclide Parent THF(i)

(j) (i)

ÄÄÄÄÄÄÄ ÄÄÄÄÄÄÄ ÄÄÄÄÄÄÄÄÄ

AC-227 PU-239 1.000E+OO

AC-227 U-235 $1.000 \mathrm{E}+0 \odot$

Ac-227 äDOSE $(j)$

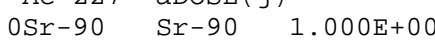

OU-238 U-238 5.400E- 05

$\begin{array}{lll}\mathrm{U}-238 & \mathrm{U}-238 & 5.400 \mathrm{E}-05 \\ \mathrm{U}-238 & \mathrm{a}-\mathrm{OSE}(\mathrm{j})\end{array}$

$U-238$ äDOSE $(j)$

Íííííi íííííí íííííít
$\operatorname{DOSE}(j, t), \quad m r e m / y r$

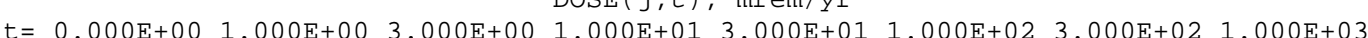

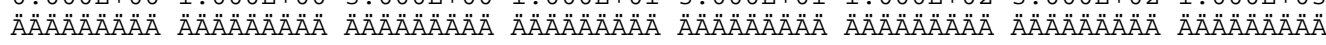

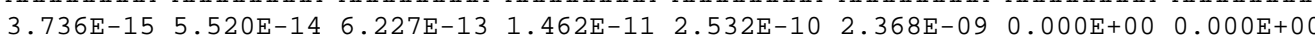

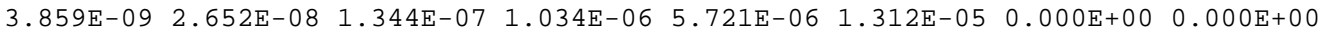

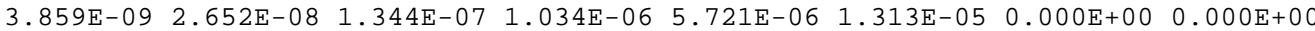

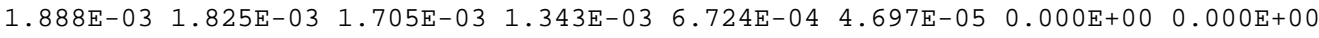

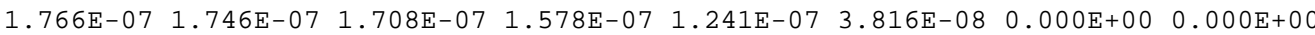

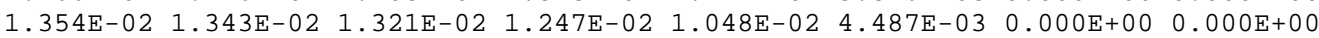

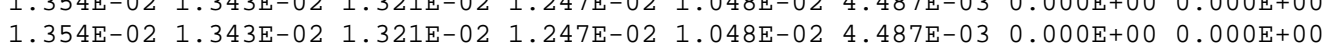

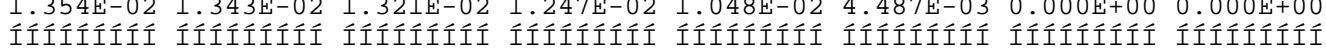
ífíííííí ífíííííí ítít 
Individual Nuclide Soil Concentration

\section{ONuclide Parent THF(i)}

ÄÄÄÄÄÄÄ ӒÄÄÄÄÄÄ ÄÄÄÄÄÄÄÄÄ

Am-241 Am-241 1.000E+@O

๑Np-237 Am-241 1.000E+०๑

○U-233 Am-241 $1.000 \mathrm{E}+\odot 0$

$\mathrm{U}-233 \quad \mathrm{U}-233 \quad 1.000 \mathrm{E}+\odot \odot$

$\mathrm{U}-233$ äS $(j)$ :

๑Th-229 Am-241 $1.000 \mathrm{E}+\odot \odot$

Th-229 U-233 $1.000 \mathrm{E}+\odot \odot$

Th-229 äS $(j)$ :

๑Cs-137 Cs-137 1.000E+०0

๑Eu-152 Eu-152 7.208E-01

Eu-152 Eu-152 2.792E-01

Eu-152 äS $(j)$ :

OGd-152 Eu-152 2.792E-01

OPU-238 Pu-238 $1.840 \mathrm{E}-09$

$\mathrm{Pu}-238$ Pu-238 $1.000 \mathrm{E}+00$

$\mathrm{Pu}-238$ äs (j):

Pu 238 âs $(j)$ :

U-234 U-238 9.999E-01

$\mathrm{U}-234$ äS $(j)$ :

๑Th-230 Pu-238 1. $000 \mathrm{E}+00$

Th-230 U-238 $9.999 \mathrm{E}-01$

Th-230 äs $(j)$

Th-230 as $(j)$

$\begin{array}{lll}\mathrm{RA}-226 & \mathrm{Pu}-238 & 1.000 \mathrm{E}+00\end{array}$

Ra-226 U-238 9.999E-01

$\mathrm{Ra}-226$ äS $(j)$ :

๑Pb-210 Pu-238 1.000E +00

$\mathrm{Pb}-210 \quad \mathrm{U}-238 \quad 9.999 \mathrm{E}-01$

$\mathrm{Pb}-210$ äS $(j)$

$\odot \mathrm{Pu}-239 \mathrm{Pu}-239$ 1. $200 \mathrm{E}+\odot \odot$

OU-235 PU-239 $1.000 \mathrm{E}+00$

$\mathrm{U}-235 \mathrm{U}-235 \quad 1.000 \mathrm{E}+00$

$\mathrm{U}-235$ äS $(j)$ :

$\odot \mathrm{Pa}-231 \mathrm{Pu}-239 \quad 1.000 \mathrm{E}+00$

$\mathrm{Pa}-231 \mathrm{U}-235 \quad 1.000 \mathrm{E}+00$

$\mathrm{Pa}-231$ äs $(j)$

Parent Nuclide and Branch Fraction Indicated

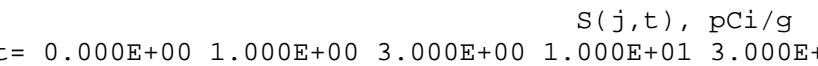

1/9 $1.000 \mathrm{E}+02 \quad 3.000 \mathrm{E}+02 \quad 1.000 \mathrm{E}+03$

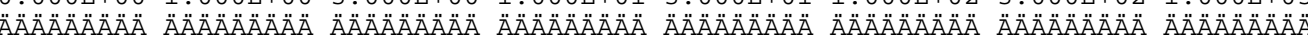

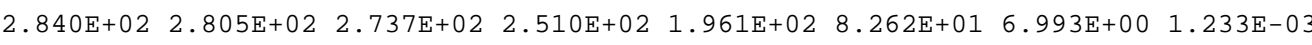
$0.000 \mathrm{E}+00$ 9.138E-05 2.706E-04 8.616E-04 2.276E-03 5.024E-03 6.014E-03 3.445E-03 $\odot .0 \odot \odot \mathrm{E}+0 \odot \quad 2.00 \odot \mathrm{E}-10 \quad 1.779 \mathrm{E}-09$ 1.898E-08 $1.523 \mathrm{E}-07 \quad 1.154 \mathrm{E}-06 \quad 3.972 \mathrm{E}-06 \quad 4.135 \mathrm{E}-06$

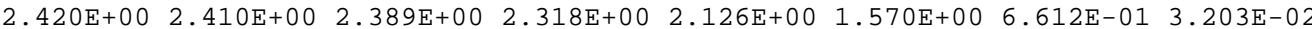

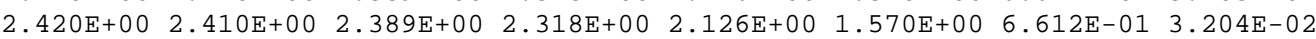
$0.000 \mathrm{E}+00 \quad 6.304 \mathrm{E}-15 \quad 1.687 \mathrm{E}-13 \quad 6.060 \mathrm{E}-12 \quad 1.501 \mathrm{E}-10 \quad 4.169 \mathrm{E}-09$ 5. $587 \mathrm{E}-08 \quad 3.494 \mathrm{E}-07$

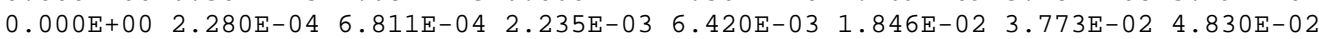

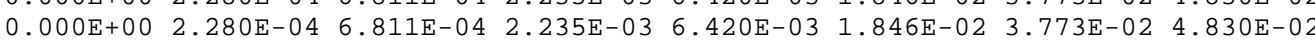

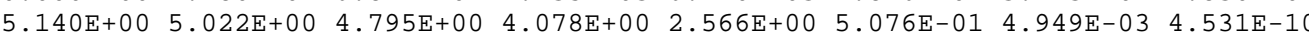

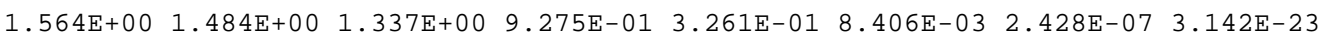
6.059E-01 5.750E-01 5.179E-01 3.593E-01 1.263E-01 3.256E-03 9.403E-08 $1.217 \mathrm{E}-23$ $2.170 \mathrm{E}+00 \quad 2.060 \mathrm{E}+00$ 1.855E+00 $1.287 \mathrm{E}+00 \quad 4.524 \mathrm{E}-01 \quad 1.166 \mathrm{E}-02 \quad 3.368 \mathrm{E}-07 \quad 4.360 \mathrm{E}-23$ $0.000 \mathrm{E}+00 \quad 3.788 \mathrm{E}-15 \quad 1.079 \mathrm{E}-14 \quad 3.024 \mathrm{E}-14 \quad 5.860 \mathrm{E}-14 \quad 7.244 \mathrm{E}-14 \quad 6.911 \mathrm{E}-14 \quad 5.750 \mathrm{E}-14$ $9.458 \mathrm{E}-090.382 \mathrm{E}-090.233 \mathrm{E}-09$ 8.730E-09 $7.438 \mathrm{E}-09$ 4.246E-09 8.558E-10 $3.146 \mathrm{E}-12$ $5.140 E+005.099 E$

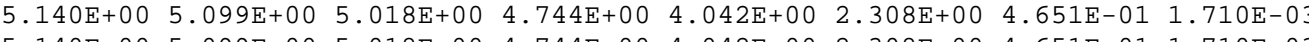

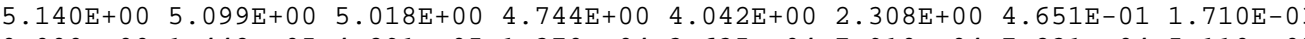
$0.000 \mathrm{E}+00$ 1.448E-05 4.291E-05 1.370E-04 3.635E-04 7.910E-04 7.231E-04 5.110E-05

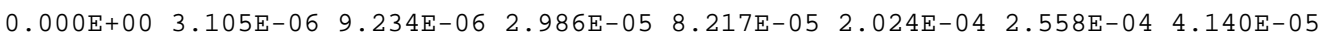
$0.000 \mathrm{E}+0 \odot$ 1.759E-05 5.215E-05 1.669E-04 4.457E-04 9.934E-04 9.789E-04 9.250E-05 $0.000 \mathrm{E}+0 \odot \quad 6.532 \mathrm{E}-11 \quad 5.830 \mathrm{E}-10 \quad 6.295 \mathrm{E}-09$ 5.224E-08 $4.405 \mathrm{E}-07$ 1.937E-06 3.650E-06 $0.000 \mathrm{E}+00$ 1.399E-11 $1.252 \mathrm{E}-10$ 1.364E-09 $1.159 \mathrm{E}-08$ 1.057E-07 $5.581 \mathrm{E}-07$ 1.386E-06 $0.000 \mathrm{E}+007.931 \mathrm{E}-117.083 \mathrm{E}-107.659 \mathrm{E}-09$ 6.383E-08 $5.462 \mathrm{E}-07$ 2.495E-06 $5.036 \mathrm{E}-06$ 0.007 . 0.000 $0.000 \mathrm{E}+00$ 2.021E-15 $5.423 \mathrm{E}-14$ 1.966E-12 $4.996 \mathrm{E}-11$ 1.500E-09 $2.263 \mathrm{E}-08$ 1.405E-07 $0.000 \mathrm{E}+00$ 1.145E-14 3.069E-13 1.107E-11 2.772E-10 7.921E-09 $1.062 \mathrm{E}-07$ 5.304E-07

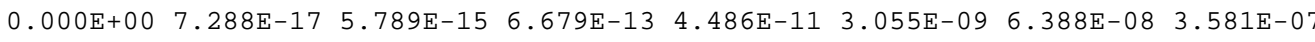
$0.000 \mathrm{E}+00$ 1.561E-17 $1.242 \mathrm{E}-15$ 1.440E-13 9.817E-12 $7.052 \mathrm{E}-10$ 1.701E-08 $1.282 \mathrm{E}-07$ $0.000 \mathrm{E}+00$ 8.849E-17 7.030E-15 8.119E-13 5.467E-11 3.760E-09 8.090E-08 4.863E-๑7

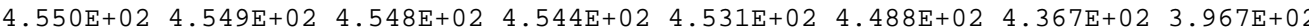

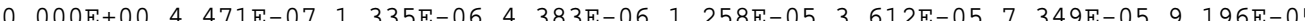

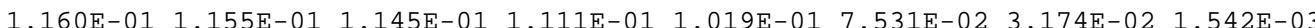
1.160E-01 1.155E-01 1.145E-01 1.111E-01 1.019E-01 7.534E-02 3.181E-02 1.634E-03 $0.000 \mathrm{E}+00$ 4.727E-12 4.229E-11 4.604E-10 3.909E-09 3.553E-08 $1.854 \mathrm{E}-07$ 4.331E- 07

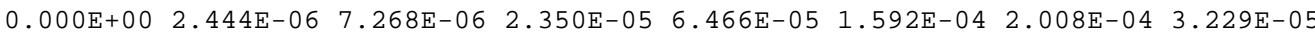

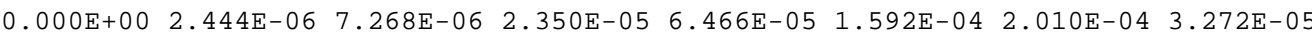


Individual Nuclide Soil Concentration

\section{ONuclide Parent THF(i)}

(j) (i)

ÄÄÄÄÄÄÄ ÄÄÄÄÄÄÄ ÄÄÄÄÄÄÄÄÄ

AC-227 PU-239 1.000E+O0

AC-227 U-235 $1.000 E+00$

$A C-227$ äS $(j)$

$\mathrm{OSr}-90 \quad \mathrm{Sr}-90 \quad 1.000 \mathrm{E}+0 \odot$

OU $-238 \quad \mathrm{U}-238-5.400 \mathrm{E}-05$

$\mathrm{U}-238 \mathrm{U}-238,5.400 \mathrm{E}-\odot 5$

$\begin{array}{lll}U-238 & U-238 & 9.999 E-01 \\ U-238 & \text { äs }(j): & \end{array}$

Íííííi íííííi ííííííí

$\operatorname{THF}(i)$ is the thread fraction

ORESCALC. EXE execution time =
Parent Nuclide and Branch Fraction Indicated

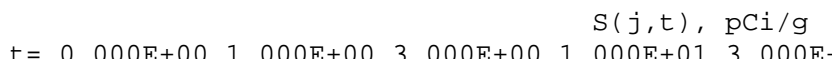

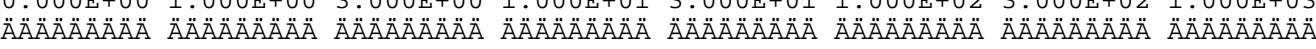

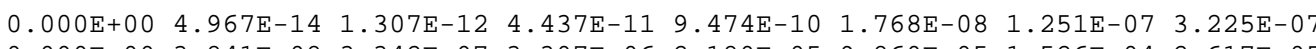
$0.000 \mathrm{E}+00$ 3.841E-08 3.342E-07 3.307E-06 2.180E-05 9.860E-05 1.526E-04 2.617E-05

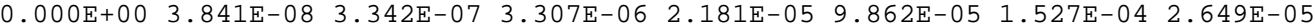
$1.100 \mathrm{E}+00$ 1.066E+00 1.002E+00 8.069E-01 4.342E-01 4.962E-02 1.010E-04 3.838E-14 5.940E-05 5.914E-05 5.864E-05 5.689E-05 5.218E-05 3.856E-05 1.625E-05 7.897E-07

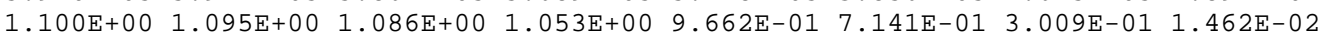

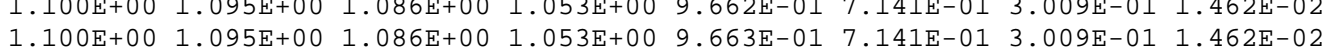
jútíl of the parent nuclide.

2.42 seconds 


\section{Appendix D}

\section{Closure Activity Summary (Use Restriction)}




\section{D.1.0 Closure Activity Summary}

The following sections document closure activities completed at CASs 03-08-03, 03-23-05, and 20-19-01, including verification activities and supporting documents. Closure activities were not necessary at the five other CASs of CAU 545 and are not discussed in this appendix.

\section{D.1.1 CAS 03-08-03 Closure Activities}

For CAS 03-08-03, though the potential for subsidence of the craters was judged to be extremely unlikely, the DQO meeting participants agreed that sufficient information was available about disposal and releases at the site and recommended that a corrective action of close in place with a UR. Sampling in the craters was not considered necessary. The radiological contamination is estimated to be comprised of isotopic $\mathrm{U}$, isotopic $\mathrm{Pu}$, fission products, and decay products.

The corrective action of closure in place with a UR was accomplished by securing the site against unauthorized entry through the repair of fencing at the site and by securing 14 UR signs (Figures D.1-1 and D.1-3) to the fencing at intervals of approximately $200 \mathrm{ft}$. The post-closure activities for this CAS include annual inspections of the postings.

\section{D.1.2 CAS 03-23-05 Closure Activities}

For CAS 03-23-05, existing information about the two buried sources and lead pig was considered to be sufficient, and safety concerns existed about the stability of the crater component. Therefore, a corrective action of close in place with a UR was recommended, and sampling at the site was not considered necessary.

The corrective action of close in place with a UR was accomplished by securing the site against unauthorized entry by attaching seven UR signs (Figures D.1-2 and D.1-4); four at each of the four sides of the fencing surrounding the burial site for the Pa-233 source and lead pig, and three at locations, at intervals of approximately $200 \mathrm{ft}$, on the fencing surrounding the burial site for the Eu-152 source. The post-closure activities for this CAS include annual inspections of the postings. 


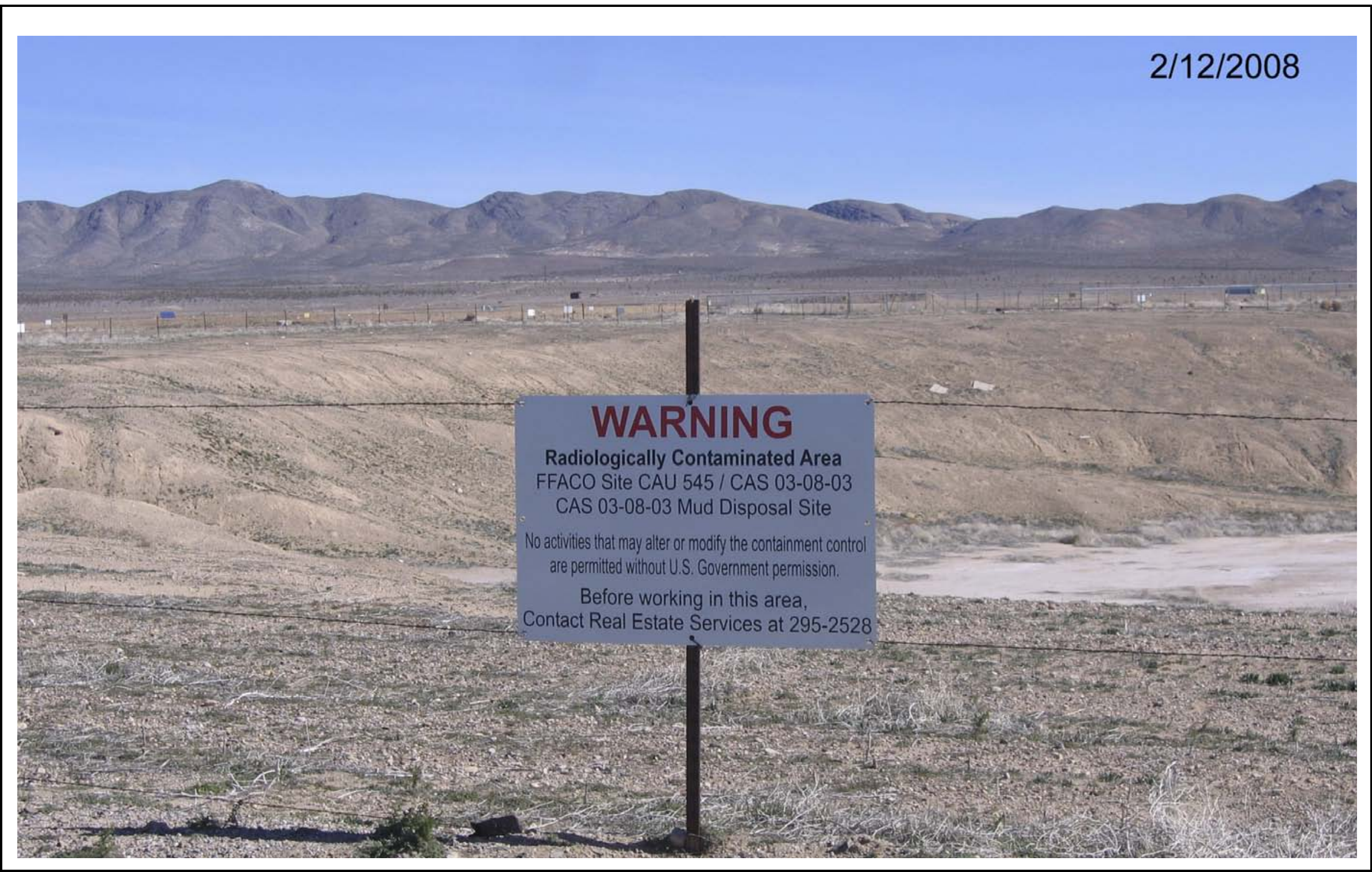

Figure D.1-1

CAS 03-08-03 Use Restriction Posting

\section{UNCONTROLLED When Printed}




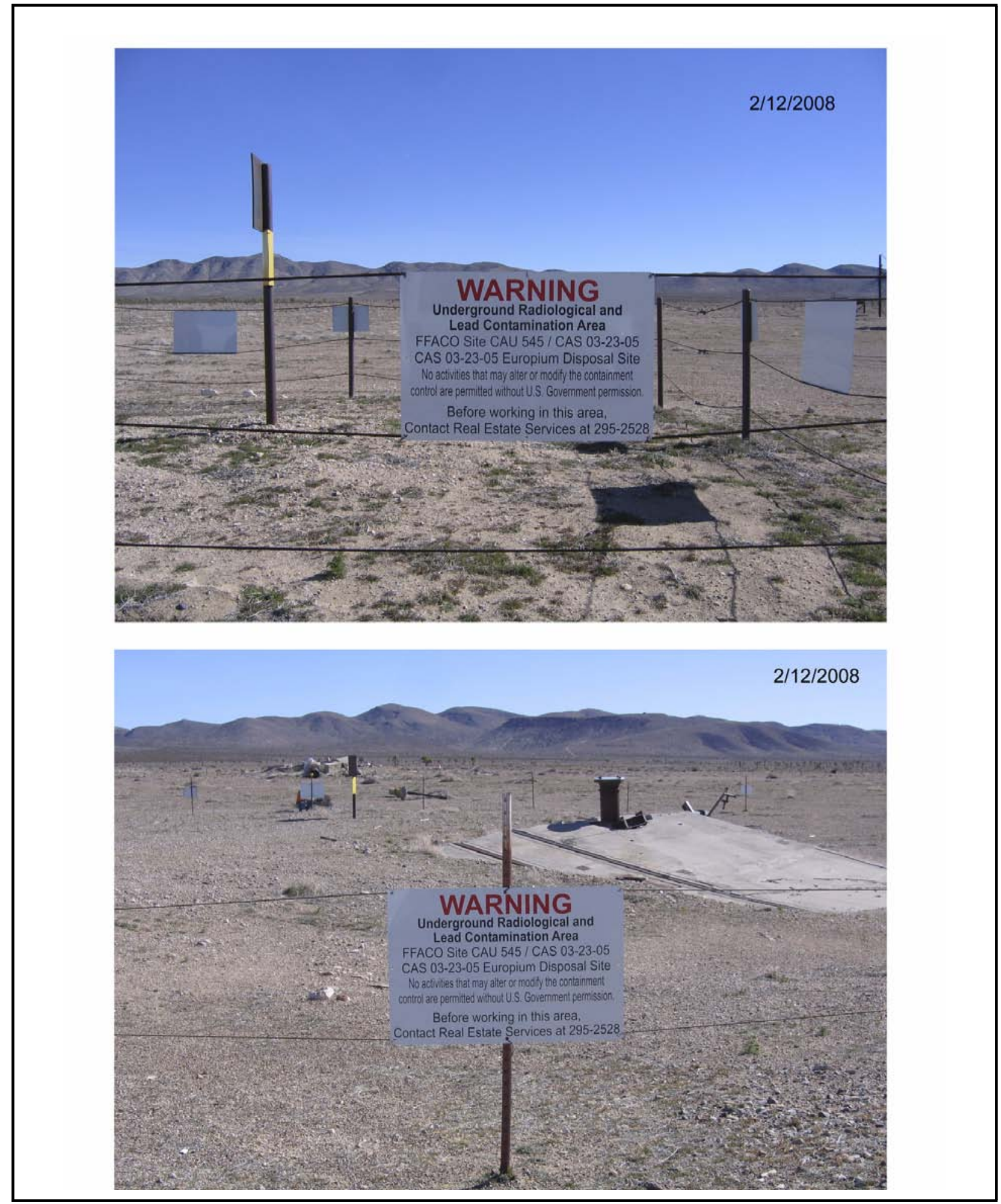

Figure D.1-2

CAS 03-23-05 Use Restriction Postings 


\section{D.1.3 CAS 20-19-01 Closure Activities}

For CAS 20-19-01, a corrective action of removal of the used oil filters was conducted to remove this PSM from the site. Also removed from the site was a grease canister and soil impacted by the oil filters.

\section{D.1.4. Disposition of Drummed IDW for CAU 545}

Eight drums of IDW from all CASs were generated as a result of this investigation. Four drums were emptied into the A23 Lagoons (see Attachment D-1 for Load Verification Form and Waste Manifest). Three drums containing solids were disposed of at the U10c Industrial Landfill (see Attachment D-1 for Load Verification Form). One drum containing hydrocarbon waste from CAS 20-19-01 was disposed of at the Area 6 Hydrocarbon Landfill (see Attachment D-1 for Load Verification Form). 


\section{CAU Use Restriction Information}

CAU Number/Description: CAU 545, Dumps, Waste Disposal Sites, and Buried Radioactive Materials

Applicable CAS Number(s)/Description(s): CAS 03-08-03, Mud Disposal Site

Contact (organization/project): NNSA/NSO Industrial Sites Federal Sub-Project Director

\begin{tabular}{|c|c|c|}
\hline outheast Side: & $N=L$ & $E=586$ \\
\hline SE Side: & & $E=58$ \\
\hline th Side: & $N=40$ & $E=586249.80$ \\
\hline & $N=4$ & 586193.80 \\
\hline st Side: & $N=$ & 149.68 \\
\hline MSIO & & .83 \\
\hline We & $N=4$ & 68.78 \\
\hline WNW & $N=41$ & 70.48 \\
\hline Northw & $N=4$ & 02.16 \\
\hline de: & $N=$ & 1.19 \\
\hline lorth Side: & $N=$ & 195.50 \\
\hline VNE Side: & $N=41$ & $E=586226.04$ \\
\hline orthea & $N=L$ & $E=586243.58$ \\
\hline NE Side: & $N=4$ & $E=58$ \\
\hline ast Side: & $\mathrm{N}=4099929.46$ & $E=586330.70$ \\
\hline SE Side: & $\mathrm{N}=4099896.65$ & $E=586336.92$ \\
\hline
\end{tabular}

Survey Date: December 2007

Survey Method (GPS, etc): Heads-up digitizing Site Monitoring Requirements: Inspection of postings

Required Frequency (quarterly, annually?): Annual

If Monitoring Has Started, Indicate last Completion Date: Not Applicable

\section{Use Restrictions}

The future use of any land related to this Corrective Action Unit (CAU), as described by the above surveyed location, is restricted from any DOE or Air Force activity that may alter or modify the containment control as approved by the state and identified in the CAU Closure Report or other CAU 545 documentation, unless appropriate concurrence is obtained in advance.

Comments: This UR is for the surface and subsurface disturbances. The use restricted area is fenced and identified with signs at approximately 200-ft intervals for the CAS. Coordinates for the 
area will be entered into the NTS database. Annual post-closure inspections will be conducted to ensure postings are in place, intact, and readable. See the CADD/CR for additional information on the condition of the site. The radiological contamination is estimated to be comprised of isotopic uranium, isotopic plutonium, fission products, and decay products.

Submitted By: $\ldots$ /s/Kevin Cabble Date: $3-27-08$

cc with copy of survey map (paper and digital (.dgn) formats):

CAU Files ( 2 copies)

The use restriction signs state the following information:

WARNING

Radiologically Contaminated Area

FFACO Site CAU 545/CAS 03-08-03

CAS 03-08-03 Mud Disposal Site

No activities that alter or modify the containment control are permitted without U.S. Government permission.

Before working in this area,

Contact Real Estate Services at 295-2528 


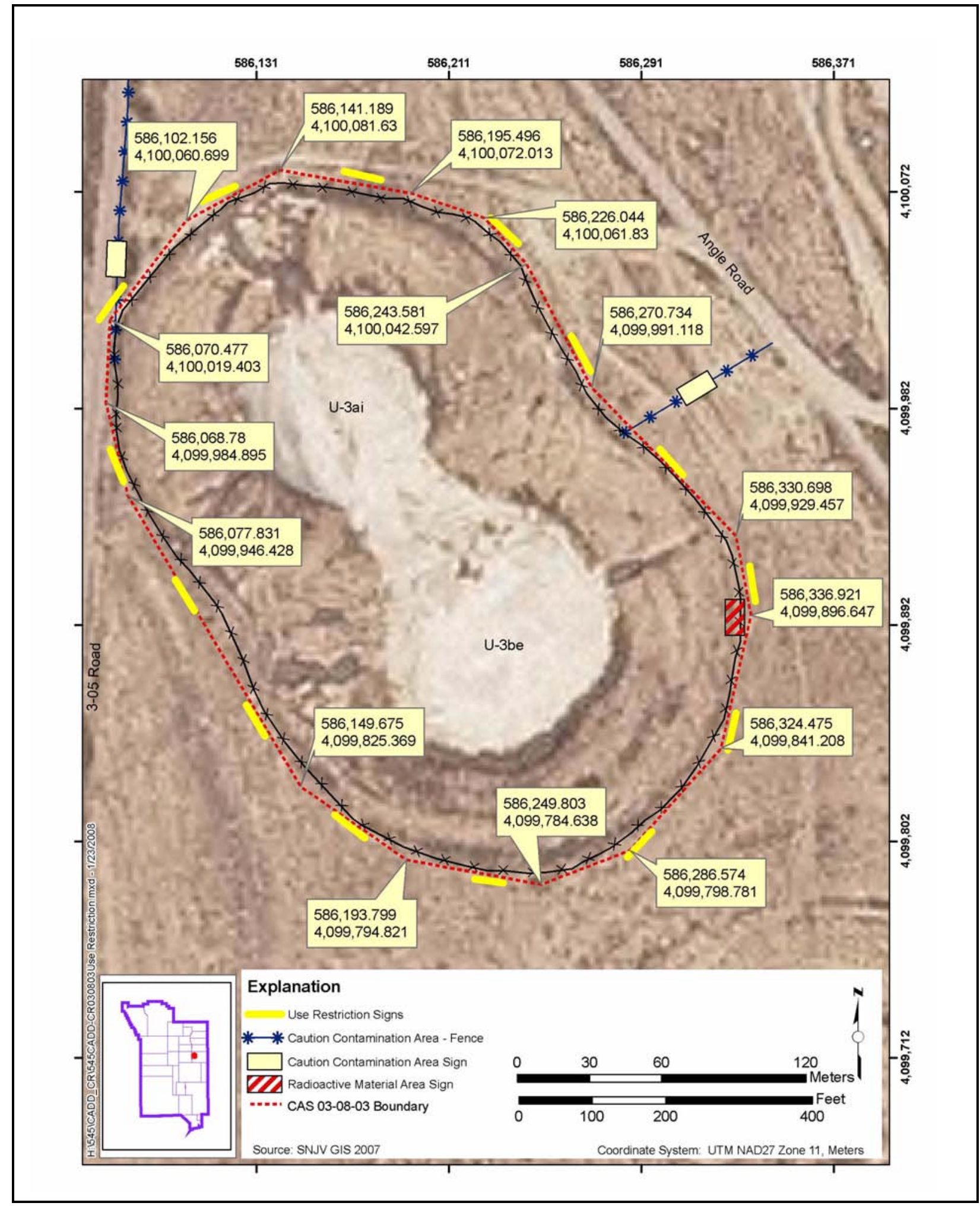

Figure D.1-3

CAS 03-08-03 Land Use Restriction Boundary 


\section{CAU Use Restriction Information}

CAU Number/Description: CAU 545, Dumps, Waste Disposal Sites, and Buried Radioactive Materials

Applicable CAS Number(s)/Description(s): CAS 03-23-05, Europium Disposal Site

Contact (organization/project): NNSA/NSO Industrial Sites Federal Sub-Project Director

Surveyed Area (UTM, Zone 11, NAD 27, meters):

Pa-233 and Lead Pig Burial Site:

Southeast Corner: $N=4100485.18 ; \quad E=587905.89$

Southwest Corner: $N=4100484.50 ; \quad E=587892.69$

Northwest Corner: $N=4100498.60 ; \quad E=587892.24$

Northeast Corner: $N=4100499.28 ; \quad E=587905.67$

Eu-235 Burial Site:

Southeast Side: $\quad N=4100403.26 ; \quad E=587980.42$

South Side: $\quad N=4100397.22 ; \quad E=587966.55$

SSW Side: $\quad N=4100398.11 ; \quad E=587952.67$

Southwest Side: $\quad N=4100407.96 ; \quad E=587938.79$

West Side: $\quad N=4100430.12 ; \quad E=587938.12$

Northwest Side: $\quad N=4100443.99 ; \quad E=587949.31$

North Side: $\quad N=4100446.46 ; \quad E=587968.78$

Northeast Side: $\quad N=4100439.52 ; \quad E=587980.65$

East Side: $\quad \mathrm{N}=4100419.15 ; \quad E=587988.26$

Survey Date: December 2007

Survey Method (GPS, etc): Heads-up digitizing Site Monitoring Requirements: Inspection of postings

Required Frequency (quarterly, annually?): Annual

If Monitoring Has Started, Indicate last Completion Date: Not Applicable

\section{Use Restrictions}

The future use of any land related to this Corrective Action Unit (CAU), as described by the above surveyed location, is restricted from any DOE or Air Force activity that may alter or modify the containment control as approved by the state and identified in the CAU Closure Report or other CAU 545 documentation, unless appropriate concurrence is obtained in advance.

Comments: This UR is for the surface and subsurface disturbances. The use restricted area is fenced. Signs, at approximately 200 -ft intervals for the CAS, have been placed to notify personnel 
visiting the site, as required by this UR. Coordinates for the area will be entered into the NTS database. Annual post-closure inspections will be conducted to ensure postings are in place, intact, and readable. See the CADD/CR for additional information on the condition of the site. Contaminants present at the site, as potential source materials, include lead (i.e., in the form of a lead "pig"), a europium-152 source (i.e., and decay product gadolinium-152), and a protactinium-233 source (i.e. and decay product uranium-233).

Submitted By: /s/Kevin Cabble

Date: $\quad 3-27-08$

cc with copy of survey map (paper and digital (.dgn) formats): CAU Files ( 2 copies)

The use restriction signs state the following information:

WARNING

Underground Radiological and Lead Contaminated Area

FFACO Site CAU 545/CAS 03-23-05

CAS 03-23-05 Europium Disposal Site

No activities that alter or modify the containment control are permitted without U.S. Government permission.

Before working in this area, Contact Real Estate Services at 295-2528 


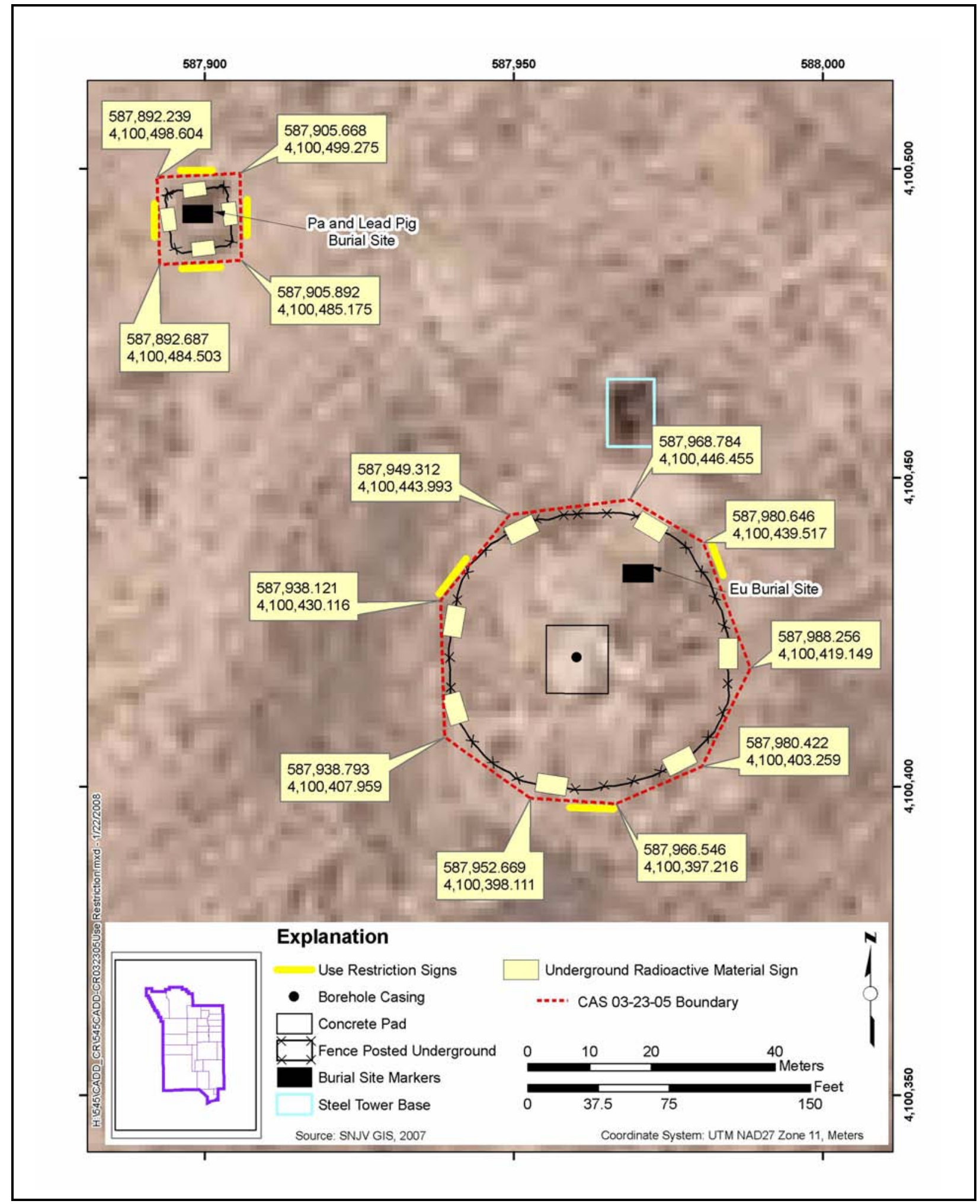

Figure D.1-4

CAS 03-23-05 Land Use Restriction Boundary 


\section{D.2.0 References}

SNJV GIS, see Stoller-Navarro Joint Venture Geographic Information Systems.

Stoller-Navarro Joint Venture Geographic Information Systems. 2007. ESRI ArcGIS Software. 


\section{Attachment D-1}

\section{Disposition of IDW}

(3 Pages) 


\begin{tabular}{|lrr}
\hline NSTec & CoS 3.17-08 & $08 / 23 / 06$ \\
Form & Rev. 0 \\
FRM-0918 & NTS LANDFILL LOAD VERIFICATION & Page 1 of 2 \\
\hline
\end{tabular}

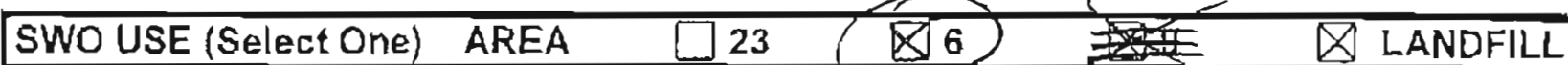

For wasle characterizalion, spproval, and/or assistance, eombct Solld Wasle Operalion (SWO) at 5-7898.

REQUIRED: WASTE GERERATOR INFORMATION

(Th's form is for rollofts, dump lucks, ond other onsite disposal of materials.)

Waste Generator. Rene Robles (SNJV, WO)

Phone Number: 5-2100

Location / Origin: CAU 546, CAS 20-19-01, Atea 20: 1 Drum (Oll stained material and soil) SNN0719

Waste Category; (check one) $\square$ Commercial

Waste Type: $\square$ NTS $\square$ Putrescribie $\square$ FFACO-onsite $\square$ WAC Exception

(cheok one) $\square$ Non-Putrescible $\square$ Asbestos Containing Material $\square$ FFACO-offsite $\square$ Historic DOE/NV

Poilution Prevention Category: (check one) $\triangle$ Environmental management $\square$ Defense Projects $\square$ YMP

Pollutlon Prevention Category: (check one) $\triangle$ Clean-Up $\square$ Routine

Method of Characterization: (check one) $\triangle$ Sampling \& Analysis Process Knowledge $\square$ contents

Prohibited Waste at all three Radjoaclive waste; RCRA waste; Hazardous waste; Free liquids, PCBs above TSCA regulatory

NTS landfills:

Additional Prohibited Wasto

at the Area 9 U10C Landfill:

leveis, and Medical wastes (needles, sharps, bloody clothing).

Sewage Sludge, Arimal carcasses, Wet garbage (food waste); and Friable asbestos

REQUIRED: WASTE CONTENTS ALLOWABLE WASTES

Check all allowable wastes thal are contained within this load:

NOTE: Waste disposal at the Area 6 Hydrocarbon Landfill must have come Into conlact with petroleum hydrocarbons or coolants, such as; gasoline (no benzene, lezd); jal fuel; diesel fuel; lubricants and hydraulics; kerosene; asphallic petroleum hydrocarbon; and ethylene glycal.
Acceptable wasto at any NTS landfill:
$\square$ Paper
$\square$ Rocks / unaltered geologic materials
$\square$ Empty combiners
$\square$ Asphalk $\square$ Meta) $\square$ Wood
$\square$ Soil
$\square$ Rubber (excluding tires)
$\square$ Demolikion debris
$\square$ Plastic $\square$ Wire
$\square$ Cable
[a] Cloth
$\square$ Insulation (non-Asbestosfontr)
$\square$ Cement \& concrete

Manufactured items: (swamp coolers, fumiture, rugs, carpet, electronic components, PPE. etc.)

Additional Waste accepted at the Area 23 Mercury Landffl: $\square$ Office Waste $\square$ Food Waste

$\square$ Asbestos $\square$ Friable $\square$ Non-Friable (contact sWo if regulated load) Quantily:

Additfonal waste accepted at the Area 9 U10c Landfill:
$\square$ Non-friable asbestos
$\square$ Drained autamoblies and miltary vehicles
$\square$ Light ballasts (contact SWO)
$\square$ Drained fuel fillers (gas \& diesel)
Hydrocarbons (contact SWO
Other
$\square$ Solid fractions from sandjoil/water
$\square$ Decontred Underground and Above Ground Tanks

Additional waste accepted at the Area 6 Hydrocarbon Landfill:

$\begin{array}{llll}\square \text { Septic sludge } & \square \text { Rags } & \square \text { Drained fuel filters (gas \& diesel) } & \bar{Q} \text { Crushed non-teme plajed oll jilters } \\ \square \text { Plants } & \square \text { Soil } & \square \text { siudge from sand/oillwater separalors } & \square \text { PCBs below } 50 \text { parts per million }\end{array}$

Initials: (if initialed, no radlologleal olearance is necessary.)

The above mentloned waste was generated outside of a Controlled Waste Manag knowledge, does not contain radiological materials.

To the best of my knowledge, the waste described above contalns only those ma site. I have verifed this through the waste characterlzation method ldentified abr prohiblted and allowable waste ltems. I have contacted Property Management an is approved for disposal in the landfill

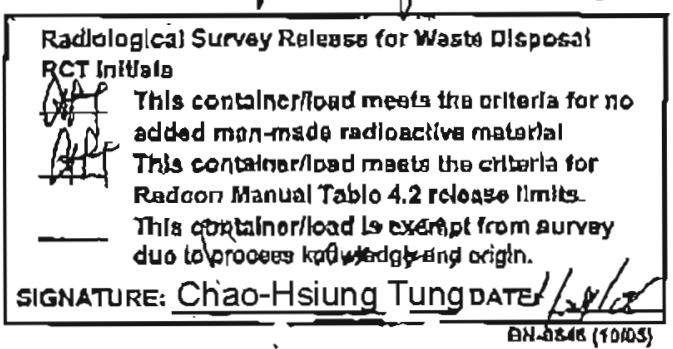

Prini Name: Joe Molter

Signalure: _._s/ Joe Molter

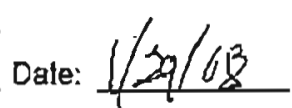

"Radjological Release Stioker" here. Onsits use only.

Nole: "Food waste, office trash and animal oarcasses do not fequire a radlological clearance. Freon-containing appliances must have signed removal certificallon statement with Load Verification."

SWO USE ONLY

Load Weight (net from scale or estimate):

$$
3-14-08
$$

Signature of Certifier: ' Jim Wadley 
NSTec

08/23/06

Form

FRM-0918

NTS LANDFILL LOAD VERIFICATION

Rev. 0

Page 1 of 2

\begin{tabular}{|llllll}
\hline SWO USE (Select One) & AREA & $\square 23$ & $\square 6$ & $\square 9$ & $\triangle$ LANDFILL
\end{tabular}

For waste characterization, approval, and/or assíslance, coniscl Solld Waste Operation (SWO) at 5u7898.

REQUIRED: WASTE GERERATOR INFORMATION

(This form is for rolloffs, dump trucks, and other onsite disposal of materials.)

Waste Generator: Rene Robles (SNJV, WO)

Phone Number: $5-2100$

Localion / Origin: CAU 545, CAS 02-09-01, Area 2; 2 Drums (Solidified Liquid) 545A01 and 545A02

Waste Category: (check one)

$\square$ Commerclal

区 Indusirial

Waste Type: $\square$ NTS

$\square$ Putrescrible

$\triangle$ FFACO-onsite

$\square$ WAC Exception

(check one) $\square$ Non-Putresclble

$\square$ Asbestos Containing Malerial

$\square$ FFACO-offsite

$\square$ Histonc DOE/NV

Pollution Prevention Category: (choek one)

Pollution Prevention Category: (check one)

Method of Characterizabion: (chack one)

Environmental management

$\square$ Defense Projects

YMP

Prohlbited Waste at all three Radloactlve waste; RCRA waste; Hazardous waste: Fres liquids, PCBs above TSCA regulatory NTS landfils:

Additjona! Prohlblted Waste

at the Area 9 U1DC LandfII: levels, and Medical wastes (neodles, sharps, bloody clolning).

Sewage Sludge, Arimal carcasses, Wet garbage (food wasle); and Friable asbestos

REQUIRED: WASTE CONTENTS ALLOWABLE WASTES

Chock all allowable wastes that are contained within this load

NOTE: Waste disposal al the Area 6 Hydrocarbon Landfill must have come Into contacl with petroleum tiydrocarbons or coolanis, such as: gasollne (no benzene. lead); jet fuel; diesel fuel; Jubricants and hydraulics; kerosene; asphaltic petroleum hydrocarbon; and elhylene glycol.
Acceptable waste at any NTS landfll:
$\square$ Paper
$\square$ Rocks / unattered geologic matoriats
Empty containers
$\square$ Asphalt $\square$ Metal $\square$ Wood
$\square$ soll
$\square$ Rubber (excluding tires)
$\square$ Demolition debris
$\square$ Plasile
Wire
$\square$ Cable
$\square$ cloln
$\square$ Insulation (non-Asbestostorm)
Cement \& concrete

Manufactured ftems: (swamp coolers, furniture, rugs, carpet, electronic components, PQE, etc.)

Additional waste accepted at the Area 23 Mercury Landfilt: $\square$ Office Waste $\square$ Food Waste $\square$ Animal Carcesses
Asbestos
Frlable
$\square$ Non-Frlable (contact SWO if regulated load)
Quantity:

Additional waste accepted at the Ares 9 U100 Landfill:
$\square$ Non-friable-aşbeslos
Dralned automobiles and military vehicles
$\square$ Solid fractions from sand/oilwater
$\square$ Light ballasts (contact swO)
$\square$ Drained fuel filters (gas \& biesel)
$\square$ Deconned Underground and Above
$\square$ Hydrocarbons (contact swo
$\bigotimes$ Other Solidified Runsale Ground Tanks

Additional waste accepted at the Area 6 Hydrocarton Landfill:
$\square$ Septlc sludge
$\square$ Rags
$\square$ Drained fuel filters (gas \& diesel)
Crushed non-teme plated oil filters
$\square$ Plants
Soil
[. Sludge from sand/oll/water separators
$\square$ PC8s below 50 parts per million REQUIRED: WASTE GENERATOR SIGNATURE

Initials: (H initialed, no radiological clearance is necessary.)

$\forall-$

$y$

Radlologkal Sutvey Relea 50 for Wasto Dlspogal RET Initinls

The above meationed waste was generated outside of a Controlled Waste Man knowledge, does not coritalin radiological materials.

To the best of my knowledge, the waste described above contains only those I sita. I have verlfied this through the waste characterizatlon method identfled a prohlbitod and allowable waste items." I have contacted Property Management is approved lor disposal in the landfily.

Print Name: Joe Rif! tor

Signalure: /s/ Joe Molter

Date: $i / 51 / 08$

QII Thls contsinerload meats the crlieris for no if added man-made radloativo matorlal

This contalnomosd meots the crlierle for Radeon Manual Table 42 releása llimils.

Thla gentrinerfload is exerngt from survoy duo morosess tgowledoe and orlgln.

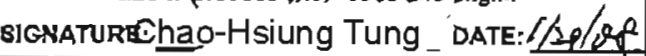
8N-0698 (N0105)

Nole: "Food wasie, office trash and animal carcasses do not require a radiologieal clearance. Freon-containino appliances must have signed removal certification statement with Load Verifjcation."

SWO USE ONLY

Load Woight (net from scale or estimale)
$3-14-08$

Signalure of Certifier' /s/ Jim Wadley 
Shippor: NSTEC FOR USDOE

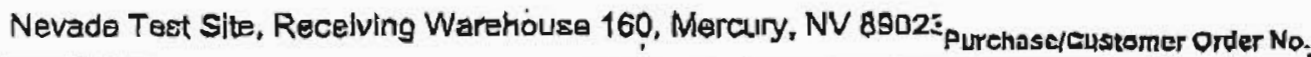

Shipper No:

Date:

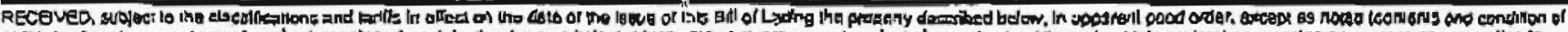

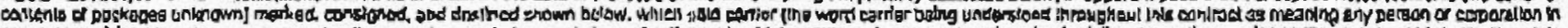

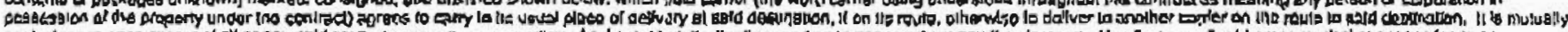

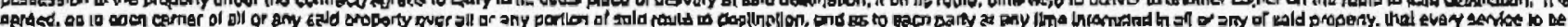

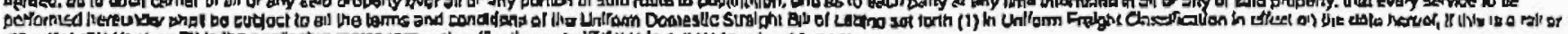

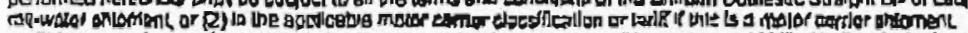

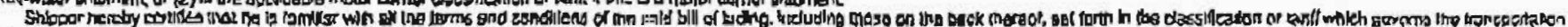

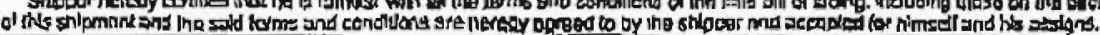

Eonsignot:

Stoller-Navarro Joint Venture Darnar NSTeoh Sanitarv Waste Operations

CAU 545 IDW Rinsate removal FRO NO:

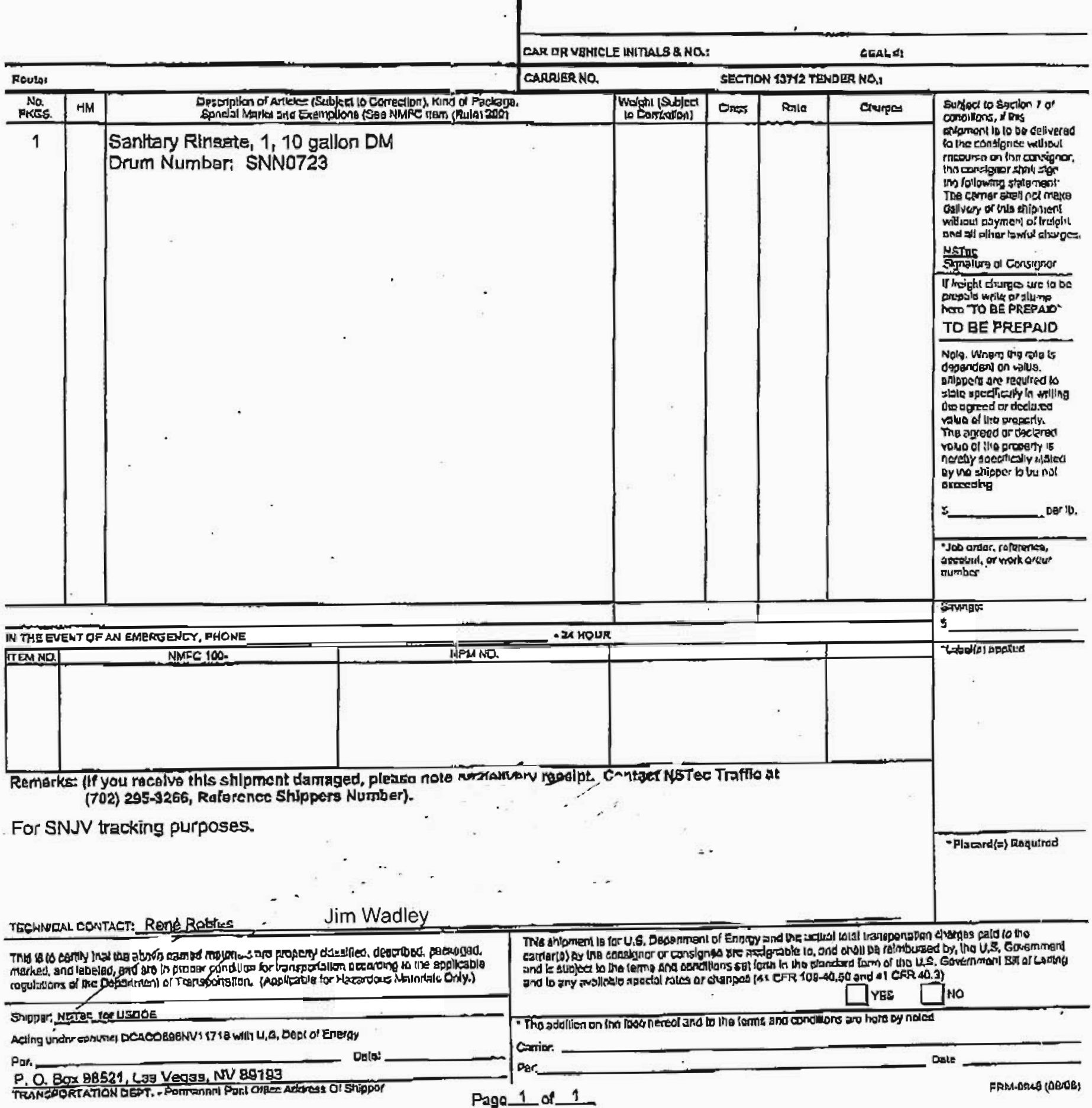
$909-9$
$\mathrm{g} 00 / E 00^{\circ} \& \quad \angle \mathbb{Q} \mid-1$
$8161-9 B 2-202$
ATdUIS NDI LYOLLSES TVINEHNOSIANB MG-LODJ
$11810: 80 \quad 8002-2 Z-2 E \mid H$ 


\section{Appendix E}

\section{Sample Location Coordinates}




\section{E.1.0 Sample Location Coordinates}

Probabilistic sample location coordinates for CAS 03-17-01 were determined by VSP software, version 4.0. Judgmental sample location coordinates for the CAI sampling were measured using a Trimble Pro XRS unit (a portion of CAS 03-17-01 and all of CAS 20-19-01), and a Trimble Geo XT GPS unit (a portion of CAS 03-17-01, and all of CASs 02-09-01, 03-99-14, and 09-23-02). These coordinates identify the Decision I and II sampling locations (easting and northing positions) at CAU 545 listed in Table E.1-1.

Table E.1-1

Sample Location Coordinates

(Page 1 of 4)

\begin{tabular}{|c|c|c|}
\hline Easting & Northing & Samples Location \\
\hline \multicolumn{3}{|c|}{ CAS 02-09-01 } \\
\hline 582613.85 & 4111858.43 & $\mathrm{~A} 01$ \\
\hline 582652.31 & 4111844.61 & A02 \\
\hline 582740.92 & 4111717.35 & A03 \\
\hline 582749.90 & 4111696.77 & $\mathrm{~A} 04$ \\
\hline 582806.20 & 4111671.82 & A05 \\
\hline 582823.36 & 4111701.85 & A06 \\
\hline 582911.73 & 4111754.34 & A07 \\
\hline 582935.82 & 4111767.09 & A08 \\
\hline \multicolumn{3}{|c|}{ CAS 03-17-01 } \\
\hline 588173.07 & 4100437.82 & B01 \\
\hline 588185.48 & 4100437.82 & B02 \\
\hline 588166.87 & 4100448.56 & B03 \\
\hline 588179.28 & 4100448.56 & B04 \\
\hline 588191.69 & 4100448.56 & B05 \\
\hline 588204.10 & 4100448.56 & B06 \\
\hline 588173.07 & 4100459.31 & B07 \\
\hline 588185.48 & 4100459.31 & B08 \\
\hline 588197.89 & 4100459.31 & B09 \\
\hline 588166.87 & 4100470.06 & B10 \\
\hline 588179.28 & 4100470.06 & B11 \\
\hline 588191.69 & 4100470.06 & B12 \\
\hline
\end{tabular}


Table E.1-1

Sample Location Coordinates

(Page 2 of 4)

\begin{tabular}{|c|c|c|}
\hline Easting & Northing & Samples Location \\
\hline 588278.85 & 4100531.69 & B13 \\
\hline 588294.33 & 4100456.52 & B14 \\
\hline 588351.69 & 4100507.51 & B15 \\
\hline 588236.98 & 4100405.53 & B16 \\
\hline 588282.77 & 4100368.47 & B17 \\
\hline 588281.65 & 4100412.18 & B18 \\
\hline 588309.82 & 4100381.36 & B19 \\
\hline 588367.17 & 4100432.35 & B20 \\
\hline 588440.00 & 4100408.17 & B21 \\
\hline 588512.83 & 4100384.00 & B22 \\
\hline 588424.52 & 4100483.34 & B23 \\
\hline 588497.35 & 4100459.16 & B24 \\
\hline 588409.04 & 4100558.50 & B25 \\
\hline 588481.87 & 4100534.32 & B26 \\
\hline 588492.64 & 4100568.19 & B27 \\
\hline 588409.55 & 4100493.24 & $\mathrm{~B} 28$ \\
\hline 588454.18 & 4100495.31 & B29 \\
\hline 588459.23 & 4100554.06 & B30 \\
\hline 588183.20 & 4100480.76 & B31 \\
\hline 588160.63 & 4100458.43 & B32 \\
\hline 588181.76 & 4100431.69 & B33 \\
\hline 588205.51 & 4100454.02 & B34 \\
\hline 588481.32 & 4100588.67 & B35 \\
\hline 588510.65 & 4100572.20 & B36 \\
\hline 588515.14 & 4100481.64 & B37 \\
\hline 588515.98 & 4100443.34 & B38 \\
\hline 588268.19 & 4100591.54 & B39 \\
\hline 588199.56 & 4100514.24 & B40 \\
\hline 588203.22 & 4100411.48 & B41 \\
\hline 588293.02 & 4100334.80 & B42 \\
\hline 588542.61 & 4100447.76 & B43 \\
\hline
\end{tabular}


Table E.1-1

Sample Location Coordinates

(Page 3 of 4)

\begin{tabular}{|c|c|c|}
\hline Easting & Northing & Samples Location \\
\hline 588472.75 & 4100334.54 & B44 \\
\hline 588538.96 & 4100545.05 & B45 \\
\hline 588478.37 & 4100616.47 & B46 \\
\hline \multicolumn{3}{|c|}{ CAS 03-99-14 } \\
\hline 587106.70 & 4099638.64 & $\mathrm{C01}$ \\
\hline 587082.51 & 4099625.29 & $\mathrm{C} 02$ \\
\hline 587050.24 & 4099624.82 & $\mathrm{C03}$ \\
\hline 587006.19 & 4099628.63 & $\mathrm{CO4}$ \\
\hline 586964.67 & 4099638.44 & $\mathrm{C05}$ \\
\hline 587083.03 & 4099641.41 & $\mathrm{C06}$ \\
\hline 587058.36 & 4099641.57 & $\mathrm{C} 07$ \\
\hline 587030.20 & 4099641.47 & $\mathrm{C08}$ \\
\hline 586999.43 & 4099641.22 & $\mathrm{C09}$ \\
\hline 587000.02 & 4099637.15 & C10 \\
\hline 587031.24 & 4099637.44 & C11 \\
\hline 587059.53 & 4099637.57 & $\mathrm{C} 12$ \\
\hline 587085.60 & 4099637.82 & C13 \\
\hline \multicolumn{3}{|c|}{ CAS 09-23-02 } \\
\hline 583924.89 & 4109444.81 & D01 \\
\hline 583950.40 & 4109437.73 & D02 \\
\hline 583975.54 & 4109411.30 & D03 \\
\hline 583987.74 & 4109402.17 & D04 \\
\hline 583931.42 & 4109431.23 & D05 \\
\hline 583970.65 & 4109419.08 & D06 \\
\hline \multicolumn{3}{|c|}{ CAS 20-19-01 } \\
\hline 542373.51 & 4132513.34 & E01 \\
\hline 542378.90 & 4132514.68 & E02 \\
\hline 542376.42 & 4132509.95 & E03 \\
\hline 542374.11 & 4132500.47 & E04 \\
\hline 542366.57 & 4132504.36 & E05 \\
\hline 542372.56 & 4132517.37 & E06 \\
\hline 542370.50 & 4132517.67 & E07 \\
\hline
\end{tabular}


Table E.1-1

Sample Location Coordinates

(Page 4 of 4)

\begin{tabular}{|c|c|c|}
\hline Easting & Northing & Samples Location \\
\hline \hline 542372.73 & 4132526.29 & E08 \\
\hline 542376.73 & 4132519.78 & E09 \\
\hline 542374.48 & 4132525.12 & E10 \\
\hline
\end{tabular}

Coordinate system: UTM, NAD 27, Zone 11, meters 


\title{
Appendix F
}

\section{Nevada Division of Environmental Protection Comments}

\author{
(2 Pages)
}




\section{NEVADA ENVIRONMENTAL RESTORATION PROJECT DOCUMENT REVIEW SHEET}

\begin{tabular}{|l|l|}
\hline \begin{tabular}{l} 
1. Document Title/Number: \\
\multicolumn{1}{|c|}{$\begin{array}{l}\text { Draft Corrective Action Decision Document/Closure Report for } \\
\text { Corrective Action Unit 545: Dumps, Waste Disposal Sites, and } \\
\text { Buried Radioactive Materials, Nevada Test Site, Nevada }\end{array}$}
\end{tabular} & 2. Document Date: 02/01/2008 \\
\hline 3. Revision Number: $0 \quad$ 4. Originator/Organization: Stoller-Navarro \\
\hline 5. Responsible NNSA/NV ERP Project Manager: Kevin J. Cabble & 6. Date Comments Due: 03/03/2008 \\
\hline 7. Review Criteria: Full & \\
\hline 8. Reviewer/Organization/Phone No: Dennis Nicodemus, NDEP, 486-2850 & 9. Reviewer's Signature: \\
\hline
\end{tabular}

\begin{tabular}{|c|c|c|c|c|}
\hline \begin{tabular}{|l|} 
10. Comment \\
Number/Location
\end{tabular} & 11. Type* & 12. Comment & 13. Comment Response & 14. Accept \\
\hline $\begin{array}{l}\text { 1.) Section 2.2.1.5 } \\
\text { Waste Disposal } \\
\text { Site }\end{array}$ & Mandatory & Include reference to Table C.1-3 in this section. & $\begin{array}{l}\text { The reference has been added to the end of the third } \\
\text { sentence. }\end{array}$ & \\
\hline \begin{tabular}{|l|} 
2.) Section 2.3 \\
Justification for No \\
Further Action
\end{tabular} & Mandatory & $\begin{array}{l}\text { Include a statement explaining why a BMP was not } \\
\text { performed at 20-19-01. Include appropriate referenced } \\
\text { documents. }\end{array}$ & $\begin{array}{l}\text { The following information has been added to Section } \\
\text { 2.3: "Based on the results of the investigation the } \\
\text { remaining debris at CAS } 20-19-01 \text { was determined to } \\
\text { not require corrective action. Soil samples were } \\
\text { collected beneath debris at locations identified as most } \\
\text { likely to contain COCs. No COCs were identified; } \\
\text { therefore, there is no indication that the debris is } \\
\text { contributing contaminants to the soil at concentrations } \\
\text { that would require corrective action. Because removal } \\
\text { of the debris from the potential crater area may pose a } \\
\text { health and safety risk to workers (Pawloski, 2003) the } \\
\text { debris was left in place." }\end{array}$ & \\
\hline 3.) Table 2-4 & Mandatory & $\begin{array}{l}\text { Bold or otherwise denote } \mathrm{Pu} 239 / 240 \text { result and } \\
\text { provide reference back to Section 2.2.1.3. }\end{array}$ & $\begin{array}{l}\text { The result has been converted to bold font, and the } \\
\text { following footnote has been added to Table 2-4: "The } \\
\text { only exceedence of the PAL for Pu-239/240 was } \\
\text { identified in a sample taken from a background } \\
\text { location for the purpose of measuring the impact from } \\
\text { nearby atmospheric testing (Section } 2.2 .1 .3 \text { ). This } \\
\text { result is not associated with CAS 03-99-14, and is only } \\
\text { included in the table for completeness. The area } \\
\text { containing the background locations will be addressed } \\
\text { by the Soils Project, CAS 03-23-10." }\end{array}$ & \\
\hline
\end{tabular}

\section{UNCONTROLLED When Printed}


NEVADA ENVIRONMENTAL RESTORATION PROJECT

DOCUMENT REVIEW SHEET

\begin{tabular}{|c|c|c|c|c|}
\hline $\begin{array}{l}\text { 10. Comment } \\
\text { Number/Location }\end{array}$ & 11. Type* & 12. Comment & 13. Comment Response & 14. Accept \\
\hline 4.) Table 2-2 & Mandatory & Include units for mean values. & $\begin{array}{l}\text { The units have been added to the table, and the word } \\
\text { "mean" has been changed to "average" for a broader } \\
\text { understanding. }\end{array}$ & \\
\hline $\begin{array}{l}\text { 5.) Section } 2.3 .1 \\
\text { Final Action } \\
\text { Levels; pg } 304 \text { th } \\
\text { and 6th } \\
\text { paragraphs }\end{array}$ & Mandatory & $\begin{array}{l}\text { Wrong CAU is used. Remove reference to TPH-GRO } \\
\text { because a Tier II evaluation was only done for TPH- } \\
\text { DRO. }\end{array}$ & $\begin{array}{l}\text { The CAU number has been corrected to list " } 545 " \text { ". } \\
\text { The reference to TPH-GRO has been removed. }\end{array}$ & \\
\hline 6.) Table C.1-1 & Mandatory & $\begin{array}{l}\text { Bold maximum values over the PALs (DRO at 20-19- } \\
001 \text { \& Pu 239/240 at 3-17-01). }\end{array}$ & $\begin{array}{l}\text { The maximum values for DRO at CAS } 20-19-01 \text {, and } \\
\text { Am- } 241 \text { and Pu-239/240 at CAS 03-17-01 have been } \\
\text { put into bold font. }\end{array}$ & \\
\hline 7.) Section C.1.10 & Mandatory & $\begin{array}{l}\text { Rewrite first paragraph. Suggest just using TPH } \\
\text { instead of TPH-DRO for first } 2 \text { sentences. Then state } \\
\text { the PAL was exceeded for TPH-DRO and thus the } \\
\text { individual potentially hazardous constituents of TPH- } \\
\text { DRO were examined. If a statement is taken from a } \\
\text { standard and in quotes it must have the same } \\
\text { language. }\end{array}$ & $\begin{array}{l}\text { All references to TPH-DRO in the first two sentences } \\
\text { have been changed to TPH. Also, following the third } \\
\text { sentence in that paragraph (ending with "will be } \\
\text { evaluated for risk in place of TPH-DRO."), the following } \\
\text { sentence has been added: "The PAL for TPH-DRO } \\
\text { was exceeded at CAS 20-19-01." }\end{array}$ & \\
\hline
\end{tabular}




\section{Library Distribution List}

\section{$\underline{\text { Copies }}$}

U.S. Department of Energy

1 (Uncontrolled, electronic copy)

National Nuclear Security Administration

Nevada Site Office

Technical Library

P.O. Box 98518, M/S 505

Las Vegas, NV 89193-8518

U.S. Department of Energy

1 (Uncontrolled, electronic copy)

Office of Scientific and Technical Information

P.O. Box 62

Oak Ridge, TN 37831-0062

Southern Nevada Public Reading Facility

2 (Uncontrolled, electronic copies)

c/o Nuclear Testing Archive

P.O. Box 98521, M/S 400

Las Vegas, NV 89193-8521

Manager, Northern Nevada FFACO

1 (Uncontrolled, electronic copy)

Public Reading Facility

c/o Nevada State Library \& Archives

100 N Stewart Street

Carson City, NV 89701-4285 